\title{
ESTUDO TEÓRICO-EXPERIMENTAL DE PILARES MISTOS COMPOSTOS POR TUBOS DE AÇO PREENCHIDOS COM CONCRETO DE ALTA RESISTÊNCIA
}

Dissertação apresentada à Escola de Engenharia de São Carlos, da Universidade de São Paulo, como parte dos requisitos necessários à obtenção do Título de Mestre em Engenharia de Estruturas.

ORIENTADORA: Prof.ㅁ Dr. ${ }^{a}$ Ana Lúcia H. de C. El Debs 
Dedico à minha família, pelo incentivo e confiança. 


\section{AGRADECIMENTOS}

Ao final desta etapa, agradeço em especial a Deus, pela oportunidade e força, sem as quais eu não poderia realizar este trabalho.

Aos meus pais Ladi e Lucrécia, agradeço pelas palavras de incentivo e apoio nos momentos mais difíceis.

À minha orientadora Ana Lúcia H. de C. El Debs, pelo apoio indispensável, pelas palavras de incentivo e, sobretudo pela amizade e compreensão.

A Alex Sander Clemente de Souza pelo carinho, paciência, compreensão e contribuição imprescindível na realização da análise numérica.

Aos amigos que conquistei no decorrer do trabalho, em especial a Aline Passos de Azevedo e Ana Cláudia Leão Borges pelo companheirismo e amizade no lar que dividimos.

Ao CNPq pela bolsa de estudos e à FAPESP pela bolsa de estudos e apoio financeiro à pesquisa.

Aos técnicos do Laboratório de Engenharia de Estruturas pela cooperação e dedicação na realização da investigação experimental.

Às bibliotecárias Maria Nadir Minatel e Eliana A. Bertin pela atenção dispendida.

A todos, que direta ou indiretamente contribuíram para realização deste trabalho. 
LISTA DE FIGURAS.........................................................................................

LISTA DE TABELAS....................................................................................v

RESUMO.................................................................................................. vii

ABSTRACT...................................................................................................viii

\section{INTRODUÇÃO}

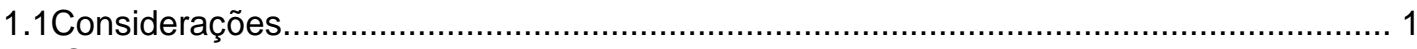

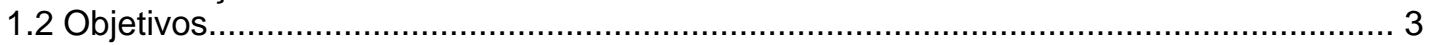

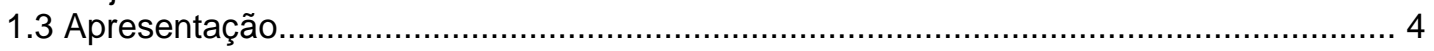

\section{OS PILARES MISTOS AÇO-CONCRETO}

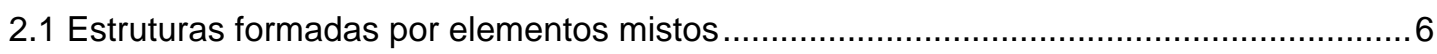

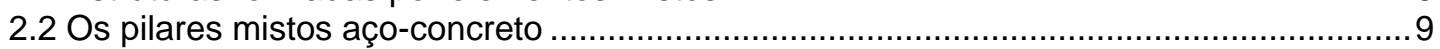

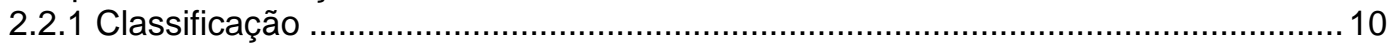

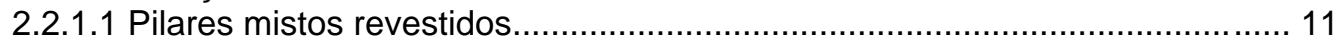

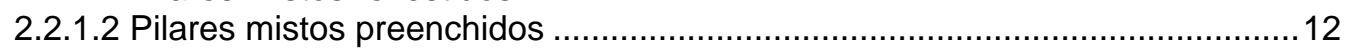

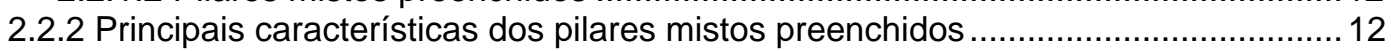

2.2.3 Utilização dos pilares mistos preenchidos ....................................................... 14

2.3 Aspectos Construtivos .................................................................................... 19

2.4 Visão geral da evolução das pesquisas e atual estado de conhecimento........................22

\section{NORMAS PARA O PROJETO DE PILARES MISTOS PREENCHIDOS}

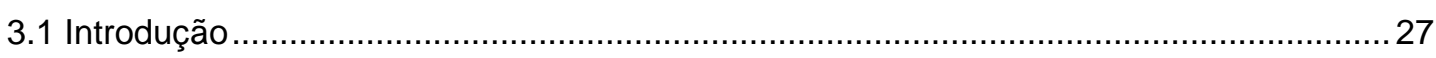

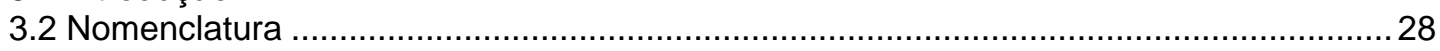

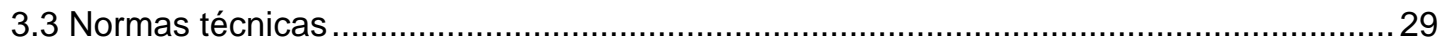

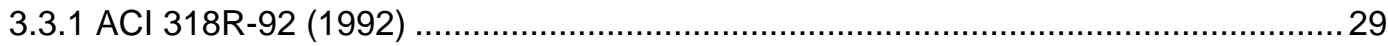

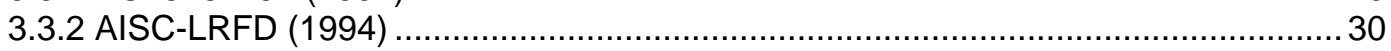

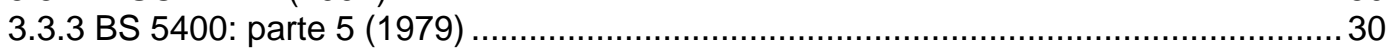

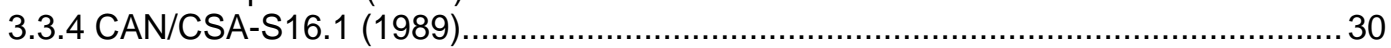

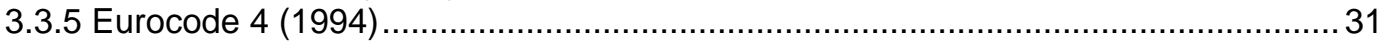

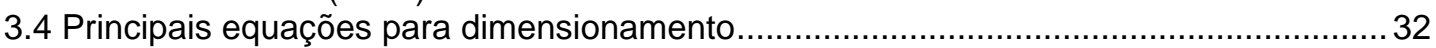

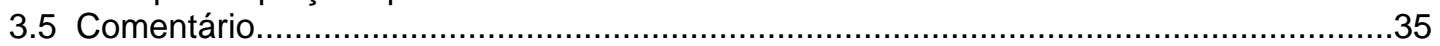

\section{Componentes dA SEÇÃo MISTA}

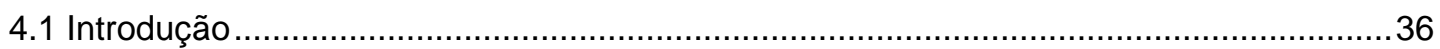

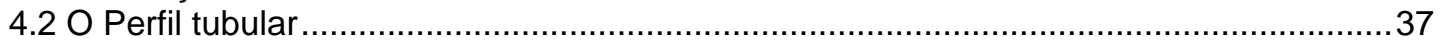

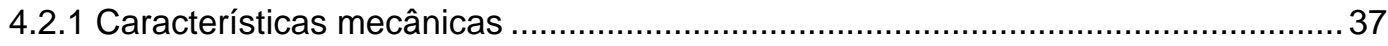

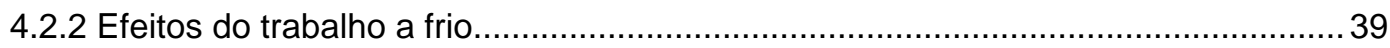

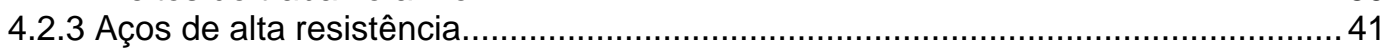

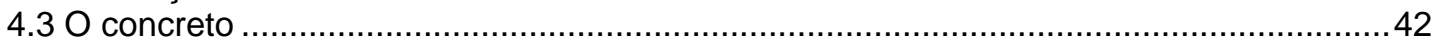

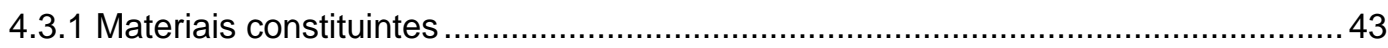

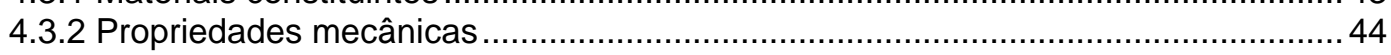

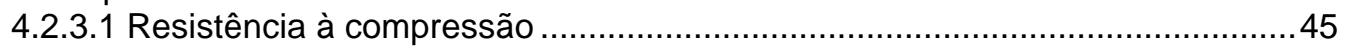


4.2.3.2 Resistência à tração.

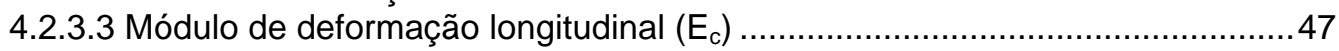

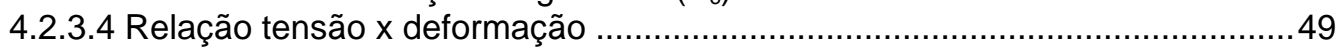

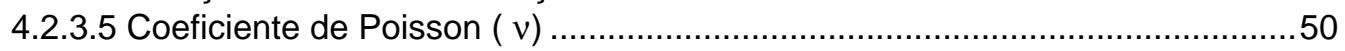

\section{COMPORTAMENTO DA SEÇÃO MISTA}

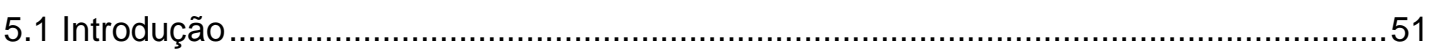

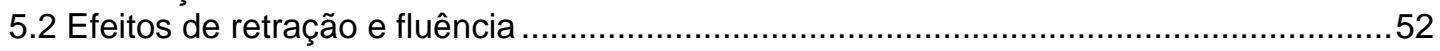

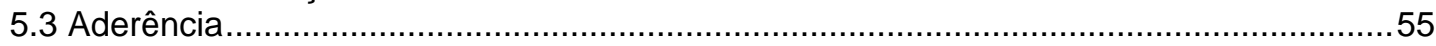

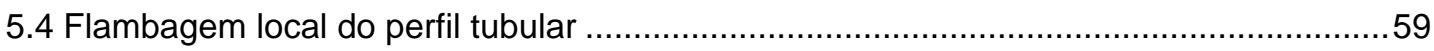

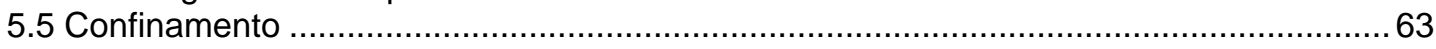

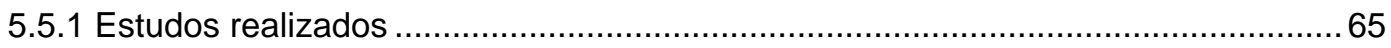

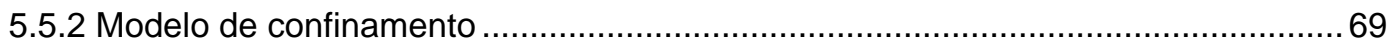

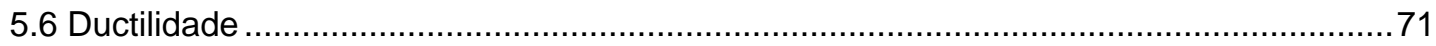

5.7 A seção mista em situação de incêndio ................................................................. 74

\section{LIGAÇÕES}

6.1 Introdução 78

6.2 Ligações entre pilares mistos preenchidos e vigas metálicas .......................................79

\section{ESTUDO TEÓRICO-EXPERIMENTAL DE PILARES MISTOS PREENCHIDOS}

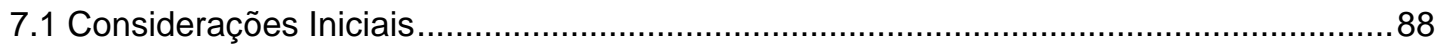

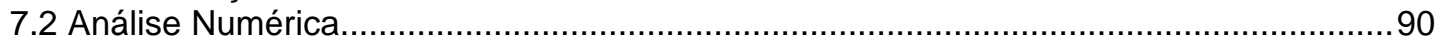

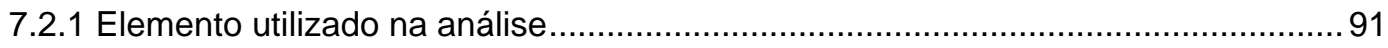

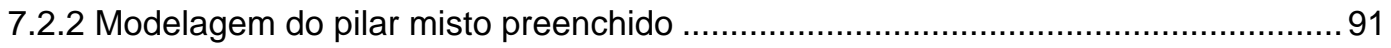

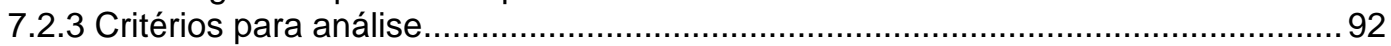

7.2.3.1 Modelos constitutivos para os materiais ....................................................... 93

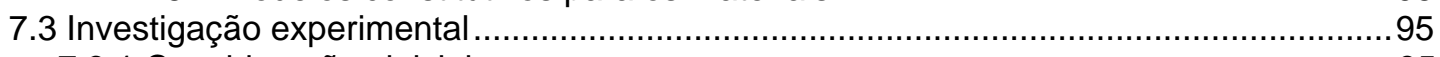

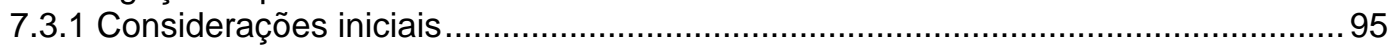

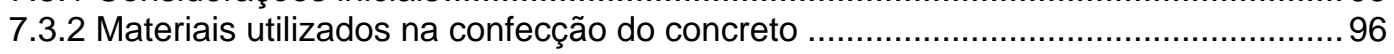

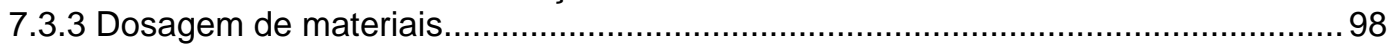

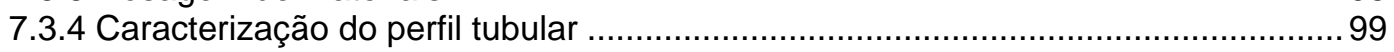

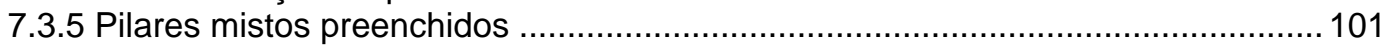

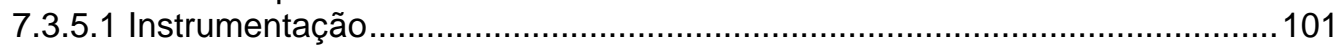

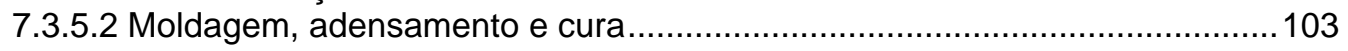

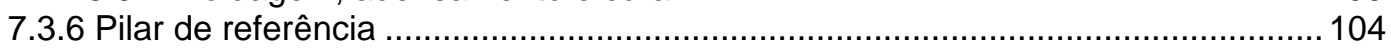

7.3.6.1 Instrumentos e equipamentos empregados............................................ 105

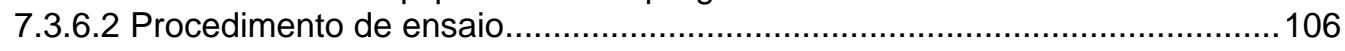

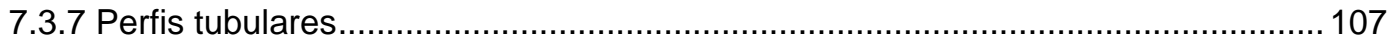

\section{Resultados e ANÁLISE}

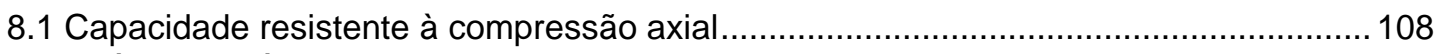

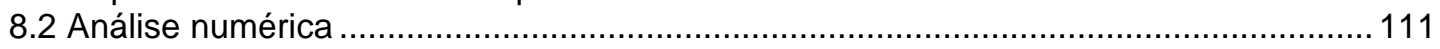

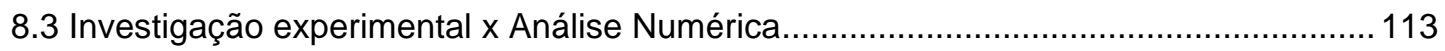

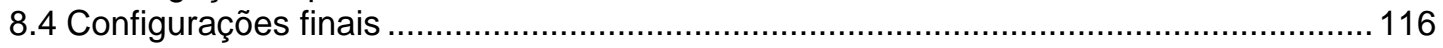

8.5 Comportamento dos pilares mistos preenchidos ..................................................... 120

8.5.1 Variação das deformações nas faces ............................................................ 120

8.5.2 Comportamento conjunto dos materiais.......................................................... 123

8.5.3 Comportamento dos elementos isolados e associados ...................................... 124

8.5.4 Influência da espessura e da forma da seção transversal no comportamento da seção mista preenchida ................................................................................... 127

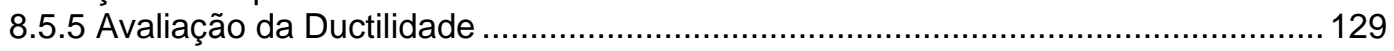

8.5.6 A questão do confinamento....................................................................... 131 
9. Conclusões

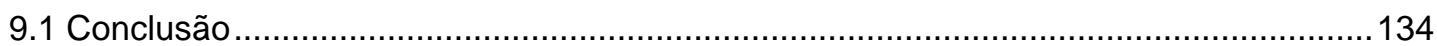

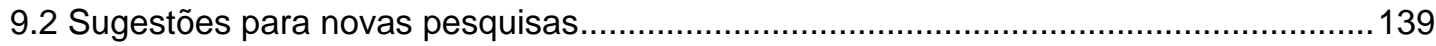

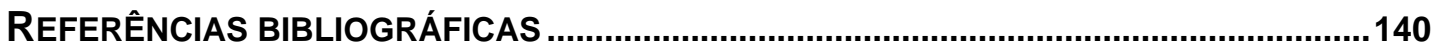

BIBLIGRAFIA COMPLEMENTAR 


\section{LISTA DE FIGURAS}

Figura 2.1 - Exemplo da aplicação de elementos mistos no sistema estrutural de uma ponte

- China 8

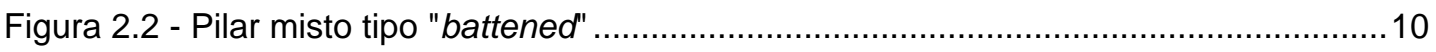

FIGURA 2.3 - Exemplo de pilar misto parcialmente revestido .............................................11

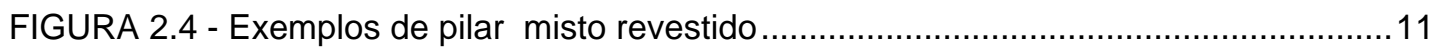

FIGURA 2.5 - Exemplos de pilares mistos preenchidos ................................................... 12

FIGURA 2.6 - Exemplos de aplicação dos pilares mistos preenchidos ………....................15

FIGURA 2.7 - Aplicação dos pilares mistos preenchidos em edifícios ................................17

FIGURA 2.8 - Arranjo estrutural típico empregado em sistemas estruturais com pilares

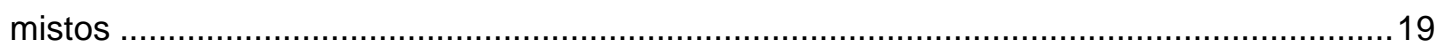

FIGURA 2.9 - Esquema de sistemas estruturais para edifícios .........................................20

FIGURA 2.10 - Técnica construtiva empregada na construção de pilares mistos preenchidos

FIGURA 2.11 - Técnica construtiva em que os pilares mistos preenchidos são escorados a meia altura 22

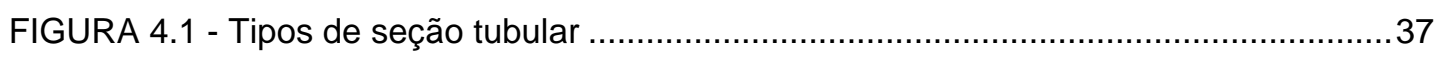

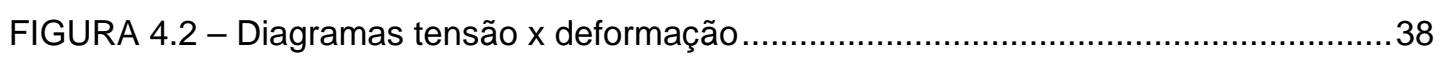

FIGURA 4.3 - Corpo-de-prova para caracterização do aço à tração, segundo a ASTM A370

FIGURA 4.4 - Efeitos do trabalho a frio nas características tensão $x$ deformação do aço ... 40

FIGURA 4.5 - Distribuição de tensões residuais em seções de perfis tubulares quadrados

FIGURA 4.6 - Influência da resistência à compressão uniaxial do concreto na relação tensão

$x$ deformação

FIGURA 4.7 - Variação das deformações nos concretos de resistência usual e de alta resistência. 50

FIGURA 5.1 - Componentes de deformação do núcleo de concreto ao longo do tempo

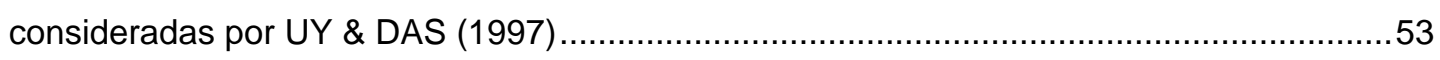

FIGURA 5.2 - Seção transversal investigada por HUNAITI \& WAKABAYASHI (1992) .........56

FIGURA 5.3 - Esquema de ensaio empregado por SHAKIR-KHALIL (1993a, 1993b) .........58

FIGURA 5.4 - Fenômeno de flambagem local no perfil tubular .........................................60

FIGURA 5.5 - Larguras e áreas efetivas para o perfil tubular preenchido com concreto .....61

FIGURA 5.6 - Tensões de confinamento em seções circulares ...........................................64 
FIGURA 5.7 - Arqueamento das tensões de confinamento em seções quadradas e

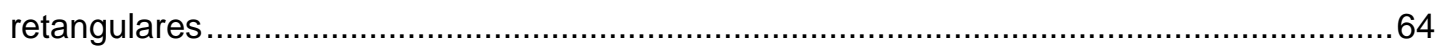

FIGURA 5.8 - Configurações de ruína para o concreto isolado e confinado ...........................65 FIGURA 5.9 - Relações tensão-deformação para diferentes formas de seção transversal

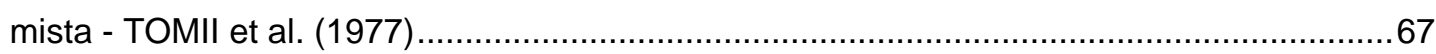

FIGURA 5.10 - Configuração da pressão lateral na seção mista preenchida .......................69 FIGURA 5.11 - Esquema geral de medição dos deslocamentos, recomendado pela JSCE -

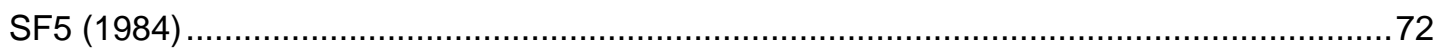

FIGURA 5.12 - Ductilidade à compressão segundo a norma JSCE - SF5 (1984).................73

FIGURA 5.13 - Diagrama para cálculo do índice de ductilidade adaptado de UY (1998a) .. 73 FIGURA 5.14 - Forno que simula a elevação de temperatura produzida pela ação do fogo e onde foram ensaiados os pilares mistos preenchidos .................................................... 75

FIGURA 5.15 - Expansão do pilar misto preenchido durante exposição ao fogo ..................76 FIGURA 5.16 - Capacidade resistente para pilares mistos, preenchidos com concreto de resistência usual e de alta resistência, submetidos a 2 horas de exposição 77 FIGURA 6.1 - Alguns tipos de ligações viga metálica - pilar preenchido, através de soldagem 79

FIGURA 6.2 - Detalhes de ligações com dispositivos ancorados no núcleo de concreto, estudados por AZIZINAMINI \& PRAKASH (1993) .80

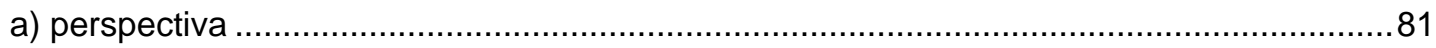

FIGURA 6.3 - Ligação viga metálica - pilar preenchido através de longos parafusos protendidos, estudada por PRION \& McLELLAN (1994).

FIGURA 6.4 - Detalhes de ligações viga I metálica x pilar misto preenchido, propostas por SCHNEIDER \& ALOSTAZ (1998)

FIGURA 6.5 - Variação da rigidez dos detalhes de ligação estudados por SCHNEIDER \&

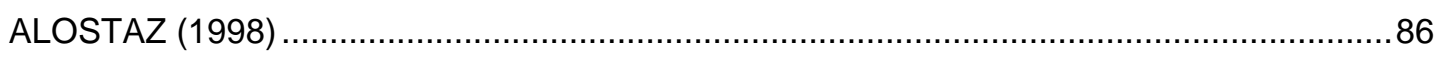

FIGURA 7.1 - Elemento cúbico SOLID 45 (biblioteca do Ansys) ........................................91

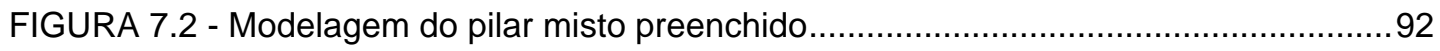

FIGURA 7.3 - Condições de vinculação dos pilares mistos preenchidos ...............................93

FIGURA 7.4 - Modelo constitutivo para o material concreto ………....................................94

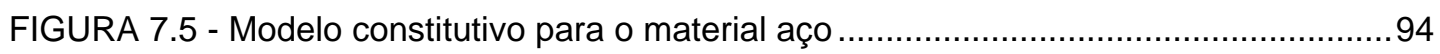

FIGURA 7.6 - Operação de moldagem dos corpos-de-prova cilíndricos de dimensões

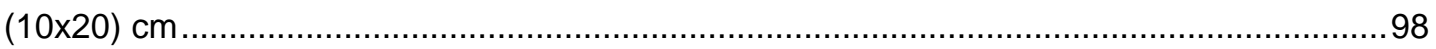

FIGURA 7.7 - Detalhe dos materiais dentro da betoneira, após a mistura ...........................99

FIGURA 7.8 - Dimensões do corpo-de-prova para ensaio à tração segundo ASTM A370/92

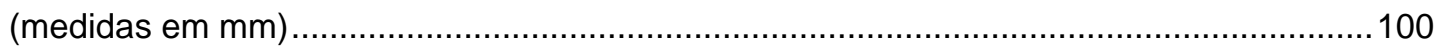

FIGURA 7.9 - Caracterização mecânica do aço dos perfis................................................. 100

FIGURA 7.10 - Região de extração dos corpos-de-prova para ensaio à tração...................101

FIGURA 7.11 - Instrumentação do pilar misto com seção quadrada ..................................102 
FIGURA 7.12 - Instrumentação do pilar misto com seção circular ....................................102

FIGURA 7.13 - Instrumentação do pilar misto com seção retangular ..................................103

FIGURA 7.14 - Instrumentação para o concreto de preenchimento .................................... 103

FIGURA 7.15- Lançamento do concreto e posicionamento dos extensômetros no interior do

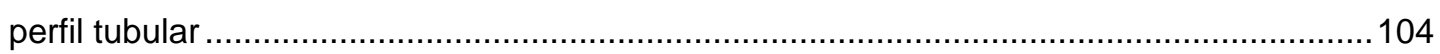

FIGURA 7.16 - Instrumentação do pilar de referência ....................................................104

FIGURA 7.17- Máquina INSTRON 8506, que permite ensaio com controle de deslocamento

FIGURA 7.18 - Espécime de perfil tubular ensaiado à compressão axial .........................107

FIGURA 8.1 - Distribuição de tensões axiais no núcleo concreto e no perfil tubular: Modelo CFT 1_2 $\left(\mathrm{kN} / \mathrm{cm}^{2}\right)$.

FIGURA 8.2 - Distribuição de tensões axiais no núcleo concreto e no perfil tubular: Modelo CFT 3_1 $\left(\mathrm{kN} / \mathrm{cm}^{2}\right)$.

FIGURA 8.3 - Resultado da investigação experimental e da análise numérica para o modelo CFT 1_1

FIGURA 8.4 - Resultado da investigação experimental e da análise numérica para o modelo CFT 1_2 114

FIGURA 8.5 - Resultado da investigação experimental e da análise numérica para o modelo CFT 3_1

FIGURA 8.6 - Resultado da investigação experimental e da análise numérica para o modelo CFT 3_2

FIGURA 8.7 - Configurações finais dos modelos investigados, submetidos à compressão axial.

FIGURA 8.8 - Comportamento das deformações axiais e transversais no concreto e no perfil 122

FIGURA 8.9 - Comportamento conjunto dos materiais aço e concreto 123 FIGURA 8.10 - Comportamento dos elementos isolados e associados formando o modelo CFT 1_1 124

FIGURA 8.11 - Comportamento dos elementos isolados e associados formando o modelo CFT 1_2

FIGURA 8.12 - Comportamento dos elementos isolados e associados formando o modelo CFT 2 1

FIGURA 8.13 - Comportamento dos elementos isolados e associados formando o modelo CFT 2_2.

FIGURA 8.14 - Comportamento dos elementos isolados e associados formando o modelo CFT 3_1

FIGURA 8.15 - Comportamento dos elementos isolados e associados formando o modelo CFT 3_2 126

FIGURA 8.16 - Seções quadradas CFT 1_1 e CFT 1_2. 127 
FIGURA 8.17 - Seções circulares CFT 2_1 e CFT 2_2 128

FIGURA 8.18 - Seções retangulares CFT 3_1 e CFT 3_2 ............................................... 128

FIGURA 8.19 -Influência da forma e da espessura no comportamento do modelo misto submetido à compressão axial 129

FIGURA 8.20 - Avaliação da ductilidade para o modelo CFT 1_1 ................................... 131

FIGURA 8.21 - Presença do efeito de confinamento nas diferentes seções e espessuras analisadas. 132 
TABELA 3.1 - Resistências e módulo de deformação longitudinal do concreto, segundo EUROCODE 4 (1994) .

TABELA 3.2 - Capacidade resistente à compressão axial segundo algumas normas de dimensionamento de pilares mistos preenchidos

TABELA 3.2 - Capacidade resistente à compressão axial segundo algumas normas de dimensionamento de pilares mistos preenchidos (cont.) ................................................33

TABELA 3.3 - Coeficientes $C_{1}$ e $C_{2}$ da Norma BS 5400: parte 5 (1979) .............................33

TABELA 3.4 - Coeficientes $\eta_{10}$ e $\eta_{20}$ da Eurocode 4: Parte 5 (1994) ....................................34

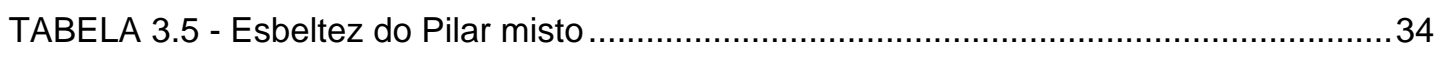

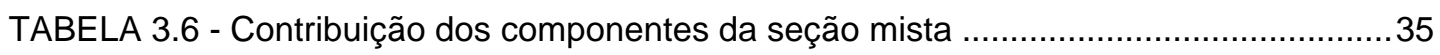

TABELA 3.7 - Comprimento efetivo do pilar - $k \ell$ - segundo a norma BS 5400: parte 5

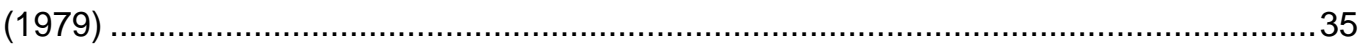

TABELA 4.1 - Classes de concreto segundo AMARAL FILHO (1992) .................................43

TABELA 4.2 - Grupos de concreto segundo texto para revisão da NB -1 (1997)...................43

TABELA 4.3 - Fatores de conversão aplicáveis à resistência de corpos-de-prova ............... 45

TABELA 4.4 - Equações para o cálculo do módulo de deformação longitudinal do concreto de alta resistência

TABELA 4.5 - Efeito do tipo de agregado no módulo de deformação longitudinal, segundo o Código Modelo - MC90 (1990) do CEB-FIP...

TABELA 5.1 - Variação das deformações e tensões, devidas aos fenômenos de retração e fluência, considerando resistência e rigidez constantes: UY \& DAS (1997)

TABELA 5.2 - Tensões no pilar misto preenchido considerando variações na resistência e

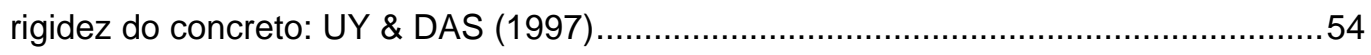

TABELA 5.3 - Valores mínimos para a espessura do perfil tubular .......................................59

TABELA 5.4 - Graus de confinamento segundo CUSSON \& PAULTRE (1993) ....................71

TABELA 5.5 - Resistência ao fogo de pilares mistos preenchidos ......................................76

TABELA 7.1 - Séries analisadas no estudo teórico-experimental........................................ 89

TABELA 7.2 - Características gerais dos pilares mistos preenchidos estudados .................90

TABELA 7.3 - Dimensões da malha utilizada na modelagem dos pilares mistos preenchidos

TABELA 7.4 - Análise granulométrica do agregado miúdo (NBR 7217/87).........................96

TABELA 7.5 - Análise granulométrica do agregado graúdo (NBR 7217/87) ........................97

TABELA 7.6 - Principais características dos materiais que compõem o concreto .................97 
TABELA 7.7 - Resultados da caracterização mecânica do aço dos perfis tubulares ...........101

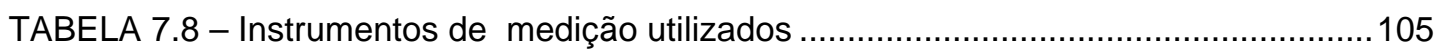

TABELA 8.1 - Propriedades gerais dos pilares mistos preenchidos ...................................109

TABELA 8.2 - Resistência à compressão dos perfis tubulares isolados: resultados do full

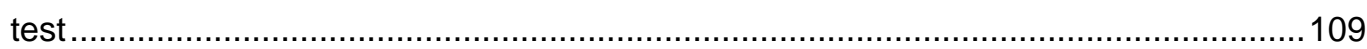

TABELA 8.3 - Capacidade Resistente dos Pilares Mistos Preenchidos .............................110

TABELA 8.4 - Índices de Ductilidade dos pilares mistos preenchidos ................................. 130 
DE NARDIN, S. Estudo teórico-experimental de pilares mistos compostos por tubos de aço preenchidos com concreto de alta resistência, São Carlos, 1999. 148p. Dissertação (mestrado) - Escola de Engenharia de São Carlos, Universidade de São Paulo.

O emprego de pilares mistos formados por tubos de aço preenchidos com concreto de alta resistência, sobretudo em edifícios altos, é uma tendência em diversos países europeus, americanos e asiáticos. A tais elementos são atribuídas vantagens como: alta resistência e ductilidade, economia de materiais e mão-deobra, redução das dimensões da seção transversal e melhoria no comportamento dos materiais aço e concreto, devido ao efeito de confinamento. Buscando suprir algumas carências de conhecimento, procura-se obter dados experimentais sobre o comportamento de pilares mistos axialmente comprimidos, possibilitando desta forma avaliar parâmetros como influência da forma da seção transversal e da espessura do perfil tubular no seu comportamento. Foram analisadas seções quadradas, circulares e retangulares, preenchidas por concreto com resistência média de 50MPa. A ruína destes elementos caracterizou-se pelo esmagamento do concreto, ocorrendo posteriormente a flambagem local do perfil em diversos pontos. A capacidade resistente prevista por diversas normas resultou em valores muito próximos dos experimentais, embora várias destas normas não considerem o efeito de confinamento. Os ensaios mostraram que o efeito de confinamento contribui de forma decisiva na melhoria do comportamento dos materiais, sobretudo ductilizando o concreto de alta resistência, entretanto seus efeitos não são significativos no aumento da capacidade resistente da seção mista. Alguns critérios para avaliação da ductilidade à compressão foram adaptados e mostraram bons resultados, possibilitando o cálculo do índice de ductilidade.

Palavras-chave: estruturas mistas, pilares mistos, pilares mistos preenchidos, pilares mistos aço-concreto, confinamento, ductilidade, concreto de alta resistência. 
DE NARDIN, S. Estudo teórico-experimental de pilares mistos compostos por tubos de aço preenchidos com concreto de alta resistência, São Carlos, 1999. 148p. Dissertação (mestrado) - Escola de Engenharia de São Carlos, Universidade de São Paulo.

The use of concrete filled steel tubes especially in tall buildings is a tendency in several european, american and asian countries. The use of these members has several advantages: high resistance and ductility, saving of materials and labour, reduction of cross section dimensions and improvement in behaviour of the materials steel and concrete due the confinement. The main purpose of this study is provide some experimental results of the behaviour of concrete filled steel tubes concentrically loaded. The main experimental parameters considered were the influence of the cross-section shape and thickness of steel tube. Square, circular and rectangular cross-section shapes infilling with concrete of the 50MPa of strength were analyzed. The failure was characterized for crushing of the concrete and later local buckling of the steel section in several points. The strength capacity predicted for several standards showed good agreement with the experimental failure values although this does not consider the confinement of the concrete. The results of tests showed that the confinement effect contributes for improvement behaviour of materials, especially increasing the ductility of the high strength concrete. However the results showed that the triaxial confinement does not increase the axial capacity of the concrete filled steel tubes. Some methods to estimate the ductility of axially compressed concrete columns were adapted and showed good results permitting the calculation of the ductility index of short columns.

Keywords: concrete filled steel tubes, ductility, composite columns, high strength concrete, tall buildings, box columns. 


\section{INTRODUÇÃO}

\subsection{Considerações}

O desenvolvimento econômico, cultural e científico fez surgir diversos sistemas estruturais e construtivos, entre os quais estão os sistemas formados por elementos mistos. Dentre os elementos estruturais que compõem tal sistema estão os pilares mistos aço-concreto.

A designação "pilar misto aço-concreto" é atribuída a pilares formados pela associação de um ou mais perfis estruturais de aço, revestidos ou preenchidos com concreto. Aos pilares cujos perfis são revestidos por concreto denominam-se pilares mistos revestidos. Este tipo de elemento misto surgiu devido à necessidade de proteger os perfis da ação nociva do fogo e da corrosão.

Posteriormente, pensou-se em usar o concreto como material de preenchimento para os perfis tubulares, surgindo desta forma os pilares mistos preenchidos. O núcleo de concreto é responsável por aumentar a rigidez e a resistência do perfil tubular, melhorando seu comportamento isolado.

Além destas características, a utilização de pilares mistos preenchidos em sistemas formados por elementos mistos confere vantagens como: facilidades construtivas devido à ausência de fôrmas e armaduras, e bom comportamento estrutural que, aliada à redução de custos com materiais e mão-de-obra são 
responsáveis pelo crescimento e divulgação de sua utilização em países como Estados Unidos, Canadá, Japão, Austrália e China.

Desde a década de 60 os pilares mistos têm sido estudados; entretanto sua crescente utilização indica a necessidade de revisões nos modelos de cálculo e a elaboração de recomendações construtivas, visando oferecer aos usuários normas que reflitam melhor o comportamento conjunto deste tipo de elemento misto.

O recente surgimento dos concretos de alta resistência - CARs -, fruto dos avanços tecnológicos e científicos verificados nas últimas décadas, permitiu ampliar a utilização dos pilares mistos preenchidos pois, além de uma melhoria no projeto arquitetônico, propiciada pela possibilidade de maiores vãos, a economia resultante do uso de maiores resistências para o concreto se reflete na redução da seção dos pilares e dos elementos de fundação.

Portanto, constatada a viabilidade de empregar concreto de alta resistência como material de preenchimento dos pilares mistos preenchidos, é preciso realizar estudos, no sentido de adequar as poucas normas existentes a esta tendência mundial.

A partir de uma análise bibliográfica, observa-se a carência de estudos, sobretudo no Brasil, que avaliem por exemplo, a influência da forma da seção transversal no comportamento dos pilares mistos, preenchidos com concreto de alta resistência. Existe também a necessidade de analisar a influência de parâmetros como a variação da espessura do perfil tubular no comportamento do pilar.

O comportamento do pilar misto preenchido, axialmente comprimido, após atingir sua capacidade máxima também era desconhecido, pois a grande maioria dos estudos experimentais de que se tem conhecimento, foi realizada com controle de aplicação de força, o que não permite conhecer o comportamento pós-pico de resistência. A realização de ensaios com controle de deslocamento torna esta análise possível.

Buscando contribuir neste sentido, desenvolve-se 0 estudo do comportamento de pilares mistos aço-concreto, preenchidos com concreto de alta resistência e submetidos à compressão axial, cujos ensaios em modelos físicos são realizados com controle de deslocamento.

São obstáculos ao desenvolvimento e utilização dos elementos mistos no Brasil, especialmente dos pilares mistos preenchidos, o conservadorismo dos profissionais da construção civil, identificado pela escolha preferencial por 
estruturas em concreto armado, e o desconhecimento quanto à existência e comportamento destes elementos.

Este trabalho adquire relevância, pois serve como meio de divulgação de um elemento estrutural cuja utilização e vantagens estão consagradas em diversos países, introduzindo no Brasil a idéia de empregar elementos mistos como solução estrutural. Contribui também fornecendo dados para o aprofundamento do atual estado de conhecimento dos pilares mistos preenchidos a nível mundial.

\subsection{OBJetivos}

Este trabalho apresenta dentre seus objetivos, um de caráter genérico, que é a divulgação da aplicação de pilares mistos preenchidos.

Além deste, o estudo teórico-experimental de pilares mistos preenchidos com concreto de alta resistência tem por objetivos:

- avaliação da capacidade resistente da seção mista e dos modelos teóricos para o seu cálculo, existentes nas normas;

- avaliação das parcelas de resistência atribuídas ao perfil tubular e ao concreto de preenchimento;

- análise do comportamento pós-pico do pilar misto ou seja, após ser atingida a capacidade máxima da seção mista;

- investigação exploratória da variação das deformações longitudinais e transversais nos materiais aço e concreto;

- análise do comportamento conjunto e isolado do perfil tubular e do concreto de alta resistência;

- investigação exploratória do acréscimo de capacidade resistente devido ao efeito de confinamento;

- análise da ductilidade de pilares mistos aço-concreto preenchidos com concreto de alta resistência, submetidos à compressão axial.

É portanto objetivo, divulgar e fornecer dados referentes aos pilares mistos preenchidos; entretanto, existem algumas limitações de abrangência e aprofundamento da pesquisa, que são fundamentalmente as seguintes: 
a) serão investigadas experimentalmente apenas algumas dimensões de seções transversais e espessuras de perfil tubular;

b) não será investigada a influência de uma série de parâmetros que interferem no comportamento dos pilares mistos preenchidos. A definição dos parâmetros analisados teve por base uma extensa revisão bibliográfica, através da qual foi possível identificar uma série de elementos que interferem no comportamento dos pilares mistos preenchidos. Podem ser citados: forma da seção transversal, espessura do perfil tubular, resistência dos materiais, excentricidade da força aplicada, tipo de carregamento, efeitos de longa duração, fenômenos de retração e fluência, índice de esbeltez, etc. Dentre estes, foram escolhidos: espessura do perfil tubular e forma da seção transversal;

c) os pilares mistos preenchidos são submetidos apenas a forças estáticas, de curta duração, aplicadas axialmente. Não são analisadas as situações de carregamentos dinâmicos e de longa duração. Os fenômenos de retração e fluência do concreto, embora ocorram, são desconsiderados;

d) em virtude da limitação de tempo para realização do curso de mestrado, é analisado um número limitado de modelos.

\subsection{ApRESENTAÇÃo}

Esta dissertação foi dividida em 9 capítulos. No primeiro capítulo é apresentado o conceito de pilar misto preenchido, enfatizando-se a utilização de concreto de alta resistência como material de preenchimento, e justificando-se desta forma, a necessidade de realização desta pesquisa. Na seqüência são estabelecidos os objetivos do trabalho e, finalmente, a apresentação de todo o conteúdo da dissertação.

O segundo capítulo trata dos pilares mistos aço-concreto, apresentando sua origem, localização dentro do sistema estrutural formado por elementos mistos, e associações possíveis. Destacam-se principais aplicações dos sistemas mistos, enfatizando a utilização dos pilares mistos preenchidos no Brasil e no exterior. Uma visão geral das aplicações e arranjos estruturais possíveis, bem como os aspectos 
construtivos envolvidos são apresentados. Por fim, apresenta-se um breve estadoda-arte destacando os principais trabalhos teóricos e experimentais desenvolvidos até então e tópicos que necessitam de novos estudos.

No terceiro capítulo faz-se um breve relato das normas de projeto existentes, destacando as equações de cálculo da capacidade resistente e as principais limitações de aplicação destas normas.

O quarto capítulo apresenta os componentes da seção mista: perfil tubular e concreto de alta resistência. São destacadas as principais propriedades mecânicas e aspectos relativos às características dos materiais que compõem o concreto.

No quinto capítulo são abordadas questões relativas ao comportamento da seção mista preenchida. Destacam-se aspectos como a deformabilidade do concreto ao longo do tempo, importância da aderência, fenômenos de flambagem local, ductilidade e comportamento frente à ação do fogo. Especial atenção é dada ao efeito de confinamento provocado pelo perfil tubular.

No sexto capítulo é desenvolvido um breve estudo sobre as ligações dos pilares mistos com as vigas metálicas de seção I. Os diversos detalhes de ligação propostos, bem como resultados de investigações experimentais são apresentados, destacando-se o comportamento de cada um destes detalhes e chamando a atenção para a ausência de normalização sobre este assunto.

O sétimo capítulo apresenta o estudo realizado, dividido em análise numérica e experimentação física de modelos. Destacam-se metodologias empregadas na execução dos ensaios, instrumentação utilizada e procedimentos de moldagem, adensamento e cura, bem como aspectos relativos à análise numérica dos pilares preenchidos .

No oitavo capítulo são apresentados os resultados obtidos na análise numérica e nos ensaios, bem como discussões a respeito destes. Para todos os ensaios realizados, são apresentadas as capacidades resistentes teóricas e experimentais, as configurações de ruína dos elementos mistos, e valores de deslocamentos, deformações e forças.

O nono capítulo trata das conclusões finais do trabalho e apresenta sugestões para novas pesquisas sobre o assunto.

Finalizando, apresentam-se as referências bibliográficas e bibliografia complementar utilizadas no desenvolvimento deste trabalho. 


\section{OS PILARES MISTOS AÇO-CONCRETO}

\subsection{ESTRUTURAS FORMADAS POR ELEMENTOS MISTOS}

Os pilares mistos preenchidos estão inseridos dentro de um amplo sistema estrutural denominado "sistema estrutural formado por elementos mistos".

O surgimento das primeiras estruturas mistas data de 1894 quando, segundo GRIFFIS (1994) foram construídas uma ponte em lowa e o Edifício Methodist Building em Pittsburgh, nos EUA, ambos utilizando vigas metálicas de seção I, revestidas com concreto. Estas duas construções evidenciaram duas importantes vantagens atribuídas a alguns tipos de estruturas mistas: a proteção contra a ação do fogo e da corrosão.

O início dos estudos dos elementos estruturais mistos data de 1914 na Inglaterra. Em meados de 1930 alguns métodos de dimensionamento para vigas mistas já estavam estabelecidos, sendo em 1944 introduzidos na norma da American Association of State Highway (AASHO), e em 1952 no American Institute of Steel Construction (AISC). 
Os primeiros edifícios altos foram construídos nos Estados Unidos entre 1920 e 1930; é o caso do Empire State Building e do Chrysler Building. Neles, muitos elementos de aço receberam, segundo GRIFFIS (1994), uma capa de concreto para protegê-los da corrosão e do fogo, sem contudo considerá-lo como material resistente.

Os sistemas estruturais formados por elementos mistos foram introduzidos no Brasil na década de 50. Sua utilização contudo, foi e continua sendo restrita a umas poucas obras, devido à cultura preferencial dos engenheiros civis, arquitetos e construtores, por estruturas em concreto armado.

A seguir são apresentados alguns edifícios onde foram utilizados elementos mistos na composição do sistema estrutura:

\section{Edifício Garagem AmÉrica (1957) ${ }^{1}$}

Edifício garagem localizado em São Paulo cujo projeto estrutural é do Eng. Paulo R. Fragoso possui 16 pavimentos totalizando uma área de $15.214 \mathrm{~m}^{2}$, consumo de 948 t de aço ASTM A-7 e sem aplicação de proteção especial quanto à ação do fogo.

\section{EdifícIo PALÁCIO do COMÉRCIO (1959) ${ }^{1}$}

Localizado em São Paulo, trata-se de um edifício comercial de escritórios com 24 pavimentos, $73 \mathrm{~m}$ de altura e pé direito de $3,15 \mathrm{~m}$. O projeto estrutural é do Eng. Paulo R. Fragoso e consumiu 1.360 t de aço ASTM A-7.

\section{Edifício Avenida Central (1961) ${ }^{1}$}

Trata-se de um edifício comercial de escritórios localizado no Rio de Janeiro. Possui 36 pavimentos, altura total de $112 \mathrm{~m}$ e o projeto estrutural é do Eng. Paulo R. Fragoso. As vigas de aço foram revestidas com concreto para protegê-los contra a ação do fogo. Este projeto consumiu 5.620 t de aço ASTM A-7.

\section{Edifício Santa Cruz (1963) ${ }^{1}$}

Edifício de uso residencial e comercial, localizado em Porto Alegre e cujo sistema estrutural foi projetado pelo Eng. Paulo R. Fragoso. Possui altura total de 103 m, distribuídos em 34 pavimentos.

\footnotetext{
1 FIGUEIREDO, L. M. B. (1998). Projeto e construção de pilares mistos aço-concreto. São Carlos. 142p. Dissertação (mestrado) - Escola de Engenharia de São Carlos, Universidade de São Paulo.
} 
O consumo total de aço ASTM A-7 foi de $4.011 \mathrm{t}$ e todos os elementos de aço foram protegidos contra incêndio por sistema de recobrimento do tipo caixa.

\section{EdIFícIo SEDE DO IPERJ (1965) ${ }^{1}$}

Edifício localizado no Rio de Janeiro e de uso comercial. Possui 24 pavimentos com pé direito de 2,65 $\mathrm{m}$ e altura total de $76,5 \mathrm{~m}$. O projeto estrutural é do Eng. Paulo R. Fragoso e foram gastos 1.218 t de aço ASTM A-7. Foram utilizadas alvenarias de tijolos cobrindo as almas dos perfis e argamassa de cimento e vermiculita com espessura de $1,5 \mathrm{~cm}$ para as vigas e $3,5 \mathrm{~cm}$ para os pilares, como sistema de proteção contra a ação do fogo.

\section{ESCRITÓRIO CENTRAL DA CSN 1963) ${ }^{1}$}

Este edifício localizado em Volta Redonda possui 18 pavimentos com pé direito de $3,5 \mathrm{~m}$ e consumo total de aço ASTM A-7 igual a $2.600 \mathrm{t}$. O projeto estrutural é do Eng. José Villas Boas.

Atualmente, os sistemas estruturais mistos são largamente empregados em estruturas de pontes e edifícios altos. Como pólos de utilização citam-se países como Estados Unidos, Canadá, Inglaterra, Alemanha, Austrália, China e Japão. Na FIGURA 2.1 é apresentado um exemplo de utilização de elementos mistos no sistema estrutural de uma ponte localizada na China. Neste tipo de aplicação, os elementos tubulares preenchidos com concreto propiciam vantagens como: facilidade de transporte dos elementos de aço devido ao seu pequeno peso, grande rigidez e capacidade resistente da seção mista final.

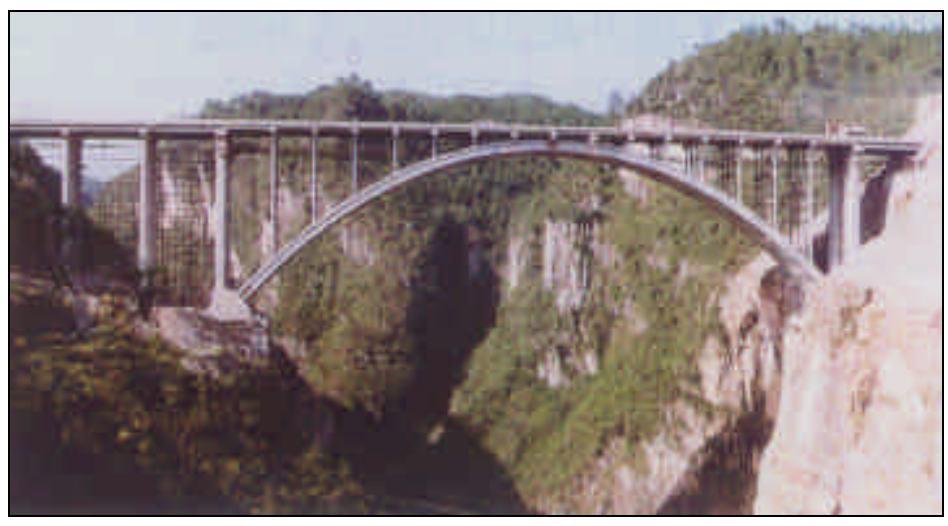

FIGURA 2.1 - EXEMPLO DA APLICAÇÃO DE ELEMENTOS MISTOS NO SISTEMA ESTRUTURAL DE UMA PONTE - CHINA ${ }^{2}$

\footnotetext{
${ }^{2}$ Fonte: Revista Structural Engineering International, v.07, n.03, p.155, 1997.
} 
A crescente utilização de sistemas estruturais formados por elementos mistos é atribuída por ZANDONINI (1994) a fatores como:

1) os avanços tecnológicos nos processos de obtenção de perfis tubulares e de conectores metálicos tornaram mais fácil o acesso a tais materiais e diminuíram os custos de produção;

2) os projetos arquitetônicos atuais exigem grandes áreas livres, implicando em grandes vãos para as vigas, acréscimo de força nos pilares e um maior espaçamento entre eles. Os elementos mistos possibilitam a redução das dimensões da seção transversal, ampliando as áreas livres;

3) a necessidade de atender aos prazos de entrega da construção requer que sejam empregados sistemas estruturais para os quais seja possível obter rapidez e facilidade de execução, sem acréscimo no custo final da edificação;

4) os avanços tecnológicos permitem obter concretos e aços com alta resistência e melhor comportamento. Tais avanços possibilitaram também o surgimento de guindastes móveis e outros equipamentos que facilitam o transporte dos elementos.

O conjunto de todos estes fatores é o grande responsável pelos avanços tecnológicos verificados nos processos construtivos. É importante frisar que o emprego de elementos mistos constitui não só uma opção de sistema estrutural, mas também de processo construtivo e como tal, suas vantagens estendem-se também a estes aspectos.

\subsection{OS PILARES MISTOS AÇO-CONCRETO}

O concreto associado ao aço, compondo elementos mistos surgiu como uma alternativa simples e pouco onerosa de proteção contra o fogo e a corrosão.

Os primeiros elementos mistos a surgir foram vigas de seção I, revestidas com concreto a fim de conferir-lhes proteção contra a ação do fogo. A partir desta aplicação inicial, o mesmo raciocínio foi estendido aos pilares metálicos.

Como possuía apenas função protetora, o concreto utilizado era de baixa resistência e sua contribuição para a capacidade resistente da seção, pequena devido à sua qualidade não estrutural, era desprezada. 
Atualmente, graças à evolução das técnicas de produção de materiais, são encontrados no mercado, materiais de proteção contra ação do fogo e da corrosão com custo muito inferior ao do concreto. Decorrente disso, o emprego do concreto, seja contra a ação do fogo ou da corrosão, nem sempre é a alternativa mais viável economicamente.

A idéia de proteção aos pilares metálicos impulsionou o surgimento dos primeiros pilares mistos aço-concreto, que desde então evoluíram e hoje apresentam variações no arranjo destes materiais, sendo classificados em função deste.

\subsubsection{ClassificaÇÃo}

De maneira geral, um pilar misto aço-concreto é um elemento estrutural sujeito a forças predominantes de compressão, no qual o material aço é formado por um ou mais perfis em aço estrutural. Em função da posição que o concreto ocupa na seção mista, os pilares mistos podem ser classificados como revestidos ou preenchidos, embora existam outras formas de associação, dentre as quais se destacam os pilares mistos tipo "battened" e os parcialmente revestidos.

Os pilares tipo "battened" são formados por dois perfis tipo U, ligados entre si por talas e preenchidos com concreto. Sua utilização restringe-se a investigações experimentais devido à facilidade de instrumentação do concreto. Na FIGURA 2.2 é apresentado um pilar misto tipo "battened" .
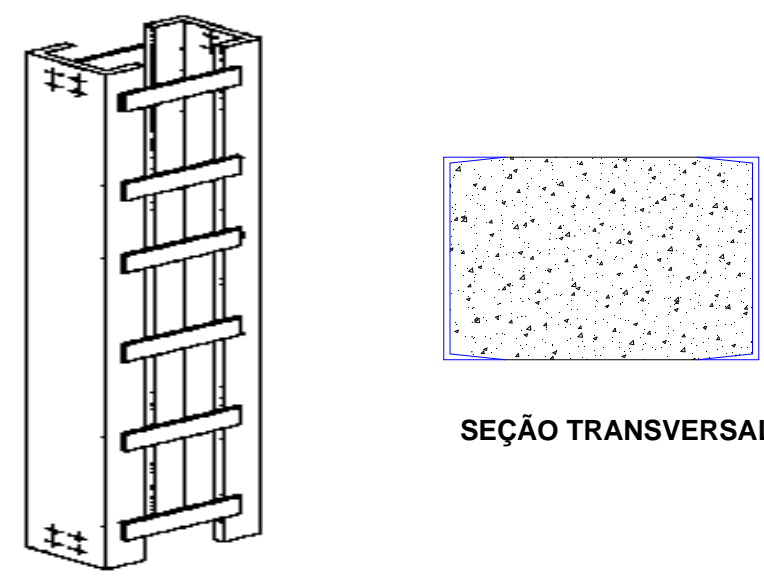

SEÇÃO TRANSVERSAL

Figura 2.2 - PILAR MISTO TIPO "BATTENED" 
Os pilares mistos parcialmente revestidos caracterizam-se pelo não envolvimento completo da seção de aço pelo concreto, conforme ilustra a FIGURA 2.3.

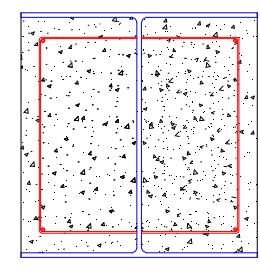

FIGURA 2.3 - EXEMPLO DE PILAR MISTO PARCIALMENTE REVESTIDO

\subsubsection{Pilares Mistos REVESTIDOS}

Este tipo de pilar (FIGURA 2.4) caracteriza-se pelo envolvimento, por concreto, do elemento estrutural em aço, composto por um ou mais perfis de aço.

Os pilares mistos revestidos foram os primeiros pilares mistos a surgir e os primeiros a serem estudados.
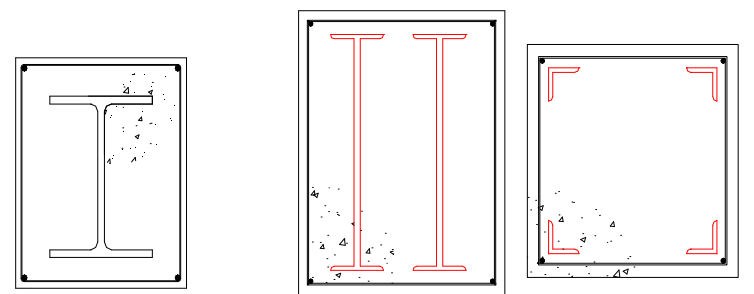

FIGURA 2.4 - EXEMPLOS DE PILAR MISTO REVESTIDO

A presença do concreto estrutural como revestimento promove um aumento na capacidade resistente da seção de aço, pois os dois materiais trabalham em conjunto, minimizando os fenômenos de flambagem local e global do pilar de aço e funcionando como proteção contra o fogo e a corrosão. Além do aspecto de proteção, outra vantagem atribuída aos pilares revestidos é a variabilidade de formas que a seção final mista pode apresentar.

Contrapondo-se às vantagens, a execução deste tipo de pilar é trabalhosa pois exige a utilização de formas durante a concretagem e cuidados no posicionamento e fixação dos perfis e barras de armadura. As barras de armadura são necessárias e recomendadas pelas normas a fim de combater o fendilhamento na capa de concreto. A localização destas barras pode ser vista na FIGURA 2.4. 


\subsubsection{PILARES MISTOS PREENCHIDOS}

Os pilares mistos preenchidos são elementos estruturais formados por perfis tubulares, preenchidos com concreto de qualidade estrutural (FIGURA 2.5).

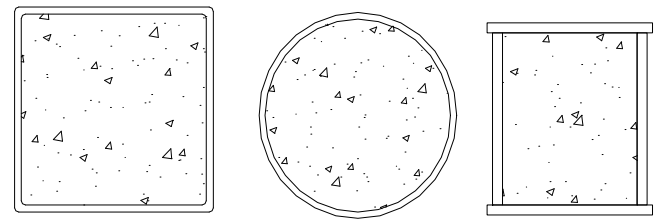

FIGURA 2.5 - EXEMPLOS DE PILARES MISTOS PREENCHIDOS

\subsubsection{Principals CARACTERÍsticas dos PILARES MISTOS PREENCHIDOS}

A crescente utilização dos pilares mistos preenchidos em países europeus, asiáticos e americanos deve-se ao grande número de qualidades resultantes deste tipo de associação de materiais. Tais qualidades abrangem aspectos construtivos, econômicos e de comportamento estrutural tais como:

excelentes propriedades resistentes quanto à atuação de ações sísmicas, proporcionando alta resistência, rigidez e capacidade de absorver energia. UY \& PATIL (1996) confirmam que a alta resistência e o baixo peso do pilar misto são fatores que se somam, contribuindo para um melhor comportamento frente às ações sísmicas. BRAUNS (1999) destaca que o preenchimento com concreto aumenta a resistência e a rigidez do perfil tubular isolado, sem aumentar suas dimensões externas;

$\rightarrow$ a aplicação de proteção contra a ação do fogo é simples e às vezes desnecessária. SHAKIR-KHALIL (1994) afirma que sob situação de fogo, o núcleo de concreto funciona como uma espécie de "dissipador" de calor, melhorando a resistência da seção de aço ao fogo, a tal ponto de tornar desnecessário o uso de materiais específicos para este fim. Tal questão será abordada com maiores detalhes no capítulo 5;

$\Rightarrow$ durante o processo construtivo, o perfil tubular é usado como elemento resistente às ações construtivas, de lançamento e/ou bombeamento do concreto, até que este atinja resistência adequada para colaborar na capacidade resistente. O perfil funciona como forma permanente, minimizando custos com materiais e mão-de-obra; 
$\Rightarrow$ devido à ação conjunta dos materiais, são necessárias menores quantidades de aço e concreto para resistir a esforços de compressão e momentos fletores. Segundo KVEDARAS \& SAPALAS (1999), a atuação do carregamento é responsável por esta ação conjunta, que resulta em aumentos significativos de resistência dos materiais aço e concreto. UY \& PATIL (1996) lembram que um aspecto muito importante para os edifícios altos é a disponibilidade da maior área livre possível em cada pavimento, especialmente nos inferiores, onde as solicitações nos pilares são maiores e por isso, na maioria das vezes, suas dimensões também o são. Estes pesquisadores sugerem que sejam usados aço e concreto de alta resistência, para diminuir ainda mais as dimensões dos pilares. UY \& DAS (1997) concordam com esta recomendação, lembrando que isto conduz, além das vantagens há pouco citadas, a forças de menor intensidade nos elementos de fundação, reduzindo suas dimensões e o consumo de materiais. Comparado com seções em concreto armado, a utilização de um pilar misto permite obter a mesma capacidade resistente, porém consumindo menores quantidades de materiais.

A viabilidade do emprego dos pilares mistos preenchidos é destacada por PRION \& BOEHME (1994). Para eles, a associação de perfis de aço com concreto simples, formando os pilares mistos preenchidos, é a ideal para estes materiais pois o perfil de aço confina lateralmente o concreto de preenchimento, aumentando sua resistência à compressão e em contrapartida, o concreto previne e minimiza a possibilidade de ocorrência de flambagem local do perfil tubular.

O aspecto de melhoria no comportamento dos materiais, sobretudo do concreto é muito importante. Sabe-se que o concreto de preenchimento pode ser de resistência normal ou de alta resistência, entretanto os avanços tecnológicos impulsionaram a fácil obtenção de concretos de alta resistência, tornando tal opção de preenchimento muito atrativa, sobretudo do ponto de vista estrutural. As investigações teóricas e experimentais com concreto de alta resistência, empregado em pilares de concreto armado indicaram dois problemas na ruptura:

1) apenas o volume de concreto envolto pelas armaduras transversal e longitudinal pode ser computado como material resistente. Conseqüentemente, a área resistente de concreto é menor que a área bruta da seção; 
2) os pilares em concreto de alta resistência requerem altas taxas de armadura longitudinal e transversal para que seja conseguido um certo grau de ductilidade, que minimize os efeitos negativos da ruptura frágil, característica do concreto de alta resistência.

Desta forma, já que são necessárias altas taxas de armadura para que os pilares em concreto de alta resistência tenham comportamento satisfatório, por que não recorrer ao encamisamento deste concreto com um perfil tubular? Com isto consegue-se uma solução em que toda a seção de concreto resiste aos esforços, há como conseqüência um melhor aproveitamento deste material e ainda, as vantagens construtivas e estruturais inerentes a este tipo de elemento misto.

Embora seja uma associação eficaz entre aço e concreto, PRION \& BOEHME (1994) destacam como desvantagem e atual limitação de utilização deste tipo de pilar misto, o custo das ligações viga-pilar e a escassez de procedimentos construtivos eficientes, quer sejam das ligações ou da estrutura como um todo.

\subsubsection{UTILIZAÇÃO DOS PILARES MISTOS PREENCHIDOS}

Devido às características resultantes da associação de perfis e concreto, os pilares mistos preenchidos têm sido empregados na composição do sistema estrutural de diversos tipos de construções, sempre buscando explorar esta associação da melhor forma possível. Dentro deste contexto destaca-se sua aplicação em obras de arte como viadutos e pontes, em cais de porto e estruturas de apoio em plataformas marítimas. Alguns destes exemplos de aplicação são ilustrados na FIGURA 2.6.

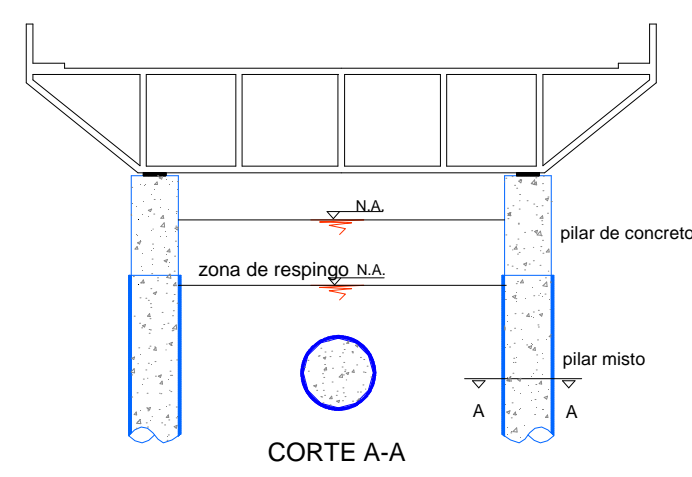

A) PONTE

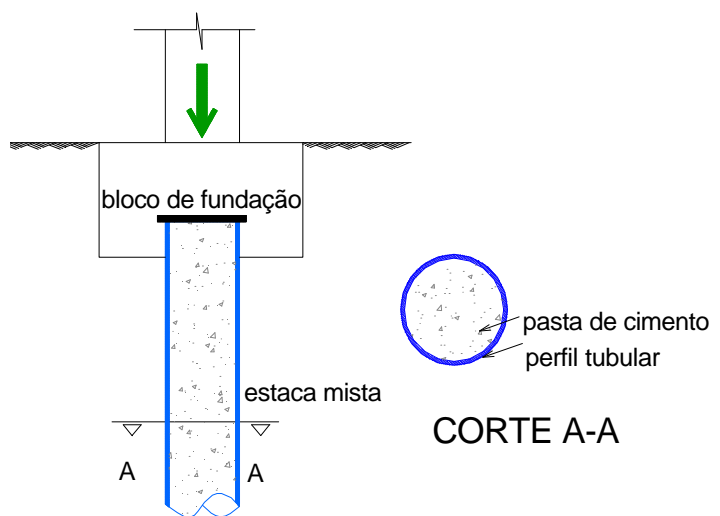

B) ESTACAS

FIGURA 2.6 - EXEMPLOS DE APLICAÇÃO DOS PILARES MISTOS PREENCHIDOS 
Embora de aplicação diversa, nos sistemas estruturais de edifícios, sobretudo de edifícios altos, é onde se verifica o maior número de aplicações dos pilares mistos preenchidos. A opção por tal elemento estrutural não se deve ao acaso, e sim à comparação dos custos relativos a materiais, equipamentos e mãode-obra envolvidos no processo construtivo. Neste sentido, UY \& PATIL (1996) apresentam os custos relativos a diversas alternativas estruturais, comprovando que a opção por pilares mistos preenchidos é extremamente vantajosa. Os autores destacam que esta opção representa uma economia de $30 \%$ nos custos referentes às etapas construtivas, quando comparado com pilares convencionais de aço. Estes custos podem sofrer reduções ainda maiores se forem utilizados aços e concretos de alta resistência.

Ainda com relação ao aspecto econômico, para GOMES (1994) os sistemas construtivos com elementos mistos permitem construir grandes torres, com relação custo/altura relativamente pequena, de forma que o custo deixa de ser uma desvantagem na construção de edifícios altos.

Na FIGURA 2.7 são apresentados alguns edifícios altos, nos quais os pilares mistos preenchidos fazem parte do sistema estrutural. 


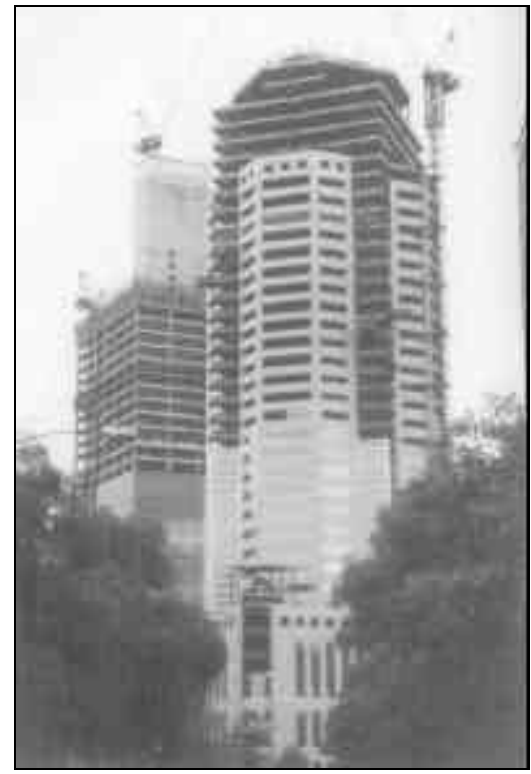

Edifício Casselden Place ${ }^{3}$ (1992) 46 pavimentos; $f_{\mathrm{ck}}=70 \mathrm{MPa}$ (nos pilares) localização: Melbourne - Austrália

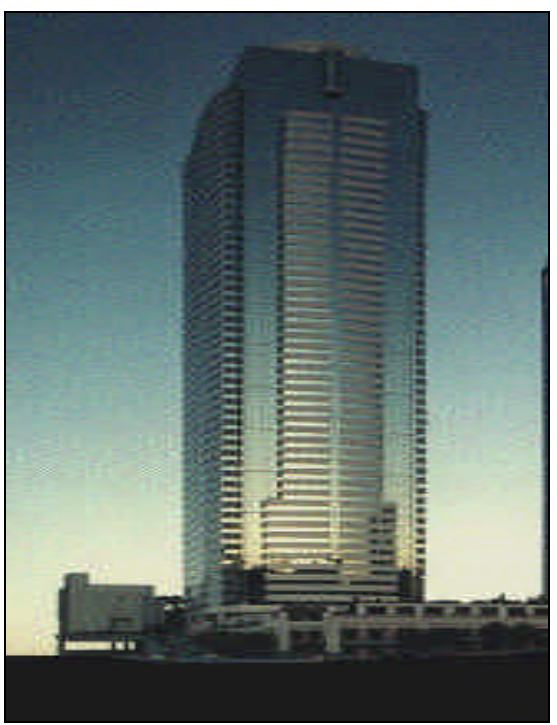

Edifício Two Union Square ${ }^{5}$

60 pavimentos; $f_{\mathrm{ck}}=110 \mathrm{MPa}$ (nos pilares) localização: Washington - Estados Unidos

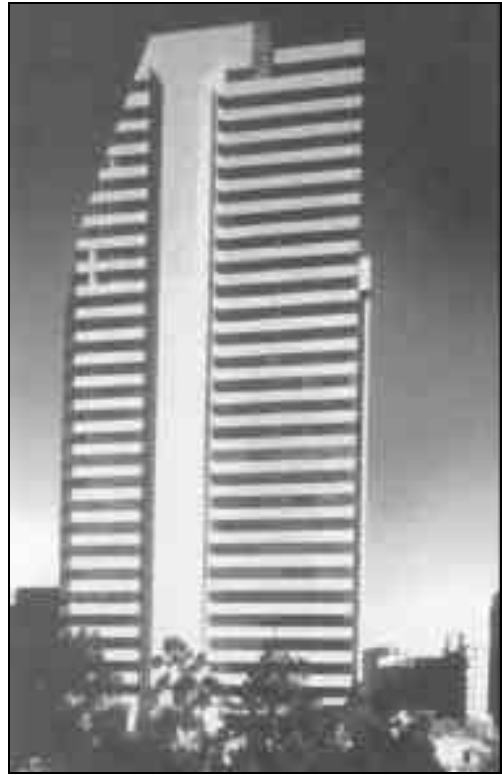

Edifício Forrest Centre ${ }^{4}$ localização: Perth - Austrália

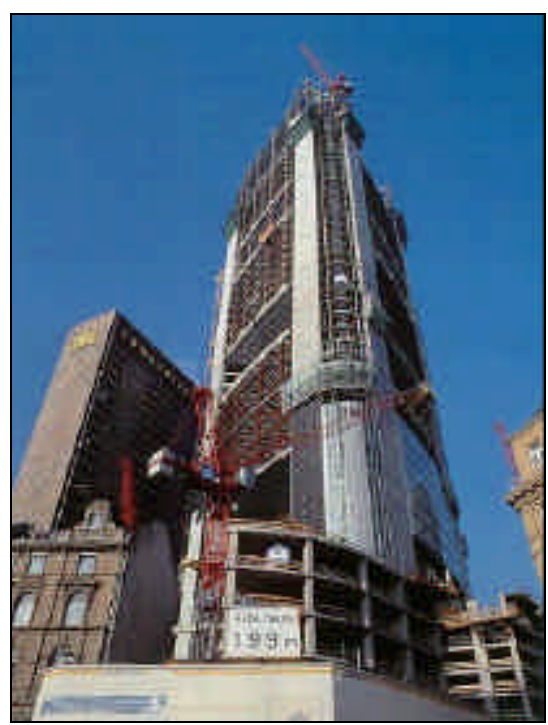

Edifício Commerzbank ${ }^{6}$ 63 pavimentos

localização: Frankfurt - Alemanha

${ }^{3}$ Council on tall buildings and urban habitat. Committee 3, p.128, 1995.

${ }^{4}$ Council on tall buildings and urban habitat. Committee 3, p.357, 1995.

${ }^{5}$ Commercial desing (1998). http://www.nbbj.com/SEAPRO 3.HTM (06/06/1998)

${ }^{6}$ The highest office building in Europe (1998). http:Ilwww.hebel.com/commerzb.htm (06/06/98) 


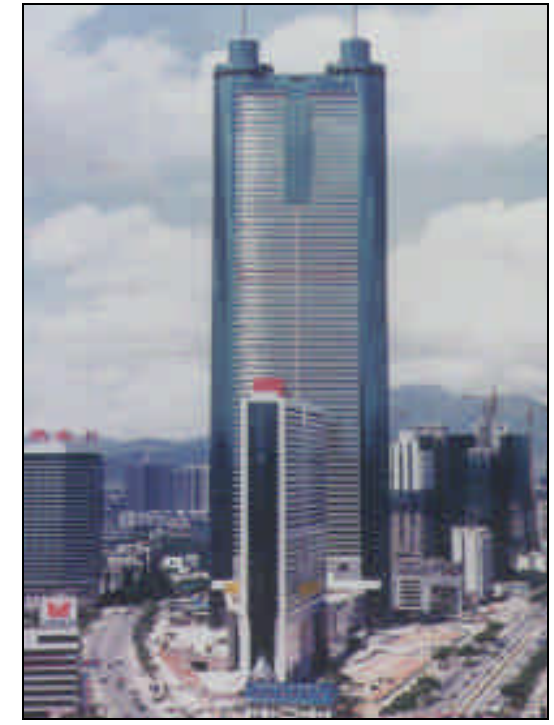

Edifício Shun Hing Square ${ }^{7}$ (1997) 77 pavimentos; $f_{c k}=45 \mathrm{MPa}$ (nos pilares) localização: Shenzhen - China

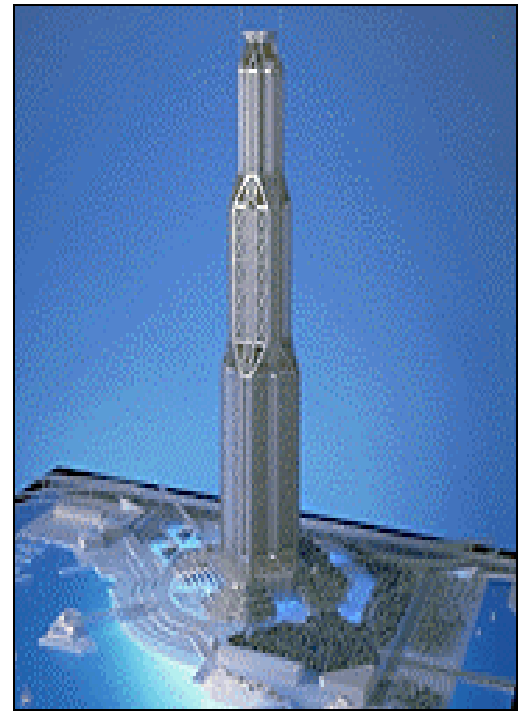

Edifício Shimizu Super High Rise Building ${ }^{8}$ 127 pavimentos localização: Tóquio - Japão

FIGURA 2.7 - APLICAÇÃO DOS PILARES MISTOS PREENCHIDOS EM EDIFÍCIOS

Alguns detalhes sobre os edifícios mostrados na FIGURA 2.7 são apresentados a seguir:

\section{Casselden Place}

Localizado em Melbourne na Austrália, este edifício comercial foi concluído em 1992 e possui 46 pavimentos, totalizando $160 \mathrm{~m}$ de altura. Os pavimentos possuem cerca de $3,75 \mathrm{~m}$ de altura; as vigas têm $61 \mathrm{~cm}$ de altura, $3 \mathrm{~m}$ de vão e espaçamento de $12 \mathrm{~m}$. As lajes são do tipo steel deck com altura de $13 \mathrm{~cm}$, já incluída a capa de concreto. Quanto aos pilares, possuem seção circular com 95 $\mathrm{cm}$ de diâmetro, preenchida com concreto de $70 \mathrm{MPa}$ de resistência à compressão. O sistema construtivo empregado nos pilares mistos preenchidos é um fator de destaque. Os perfis tubulares foram posicionados e fixados com altura de seis pavimentos e em seguida, o concreto foi bombeado para dentro do perfil, por meio de aberturas na base do pilar. Mais detalhes sobre tal processo construtivo serão vistos posteriormente.

\footnotetext{
7 Revista Structural Engineering International, v. 07, n.o 03, p.157, 1997.

8 Shimizu corporations (1998).

http://www.shimz.co.jp/japanese/tech/technology/solution/solution.html. (06/06/1998)
} 
O custo total com o processo construtivo foi semelhante ao de um sistema estrutural em concreto armado, porém com as vantagens inerentes à utilização de sistemas estruturais mistos.

\section{TWO UNION SQUARE}

Este edifício comercial possui 60 pavimentos, com altura total de $220 \mathrm{~m}$ e está localizado em Washington, numa região em que é preciso considerar a ocorrência de ações sísmicas. O estudo de diversas opções estruturais indicou que a utilização de pilares mistos preenchidos era a mais vantajosa. A resistência do concreto de preenchimento chegou a atingir $130 \mathrm{MPa}$.

\section{COMMERZBANK}

Localiza-se em Frankfurt na Alemanha, tem 63 pavimentos e é um dos edifícios mais altos da Europa, com $259 \mathrm{~m}$ de altura. Três grandes pilares mistos preenchidos, de seção triangular, compõem seu sistema estrutural. Vistos em planta, estes pilares formam um grande triângulo equilátero.

\section{SHIMIZU SUPER HIGH RISE BUILDING}

Tal edifício possuirá aproximadamente $550 \mathrm{~m}$ de altura nos quais estarão distribuídos hotéis, escritórios e estacionamentos. Possuirá ao todo, 127 pavimentos. As vigas serão metálicas com alturas de 120 e $90 \mathrm{~cm}$, vãos de 22,4 e $15,8 \mathrm{~m}$ e espaçadas de 12,8 e $20 \mathrm{~m}$. As lajes serão do tipo steel deck, acrescidas de uma camada de concreto leve. Os pilares serão preenchidos com concreto de alta resistência para garantir comportamento melhor. Quando concluído, será o edifício mais alto do mundo.

Podem ser citados ainda:

- Edifícios Riverside Office e Myer Centre: pilares preenchidos circulares localização: Adelaide/Austrália.

- Edifício Commowealth Centre - localização: Melbourne.

- Edifício Market City: pilares preenchidos circulares - localização: Sidney /Austrália.

- Edifícios Exchange Plaza e Westralia Square: pilares preenchidos retangulares - localização: Perth/Austrália. 
A aplicação dos pilares mistos preenchidos em sistemas estruturais de edifícios altos é uma opção atrativa, entretanto não deve ser vista como restrita a este tipo de edifício. Como já destacado anteriormente, os pilares mistos preenchidos não são vantajosos apenas do ponto de vista estrutural. Em diversas situações, características como velocidade construtiva e economia de materiais são tão importantes quanto o aspecto estrutural. Nestes casos, é fundamental ter em mente que é possível executar edifícios de altura usual empregando pilares mistos preenchidos.

\subsection{ASPECTOS CONSTRUTIVOS}

Optar por sistemas estruturais formados por elementos mistos é uma escolha que requer o conhecimento do comportamento estrutural do conjunto e de todas as atividades necessárias à sua execução, pois todos estes fatores interferem em aspectos como economia, produtividade e comportamento estrutural.

Segundo VALLENILLA \& BJORHOVDE (1990) os elementos mistos são normalmente utilizados em estruturas metálicas com o objetivo de empregar 0 concreto para aumentar a resistência e a rigidez das seções de aço. Desta forma, os sistemas estruturais mistos combinam uma estrutura externa de pilares mistos ligados a vigas, metálicas ou mistas, as quais recebem as lajes. UY \& DAS (1996) sugerem como arranjo estrutural empregado em sistemas estruturais mistos, o posicionamento dos pilares mistos preenchidos no contorno do edifício, associados a núcleos estruturais localizados na região central e ligados por vigas e lajes. Tal arranjo é ilustrado na FIGURA 2.8 e assemelha-se ao sugerido por VALLENILLA \& BJORHOVDE (1990).

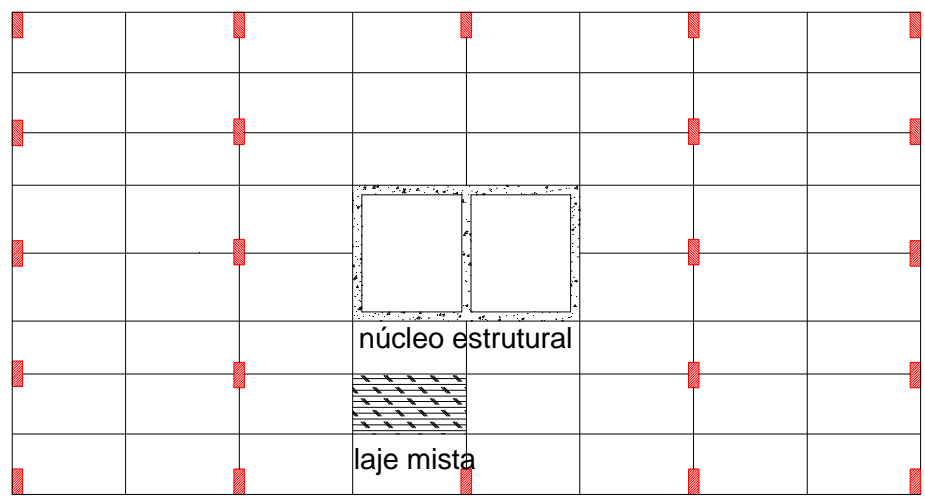

pilar misto preenchido

FIGURA 2.8 - ARRANJO ESTRUTURAL TíPICO EMPREgADO EM SISTEMAS ESTRUTURAIS COM PILARES MISTOS 
Em alguns casos, devido a imposições arquitetônicas ou estruturais, os pilares mistos preenchidos são usados apenas nos primeiros pavimentos do edifício e nos demais, são empregados perfis tubulares metálicos isolados ou, pilares em concreto armado (FIGURA 2.9a).

VALLENILLA \& BJORHOVDE (1990) propõem que o sistema estrutural do edifício seja formado por pórticos mistos nos primeiros pavimentos, vigas mistas nos pavimentos intermediários e pórticos de aço nos pavimentos superiores, como ilustra a FIGURA 2.9b. Tal disposição é interessante pois são empregados pórticos mistos nos primeiros pavimentos, onde as solicitações verticais são grandes.

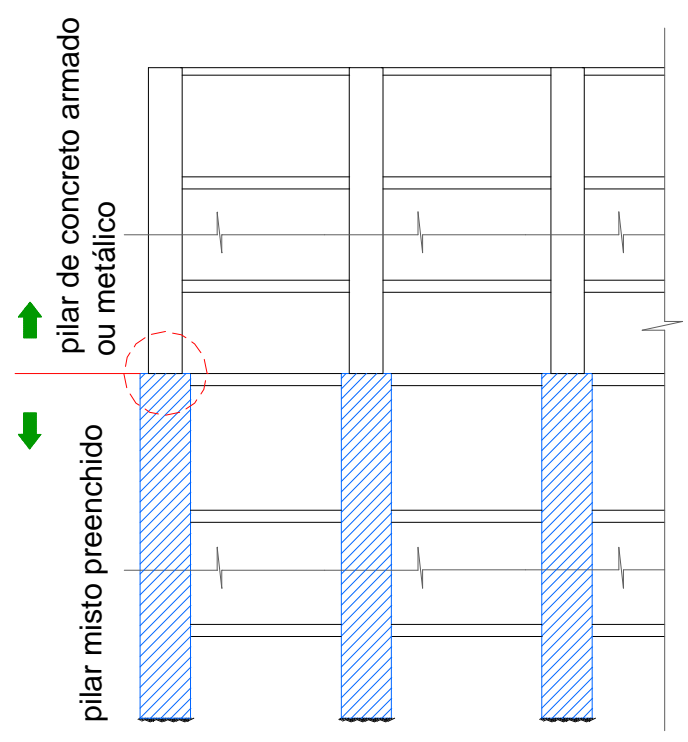

a) Pilares mistos preenchidos associados A PILARES DE AÇO OU DE CONCRETO ARMADO

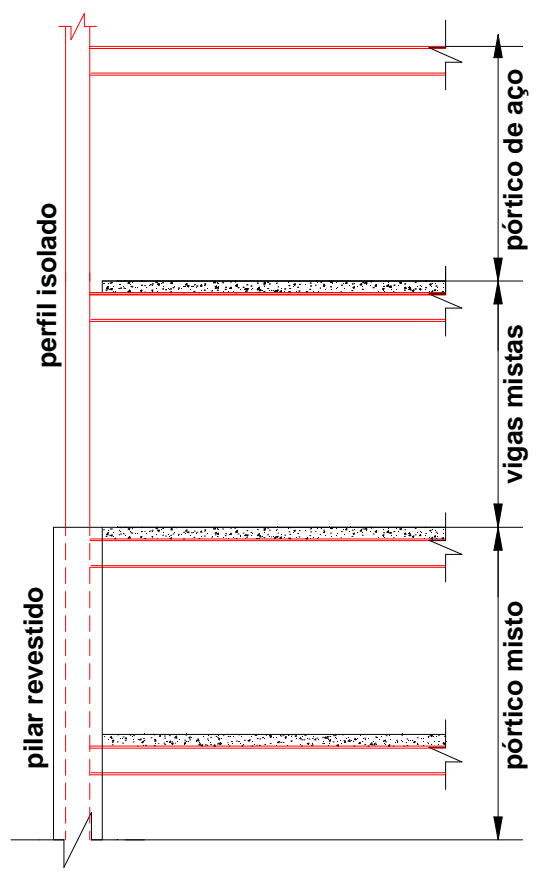

b) Pórticos mistos

FIGURA 2.9 - ESQUEMA DE SISTEMAS ESTRUTURAIS PARA EDIFíCIOS

Para a análise estrutural destes edifícios, VALLENILLA \& BJORHOVDE (1990) sugerem que a resistência às forças laterais seja garantida apenas pelos pilares mistos situados no contorno do edifício. Entretanto, para grandes edifícios, é recomendável a análise tridimensional, considerando pórticos espaciais e incluindo as características de todos os elementos e das ligações, bem como os efeitos de segunda ordem.

No projeto de um sistema estrutural formado por elementos mistos devem ser consideradas a resistência e a rigidez da estrutura durante a fase construtiva. 
Deve haver a preocupação com a estabilidade dos elementos durante a fase de montagem, de forma a garantir a segurança da edificação e dos trabalhadores. Os intervalos entre atividades devem ser tais que evitem problemas de estabilidade e elementos muito solicitados.

A técnica construtiva empregada em sistemas estruturais formados por pilares mistos preenchidos consiste em posicionar e fixar os perfis tubulares, vigas e lajes para diversos pavimentos e em seguida, bombear o concreto para o interior dos pilares, preenchendo os perfis. Esta técnica é apresentada de forma esquemática na FIGURA 2.10 e foi utilizada pela primeira vez na construção do edifício Casselden Place e posteriormente, no Commonwealth Center, ambos situados em Melbourne. Em ambos, foi constatada a viabilidade construtiva dos pilares mistos preenchidos pois se conseguiu redução dos custos de mão-de-obra e maior produtividade, com redução de perdas de materiais.

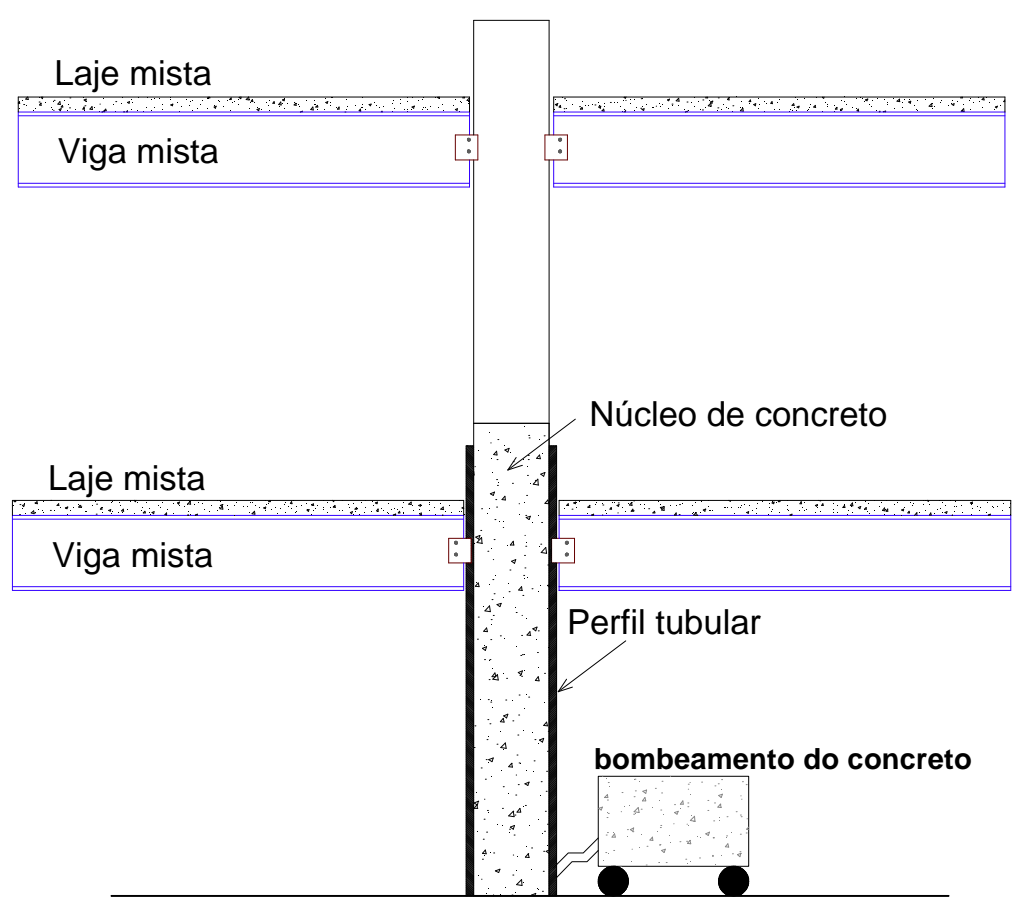

FIGURA 2.10 - TÉCNICA CONSTRUTIVA EMPREGADA NA CONSTRUÇÃO DE PILARES MISTOS PREENCHIDOS

Na execução do edifício Casselden Place foram adotadas sete operações de bombeamento e para cada uma delas montavam-se seis pavimentos. Já na execução do Commonwealth Center foram realizadas doze operações de bombeamento, cada uma correspondendo a 4 pavimentos.

Alguns cuidados devem ser tomados quanto ao número de pavimentos a ser montado para depois bombear o concreto. Tal número é limitado pela estabilidade 
da edificação ou pela resistência do perfil tubular, uma vez que ele é o único elemento resistente do pilar misto, até que o concreto de preenchimento atinja resistência adequada.

O concreto bombeado aplica pressões hidrostáticas no perfil tubular e estas pressões podem causar deslocamentos excessivos à meia altura do pilar, devendose portanto, utilizar limites adequados de esbeltez. Uma forma de reduzir a intensidade destes deslocamentos laterais é fazer o escoramento dos perfis tubulares a meia altura, conforme sugerido por UY \& DAS (1997) e apresentado na FIGURA 2.11.
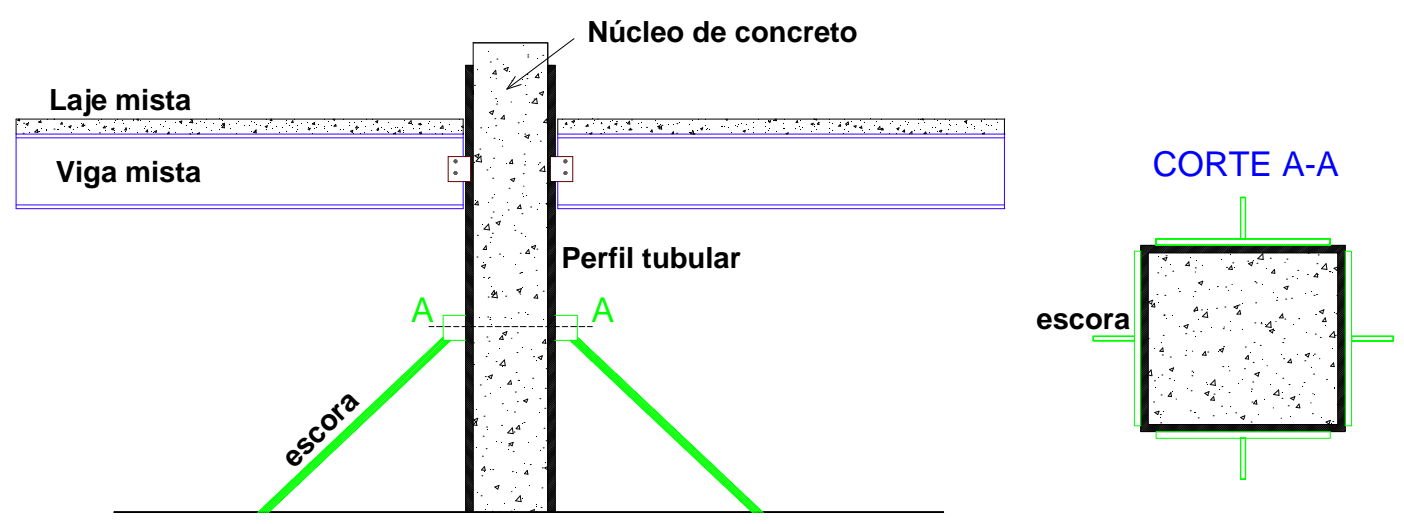

FIGURA 2.11 - TÉCNICA CONSTRUTIVA EM QUE OS PILARES MISTOS PREENCHIDOS SÃO ESCORADOS A MEIA ALTURA

As normas de projeto de pilares mistos preenchidos apresentam pouquíssimas recomendações quanto à fase construtiva. Como exceção, cita-se a norma EUROCODE 4 (1994). Segundo ela, a seqüência construtiva deve ser compatível com o projeto, pois esta exerce grande influência sobre aspectos como tensões, esforços nas ligações e deformações nos elementos. Todas as informações necessárias a esta compatibilidade devem ser claramente indicadas e descritas no projeto e, posteriormente encaminhadas ao setor construtivo. A velocidade e seqüência de concretagem também devem ser especificadas.

\subsection{VISÃo GERAL dA EVOLUÇÃo dAS PESQUISAS E ATUAL ESTADO DE CONHECIMENTO}

Desde suas primeiras aplicações, os pilares mistos preenchidos têm sido estudados com 0 objetivo de conhecer, compreender e equacionar 0 
comportamento desta associação de materiais e com isto oferecer normas de projeto seguras, confiáveis e de fácil aplicação.

Da utilização do concreto como material de proteção para os perfis de aço surgiram os primeiros pilares mistos, que devido à sua origem, eram do tipo revestido.

Os primeiros estudos teóricos e experimentais com pilares mistos foram realizados por Burr em 1912, que estudou os pilares revestidos. Após isto, somente em meados de 1950 os pilares revestidos voltaram a ser objeto de estudo. Nesta mesma década, os pilares preenchidos começaram a ser estudados.

A preocupação inicial era prever a capacidade resistente da seção mista preenchida. Desta forma, em 1957, Kloppel e Goder estabeleceram os limites superior e inferior da capacidade resistente para seções axialmente comprimidas. Furlong em 1967 mostra que o limite inferior de resistência à compressão é dado pela soma de duas forças: a força necessária para causar o escoamento do aço e a força que causaria no concreto, a mesma deformação do aço.

No caso de pilares esbeltos, a capacidade resistente é limitada também pela força normal crítica. Para o seu cálculo utilizam-se valores equivalentes de rigidez, dados pela soma algébrica da rigidez de cada elemento.

Estabelecidas as equações para previsão da capacidade resistente, foram realizados alguns estudos buscando investigar fatores que pudessem interferir no comportamento dos pilares mistos preenchidos.

Neste sentido, um dos primeiros fatores estudados foi 0 efeito do confinamento do concreto.

O efeito de confinamento foi estudado inicialmente por Gardner e Jacobson em 1967. Foi considerado como fator que aumenta a resistência à compressão uniaxial do concreto. Deste estudo resultou uma equação para calcular a capacidade resistente de seções mistas circulares, que diferiu dos resultados experimentais em até $10 \%$.

KNOWLES \& PARK (1969) também estudaram o efeito do confinamento e confirmaram sua contribuição na capacidade resistente de seções mistas preenchidas circulares. Quanto às seções quadradas, a princípio esta contribuição foi muito pequena, sendo por isso desprezada. Os resultados mostraram também que o efeito do confinamento perde intensidade à medida que o comprimento do 
pilar aumenta. Assim, a partir de um determinado limite de esbeltez, sua contribuição deve ser desprezada, mesmo para pilares mistos circulares.

SAADEGHVAZIRI \& SHAMS(1997) destacam as equações propostas por Sen, aplicáveis a seções circulares com relação comprimento/diâmetro ( $\ell / D$ ) menor que 5, a fim de levar em conta o efeito do confinamento nas resistências do concreto e do aço. Para tais índices, foram verificados ganhos de capacidade resistente de até $60 \%$ quando comparadas com a soma das resistências dos materiais aço e concreto $\left(A_{s} \cdot f_{y}+A_{c} \cdot f_{c k}\right)$.

O efeito do confinamento foi confirmado por Neogi, Sen e Chapman em 1969, através de análise numérica com pilares axialmente comprimidos e flexocomprimidos. Foi comprovado também que tal fenômeno diminui à medida que a altura do pilar e/ou a excentricidade da força aumentam.

Os diversos resultados experimentais permitiram introduzir o efeito benéfico das tensões de confinamento nas normas de projeto de pilares mistos preenchidos circulares, que são empregados até hoje.

Uma abordagem detalhada sobre os efeitos do confinamento será apresentada no capítulo 5, entretanto até o momento, as normas existentes consideram o seu efeito benéfico apenas para pilares preenchidos curtos, de seção circular.

Outro fator que poderia interferir no comportamento dos pilares mistos preenchidos era a aderência entre aço e concreto. Estudos para avaliar as tensões de aderência foram realizados por SHAKIR-KHALIL (1988, 1993a e 1993b) e SHAKIR-KHALIL \& ZEGHICHE (1989), com pilares mistos preenchidos. HUNAITI \& WAKABAYASHI (1992) e HUNAITI (1992) estudaram experimentalmente pilares do tipo "battened" (FIGURA 2.2), buscando investigar a aderência.

Os diversos estudos sobre a questão da aderência são apresentados com maiores detalhes no capítulo 5, porém sabe-se que este tema é motivo de pesquisas porque existem dúvidas quanto à sua influência na capacidade resistente e no comportamento do pilar misto preenchido.

Uma série de pesquisas foram desenvolvidas buscando avaliar o grau de segurança presente nas normas de dimensionamento de pilares mistos preenchidos, sobretudo na previsão da capacidade resistente da seção mista. Neste sentido, destacam-se a seguir, alguns trabalhos experimentais. 
SHAKIR-KHALIL \& ZEGHICHE (1989) e SHAKIR-KHALIL \& MOULI (1990) analisaram o comportamento de pilares mistos preenchidos retangulares e compararam a força de ruptura com a capacidade resistente prevista pela BS 5400: parte 5. Os resultados experimentais mostraram que tal norma permite uma estimativa razoável da capacidade resistente.

Os resultados de SHAKIR-KHALIL \& MOULI (1990) mostraram também que o preenchimento com concreto aumenta a resistência do pilar de aço. Este acréscimo chega a atingir $65 \%$, quando se compara a capacidade resistente da seção mista com a capacidade resistente do perfil tubular metálico.

Para WANG \& MOORE (1997), embora haja algumas normas destinadas ao projeto de pilares mistos preenchidos, a comparação da capacidade resistente obtida a partir das normas BS 5400: parte 5 e EUROCODE 4 permitiu constatar uma discrepância significativa entre elas. Esta discrepância é ainda maior para pilares esbeltos flexo-comprimidos.

Atualmente, os pilares mistos preenchidos são dimensionados a partir de algumas normas de projeto específicas. Entretanto, SAADEGHVAZIRI \& SHAMS (1997) são categóricos ao afirmar que ainda há uma série de questões relativas ao comportamento dos pilares mistos preenchidos que precisam ser respondidas. Para eles, a capacidade resistente da seção mista ainda não é prevista com critérios adequados pois para algumas normas, o efeito benéfico do confinamento não é levado em conta. Efeitos de fatores como índice de esbeltez, índice de forma $\mathrm{D} / \mathrm{t}$, forma da seção transversal e fluência do concreto são ignorados.

A aderência ainda não é uma questão bem resolvida, especialmente no que se refere à sua importância para pilares mistos preenchidos esbeltos ou sujeitos a flexo-compressão. O efeito de fatores como índice de esbeltez e uso de conectores de cisalhamento sobre a aderência também precisa ser bem conhecido.

Quanto aos materiais utilizados, sabe-se que os pilares mistos preenchidos são empregados devido, além de outros fatores, à sua alta rigidez. O emprego de concretos de alta resistência afeta tanto a rigidez quanto a ductilidade destes elementos no entanto, não há estudos que quantifiquem estes parâmetros e as normas de projeto não estão adequadas às mudanças de comportamento que a utilização deste material provoca. 
Diante do que foi encontrado na revisão bibliográfica constata-se que ainda há muito que estudar, até que se chegue a um consenso quanto aos critérios adequados de dimensionamento e de verificação dos pilares mistos preenchidos.

Sendo assim, estudos adicionais são imprescindíveis a fim de responder a diversos pontos duvidosos aqui detectados e introduzi-los nas normas existentes, buscando aproximá-las ainda mais, do comportamento real do pilar misto preenchido. 


\section{NORMAS TÉCNICAS PARA O PROJETO DE PILARES MISTOS PREENCHIDOS}

\subsection{INTRODUÇÃO}

As pesquisas teóricas e experimentais buscando conhecer e esclarecer 0 comportamento dos pilares mistos preenchidos, desenvolvidas ao longo das últimas décadas, deram origem a algumas normas que fornecem recomendações para o projeto destes elementos estruturais, sobretudo no que se refere à previsão da sua capacidade resistente.

Por serem oriundas de estudos experimentais cujos procedimentos e considerações variam muito de um país para outro, as normas de dimensionamento abordam os pilares mistos preenchidos sob diferentes ângulos. Algumas normas consideram os pilares mistos preenchidos como pilares de aço cuja capacidade estrutural é aumentada pela presença do núcleo de concreto. Assim, a seção mista é reduzida a uma seção equivalente de aço, modificando-se alguns parâmetros de forma a considerar a presença do concreto. Com esta filosofia destacam-se a norma americana AISC-LRFD (1994), a norma canadense CAN/CSA-S16.1 (1989) e a norma britânica BS 5400: parte 5 (1979). Outra forma de abordar estes elementos é considerá-los pilares de concreto armado, cuja armadura é composta por perfis metálicos. Esta é a filosofia adotada 
pelo ACl 318R-92 (1992), que aplica aos pilares preenchidos as mesmas recomendações aplicáveis aos pilares de concreto armado.

Há uma outra forma de abordar a seção mista, que consiste em usar a combinação dos dois raciocínios apresentados; tal procedimento é adotado pela norma européia EUROCODE 4 (1994).

Por estarem fundamentadas em estudos experimentais, a simples comparação entre os resultados obtidos a partir das diferentes normas não é um procedimento adequado pois conduz a grandes discrepâncias, especialmente quando da previsão da capacidade resistente à compressão. Estas discrepâncias são atribuídas, entre outros fatores, às diferentes filosofias de projeto empregadas, às diferentes formas de corpos-de-prova empregados na determinação da resistência característica do concreto, e ainda, a alguns coeficientes determinados empiricamente.

A observação das equações propostas para o cálculo da capacidade resistente à compressão, indica que algumas normas levam em conta o efeito do confinamento do concreto e o fazem apenas para seções circulares. Este efeito é introduzido através de coeficientes que majoram a resistência à compressão uniaxial do concreto e diminuem a resistência ao escoamento do perfil tubular.

\subsection{NOMENCLATURA}

As principais normas de projeto aplicáveis a pilares mistos preenchidos são apresentadas a seguir, de forma breve. Para facilitar sua compreensão e utilização procurou-se uniformizar a nomenclatura. Assim, apresenta-se a seguir, a nomenclatura empregada neste texto.

$\boldsymbol{A}_{c}$ : área da seção transversal de concreto

$\boldsymbol{A}_{\boldsymbol{s}}$ : área da seção transversal do perfil tubular

$\boldsymbol{A}_{\boldsymbol{t}}$ : área total da seção mista, incluindo os dois componentes

$C_{r}$ : resistência do perfil tubular, empregada pela CAN/CSA-S16.1 (1989)

$D$ : diâmetro externo do perfil tubular

$E_{c}$ : módulo de deformação longitudinal do concreto de preenchimento

$E_{c}^{\prime}$ : módulo de deformação longitudinal do concreto de preenchimento, considerando a retração

$\boldsymbol{E}_{\boldsymbol{m}}$ : módulo de elasticidade modificado, empregado pelo AISC-LRFD (1994) 
$\boldsymbol{N}_{\text {nd }}$ : capacidade resistente à compressão axial

b: menor dimensão do pilar misto

$\boldsymbol{f}_{c c}$ : valor de $\mathrm{f}_{\text {cu }}$ modificado devido ao efeito de confinamento, empregado pela BS 5400: parte 5 (1979) para seções circulares

$\boldsymbol{f}_{c k}$ : resistência à compressão do concreto, medida em corpos-de-prova cilíndricos $15 \times 30 \mathrm{~cm}$

$f_{c u}$ : resistência à compressão do concreto, medida em corpos-de-prova cúbicos de $10 \mathrm{~cm}$ de lado, empregado pela BS 5400: parte 5 (1979)

$\boldsymbol{f}_{c t m}$ : resistência à tração adotada pelo EUROCODE 4 (1994)

$\boldsymbol{f}_{\boldsymbol{m} y}$ : resistência ao escoamento modificada, empregada pelo AISC-LRFD (1994)

$\boldsymbol{f}_{\boldsymbol{y}}$ : resistência ao escoamento do perfil tubular

$\boldsymbol{f}_{\boldsymbol{y}}$ : $\mathrm{f}_{\mathrm{y}}$ modificado devido ao efeito de confinamento, empregado pela BS 5400: parte 5 (1979) para seções circulares

$\boldsymbol{k} \ell$ : comprimento efetivo do pilar misto

$\ell$ : comprimento real do pilar misto, dado pela distância entre centros de vinculação

$r_{c}$ : raio de giração do núcleo de concreto

$\boldsymbol{r}_{\boldsymbol{m}}$ : raio de giração do perfil tubular

$t$ : espessura do perfil tubular

$\alpha_{c}$ : fator de contribuição do concreto

$\delta$ : fator de contribuição do perfil tubular

$\lambda_{s}$ : índice de esbeltez do perfil tubular

$\lambda_{c}$ : índice de esbeltez do núcleo de concreto

$\lambda_{p m}$ : índice de esbeltez modificado, empregado pelo AISC-LRFD (1994)

$\bar{\lambda}_{\mathrm{m}}$ : índice de esbeltez reduzida, empregado pelo AISC-LRFD (1994)

\subsection{NORMAS TÉCNICAS}

As normas aqui citadas estão fundamentadas no método dos estados limites.

As principais características de cada uma delas são destacadas a seguir.

\subsubsection{ACI 318R-92 (1992)}

Esta norma aborda o dimensionamento dos pilares mistos de forma breve e sucinta. Os elementos mistos são dimensionados como elementos em concreto 
armado cuja armadura é formada por um ou mais perfis. Efeitos como confinamento e influência do índice de esbeltez não são considerados.

\subsubsection{AISC-LRFD (1994)}

A formulação apresentada para pilares mistos parte dos procedimentos empregados para o cálculo de pilares de aço, porém parâmetros como esbeltez e módulo de deformação são modificados para considerar a presença benéfica do concreto.

\subsubsection{BS 5400: PARTE 5 (1979)}

A norma BS 5400: Parte 5 (1979) cuja denominação é "Steel, Concrete and Composite Bridges - Part 5: Code of practice for design of composite bridges", tem seu procedimento de cálculo fundamentado em estudos experimentais e teóricos desenvolvidos principalmente no Imperial College.

A formulação apresentada é aplicável a situações de compressão axial, flexão composta normal e flexão composta oblíqua. Caso a situação analisada seja de flexão composta oblíqua, é recomendada a superposição de dois casos de flexão composta normal, cada um ocorrendo num dos planos principais e atuando separadamente.

\subsubsection{CAN/CSA-S16.1 (1989)}

Os pilares mistos preenchidos são abordados pela norma canadense CAN/CSA-S16.1, destinada a elementos de aço. Ela considera pilares mistos aqueles cujas seções de aço vazadas são completamente preenchidas com concreto.

Para a norma canadense, o efeito de confinamento não é considerado para nenhuma forma de seção transversal.

Para aplicação da norma canadense destinada a pilares mistos, os perfis tubulares são divididos em duas classes em função do seu processo de obtenção:

seções classe $\boldsymbol{H}$ : inclui todos os perfis laminados, trabalhados a quente e aqueles formados a frio, que sofreram posterior alívio de tensões

seções classe $\boldsymbol{C}$ : perfis formados a frio sem posterior alívio de tensões. 


\subsubsection{EUROCODE 4 (1994)}

O EUROCODE 4 foi redigido e adaptado a fim de abordar estruturas mistas formadas por aço e concreto. Na análise da seção mista é importante empregar propriedades adequadas para os materiais aço e concreto, levando em conta aspectos como instabilidade do perfil tubular, fissuração e esmagamento do concreto.

Quando uma seção tubular é preenchida com concreto, o perfil funciona como forma incorporada, devendo ter resistência para os carregamentos envolvidos nesta etapa construtiva.

Quanto às propriedades dos materiais, valores para o módulo de deformação longitudinal do concreto são sugeridos na TABELA 3.1, em função da resistência à compressão do concreto.

TABELA 3.1 - Resistências e módulo de deformação longitudinal do concreto, segundo EUROCODE 4 (1994)

\begin{tabular}{|c|c|c|c|c|c|c|c|}
\hline $\begin{array}{l}\text { Classes de } \\
\text { resistência }\end{array}$ & $\mathrm{C} 20 / 25^{*}$ & $\mathrm{C} 25 / 30^{*}$ & $\mathrm{C} 30 / 35^{\star}$ & C35/40* & $\mathrm{C} 40 / 45^{\star}$ & $\mathrm{C} 45 / 50^{*}$ & C50/55* \\
\hline$f_{c k}(M P a)$ & 20 & 25 & 30 & 35 & 40 & 45 & 50 \\
\hline $\mathrm{f}_{\mathrm{ctm}}(\mathrm{MPa})$ & 2,2 & 2,6 & 2,9 & 3,2 & 3,5 & 3,8 & 4,1 \\
\hline $\mathrm{E}_{\mathrm{cm}}(\mathrm{GPa})$ & 29 & 30,5 & 32 & 33,5 & 35 & 36 & 37 \\
\hline
\end{tabular}

*: o primeiro número é relativo a corpos-de-prova cilíndricos e o segundo, a corpos-de-prova cúbicos

O módulo de elasticidade secante $\left(E_{c}^{\prime}\right)$ é calculado a partir dos valores presentes na TABELA 3.1. Para forças de longa duração, o módulo de deformação longitudinal do concreto deve ser reduzido devido a fenômenos como a retração, para o valor:

$$
E_{c}^{\prime}=\frac{E_{c m}}{3}
$$

Para outras situações de carregamento, por exemplo forças de curta duração, adota-se:

$$
E_{c}^{\prime}=\frac{E_{c m}}{2}
$$




\subsection{Principais eQUAÇões PARA Dimensionamento}

As equações recomendadas por algumas normas de dimensionamento, para o cálculo da capacidade resistente à compressão são apresentadas na TABELA 3.2.

TABELA 3.2 - Capacidade resistente à compressão axial segundo algumas normas de dimensionamento de pilares mistos preenchidos

\begin{tabular}{|c|c|}
\hline NORMA & CAPACIDADE RESISTENTE À COMPRESSÃO \\
\hline $\begin{array}{l}\text { ACI 318R-92 (1992) } \\
\text { corpo-de-prova cilíndrico } \\
15 \times 30 \mathrm{~cm}\end{array}$ & $N_{n d}=0,85 \cdot\left(0,85 \cdot f_{c k} \cdot A_{c}+f_{y} \cdot A_{s}\right)$ \\
\hline $\begin{array}{l}\text { AISC-LRFD (1994) } \\
\text { corpo-de-prova cilíndrico } \\
15 \times 30 \mathrm{~cm}\end{array}$ & $\begin{array}{l}\mathrm{N}_{\mathrm{nd}}=\left(0,658^{\bar{\lambda}_{\mathrm{m}}{ }^{2}}\right) \cdot \mathrm{f}_{\mathrm{my}} \cdot \mathrm{A}_{\mathrm{s}} \quad \text { para } \bar{\lambda}_{\mathrm{m}} \leq 1,5 \\
\mathrm{~N}_{\mathrm{nd}}=\frac{0,877}{\bar{\lambda}_{\mathrm{m}}{ }^{2}} \cdot \mathrm{f}_{\mathrm{my}} \cdot \mathrm{A}_{\mathrm{s}} \quad \text { para } \bar{\lambda}_{\mathrm{m}}>1,5 \\
\mathrm{f}_{\mathrm{my}}=\mathrm{f}_{\mathrm{y}}+0,85 \cdot \mathrm{f}_{\mathrm{ck}} \cdot \frac{\mathrm{A}_{\mathrm{c}}}{\mathrm{A}_{\mathrm{s}}} ; \quad \mathrm{E}_{\mathrm{m}}=\mathrm{E}_{\mathrm{s}}+0,40 \cdot \mathrm{E}_{\mathrm{c}} \cdot \frac{\mathrm{A}_{\mathrm{c}}}{\mathrm{A}_{\mathrm{s}}} \\
\lambda_{\mathrm{pm}}=\sqrt{\pi^{2} \cdot \frac{\mathrm{E}_{\mathrm{m}}}{\mathrm{f}_{\mathrm{my}}} ; \quad \bar{\lambda}_{\mathrm{m}}=\frac{\lambda_{\mathrm{s}}}{\lambda_{\mathrm{pm}}} ; \quad \lambda_{\mathrm{s}}=\frac{\mathrm{k} \ell}{\mathrm{r}_{\mathrm{m}}}}\end{array}$ \\
\hline $\begin{array}{l}\text { BS 5400: parte } 5 \text { (1979) } \\
\text { coeficientes de minoração: } \\
\text { concreto: } \gamma_{\mathrm{c}}=1,50 \\
\text { perfil tubular: } \gamma_{\mathrm{s}}=1,10 \\
\text { corpo-de-prova cúbico de } \\
\text { lado } 10 \mathrm{~cm} ; \mathrm{f}_{\mathrm{cu}} \geq 20 \mathrm{MPa}\end{array}$ & $\begin{array}{l}\text { seção retangular } \Rightarrow N_{n d}=0,91 \cdot A_{s} \cdot f_{y}+0,45 \cdot A_{c} \cdot f_{c u} \\
\text { seção circular } \Rightarrow N_{n d}=0,91 \cdot A_{s} \cdot f_{y}^{\prime}+0,45 \cdot A_{c} \cdot f_{c c} \\
f_{c c}=f_{c u}+C_{1} \cdot \frac{t}{D} \cdot f_{y} ; \quad f_{y}^{\prime}=C_{2} \cdot f_{y} \\
C_{1} \text { e } C_{2} \text { : tabelados em função da relação } \mathrm{k} \ell / D\end{array}$ \\
\hline $\begin{array}{l}\text { CAN/CSA-S16.1 (1989) } \\
\text { Coeficiente de minoração } \\
\text { para o concreto: } \phi_{\mathrm{c}}=0,6 \\
\text { corpo-de-prova cilíndrico } \\
15 \times 30 \mathrm{~cm}\end{array}$ & $\begin{array}{l}\mathrm{N}_{\mathrm{nd}}=\tau \cdot \mathrm{C}_{\mathrm{r}}+\tau^{\prime} \cdot \mathrm{C}_{\mathrm{r}}^{\prime} \\
\text { para } \ell / \mathrm{D} \geq 25 \Rightarrow \tau=\tau^{\prime}=1,0 \\
\text { para } \ell / \mathrm{D}<25 \Rightarrow \tau=\frac{1}{\sqrt{1+\rho+\rho^{2}}} \\
\tau^{\prime}=1+25 \cdot \frac{\rho^{2} \cdot \tau}{\frac{\mathrm{D}}{\mathrm{t}}} \cdot \frac{\mathrm{f}_{\mathrm{y}}}{0,85 \cdot \mathrm{f}_{\mathrm{ck}}} ; \quad \rho=0,02 \cdot\left(25-\frac{\ell}{\mathrm{D}}\right) \\
\mathrm{C}_{\mathrm{r}}^{\prime}=\frac{0,85 \cdot \phi_{\mathrm{c}} \cdot \mathrm{f}_{\mathrm{ck}} \cdot \mathrm{A}_{\mathrm{c}}}{\lambda_{\mathrm{c}}^{2}} \cdot\left[\sqrt{1+\frac{0,25}{\lambda_{\mathrm{c}}^{4}}}-\frac{0,5}{\lambda_{\mathrm{c}}^{2}}\right] \\
\lambda_{\mathrm{c}}=\frac{\mathrm{k} \ell}{\mathrm{r}_{\mathrm{c}}} \cdot \sqrt{\frac{\mathrm{f}_{\mathrm{ck}}}{\pi^{2} \cdot \mathrm{E}_{\mathrm{c}}}}\end{array}$ \\
\hline
\end{tabular}


TABELA 3.2 - Capacidade resistente à compressão axial segundo algumas normas de dimensionamento de pilares mistos preenchidos (cont.)

EUROCODE 4 (1994)

coeficientes de ponderação: concreto: $\gamma_{c}=1,50$

perfil tubular: $\gamma_{\mathrm{s}}=1,10$

corpo-de-prova cilíndrico

$15 \times 30 \mathrm{~cm}$

$20 \mathrm{MPa} \leq \mathrm{f}_{\mathrm{ck}} \leq 50 \mathrm{MPa}$ seção retangular $\Rightarrow N_{n d}=\frac{A_{s} \cdot f_{y}}{\gamma_{s}}+1,0 \cdot \frac{A_{c} \cdot f_{c k}}{\gamma_{c}}$ seção circular $\Rightarrow N_{n d}=A_{s} \cdot \eta_{2} \cdot \frac{f_{y}}{\gamma_{s}}+A_{c} \cdot \frac{f_{c k}}{\gamma_{c}}+\eta_{1} \cdot \frac{t}{D} \cdot \frac{f_{y}}{f_{c k}}$ $\eta_{1}=\eta_{10} \cdot\left(1-10 \cdot \frac{e}{D}\right) ; \quad \eta_{2}=\eta_{20}+\left(1-\eta_{20}\right) \cdot 10 \cdot \frac{e}{D}$ $\eta_{10}=4,9-18,5 \cdot \bar{\lambda}+17 \cdot \bar{\lambda}^{2} \geq 0$

$\eta_{20}=0,25 \cdot(3+2 \cdot \bar{\lambda}) \leq 1,0 ; \quad \mathrm{N}_{\mathrm{cr}}=\pi^{2} \cdot \frac{(\mathrm{El})_{\mathrm{e}}}{\ell^{2}}$

$(E I)_{e}=E_{s} \cdot I_{s}+0,8 \cdot E_{c d} \cdot I_{c} ; \quad E_{c d}=\frac{E_{c}}{1,35} ; \quad \bar{\lambda}=\sqrt{\frac{N_{p \ell, R}}{N_{c r}}}$ $N_{p \ell, R}=A_{s} \cdot \eta_{2} \cdot \frac{f_{y}}{1,0}+A_{c} \cdot \frac{f_{c k}}{1,0}+\eta_{1} \cdot \frac{t}{D} \cdot \frac{f_{y}}{f_{c k}}$

e: excentricidade da força axial

O efeito do confinamento é considerado no projeto de pilares mistos preenchidos circulares, pelas normas técnicas EUROCODE 4 (1994) e BS 5400: Parte 5 (1979).

A norma BS 5400: Parte 5 (1979) introduz este efeito utilizando os coeficientes $\mathrm{C}_{1}$ e $\mathrm{C}_{2}$, cujos valores são apresentados na TABELA 3.3.

TABELA 3.3 - Coeficientes $C_{1}$ e $C_{2}$ da Norma BS 5400: parte 5 (1979)

\begin{tabular}{|c|c|c|}
\hline$\ell_{\mathbf{e}} / \mathbf{D}_{\mathbf{e}}$ & $\mathbf{C}_{1}$ & $\mathbf{C}_{2}$ \\
\hline 0 & 9,47 & 0,76 \\
\hline 5 & 6,40 & 0,80 \\
\hline 10 & 3,81 & 0,85 \\
\hline 15 & 1,80 & 0,90 \\
\hline 20 & 0,48 & 0,95 \\
\hline 25 & 0,00 & 1,00 \\
\hline
\end{tabular}

A norma EUROCODE 4 (1994) adota os coeficientes $\eta_{10}$ e $\eta_{20}$, apresentados na TABELA 3.4. 
TABELA 3.4 - Coeficientes $\eta_{10}$ e $\eta_{20}$ da Eurocode 4: Parte 5 (1994)

\begin{tabular}{|c|c|c|}
\hline $\bar{\lambda}$ & $\eta_{10}$ & $\eta_{20}$ \\
\hline 0 & 4,90 & 0,75 \\
\hline 0,1 & 3,22 & 0,80 \\
\hline 0,2 & 1,88 & 0,85 \\
\hline 0,3 & 0,88 & 0,90 \\
\hline 0,4 & 0,22 & 0,95 \\
\hline$\geq 0,5$ & 0,00 & 1,00 \\
\hline
\end{tabular}

Uma grande limitação das normas para pilares mistos preenchidos são os limites de resistência impostos ao perfil tubular e ao concreto. Na sua grande maioria, estas normas aplicam-se a pilares preenchidos cujos materiais são de resistência usual, embora os avanços tecnológicos tenham tornado fácil a obtenção de concretos e aços de alta resistência. A imposição de limites de resistência e de esbeltez é um reflexo da quantidade limitada de resultados experimentais.

A esbeltez dos pilares mistos preenchidos é outro fator limitante imposto pelas normas de projeto. Na TABELA 3.5 são apresentadas as recomendações de norma neste sentido.

TABELA 3.5 - Esbeltez do Pilar misto

\begin{tabular}{|l|c|}
\hline NORMA & RECOMENDAÇÃo \\
\hline BS 5400: Parte 5 (1979) & $\frac{\ell_{\mathrm{e}}}{\mathrm{b}} \leq 55$ - para pilares preenchidos circulares \\
& $\frac{\ell_{\mathrm{e}}}{\mathrm{b}} \leq 65$ - para pilares preenchidos retangulares \\
\hline EUROCODE 4 (1994) & $\bar{\lambda} \leq 2,0$ (calculado conforme tabela 3.2) \\
\hline
\end{tabular}

Outro aspecto importante é a contribuição dos componentes aço e concreto na capacidade resistente da seção mista. As recomendações de norma neste sentido são mostradas na TABELA 3.6. 
TABELA 3.6 - Contribuição dos componentes da seção mista

\begin{tabular}{|l|c|}
\hline \multicolumn{1}{|c|}{ NORMA } & RECOMENDAÇÃo \\
\hline $\begin{array}{l}\text { ACI 318-R92 (1992) } \\
\text { relação mínima entre as áreas do perfil tubular } \\
\left(A_{s}\right) \text { e do concreto }\left(A_{c}\right)\end{array}$ & $\frac{A_{s}}{A_{c}} \leq 0,08$ \\
\hline AISC-LRFD (1994) & \multicolumn{1}{|c|}{$\frac{A_{s}}{A_{t}} \leq 0,04$} \\
\hline $\begin{array}{l}\text { BS 5400: Parte 5 (1979) } \\
\text { fator de contribuição do concreto }\end{array}$ & $0,10<\alpha_{c}<0,80 \Rightarrow \alpha_{c}=\frac{0,45 \cdot A_{c} \cdot f_{c u}}{N_{u}}$ \\
\hline $\begin{array}{l}\text { EUROCODE 4 (1994) } \\
\text { fator de contribuição do perfil tubular }\end{array}$ & $0,2 \leq \delta \leq 0,9 \quad \Rightarrow \quad \delta \quad \frac{A_{s} \cdot f_{y}}{1,10}$ \\
\hline
\end{tabular}

O cálculo dos pilares mistos preenchidos cujos perfis são formados a frio pode ser feito através da substituição das curvas de resistência do AISC-LRFD (1994) pelas curvas de resistência do AISI-LRFD (1996).

Quanto aos comprimentos de flambagem, na TABELA 3.7 são apresentadas as recomendações da norma BS 5400: parte 5 (1979).

TABELA 3.7 - Comprimento efetivo do pilar - $k \ell-$ segundo a norma BS 5400: parte 5 (1979)

\begin{tabular}{|c|c|}
\hline CONDIÇÃO DE VINCULAÇÃO & $\mathbf{K} \ell$ \\
\hline $\begin{array}{l}\text { Rotação e translação impedidas nas duas } \\
\text { extremidades }\end{array}$ & -1 \\
\hline $\begin{array}{l}\text { Translação impedida nas duas extremidades } \\
\text { e rotação impedida numa extremidade }\end{array}$ & 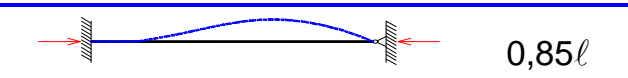 \\
\hline $\begin{array}{l}\text { Translação impedida nas duas extremidades } \\
\text { e rotaçâo livre }\end{array}$ & 事 \\
\hline $\begin{array}{l}\text { Translação e rotação impedidas numa } \\
\text { extremidade, rotação parcialmente impedida } \\
\text { e translação livre na outra extremidade }\end{array}$ & $1,50 \ell$ \\
\hline $\begin{array}{l}\text { Translação e rotação impedidas numa } \\
\text { extremidade e livres na outra }\end{array}$ & -1 \\
\hline
\end{tabular}

\subsection{COMENTÁRIO}

Quanto ao Brasil, existe uma comissão técnica trabalhando na elaboração de uma norma que aborde os pilares mistos. Esta norma ainda não foi publicada e sua formulação é baseada no EUROCODE 4 (1994) aqui abordado. 


\section{COMPONENTES DA SEÇÃO MISTA}

\subsection{INTRODUÇÃO}

Os materiais aço e concreto são associados visando obter uma seção mista que reúna as qualidades inerentes a estes dois materiais, explorando-as da melhor forma possível. Para associá-los é necessário conhecer suas propriedades mecânicas e assim obter valores adequados de resistência e rigidez, utilizados nas equações de dimensionamento e verificação da seção mista.

A caracterização mecânica dos dois materiais é conseguida através de ensaios de caracterização. Para o material concreto, que é resultante da mistura em proporções adequadas de materiais como cimento, água, areia, brita, aditivos e adições, são necessários ensaios de caracterização de cada material e em seguida, quando dos materiais constituintes já misturados, ensaios que permitam conhecer a resistência à tração $\left(\mathrm{f}_{\mathrm{t}}\right)$, resistência à compressão $\left(\mathrm{f}_{\mathrm{c}}\right)$, módulo de deformação longitudinal $\left(E_{c}\right)$ e coeficiente de Poisson $\left(v_{c}\right)$.

Quanto ao perfil tubular, devem ser conhecidos os valores de resistência ao escoamento $\left(f_{y}\right)$ e resistência à tração $\left(f_{u}\right)$. Características como módulo de elasticidade $\left(E_{s}\right)$ e coeficiente de Poisson $\left(v_{s}\right)$ sofrem poucas variações e por isso os valores recomendados pela norma NBR 8800 (1986) podem ser usados. 
Conhecendo as características há pouco destacadas é possível, com o auxílio de conceitos adequados, estudar o comportamento dos pilares mistos preenchidos. A seguir, os dois elementos que compõem a seção mista serão abordados.

\subsection{O PERFIL TUBULAR}

Os perfis tubulares podem ter vários tipos de seção transversal, estando as mais comuns apresentadas na FIGURA 4.1.
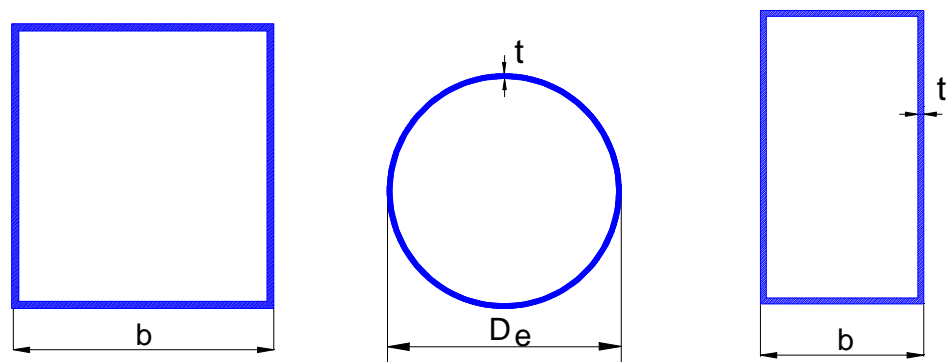

FIGURA 4.1 - TIPOS DE SEÇÃO TUBULAR

De forma sucinta, os perfis tubulares podem ser classificados quanto ao processo de obtenção em: perfis laminados, perfis soldados e perfis de chapa dobrada. Os perfis de chapa dobrada ou também conhecidos no mercado por "perfis leves", são obtidos a partir de tiras de chapa metálica, cortadas nas dimensões desejadas e dobradas através de prensagem em viradeiras hidráulicas (prensas). A prensagem é produzida pelo impacto de uma barra biselada superior contra uma inferior fixa. Tal processo é empregado na produção de perfis $U$ e $Z$. Além deste processo, a produção de perfis pode ser feita por meio de perfiladeiras.

\subsubsection{CARACTERÍSTICAS MECÂNICAS}

A composição química do aço que constitui a chapa metálica é responsável por muitas das suas características mecânicas. Dentre os elementos químicos presentes na composição do aço destaca-se o carbono, que é o principal responsável por propriedades como resistência, ductilidade e soldabilidade.

Uma característica essencial nos perfis tubulares é a ductilidade, que permite ao aço se deformar plasticamente sem ruptura. Sua presença é 
fundamental nas chapas de aço que sofrerão processo de formação a frio, pois permite que estas sejam dobradas sem que ocorram fissuras na região das dobras. Esta propriedade pode ser quantificada pelo alongamento de um comprimento de $50 \mathrm{~mm}$ em corpos-de-prova ensaiados à tração, como o apresentado na FIGURA 4.3.

Quanto ao módulo de elasticidade do aço, sua variação é muito pequena e por isso, a maioria das normas de dimensionamento sugerem que seja adotado um valor pré-definido. A norma brasileira NBR 8800 (1986) recomenda que seja adotado $E_{\mathrm{s}}=20500 \mathrm{kN} / \mathrm{cm}^{2}$.

Matematicamente, o módulo de elasticidade é dado pela relação tensão deformação do trecho linear (reta de Hooke) do diagrama tensão x deformação axial. Na FIGURA 4.2a é apresentado o diagrama tensão $x$ deformação característico de aços carbono laminados a quente, os quais apresentam curva tensão $\mathrm{x}$ deformação com escoamento definido. Os aços trabalhados a frio apresentam escoamento gradual e sua resistência ao escoamento é um valor convencional, que pode ser definido por dois métodos: o método "offset" e o método da tensão correspondente a uma deformação arbitrada. No método "offset", a resistência ao escoamento é definida pela intersecção da curva tensão $x$ deformação com a reta paralela à reta de Hooke (trecho elástico) para uma deformação especificada, em geral 0,2\%.

Na FIGURA 4.2b é apresentado o diagrama tensão $x$ deformação para aços com escoamento gradual.

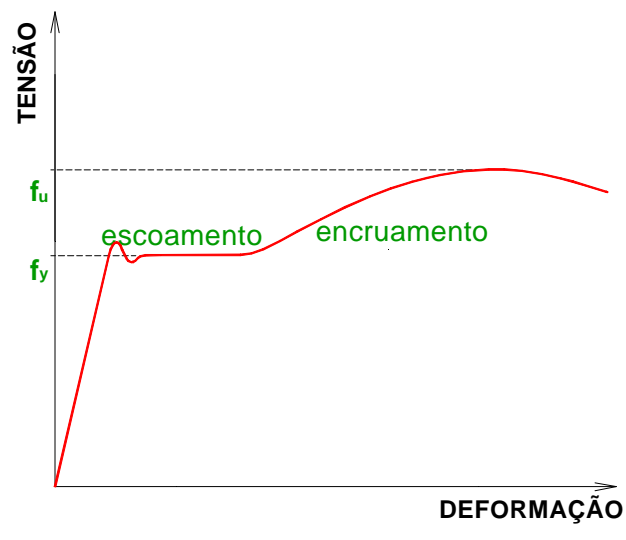

a) com escoamento definido

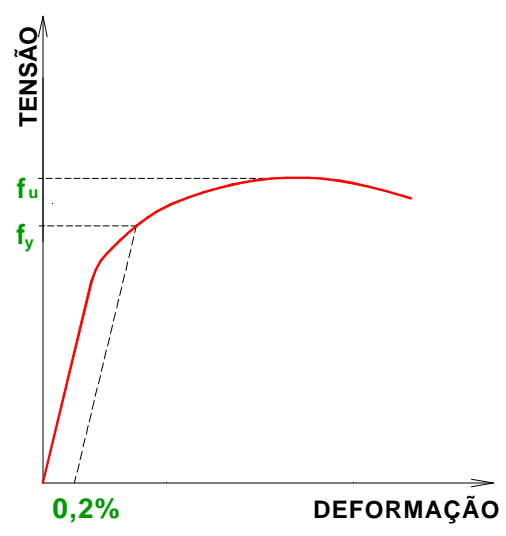

b) com escoamento gradual

FIGURA 4.2 - DIAGRAMAS TENSÃO X DEFORMAÇÃO 
Os diagramas tensão $\mathrm{x}$ deformação são obtidos através de ensaios padronizados. No caso dos perfis tubulares é recomendado o ensaio à tração padronizado pela ASTM A370 (1994). O corpo-de-prova empregado para realização deste ensaio deve ter as dimensões apresentadas na FIGURA 4.3.

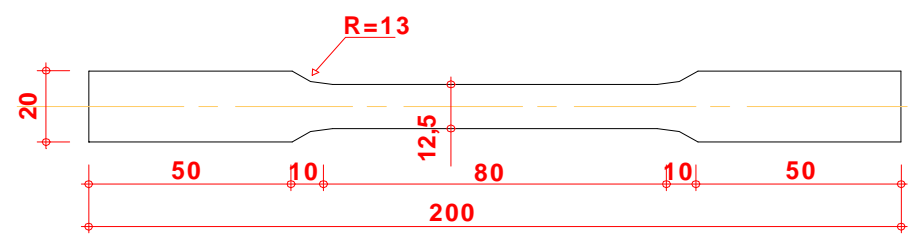

FIGURA 4.3 - CORPO-DE-PROVA PARA CARACTERIZAÇÃO DO AÇO À TRAÇÃO, SEGUNDO A ASTM A370 (1994)

O ensaio é realizado prendendo-se as extremidades do corpo-de-prova com garras especiais e submetendo-o a valores crescentes de esforços de tração. Para cada estágio de força aplicada, são registradas as deformações na região central da amostra, por meio de clip-gages (extensômetros removíveis).

\subsubsection{EFEITOS DO TRABALHO A FRIO}

Em virtude do elevado custo dos perfis laminados, é comum o emprego de perfis dobrados, que sofrem trabalho a frio e por isso estão sujeitos aos seus efeitos.

O trabalho a frio provoca deformações plásticas no aço do perfil tubular e os seus efeitos incidem diretamente sobre os valores de resistência e ductilidade do aço trabalhado, podendo ser reduzidos fazendo-se o alívio térmico de tensões ou recozimento.

Nos cantos ou regiões de dobras da seção tubular, a influência do trabalho a frio é mais significativa do que nas partes planas. Este efeito é perceptível quando se observa a variação das propriedades mecânicas do aço em diferentes pontos da seção transversal, pois a formação a frio aumenta a resistência ao escoamento e a resistência à tração, ao passo que diminui a ductilidade nas regiões de dobramento. $\mathrm{O}$ aumento na resistência à tração $\left(\mathrm{f}_{\mathrm{u}}\right)$ é inferior ao aumento na resistência ao escoamento $\left(f_{y}\right)$, havendo uma conseqüente redução na amplitude entre estes valores, que se reflete na redução da ductilidade.

A variação das propriedades mecânicas na seção faz com que o início do escoamento ou a flambagem ocorram sempre na porção plana, onde a resistência 
ao escoamento é menor, havendo uma redistribuição de tensões das partes planas para os cantos. Na FIGURA 4.4 é possível observar as mudanças nas propriedades mecânicas devido ao trabalho a frio, causadas principalmente pelo encruamento e pela ação da deformação.

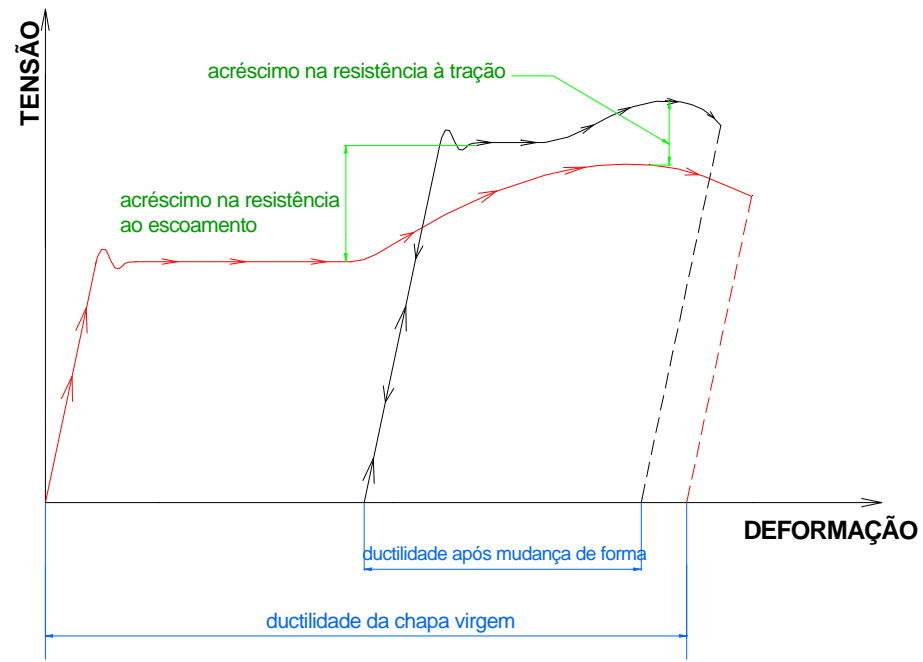
FIGURA 4.4 - EFEITOS DO TRABALHO A FRIO NAS CARACTERÍSTICAS TENSÃo X DEFORMAÇÃo do
AÇO

Os ensaios realizados por YU (1985) com uma seção formada por cantos a 90 - mostram que a resistência ao escoamento aumenta em até $65 \%$ da região plana para o canto, enquanto a resistência à tração cresce em cerca de $25 \%$. Portanto, também ocorre grande acréscimo nos valores das resistências de escoamento e, acréscimos significativamente menores na resistência à tração, quando a chapa recebe trabalho a frio.

Ainda devido ao processo de formação a frio, surgem tensões residuais na região da solda, as quais para GOMES (1994), irão influenciar na capacidade resistente dos pilares mistos formados por esses perfis tubulares.

Segundo GOMES (1994), pesquisadores japoneses avaliaram as tensões residuais impostas pelo processo de formação a frio em seções quadradas e circulares. Os resultados mostraram tensões residuais plásticas significativas, decorrentes da flexão da chapa metálica que forma o perfil tubular. Tais tensões podem atingir até $200 \mathrm{MPa}$ no sentido longitudinal e $140 \mathrm{MPa}$ no sentido circunferencial. Este mesmo estudo mostrou que nos cantos de perfis tubulares quadrados há uma grande concentração de deformações e tensões residuais, devidas ao trabalho a frio, conforme ilustra a FIGURA 4.5. 


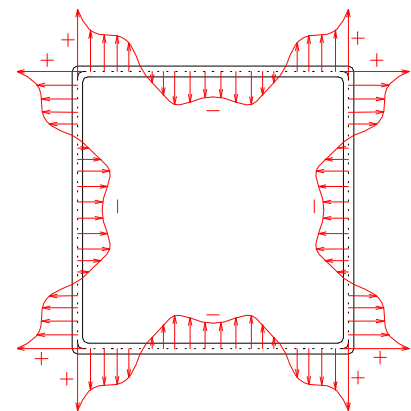

a) seção transversal

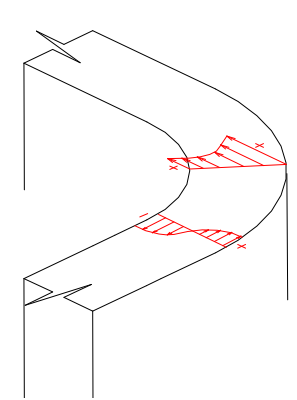

b) deformação longitudinal no canto a $90^{\circ}$

\section{FIGURA 4.5 - DISTRIBUIÇÃO DE TENSÕES RESIDUAIS EM SEÇõES DE PERFIS TUBULARES QUADRADOS}

MERRIT (1972) lembra que a presença de tensões residuais numa seção carregada causa alguns efeitos plásticos prematuros porque ocorre o escoamento do aço em regiões localizadas e, para elementos comprimidos, estas tensões diminuem a resistência à flambagem.

\subsubsection{AÇOS DE ALTA RESISTÊNCIA}

Os avanços tecnológicos têm permitido a obtenção de aços com alta resistência ao escoamento. Segundo UY \& PATIL (1996) o projeto das torres gêmeas do World Trade Centre, em Nova lorque, inclui aços com resistências ao escoamento variando entre 450 e $690 \mathrm{MPa}$.

A combinação de aços e concretos de alta resistência vêm trazer novas vantagens ao emprego destes pilares em edifícios altos. Neste sentido, UY \& PATIL (1996) destacam:

- alta resistência e baixo peso melhoram o comportamento quanto à atuação de forças sísmicas;

- redução nas dimensões das seções e conseqüente aumento na disponibilidade de área livre nos pavimentos;

- redução dos custos de fabricação, transporte e equipamentos de transporte;

- benefícios arquitetônicos e estruturais pois há menos variações verticais nas dimensões dos pilares e conseqüentemente, das vigas; e

- maior ductilidade dos aços de alta resistência, se comparados com os aços de resistência usual. 
O Centro Japonês de Arquitetura promoveu o estudo de aços com $780 \mathrm{MPa}$ de resistência ao escoamento. O aumento na resistência e na ductilidade foi conseguido reduzindo-se o tamanho dos grãos usando nióbio como grão refinado. Desta forma, foi reduzida a possibilidade de fratura nos aços de alta resistência.

\subsection{O CONCRETO}

O concreto simples ou armado é utilizado para o preenchimento do perfil tubular, resultando uma seção mista preenchida.

Com o avanço tecnológico na produção de concretos com resistência cada vez maior, o emprego de concretos de alta resistência (CAR) tem sido uma opção que permite ampliar as vantagens da utilização dos pilares mistos preenchidos como elementos estruturais comprimidos.

Existem diversas classificações do concreto quanto à sua resistência, sempre fundamentadas na mudança de comportamento do diagrama tensão $x$ deformação, à medida que a resistência aumenta.

Definir o limite de resistência à compressão a partir do qual o material concreto é denominado de alta resistência gera grande controvérsia entre os pesquisadores deste material. Isto ocorre devido à natureza heterogênea do concreto, que é a principal responsável pela dificuldade em representar o seu comportamento através de modelos teóricos.

De forma simplista, AMARAL FILHO (1992a) define: " concretos com valores de resistência acima dos usuais num dado local ou época são comumente chamados concretos de alta resistência." Esta definição simplista parece geograficamente adequada em função do grau de desenvolvimento de cada região e dos recursos disponíveis à produção do concreto, entretanto não permite caracterizar adequadamente os limites de comportamento, que devem ser responsáveis pela distinção entre concretos usuais e concretos de alta resistência.

AMARAL FILHO (1992b) apresenta, baseado na norma norueguesa, uma classificação que agrupa os concretos em classes, dispondo-os de acordo com a variação de suas características mecânicas. Tal classificação é apresentada na TABELA 4.1. 
TABELA 4.1 - Classes de concreto segundo AMARAL FILHO (1992)

\begin{tabular}{|c|c|l|}
\hline CLASSE & RESISTÊNCIA À COMPRESSÃO (MPa) & TIPO DE RUPTURA À COMPRESSÃo \\
\hline Baixa & $<25$ & $\begin{array}{l}\text { superfície de ruptura áspera, com } \\
\text { agregados intactos }\end{array}$ \\
\hline média & $25-50$ & $\begin{array}{l}\text { superfície de ruptura áspera, com } \\
\text { parte dos agregados cisalhados }\end{array}$ \\
\hline alta & $50-90$ & $\begin{array}{l}\text { superfície de ruptura lisa, com } \\
\text { agregados cisalhados - ruptura frágil }\end{array}$ \\
\hline ultra alta & $90-400$ & $\begin{array}{l}\text { diferente em cada caso - ruptura } \\
\text { totalmente frágil }\end{array}$ \\
\hline
\end{tabular}

O texto para revisão da NB -1 (1997) apresenta a seguinte classificação para os concretos, dividindo-os em dois grupos:

TABELA 4.2 - Grupos de concreto segundo texto para revisão da NB -1 (1997)

\begin{tabular}{|c|c|}
\hline GRUPOS & RESISTÊNCIA À COMPRESSÃO (MPa) \\
\hline I & 20 a 50 \\
\hline II & acima de 50 \\
\hline
\end{tabular}

Assim, de acordo com a normalização nacional, concretos de alta resistência são aqueles com resistência característica à compressão maior ou igual a $50 \mathrm{MPa}$.

Para fins de compreensão deste trabalho, são considerados concretos usuais aqueles cuja resistência à compressão não ultrapassa $50 \mathrm{MPa}$. Caso contrário, são denominados concretos de alta resistência - CAR.

\subsubsection{MATERIAIS CONSTITUINTES}

A seleção dos materiais para produção de CARs não é uma tarefa simples pois existe grande variação na composição química e propriedades de cimentos e agregados.

Os materiais que formam o CAR devem ser dosados de forma racional, serem bem caracterizados e proporcionados de forma a garantir: elevada resistência à compressão, resposta adequada às solicitações e boas condições de utilização. 
Para a confecção de concretos de alta resistência empregam-se os materiais comuns empregados na obtenção de concretos usuais, acrescidos de adições, comumente sílica ativa e aditivos (superplastificantes).

Os materiais que mais interferem no comportamento do concreto de alta resistência são os agregados, em especial os agregados graúdos. Os agregados graúdos e miúdos ocupam de 60 a $80 \%$ do volume do concreto. Os agregados miúdos, sejam eles areias naturais ou obtidas por britamento de rochas devem ter preferencialmente granulometria descontínua e módulo de finura superior a 2,8. Tais recomendações visam diminuir a quantidade de água de amassamento, necessária devido à já grande quantidade de finos no CAR.

A influência dos agregados graúdos na resistência à compressão é acentuada. Em geral, a superfície de ruptura dos corpos-de-prova atravessa a maioria dos grãos do agregado graúdo porque ocorre o fortalecimento da zona de transição.

Para os agregados graúdos é recomendada uma dimensão máxima característica de $12,5 \mathrm{~mm}$, em função da maior área de contato entre as partículas de agregado graúdo e pasta.

Como principais características, os agregados graúdos devem apresentar alta resistência à compressão, módulo de deformação longitudinal maior ou igual ao da pasta de cimento, granulometria que minimize o consumo de água, forma cúbica, textura superficial áspera e ausência de pó.

A sílica ativa é a adição empregada para aumentar a resistência do concreto à compressão. Trata-se de um pó fino cujos grãos esféricos melhoram as condições de hidratação do cimento. Ela atua na zona de transição do concreto preenchendo os vazios existentes entre os grãos de cimento.

Embora a adição de sílica ativa proporcione a diminuição da porosidade do concreto e melhore seu comportamento na questão durabilidade, sendo a principal responsável pelo acréscimo na resistência à compressão, é possível obter concretos com resistência média de $50 \mathrm{MPa}$ sem utilizá-la, bastando estudar proporções adequadas dos demais materiais constituintes do concreto.

\subsubsection{PROPRIEDAdes MECÂNICAS}

Os concretos de alta resistência apresentam comportamento diferente dos concretos de resistência usual, quando submetidos às mesmas condições de 
carregamento. Suas propriedades mecânicas dependem das propriedades da pasta de cimento hidratada, dos agregados e, principalmente, das propriedades da zona de transição pasta-agregado, considerada a zona mais fraca da mistura segundo METHA \& MONTEIRO (1994).

\subsubsection{RESISTÊNCIA À COMPRESSÃO}

Para METHA \& MONTEIRO (1994) ..."A resistência à compressão é a propriedade geralmente especificada no projeto de estruturas de concreto porque ela é relativamente fácil de ser determinada através de ensaios".

A resistência à compressão uniaxial do concreto é avaliada através de ensaios em corpos-de-prova, cujas dimensões e forma variam em função das normas vigentes em cada país. No Brasil, este ensaio é padronizado pela $N B R$ 5789/80: Ensaio de compressão de corpos-de-prova cilíndricos de concreto, tendo os corpos-de-prova, dimensões $(15 \times 30) \mathrm{cm}$. Contudo, para avaliar a resistência à compressão do concreto de alta resistência é comum o emprego de corpos-deprova com dimensões $(10 \times 20) \mathrm{cm}$; isso devido à capacidade limite da maioria das prensas existentes nos laboratórios onde o estudo experimental é realizado. Como há redução nas dimensões dos corpos-de-prova, é preciso estabelecer a correlação existente entre as resistências à compressão, determinadas com as duas dimensões há pouco citadas.

CARRASQUILLO et al. (1981) ${ }^{1}$ apud DAL MOLIN (1995), após estudar o efeito da redução do tamanho de corpos-de-prova cilíndricos, encontraram um fator de correlação próximo a 10\%, independente da resistência avaliada (entre 20 e $80 \mathrm{MPa})$.

$$
\text { cp } 15 \mathrm{~cm} \times 30 \mathrm{~cm}=0,90 \mathrm{cp} 10 \mathrm{~cm} \times 20 \mathrm{~cm}
$$

A forma dos corpos-de-prova varia de um país para outro. Para corrigir estas diferenças são aplicados fatores de conversão propostos por algumas normas de concreto, como é o caso do Código Modelo CEB (1990) e da norma norueguesa NS 3473 (1992). Alguns destes fatores são apresentados na TABELA 4.3.

\footnotetext{
${ }^{1}$ CARRASQUILLO, P. M. et al. (1981) Properties of high strength concrete subject to short-term loads. ACI Materials Journal, p.171-181, may/june 1981.
} 
TABELA 4.3 - Fatores de conversão aplicáveis à resistência de corpos-de-prova

\begin{tabular}{|c|c|c|c|c|c|c|c|c|c|}
\hline \multicolumn{10}{|c|}{ FATORES DE CONVERSÃO } \\
\hline \multicolumn{10}{|c|}{ Código Modelo CEB (1990) } \\
\hline $\mathrm{f}_{\mathrm{ck}}$ & & $\mathrm{C}_{12}$ & $\mathrm{C}_{20}$ & $\mathrm{C}_{30}$ & $\mathrm{C}_{40}$ & $\mathrm{C}_{50}$ & $\mathrm{C}_{60}$ & $\mathrm{C}_{70}$ & $\mathrm{C}_{80}$ \\
\hline Cilindro $(15 \times 30) \mathrm{cm}$ & & 12 & 20 & 30 & 40 & 50 & 60 & 70 & 80 \\
\hline Cubos com $15 \mathrm{~cm}$ de lado & & 15 & 25 & 37 & 50 & 60 & 70 & 80 & 90 \\
\hline \multicolumn{10}{|c|}{ NS 3473 (1992) } \\
\hline $\mathrm{f}_{\mathrm{ck}}$ & $\mathrm{C}_{25}$ & $\mathrm{C}_{35}$ & $\mathrm{C}_{45}$ & $\mathrm{C}_{55}$ & $\mathrm{C}_{65}$ & $\mathrm{C}_{75}$ & $\mathrm{C}_{85}$ & $\mathrm{C}_{95}$ & $\mathrm{C}_{105}$ \\
\hline Cubo com $10 \mathrm{~cm}$ de lado & 25 & 35 & 45 & 55 & 65 & 75 & 85 & 95 & 105 \\
\hline Cilindro $(15 \times 30) \mathrm{cm}$ & 20 & 28 & 36 & 44 & 54 & 64 & 74 & 84 & 94 \\
\hline
\end{tabular}

Os resultados de resistência à compressão obtidos para os corpos-de-prova não podem ser adotados diretamente como valor de resistência média $f_{c m}$. A tais valores de resistência é aplicado um coeficiente denominado coeficiente de modificação $k_{\bmod }$, o qual é fruto de outros três coeficientes:

$$
\mathrm{k}_{\bmod }=\mathrm{k}_{\bmod 1} \cdot \mathrm{k}_{\bmod 2} \cdot \mathrm{k}_{\bmod 3}
$$

que representam:

$\mathrm{k}_{\text {mod1 }}$ : crescimento da resistência do concreto ao longo do tempo, contado a partir dos 28 dias. Tal valor, segundo LIMA (1997) varia entre 1,0 e 1,1.

$\mathrm{k}_{\text {mod2: }}$ influência das dimensões do corpo-de-prova. Sabe-se que a resistência média obtida em corpos-de-prova de tamanho maior é menor, porque há menor influência do atrito do corpo-de-prova com os pratos da prensa de ensaio. Adota-se $\mathrm{k}_{\bmod 2}=0,95$ para corpos-de-prova cilíndricos de $(15 \times 30) \mathrm{cm}$. Para corposde-prova cilíndricos $(10 \times 20) \mathrm{cm}$ admite-se uma redução de $5 \%$ neste coeficiente obtendo-se $\mathrm{k}_{\bmod 2}=0,90$

$\mathrm{k}_{\bmod 3}$ : considera o efeito deletério de ações de longa duração na resistência do concreto. Nos concretos de alta resistência submetidos a ações de longa duração, a redução da resistência é da ordem de 15 a 20\%. Para forças de curta duração, deve-se tomar $\mathrm{k}_{\bmod 3}=1,0$.

resultando, para as condições de ensaio:

$$
\mathbf{k}_{\text {mod }}=0,90
$$

e

$$
f_{c m}=0,9 f_{c}
$$

sendo

$f_{c}$ : resistência média à compressão de três corpos-de-prova de dimensões $(10$ x 20 $) \mathrm{cm}$. 
O coeficiente $k_{\text {mod }}=0,90$ será utilizado nas equações propostas pelas normas de dimensionamento apresentadas no capítulo 03, para calcular a capacidade resistente.

\subsubsection{RESISTÊNCIA À TRAÇÃO}

Conhecer a resistência à tração é importante porque através dela é possível avaliar o comportamento do concreto quanto à fissuração.

A resistência à tração do concreto, seja ele usual ou CAR pode ser obtida através de três ensaios distintos: resistência à tração por compressão diametral $\left(\mathrm{f}_{\mathrm{t}, \mathrm{D}}\right)$, resistência à tração na flexão $\left(\mathrm{f}_{\mathrm{t}, \mathrm{F}}\right)$ e resistência à tração direta $\left(\mathrm{f}_{\mathrm{t}}\right)$.

Existe uma relação entre a resistência à tração e à compressão para o concreto de alta resistência. Aumentando-se a resistência à compressão, a resistência à tração também aumenta, porém para os concretos de alta resistência a relação entre ambas não é a mesma verificada para os concretos usuais.

$\mathrm{Na}$ ausência de resultados experimentais, CARRASQUILLO et al. (1981) ${ }^{1}$ apud DAL MOLIN (1995) ajustaram uma equação para estimar a resistência à tração por compressão diametral a partir da resistência à compressão, válida para $21 \leq \mathrm{f}_{\mathrm{ck}} \leq 83 \mathrm{MPa}$ :

$$
\mathrm{f}_{\mathrm{t}, \mathrm{D}}=0,54 \cdot \sqrt{\mathrm{f}_{\mathrm{ck}}}(\mathrm{MPa})
$$

sendo

$f_{c k}$ : resistência à compressão medida em corpos-de-prova cilíndricos $(10$ x 20) cm.

\subsubsection{MódULO DE DEFORMAÇÃo LONGITUDINAL $\left(E_{c}\right)$}

Para materiais heterogêneos como o concreto, o módulo de deformação longitudinal sofre influência de uma série de fatores e por isso, determinar seu valor para concretos de alta resistência é uma tarefa difícil.

PEREIRA NETO \& DJANIKIAN (1995) definem o módulo de deformação longitudinal do concreto como ... " a relação entre um incremento da tensão e o correspondente incremento na deformação instantânea ", já que as curvas tensão $\mathrm{x}$ deformação do concreto não são inteiramente retas.

No caso do concreto de alta resistência, as características do agregado, da pasta de cimento e da zona de transição interferem de forma significativa no valor 
do módulo de deformação longitudinal. A porosidade do agregado graúdo é o fator mais importante. O módulo de deformação longitudinal da pasta de cimento é determinado pela sua porosidade. Os fatores que controlam tal porosidade são: relação água/cimento, conteúdo de ar, adições minerais e grau de hidratação do cimento. Quanto à zona de transição, a presença de vazios, microfissuras e cristais orientados de hidróxido de cálcio são elementos que desempenham papel importante na determinação do módulo de deformação longitudinal.

Um grande número de resultados experimentais indica que o módulo de deformação longitudinal do concreto de alta resistência é maior que o de um concreto de resistência usual, entretanto este aumento não acompanha na mesma proporção, o aumento da resistência à compressão. Portanto, extrapolar as expressões existentes para concretos usuais, relacionando módulo de deformação longitudinal e resistência à compressão, para concretos de alta resistência conduz a erros grosseiros de análise.

Para DAL MOLIN (1995) o aumento no valor do módulo de deformação longitudinal, em função do aumento na resistência à compressão é decorrente da maior rigidez da argamassa e da maior aderência pasta-agregado.

A seguir, na TABELA 4.4, baseada em BACCIN \& PINHEIRO (1997), são apresentadas algumas expressões que permitem estimar o valor do módulo de deformação longitudinal, na ausência de determinação experimental.

TABELA 4.4 - Equações para o cálculo do módulo de deformação longitudinal do concreto de alta resistência

\begin{tabular}{|c|c|c|}
\hline FONTE & EXPRESSÃO & RESTRIÇÕES \\
\hline FIP/CEB (1990) & $\mathrm{E}_{\mathrm{c}}=10^{4} \cdot \alpha_{\mathrm{e}} \cdot \sqrt[3]{\mathrm{f}_{\mathrm{ck}}+8}(\mathrm{MPa})$ & $12 \mathrm{MPa} \leq \mathrm{f}_{\mathrm{ck}} \leq 80 \mathrm{MPa}$ \\
\hline EUROCODE 2 (1992) & $\mathrm{E}_{\mathrm{c}}=9500 \cdot\left(\mathrm{f}_{\mathrm{ck}}+8\right)^{\frac{1}{3}}(\mathrm{MPa})$ & $\mathrm{f}_{\mathrm{ck}}<60 \mathrm{MPa}$ \\
\hline NS 3473 (1992) & $\mathrm{E}_{\mathrm{c}}=9500 \cdot \mathrm{f}_{\mathrm{ck}}^{0,3}(\mathrm{MPa})$ & $20 \mathrm{MPa} \leq \mathrm{f}_{\mathrm{ck}} \leq 94 \mathrm{MPa}$ * \\
\hline ACI $363(1992)$ & $\mathrm{E}_{\mathrm{c}}=3320 \cdot \sqrt{\mathrm{f}_{\mathrm{ck}}}+6900(\mathrm{MPa})$ & $21 \mathrm{MPa}<\mathrm{f}_{\mathrm{ck}}<83 \mathrm{MPa}$ \\
\hline NBR 6118 (1978) & $\mathrm{E}_{\mathrm{c}}=5940 \cdot \sqrt{\mathrm{f}_{\mathrm{ck}}+3,5}(\mathrm{MPa})$ & $\mathrm{f}_{\mathrm{ck}} \leq 50 \mathrm{MPa}$ \\
\hline
\end{tabular}

* corpos-de-prova cilíndricos $15 \mathrm{~cm} \times 30 \mathrm{~cm}$ ensaiados aos 28 dias

$\alpha_{e}$ : coeficiente que considera o efeito do tipo de agregado e cujos valores são apresentados na TABELA 4.5. 
TABELA 4.5 - Efeito do tipo de agregado no módulo de deformação longitudinal, segundo o Código Modelo - MC90 (1990) do CEB-FIP

\begin{tabular}{|c|c|}
\hline Tipo de agregado & $\alpha_{\mathrm{e}}$ \\
\hline basalto & 1,2 \\
\hline quartzo & 1,0 \\
\hline calcário & 0,9 \\
\hline arenito & 0,7 \\
\hline
\end{tabular}

\subsubsection{RELAÇÃO TENSÃO X DEFORMAÇÃO}

O comportamento do concreto de alta resistência pode ser caracterizado pela relação tensão $x$ deformação, obtida através de ensaios em corpos-de-prova, submetidos à compressão uniaxial. A observação de diagramas que relacionam tensão e deformação axial evidencia a diferente resposta ao carregamento, existente entre o concreto de alta resistência e o concreto de resistência usual (FIGURA 4.6a). A ruptura de corpos-de-prova de concreto de alta resistência ocorre de forma brusca, sem plastificação, caracterizada pelo pico no diagrama tensão $x$ deformação. Na FIGURA 4.6b vê-se que parte dos agregados sofreram ruptura por cisalhamento.

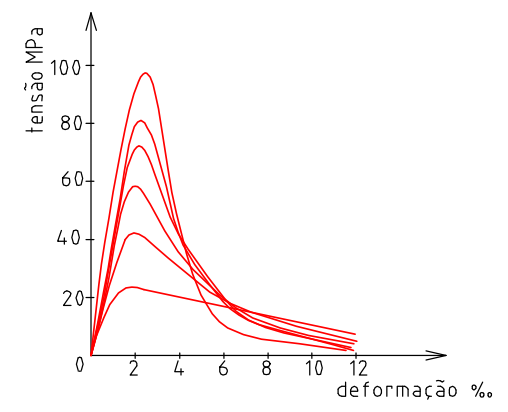

a) diagrama tensão $x$ deformação

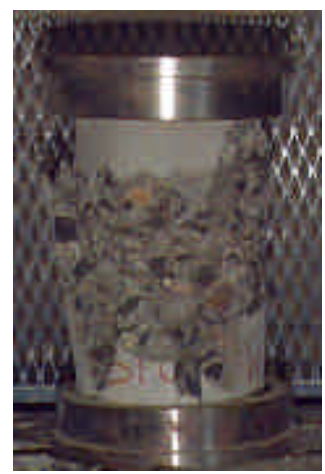

b) ruptura de um corpo-de-prova em CAR, comprimido axialmente

FIGURA 4.6 - INFLUÊNCIA DA RESISTÊNCIA À COMPRESSÃO UNIAXIAL DO CONCRETO NA RELAÇÃO TENSÃO X DEFORMAÇÃO

Segundo AMARAL FILHO (1992a), a forma da curva tensão x deformação está relacionada com a microfissuração do concreto. Para concretos usuais, a ocorrência da microfissuração impede a ruptura frágil. Já os concretos de alta resistência, quando levados à ruína, quase não apresentam microfissuração e por isso, a ruptura é explosiva. Para uma mesma deformação, os CAR's apresentam menos microfissuração que os concretos usuais e assim, o aumento relativo na 
deformação é menor para aqueles. Este comportamento é mostrado na FIGURA 4.7 .

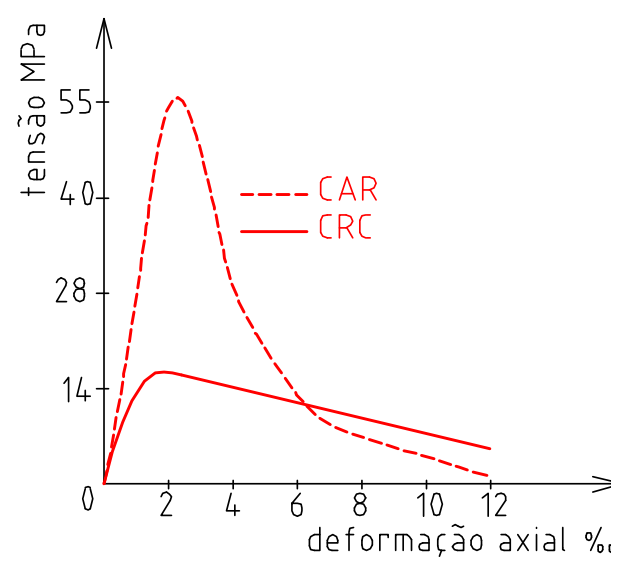

a) deformação axial $x$ tensão axial

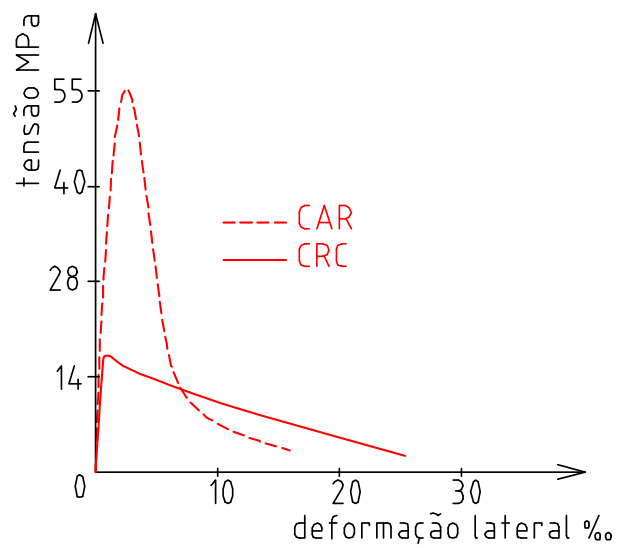

b) deformação transversal $x$ tensão axial

FIGURA 4.7 - VARIAÇÃO DAS DEFORMAÇÕES NOS CONCRETOS DE RESISTÊNCIA USUAL E DE ALTA RESISTÊNCIA

\subsubsection{Coeficiente de Poisson ( $v$ )}

Os resultados experimentais obtidos por DAL MOLIN (1995) indicam 0,19 como valor médio para o coeficiente de Poisson dos CARs. 


\section{COMPORTAMENTO DA SEÇÃO MISTA}

\subsection{INTRODUÇÃo}

O comportamento do pilar misto preenchido difere muito do comportamento de um pilar em concreto armado, mostrando que a ação conjunta de aço e concreto é fundamental e responsável por minimizar a fragilidade do concreto de alta resistência e a possibilidade da ocorrência de flambagem local do perfil tubular.

Diversos parâmetros influem no comportamento conjunto dos componentes aço e concreto, e conseqüentemente, no comportamento do pilar misto. Alguns destes serão vistos a seguir, entretanto a influência de alguns parâmetros ainda não foi devidamente esclarecida. Como exemplos podem ser citados fenômenos como retração e fluência do concreto, em especial do concreto de alta resistência, que embora os primeiros estudos teóricos tenham mostrado serem responsáveis por acréscimos consideráveis de tensões no perfil tubular, é preciso quantificá-los para constatar se de fato são significativos.

A seguir são apresentados alguns parâmetros que interferem no comportamento da seção mista. 


\subsection{EFEITOS DE RETRAÇÃO E FLUÊNCIA}

O material concreto sofre ao longo do tempo, além de outros efeitos, os efeitos de retração hidráulica e fluência. A retração hidráulica independe da aplicação do carregamento; já a fluência, inicia quando o carregamento é aplicado e, a um estado de tensão uniforme permanente, corresponde um acréscimo das deformações que independe do acréscimo do carregamento.

No núcleo de concreto do pilar misto, a intensidade do fenômeno de retração é menor que no caso de pilares de concreto armado pois a perda de umidade é inibida pelo perfil. Embora seja menor, ao que os primeiros estudos teóricos indicam, seus efeitos sobre a distribuição de tensões e deformações são significativos.

Buscando conhecer o comportamento do concreto confinado ao longo do tempo, GOMES (1994) estudou experimentalmente os efeitos da retração e da fluência sobre as tensões no concreto, para seções tubulares axialmente comprimidas. Seu estudo conduziu às seguintes conclusões:

1) os efeitos da retração do concreto sobre a resistência da seção mista são desprezíveis. Embora a retração provoque a redução do volume de concreto, tendendo a destruir parte da aderência entre o perfil e o concreto, diversos estudos mostraram que a perda de aderência não afeta a resistência à compressão de elementos mistos axialmente comprimidos;

2) a deformação por fluência leva a acréscimos de forças transferidas do concreto para o perfil tubular. Quanto maior a resistência do concreto, menor será a intensidade do fenômeno de fluência e portanto, menor a transferência de forças para o perfil, ou seja, menor o acréscimo de tensões neste;

3) os efeitos da fluência podem ser minimizados adotando medidas como: aumentar a resistência do concreto de preenchimento ou empregar uma dosagem adequada de materiais, aumentar a área de concreto ou a espessura do perfil tubular, embora esta última contribua pouco neste sentido. Outra alternativa, trabalhosa porém de bons resultados, é a colocação de barras longitudinais de armadura. 
UY \& DAS (1997) também estudaram o efeito dos fenômenos de retração e fluência no comportamento do pilar misto e destacam a importância deste estudo para pilares mistos preenchidos, referindo-se a tais fenômenos como responsáveis por acréscimos consideráveis nas deformações finais apresentadas por estes elementos.

Estes pesquisadores estudaram os mesmos fenômenos estudados por GOMES (1994), porém de forma teórica, por meio de análises numéricas.

Durante a análise, as forças de cada pavimento foram aplicadas na forma de incrementos, simulando o processo construtivo empregado e considerando, desta forma, a história de carregamento do edifício.

Os efeitos da fluência e da retração do concreto sobre as tensões e deformações implicam na redistribuição de tensões no pilar misto preenchido, causando alívio de tensões no concreto e acréscimo de tensões no perfil tubular. Em função desta redistribuição, é preciso verificar se as tensões no perfil tubular não excedem a resistência ao escoamento ou sua tensão de flambagem local.

UY \& DAS (1997) consideraram que a deformação total $\varepsilon_{\text {total }}(\mathrm{t}, \tau)$ num elemento em concreto, para um tempo t após o carregamento é dada por:

$$
\varepsilon_{\text {total }}(\mathrm{t}, \tau)=\varepsilon_{\text {elástica }}(\mathrm{t}, \tau)+\varepsilon_{\text {fluência }}(\mathrm{t}, \tau)+\varepsilon_{\text {retração }}(\mathrm{t})
$$

onde:

- a deformação elástica e por fluência dependem do tempo $\underline{t}$, decorrido desde o início da atuação do carregamento

- a deformação por retração depende do tempo $\underline{\tau}$ contado a partir do início da cura do concreto.

$\mathrm{Na}$ FIGURA 5.1 são apresentadas as componentes de deformação consideradas por YU \& DAS (1997).

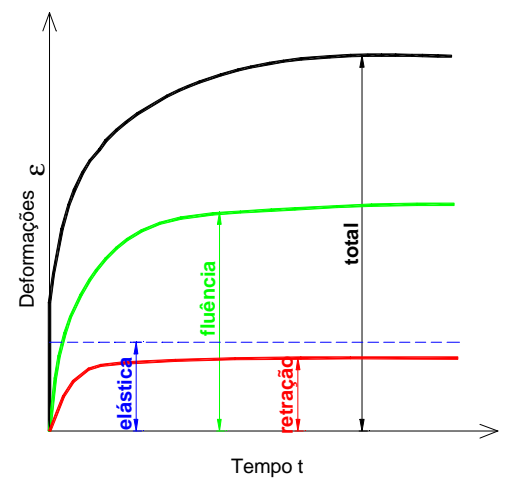

FIGURA 5.1 - COMPONENTES DE DEFORMAÇÃO DO NÚCLEO DE CONCRETO AO LONGO DO TEMPO, CONSIDERADAS POR UY \& DAS (1997) 
Dos diversos parâmetros que influem no comportamento do pilar misto ao longo do tempo, UY \& DAS (1997) investigaram a influência do número de pavimentos construído, da resistência do concreto e da rigidez da seção transversal.

O estudo permitiu quantificar o acréscimo de tensões no perfil tubular e o alívio de tensões no concreto de preenchimento, ambos ao longo do tempo. Os resultados obtidos considerando resistência e rigidez constantes e variando o número de pavimentos são apresentados na TABELA 5.1 .

TABELA 5.1 - Variação das deformações e tensões, devidas aos fenômenos de retração e fluência, considerando resistência e rigidez constantes: UY \& DAS (1997)

\begin{tabular}{|c|c|c|c|}
\hline n. de pavimentos & $\begin{array}{c}\text { \% da deformação total } \\
\text { correspondente a } \\
\text { fluência e retração }\end{array}$ & $\begin{array}{c}\text { \% de redução da } \\
\text { tensão no concreto }\end{array}$ & $\begin{array}{c}\text { \% de aumento da } \\
\text { tensão no perfil } \\
\text { tubular }\end{array}$ \\
\hline 10 & 67 & 250 & 100 \\
\hline 20 & 55 & 79 & 76 \\
\hline 30 & 50 & 63 & 45 \\
\hline 40 & 47 & 63 & 31 \\
\hline
\end{tabular}

Com base nos resultados de UY \& DAS (1997) pode-se afirmar que os fenômenos de retração e fluência perdem importância à medida que o número de pavimentos aumenta, pois a parcela de deformação elástica tende a aumentar e a porcentagem correspondente às deformações por fluência e retração tende a diminuir.

$\mathrm{Na}$ TABELA 5.2 são apresentados os resultados obtidos considerando variações na resistência e rigidez do concreto.

TABELA 5.2 - Tensões no pilar misto preenchido considerando variações na resistência e rigidez do concreto: UY \& DAS (1997)

\begin{tabular}{|c|c|c|c|c|c|c|c|}
\cline { 2 - 8 } \multicolumn{1}{c|}{} & \multicolumn{4}{c|}{ Concreto } & \multicolumn{4}{c|}{ PERFIL TUBULAR } \\
\hline $\mathbf{N}$ & $\begin{array}{c}\mathrm{f}_{\mathrm{c}} \\
(\mathrm{MPa})\end{array}$ & $\begin{array}{c}\mathrm{E}_{\mathrm{c}} \\
(\mathrm{MPa})\end{array}$ & $\begin{array}{c}\text { \% redução de } \\
\text { tensão }\end{array}$ & $\begin{array}{c}\mathrm{b} \\
(\mathrm{mm})\end{array}$ & $\begin{array}{c}\mathrm{t} \\
(\mathrm{mm})\end{array}$ & $\begin{array}{c}\mathrm{E}_{\mathrm{s}} \\
(\mathrm{MPa})\end{array}$ & $\begin{array}{c}\text { \% de acréscimo de } \\
\text { tensão }\end{array}$ \\
\hline 20 & 40 & 31600 & $35 \%$ & 1000 & 25 & 200000 & $65 \%$ \\
\hline 40 & 50 & 35400 & $38 \%$ & 1000 & 25 & 200000 & $67 \%$ \\
\hline 60 & 60 & 38700 & $39 \%$ & 1000 & 40 & 200000 & $49 \%$ \\
\hline 80 & 80 & 44700 & $33 \%$ & 1000 & 40 & 200000 & $57 \%$ \\
\hline 100 & 100 & 50500 & $34 \%$ & 1000 & 40 & 200000 & $50 \%$ \\
\hline
\end{tabular}

UY \& DAS (1997), a partir dos resultados obtidos na investigação numérica alertam que os efeitos do tempo no comportamento de tensões e deformações, 
para os componentes da seção mista, não podem ser ignorados. Os resultados indicam sua importância, contudo não são conclusivos. Novas pesquisas são necessárias visando trazer informações adicionais quanto à influência dos materiais nos fenômenos de deformabilidade, tanto para concretos de resistência normal quanto para concretos de alta resistência.

\subsection{ADERÊNCIA}

A princípio, é razoável pensar que a aderência aço-concreto exerce efeito significativo no comportamento dos pilares mistos preenchidos. Entretanto, uma análise minuciosa dos resultados experimentais obtidos por diversos pesquisadores indica que o efeito da aderência, na resposta global dos pilares mistos preenchidos, ainda é um assunto que inspira cuidados e requer novos estudos.

As normas de projeto consideram como hipótese básica, a ação conjunta dos materiais, supondo interação completa entre eles. A fim de garantir esta condição, algumas normas sugerem a utilização de conectores de cisalhamento ou outro dispositivo, que garanta a ação conjunta dos materiais. Como exemplo das recomendações de norma, cita-se a BS 5400: parte 5 (1979), que recomenda o emprego de conectores metálicos quando as tensões de cisalhamento na interface aço-concreto superarem 0,4 MPa $\left(0,4 \mathrm{~N} / \mathrm{mm}^{2}\right)$.

As investigações experimentais realizadas até então, destinaram-se a estudar os diversos fatores que influem na aderência e sobretudo, dedicaram-se à investigação da influência da aderência na capacidade resistente da seção mista preenchida.

Neste sentido, HUNAITI (1992) investigou a influência de parâmetros como: dimensões da seção transversal, idade e resistência do concreto, temperatura e condições de cura. Os estudos mostraram perdas significativas de aderência com o envelhecimento do concreto ou o aumento de temperatura. O pesquisador ressalta que os pilares ensaiados eram do tipo battened e por isso, seções preenchidas quadradas e circulares devem apresentar aderência superior à constatada para os elementos estudados. 
Quanto à influência da aderência na capacidade resistente, HUNAITI \& WAKABAYASHI (1992) ensaiaram quatorze pilares esbeltos do tipo battened, submetidos a compressão axial e flexo-compressão. Os ensaios foram realizados com a flexão atuando nos planos de maior e menor inércia. Para alguns destes pilares, a aderência foi atenuada com a aplicação de graxa na superfície interna dos painéis metálicos. As principais características da seção investigada são apresentadas na FIGURA 5.2.

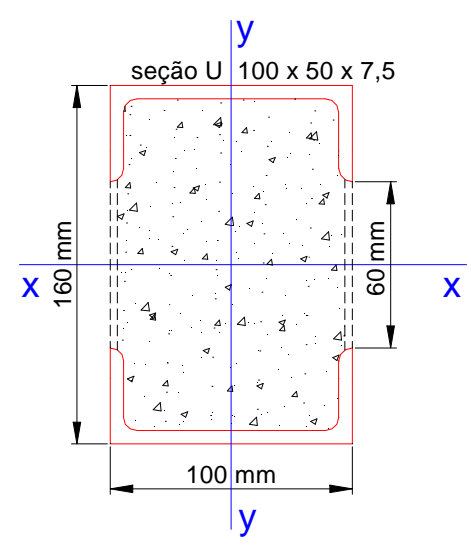

FIGURA 5.2 - SEÇÃO TRANSVERSAL INVESTIGADA POR HUNAITI \& WAKABAYASHI (1992)

Os resultados mostraram que a capacidade resistente não sofre influência significativa da aderência entre perfil e concreto. HUNAITI \& WAKABAYASHI (1992) afirmam que os resultados encontrados podem ser estendidos para seções revestidas e preenchidas uma vez que a seção tipo "battened" é um tipo intermediário entre elas. Quanto às deformações, também não foi constatada diferença significativa de comportamento. Em todos os casos, a separação entre o perfil e o concreto de preenchimento ocorreu antes de ser atingida a capacidade resistente.

Os resultados de HUNAITI \& WAKABAYASHI (1992) são questionáveis pois a aderência aço-concreto de preenchimento parece ser essencial na garantia da transferência de forças em elementos fletidos.

Os pilares estudados até então eram do tipo "battened", preenchidos com concreto de resistência usual. 
OKAMOTO et al. (1988) ${ }^{1}$ apud SAADEGHVAZIRI \& SHAMS (1997) realizaram experimentos com pilares mistos, preenchidos com concreto de alta resistência $(98,1 \mathrm{MPa})$, buscando estudar a influência de parâmetros como relação de aspecto $\mathrm{D} / \mathrm{t}$, intensidade da força axial e tensão de aderência, sobre a capacidade resistente à flexão. A seção tubular estudada era circular, com $175 \mathrm{~mm}$ de diâmetro, $1700 \mathrm{~mm}$ de comprimento e três espessuras diferentes: $3,2 \mathrm{~mm}$, $4,5 \mathrm{~mm}$ e $6 \mathrm{~mm}$. A aderência entre aço e concreto foi reduzida utilizando-se uma camada de argamassa com $10 \mathrm{~mm}$ de espessura.

Da análise dos resultados concluiu-se que a aderência não é significativa para a capacidade resistente à flexão de pilares mistos preenchidos. SAADEGHVAZIRI \& SHAMS (1997) questionam tal conclusão alertando que nos estudos de OKAMOTO et al., para cada pilar ensaiado, duas variáveis foram analisadas - a resistência da camada de argamassa e a intensidade da força axial aplicada - comprometendo as conclusões.

Aderência é a propriedade que impede o deslocamento relativo entre concreto e aço e, no caso de pilares mistos preenchidos, SHAKIR-KHALIL (1988) acrescenta que tal propriedade é favorecida por duas imperfeições existentes na superfície do perfil tubular: a rugosidade superficial, seja ela intencional ou oriunda do processo de fabricação e a variação das dimensões do perfil tubular ao longo de sua altura.

Resultados experimentais obtidos por SHAKIR-KHALIL (1993a) evidenciam a sensibilidade da aderência às condições da interface, no que se refere às imperfeições acima citadas. Seus estudos mostraram também a significativa sensibilidade das tensões de aderência à forma da seção transversal. Seções retangulares - 120x80x5mm - apresentaram tensões de aderência muito superiores

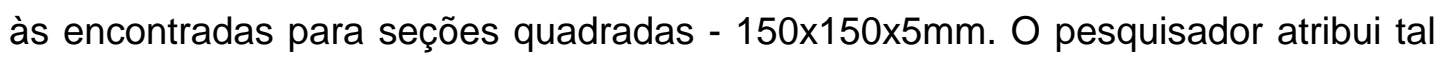
diferença à retração do concreto, que é maior em volumes maiores deste material e ainda, à maior oposição ao movimento do núcleo de concreto, proporcionada pela maior área de contato da seção retangular. Contudo, ele sugere que um número maior de ensaios seja feito, a fim de avaliar a influência das dimensões da seção e

\footnotetext{
1 OKAMOTO, T; MAENO, T. (1988). Experimental study on rectangular steel tube columns infilled with ultra high strength concrete hardened by centrifugal force. In: Annual meeting of AlJ. Proceedings. Chiba, october, p.1359.
} 
da relação $b / t$ - sendo $b$ o lado e $t$ a espessura do perfil tubular - sobre $a$ resistência da ligação aço-concreto.

Quanto às condições da superfície do perfil tubular em contato com o núcleo de concreto, há um consenso entre as normas que abordam o projeto de pilares mistos preenchidos. Todas recomendam que a superfície não deve ser pintada e deve estar livre de vestígios de óleos, graxas e de camadas superficiais soltas, decorrentes da corrosão.

A utilização de conectores de cisalhamento para reduzir as tensões de aderência na interface aço-concreto foi investigada por SHAKIR-KHALIL (1993a, 1993b). Seus resultados mostraram que a utilização de tais conectores melhora a transferência de esforços entre os materiais. Os estudos experimentais de SHAKIR-KHALIL (1993a, 1993b) abrangeram seções circulares, quadradas e retangulares, submetidas ao seguinte esquema de carregamento (FIGURA 5.3): a força é aplicada ao núcleo de concreto e posteriormente transferida ao perfil tubular por aderência aço-concreto.

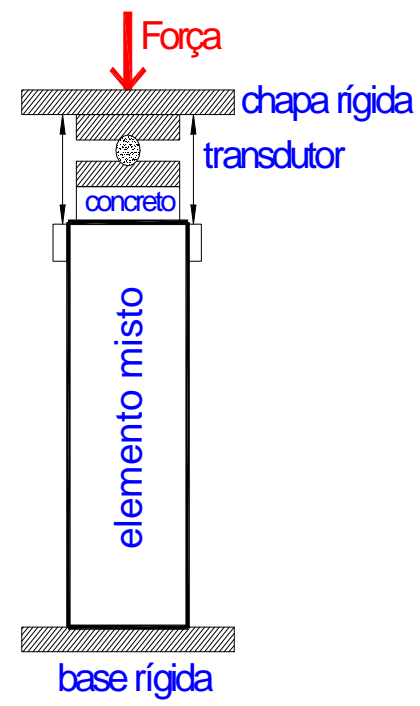

FIGURA 5.3 - ESQUEMA DE ENSAIO EMPREGADO POR SHAKIR-KHALIL (1993a, 1993b)

O estudo experimental desenvolvido por GOMES (1994), composto por 22 elementos, dos quais 12 foram ensaiados após 28 dias de moldagem e 10 novamente ensaiados após 8 anos de exposição ao ar livre, mostraram que a aderência aumenta com o tempo. Nos primeiros 12 ensaios, a aderência concretoperfil era garantida pelas parcelas de aderência química e mecânica, sendo aquela 
destruída após a execução do ensaio, devido ao deslocamento relativo entre os dois materiais. Restando apenas a parcela de aderência correspondente ao engrenamento do concreto na rugosidade superficial do perfil tubular, 10 elementos foram expostos ao ar livre por 8 anos e novamente ensaiados. A ruptura caracterizou-se pelo deslocamento relativo acentuado, visível na leitura dos transdutores, que variou ininterruptamente com força constante. Um aumento de $16 \%$ na força de ruptura foi verificado após 8 anos de exposição, o mesmo ocorrendo com as tensões de aderência.

$O$ pesquisador justifica que estes aumentos devem-se a dois fatores: 0 envelhecimento do concreto e o princípio de corrosão no perfil tubular, fatores estes que dificultam o deslizamento relativo entre os materiais.

GOMES (1994) lembra que deve ser dada atenção especial à etapa de concretagem do núcleo, pois uma perfeita vibração do concreto elimina grande parte das bolhas de ar presentes na massa e que podem comprometer a superfície de contato.

Uma menção deve ser feita ao fato de que a divisão da aderência em parcelas de aderência química e mecânica é apenas convencional, não sendo possível quantificar separadamente cada uma delas.

\subsection{FLAMBAGEM LOCAL DO PERFIL TUBULAR}

As normas aplicáveis ao projeto de pilares mistos preenchidos recomendam valores máximos para a relação b/t (lado / espessura do perfil), de forma a impedir que ocorra flambagem local do perfil tubular. Na TABELA 5.3 são mostradas algumas destas recomendações e também a sugestão de um pesquisador para perfis em aço de alta resistência.

TABELA 5.3 - Valores mínimos para a espessura do perfil tubular

\begin{tabular}{|c|c|c|}
\hline RECOMENDAÇÃO & TIPO DE SEÇÃO & DimensÃo $(\mathrm{mm})$ \\
\hline \multirow{2}{*}{$\begin{array}{l}\text { ACI 318R-92 (1992), AISC-LRFD (1994) e } \\
\text { BS 5400: Parte } 5 \text { (1979) }\end{array}$} & retangular & $t_{\text {min }}=b \cdot \sqrt{\frac{f_{y}}{3 \cdot E_{s}}}(M P a)$ \\
\hline & circular & $t_{\min }=D \cdot \sqrt{\frac{f_{y}}{8 \cdot E_{s}}}(M P a)$ \\
\hline
\end{tabular}


Tabela 5.3 - Valores mínimos para a espessura do perfil tubular (cont.)

\begin{tabular}{|c|c|c|c|}
\hline \multicolumn{2}{|c|}{ CAN/CSA-S16.1 (1989) } & circular & $\frac{\mathrm{D}}{\mathrm{t}} \leq \frac{28000}{\mathrm{f}_{\mathrm{y}}}(\mathrm{MPa})$ \\
\cline { 3 - 4 } & retangular & $\frac{\mathrm{b}}{\mathrm{t}} \leq 13,5 \cdot \sqrt{\mathrm{f}_{\mathrm{y}}}\left(\mathrm{kN} / \mathrm{cm}^{2}\right)$ \\
\hline EUROCODE 4 (1994) & $\varepsilon=\sqrt{\frac{235}{\mathrm{f}_{\mathrm{y}}}}$ & circulares & $\frac{\mathrm{d}}{\mathrm{t}} \leq 90 \cdot \varepsilon^{2}$ \\
\cline { 3 - 4 } & $\mathrm{f}_{\mathrm{y}}(\mathrm{MPa})$ & retangulares & $\frac{\mathrm{h}}{\mathrm{t}} \leq 52 \cdot \varepsilon$ \\
\hline & & retangular & $\mathrm{t}_{\min }=\frac{\mathrm{b}}{96} \cdot \sqrt{\frac{\mathrm{f}_{\mathrm{y}}}{250}}(\mathrm{MPa})$ \\
\hline
\end{tabular}

Nas situações em que tais recomendações não são seguidas, o comportamento das faces do perfil tubular, sujeito à compressão axial deve ser analisado quanto à ocorrência de flambagem local.

Alguns pesquisadores têm desenvolvido estudos teóricos e experimentais no sentido de analisar o comportamento do pilar misto quando o perfil tubular sofre flambagem local. Quando um perfil tubular é solicitado à compressão axial, pode ocorrer localmente a flambagem das paredes, da forma mostrada na FIGURA 5.4 a. Entretanto, se este mesmo perfil for preenchido com concreto, o modo de flambagem será alterado apresentando, segundo UY (1996), a configuração da FIGURA 5.4-b. A alteração na configuração deformada do perfil ocorre porque o concreto de preenchimento impede que as paredes do perfil se desloquem para o interior, sendo possível apenas o deslocamento para fora.

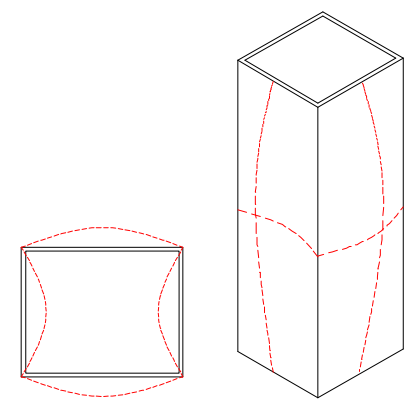

a) perfil tubular

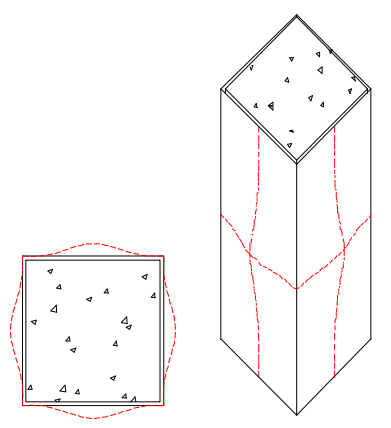

b) seção mista

FIGURA 5.4 - FENÔMENO DE FLAMBAGEM LOCAL NO PERFIL TUBULAR 
Como conseqüência do preenchimento, o concreto aumenta a resistência do perfil à flambagem local, fazendo com que alguns trechos da seção de aço não sofram deformações acentuadas. Estas regiões podem ser consideradas como áreas efetivas no cálculo da capacidade resistente da seção mista. Desta forma, surge o conceito de área efetiva, muito comum no dimensionamento de perfis tubulares.

Na FIGURA 5.5 é mostrada uma seção tubular onde as regiões hachuradas representam áreas efetivas.

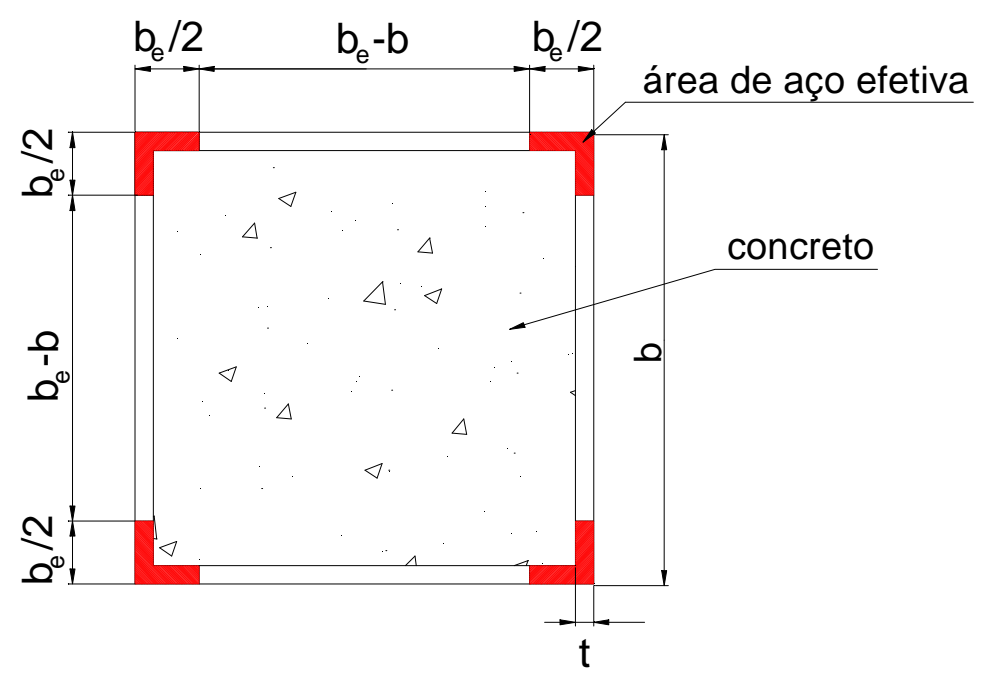

FIGURA 5.5 - LARGURAS E ÁREAS EFETIVAS PARA O PERFIL TUBULAR PREENCHIDO COM CONCRETO

O comportamento do pilar misto quanto à ocorrência de flambagem local no perfil tubular foi estudado por UY (1996), que analisou as expressões propostas por YAMAKI ${ }^{2}$ apud UY (1996), para o cálculo da largura efetiva $b_{e}$, e propõe:

$$
\text { para } 0 \leq \beta \leq 1,0 \rightarrow \frac{b_{e}}{b}=1,0
$$

ou seja, até a chapa atingir a resistência ao escoamento, a área efetiva de aço é igual à área total.

Para valores de $\beta$ maiores que 1,0 :

$$
1,0 \leq \beta \leq 1,2 \rightarrow \frac{b_{e}}{b}=1,5-0,5 \cdot \beta
$$

\footnotetext{
${ }^{2}$ IAMAKI, N. (1959). Postbuckling behaviour of rectangular plates with small initial curvature loaded in edge compression. Journal of applied mechanics, n. 14.
} 


$$
\begin{aligned}
& 1,2 \leq \beta \leq 1,6 \rightarrow \frac{b_{e}}{b}=1,2-0,25 \cdot \beta \\
& 1,6 \leq \beta \leq 2,0 \rightarrow \frac{b_{e}}{b}=1,0-0,125 \cdot \beta \\
& 2,0 \leq \beta \leq 7,2 \rightarrow \frac{b_{e}}{b}=1,036-0,144 \cdot \beta
\end{aligned}
$$

sendo:

$$
\beta=\frac{f_{y}}{\sigma_{\text {ol }}}
$$

e

$$
\sigma_{\mathrm{ol}}=\frac{\mathrm{k} \cdot \pi^{2} \cdot \mathrm{E}_{\mathrm{s}}}{12 \cdot\left(1-v^{2}\right) \cdot\left(\frac{\mathrm{b}}{\mathrm{t}}\right)^{2}}
$$

Para uma seção mista quadrada, de lado b, a área efetiva de aço será dada pela equação 5.4 :

$$
A_{s e}=\left(b^{2}-(b-2 \cdot t)^{2}-4 \cdot\left(b-b_{e}\right)\right) \cdot t
$$

UY (1998b), após vários ensaios com pilares mistos axialmente comprimidos, concluiu que a ocorrência de flambagem local pode ser identificada no diagrama Força x Deformação axial por uma região de significativa mudança de comportamento. Ele mediu em seus estudos, o comprimento da onda formada na região onde ocorre flambagem local e constatou que este é igual ao lado da seção, no caso de seções quadradas.

A utilização de espessuras inferiores às mínimas implica na possibilidade de ocorrência da flambagem local antes que seja atingida a capacidade resistente. Caso isto ocorra, há redução da área efetiva de aço e conseqüente redução na capacidade resistente do pilar misto. Por isso, para evitar tal redução é importante respeitar os limites mínimos impostos à espessura do perfil tubular. 


\subsection{CONFINAMENTO}

O efeito das tensões de confinamento devidas à presença do perfil tubular envolvendo o núcleo de concreto é um assunto até então pouco estudado e sobre o qual pairam muitas dúvidas, sobretudo no que se refere à sua ocorrência e magnitude para seções retangulares e quadradas. O pequeno número de estudos deste fenômeno justifica-se pela dificuldade de realizar investigações experimentais e teóricas cujos resultados sejam confiáveis.

O efeito de confinamento surge da seguinte forma: nos primeiros estágios de carregamento, o coeficiente de Poisson do concreto é menor que o do aço e por isso o perfil não exerce efeito de confinamento sobre o núcleo de concreto. À medida que as deformações longitudinais aumentam, a expansão lateral do concreto não confinado torna-se gradualmente maior que a do aço. Conseqüentemente, desenvolvem-se pressões radiais na interface aço-concreto. $O$ concreto envolvido pelo perfil tubular apresenta-se então, sob estado triaxial de tensões e o perfil tubular, em estado biaxial de tensões. Por causa deste estado biaxial de tensões, o perfil não consegue manter sua resistência ao escoamento e passa a transferir esforços para o núcleo de concreto.

O estado de confinamento do concreto do núcleo influi diretamente na capacidade resistente dos pilares mistos preenchidos, pois tal capacidade não é dada apenas pela soma das resistências do perfil tubular e do concreto de preenchimento. $\mathrm{Na}$ verdade o núcleo de concreto encontra-se sujeito a um de tensões diferente do uniaxial.

O grau de acréscimo na capacidade resistente causado pelo efeito de confinamento depende de uma série de fatores, dos quais destacam-se: espessura do perfil tubular, índice de esbeltez do pilar misto, excentricidade da força, resistência dos materiais e forma da seção transversal. Todos estes fatores, agindo em conjunto, irão contribuir para um maior ou menor grau de confinamento do concreto.

A questão da forma da seção transversal é importantíssima. Para seções circulares é fácil perceber que todo o concreto de preenchimento está sujeito a um mesmo grau de confinamento, conforme ilustra a FIGURA 5.6. 


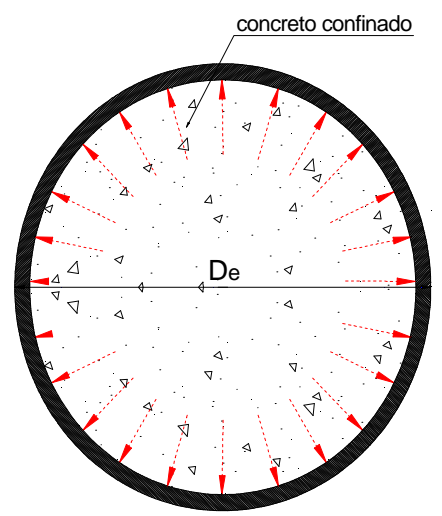

FIGURA 5.6 - TENSÕES DE CONFINAMENTO EM SEÇÕES CIRCULARES

No entanto, nas seções quadradas, o concreto do centro e dos cantos estará submetido a um grau de confinamento maior que o concreto situado nos lados. Isto porque ocorre o arqueamento das tensões de confinamento do centro da seção para os cantos. Para as seções retangulares, imagina-se que a variação do grau de confinamento do concreto seja ainda maior que a verificada nas seções quadradas. $\mathrm{O}$ arqueamento das tensões para as seções retangulares e quadradas é mostrada na FIGURA 5.7.

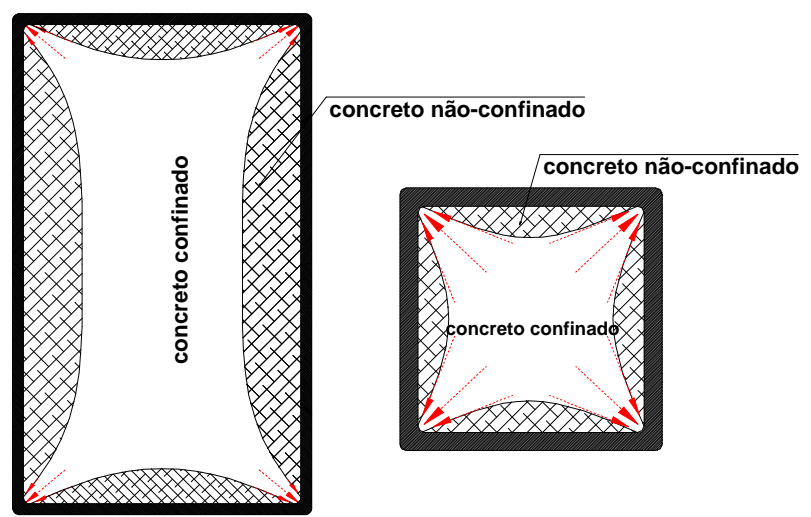

FIGURA 5.7 - ARQUEAMENTO DAS TENSÕES DE CONFINAMENTO EM SEÇÕES QUADRADAS E RETANGULARES

Atualmente, o ganho de resistência devido ao confinamento para seções quadradas é considerado tão inferior ao verificado para seções circulares, que é desprezado pelas normas de dimensionamento. Esta consideração das normas é resultado de uma série de estudos experimentais desenvolvidos até então. Contudo, há dúvidas quanto à intensidade do confinamento e sua influência na capacidade resistente de seções mistas axialmente comprimidas. 
O efeito de confinamento exercido pelo perfil sobre o concreto é responsável por melhorar o comportamento dos materiais aço e concreto. GE \& USAMI (1992) ensaiaram perfis tubulares e pilares mistos preenchidos, ambos curtos e de seção quadrada. O objetivo era avaliar a contribuição do concreto no comportamento do perfil tubular. Quanto à forma de ruína verificada, um prisma de concreto submetido à compressão uniaxial atinge a ruptura por esmagamento num plano preferencial inclinado, conforme ilustra a FIGURA 5.8-a. Estando confinado pelo perfil tubular, a ruptura ocorre por esmagamento do concreto e posterior flambagem local plástica do perfil tubular, conforme a FIGURA 5.8-b.

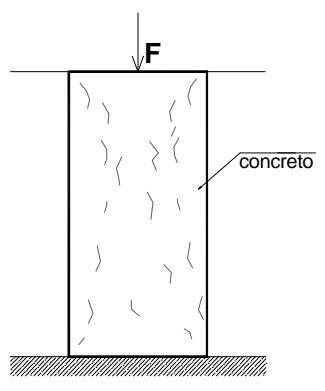

a) concreto isolado

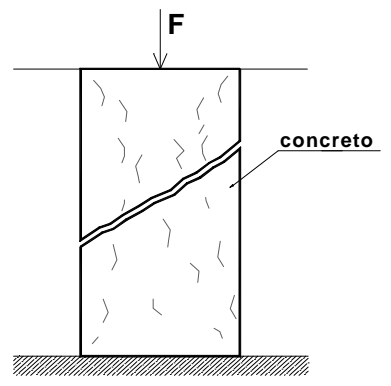

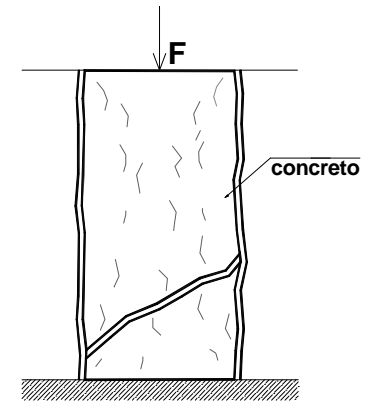

b) concreto confinado

FIGURA 5.8 - CONFIGURAÇÕES DE RUÍNA PARA O CONCRETO ISOLADO E CONFINADO

\subsubsection{ESTUdOS REALIZADOS}

Buscando elucidar a influência do confinamento e sua contribuição na capacidade resistente da seção mista, alguns pesquisadores desenvolveram estudos teóricos e experimentais, cujos principais parâmetros e conclusões são apresentados a seguir.

O primeiro estudo experimental de que se tem notícia foi realizado por KNOWLES \& PARK (1969), que estudaram o efeito do confinamento do concreto em seções circulares e quadradas. O principal objetivo do estudo foi avaliar a influência do índice de esbeltez sobre a intensidade da pressão lateral, exercida pelo perfil sobre o concreto.

Os experimentos mostraram que, para seções circulares e pequeno índice de esbeltez, o acréscimo de resistência devido ao confinamento chegou a 36\%.

Para seções quadradas, os acréscimos foram pequenos e a seguinte justificativa foi apresentada: o confinamento causado pelo perfil tubular é mais 
efetivo nos cantos da seção quadrada e o restante do concreto encontra-se livre das tensões de confinamento ou submetido a tensões muito pequenas. Embora esta tenha sido a conclusão do estudo experimental, KNOWLES \& PARK (1969) na época, recomendaram que este assunto fosse objeto de uma série de análises teóricas e experimentais para confirmar os resultados obtidos por eles, e questionados por outros pesquisadores.

TOMII et al. (1977) ${ }^{3}$ apud SAADEGHVAZIRI \& SHAMS (1997) investigaram a influência de parâmetros como forma da seção transversal, índice de esbeltez e comprimento do pilar misto, na capacidade resistente. Ao todo, foram ensaiados 286 pilares mistos, cujas seções variaram entre as formas circular e quadrada. Além de conclusões parciais a respeito do efeito de confinamento, a experimentação permitiu outras conclusões, relativas aos modos de ruína possíveis:

1) para pilares curtos a ruína ocorre por esmagamento do concreto de preenchimento e posterior flambagem local do perfil;

2) para pilares esbeltos a ruína ocorre por instabilidade global do pilar misto.

Foi observado que o comportamento da relação tensão-deformação muda sensivelmente quando ocorrem variações na forma da seção, na relação de aspecto D/t e na resistência do concreto. Para seções circulares, os diagramas força $x$ deformação indicam um comportamento elasto-plástico perfeito (FIGURA 5.9a), já para seções quadradas o comportamento é elasto-plástico com encruamento (FIGURA 5.9b). Esta diferença de comportamento pode ser vista na FIGURA 5.9, onde são representados alguns dos resultados obtidos por TOMII et al. $(1977)^{3}$.

\footnotetext{
${ }^{3}$ TOMII, M. et al. (1977). Experimental studies one concrete filled steel tubular columns under concentric loading. In: International colloquium on stability of structures under static and dynamic loads. Washington, May 17-19, p.718-741.
} 


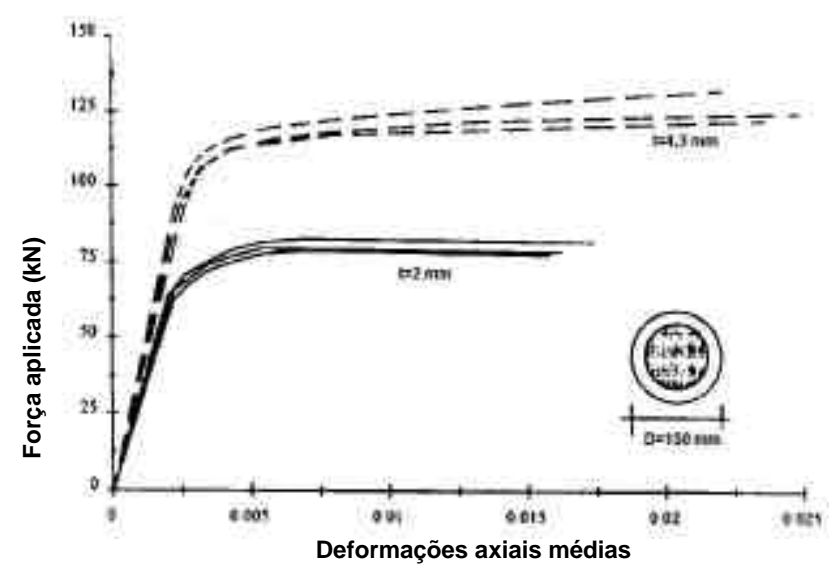

a) força $x$ deformação axial para seções mistas circulares comprimidas axialmente

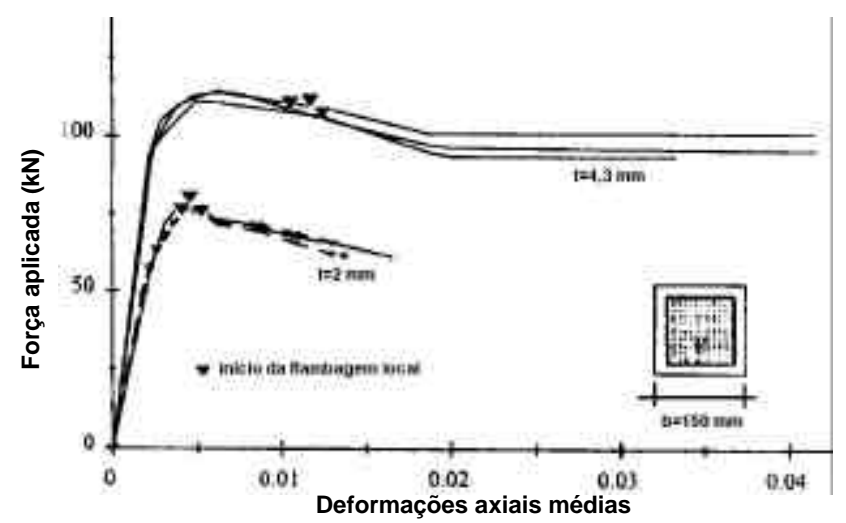

b) força aplicada $x$ deformação axial para seções mistas quadradas carregadas axialmente

FIGURA 5.9 - RELAÇÕES TENSÃO-DEFORMAÇÃO PARA DIFERENTES FORMAS DE SEÇÃO TRANSVERSAL MISTA - TOMII et al. $(1977)^{3}$

O efeito de confinamento foi comprovado experimentalmente para seções circulares. Quanto às seções quadradas, são recomendados novos estudos a fim de verificar se este efeito é relevante no comportamento da seção mista.

GUARDNER \& JACOBSON apud SAADEGHVAZIRI \& SHAMS (1997) em 1967, após estudar analiticamente o efeito de confinamento nos pilares mistos preenchidos, apresentam como equação para o cálculo da pressão radial interna $\sigma_{\mathrm{r}}$, aquela aplicável a tubos de parede fina:

$$
\sigma_{r}=\frac{t}{r} \cdot \sigma_{t}
$$

onde: $\sigma_{\mathrm{t}}$ é a tensão anelar no perfil tubular e pode ser calculada a partir do critério da máxima tensão cisalhante: 


$$
\sigma_{t}=f_{y}-\sigma_{s i}
$$

sendo:

$\sigma_{\mathrm{si}}$ : tensão no perfil tubular

t: espessura do perfil tubular

r: raio do perfil tubular circular

Conhecendo o valor da pressão radial aplicada ao núcleo de concreto é possível calcular a resistência à compressão do concreto confinado $f_{c c}$, dada por:

$$
f_{c c}=f_{c}+k \cdot \sigma_{r}
$$

onde:

$\mathrm{f}_{\mathrm{cc}}$ : resistência à compressão do concreto confinado

$\mathrm{f}_{\mathrm{c}}$ : resistência à compressão uniaxial

$\mathrm{K}$ : fator empírico cujo valor encontrado foi aproximadamente 4

A partir de 5.7 é possível calcular a capacidade resistente da seção circular mista considerando o efeito do confinamento:

$$
P_{n}=A_{c} \cdot f_{c}+A_{c} \cdot k \cdot \sigma_{t} \cdot \frac{t}{r}+A_{s} \cdot \sigma_{s i}
$$

Os resultados encontrados a partir da equação 5.8 diferiram em até $20 \%$ dos experimentais. Nesta equação, a parcela $A_{c} \cdot k \cdot \sigma_{t} \cdot(t / r)$ representa 0 acréscimo na resistência à compressão do concreto, devido ao confinamento.

Sen apud SAADEGHVAZIRI \& SHAMS (1997) também estudou o efeito do confinamento na resistência à compressão axial do concreto. Ele propõe que o efeito do confinamento seja introduzido nas equações de dimensionamento através de um acréscimo na resistência do concreto comprimido e de um decréscimo na resistência do aço. O acréscimo total $P_{\text {inc }}$ na capacidade resistente da seção mista é expresso pela equação 5.9, válida para seções circulares:

$$
P_{\text {inc }}=0,75 \cdot f_{y} \cdot A_{s}+A_{c} \cdot\left[f_{c k}+3,8 \cdot t \cdot \frac{f_{y}}{D-t}\right]
$$

D e t: diâmetro e espessura do perfil tubular circular

CEDERWALL, ENGSTROM \& GRAUERS (1990) estudaram o efeito do confinamento em seções quadradas $(12 \times 12) \mathrm{cm}$, preenchidas com concreto de alta resistência. Foram investigados experimentalmente, pilares curtos e esbeltos. A capacidade resistente dos pilares curtos foi denominada $N_{u}$ e as parcelas correspondentes aos materiais aço e concreto, $N_{s}$ e $N_{c}$ respectivamente. A relação 
$\mathrm{N}_{\mathrm{u}} /\left(\mathrm{N}_{\mathrm{s}}+\mathrm{N}_{\mathrm{c}}\right)$ mostrou-se maior que 1. Esta diferença indica o aumento na resistência à compressão do concreto devido ao efeito de confinamento. No caso dos pilares curtos, a capacidade resistente sofreu acréscimos médios de resistência de $6 \%$ quando comparados com a capacidade nominal da seção mista $\left(\mathrm{N}_{\mathrm{s}}+\mathrm{N}_{\mathrm{c}}\right)$.

\subsubsection{MOdELO DE CONFINAMENTO}

O confinamento é comumente avaliado através do equilíbrio de forças, considerando as distribuições de pressões laterais $\mathrm{f}_{\ell}$ apresentadas na FIGURA 5.10 .
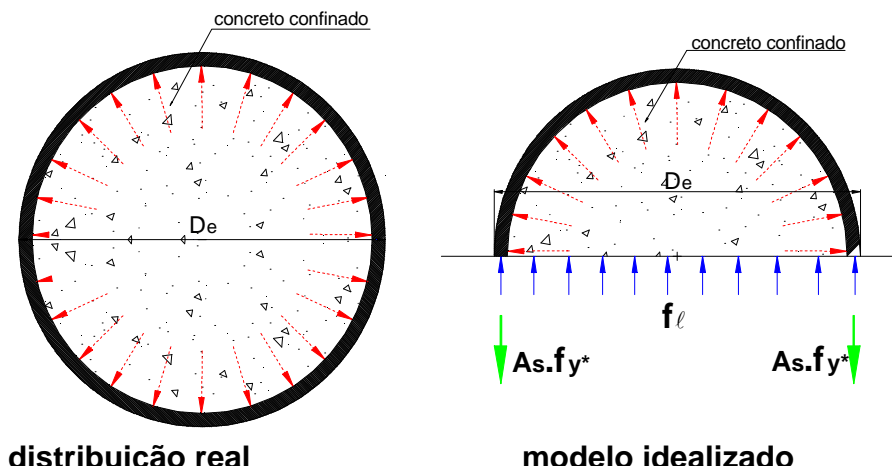

a) SEÇÃO CIRCULAR

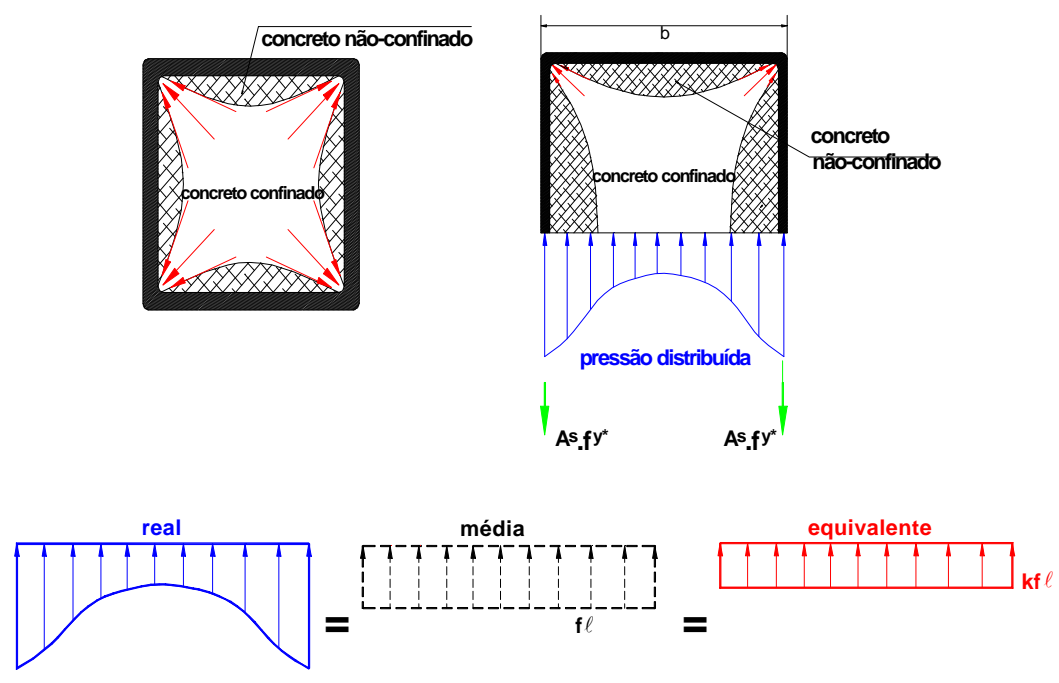

b) SEÇÃO QUADRADA

FIGURA 5.10 - CONFIGURAÇÃo dA PRESSÃo LATERAL NA SEÇÃo MISTA PREENCHIDA 
Como pode ser visto na FIGURA 5.10b, o coeficiente $k$ - denominado coeficiente de efetividade - é introduzido para levar em conta a variação no grau de confinamento devido ao arqueamento das tensões, para seções quadradas e retangulares. Seu valor, ou uma lei de variação que o represente adequadamente ainda não foi determinado.

A efetividade do confinamento ou o grau de confinamento é medido pelo aumento na resistência do concreto confinado $\left(f_{c c}\right)$ quando comparada com 0 concreto não-confinado $\left(f_{c}\right)$. A resistência do concreto confinado, que é função do coeficiente $\mathrm{k}$, aumenta devido às pressões laterais de confinamento $\left(\mathrm{f}_{\ell}\right) \mathrm{da}$ seguinte forma:

$$
\mathrm{f}_{\mathrm{cc}}=\mathrm{f}_{\mathrm{c}}+\mathrm{k} \cdot \mathrm{f}_{\ell}
$$

Muitos modelos de confinamento desenvolvidos para pilares em concreto armado assumem um valor constante para $\mathrm{k}$, entretanto o confinamento varia em função da variação da pressão lateral $f_{\ell}$. SAATCIOGLU \& RAZVI (1992) sugerem que $\mathrm{k}$ varie de forma inversamente proporcional ao coeficiente de Poisson. Portanto, a pressão lateral $\mathrm{f}_{\ell}$ aumenta com o aumento do coeficiente de Poisson, resultando na redução do coeficiente $k$, conforme a equação 5.11 :

$$
\mathrm{k}=\mathrm{a} \cdot \mathrm{f}_{\ell}^{-\mathrm{b}}(\mathrm{MPa})
$$

É preciso quantificar $a$ e $b$, a fim de expressar $k$ em função destes coeficientes. Quantificados tais coeficientes, a resistência à compressão do concreto confinado $f_{c c}$ é então calculada por:

$$
f_{c c}=f_{c}+a \cdot f_{\ell}{ }^{1-b}
$$

Para o concreto armado, SAATCIOGLU \& RAZVI (1998) encontraram a=6,7 e $b=0,17$.

A pressão de confinamento $\mathrm{f}_{\ell}$ é calculada através da equação 5.13:

$$
\mathrm{f}_{\ell}=\frac{2 \cdot \mathrm{f}_{\mathrm{t}^{*}} \cdot \mathrm{t}}{\mathrm{D}}
$$

sendo:

$\mathrm{f}_{\mathrm{t}^{*}}$ : tensão de tração radial no perfil tubular 
t: espessura do perfil tubular

D: diâmetro do núcleo confinado

A efetividade do confinamento - EC - é medida através da equação 5.14:

$$
E C=\frac{f_{c c}}{f_{c}}
$$

e o grau de confinamento - GC - é expresso pela relação entre a pressão lateral de confinamento e a resistência à compressão uniaxial do concreto e dado por:

$$
\mathrm{GC}=\frac{\mathrm{f}_{\ell}}{\mathrm{f}_{\mathrm{c}}}
$$

CUSSON \& PAULTRE (1993) sugerem a seguinte classificação para o grau de confinamento dos pilares em concreto armado, cujo concreto é de alta resistência.

TABELA 5.4 - Graus de confinamento segundo CUSSON \& PAULTRE (1993)

\begin{tabular}{|c|c|c|}
\hline CLASSE & GC & CLASSIFICAÇÃO \\
\hline 1 & $0 \%<\mathrm{GC}<5 \%$ & baixo grau de confinamento \\
\hline 2 & $5 \%<\mathrm{GC}<20 \%$ & médio grau de confinamento \\
\hline 3 & $\mathrm{GC}>20 \%$ & alto grau de confinamento \\
\hline
\end{tabular}

\subsection{DUCTILIDADE}

Uma das principais vantagens atribuídas aos pilares mistos preenchidos é a sua ductilidade, a qual é característica fundamental para elementos sujeitos a ações sísmicas.

A ductilidade é uma medida da capacidade de absorver energia de um elemento por isso, é usada para caracterizar a habilidade deste elemento continuar resistindo a grandes deslocamentos/deformações quando submetido a forças.

Sua quantificação é importante pois, no desenvolvimento de alguns projetos, ela é característica essencial para a estrutura. Esta capacidade de sofrer deformações plásticas é indispensável, segundo o CEB-Bulletin 242 (1998):

- para fornecer indícios de que a estrutura está sofrendo grandes deformações, antes que a ruína ocorra;

- para resistir a impactos locais e carregamentos acidentais sem que ocorra o colapso da estrutura;

- permitir a redistribuição interna de esforços em estruturas sujeitas à ação do fogo; 
- para que os elementos estruturais possam absorver energia quando sujeitos a carregamentos cíclicos.

Embora seja uma característica importante e sempre destacada quando se abordam os pilares mistos preenchidos, não há normas específicas para avaliação desta propriedade. Recomendações são encontradas em normas como o ACl 544.2R - 89 (1989), ASTM C 1018 (1992) e JSCE - SF5 (1984) mas referem-se a elementos em concreto armado com fibras. Destas normas, as duas primeiras aplicam-se a elementos fletidos e a última, a elementos comprimidos axialmente.

O estudo das normas citadas indica que é possível aplicar a norma japonesa para avaliação da ductilidade de pilares mistos preenchidos. Esta recomenda a realização de ensaios com controle de deslocamento, em corpos-deprova cilíndricos, de concreto armado com fibras. Destes ensaios devem ser obtidas medidas de força aplicada e deslocamento médio na região central de comprimento igual a $\ell / 2$. Tais deslocamentos são medidos por transdutores de deslocamento, conforme a FIGURA 5.11.

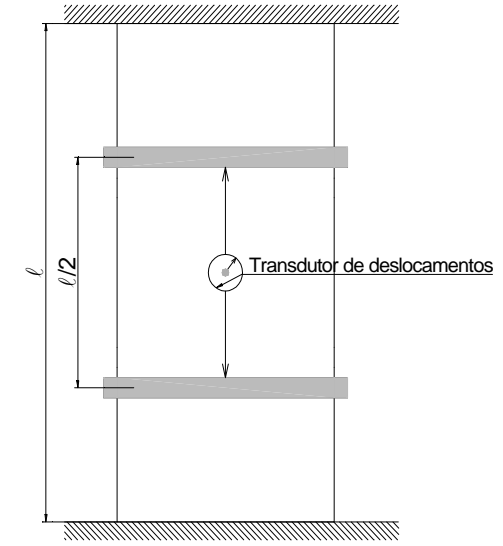

FIGURA 5.11 - ESQUEMA GERAL DE MEDIÇÃO DOS DESLOCAMENTOS, RECOMENDADO PELA JSCE - SF5 (1984)

A ductilidade à compressão é avaliada através do índice de ductilidade $\left(\bar{\sigma}_{c}\right)$, calculado pela equação 5.16 :

$$
\bar{\sigma}_{\mathrm{c}}=\frac{\tau_{\mathrm{c}}}{\mathrm{A} \cdot \delta_{\mathrm{tc}}}
$$

sendo:

$\tau_{c}$ : trabalho exercido pela força à compressão, dado pela área do gráfico $F \times \delta$, mostrada na FIGURA 5.12

$\delta_{\mathrm{tc}}$ : deslocamento correspondente a $0,75 \%$ de $\ell / 2$

A: área da seção mista 
O valor de $\tau_{c}$, dado pela área do diagrama Força $x$ Deslocamento, é calculado até $\delta_{\mathrm{tc}}=0,0075$. $\ell / 2$. A área correspondente a $\tau_{\mathrm{c}}$ é indicada na FIGURA 5.12 .

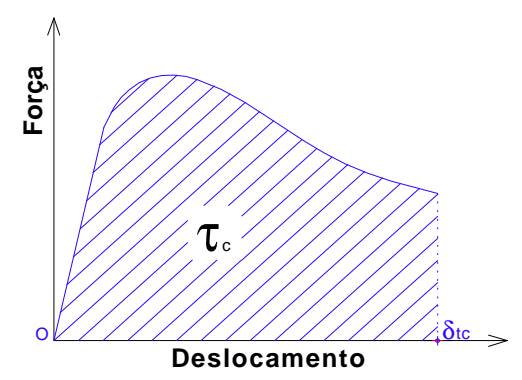

FIGURA 5.12 - DUCTILIDADE À COMPRESSÃO SEGUNDO A NORMA JSCE - SF5 (1984)

Outra forma de avaliar a ductilidade pode ser conseguida partindo das sugestões de UY (1998a), que propõe a avaliação da ductilidade de pilares mistos curtos, do tipo preenchido, submetidos à flexo-compressão. Neste caso, o índice de ductilidade é calculado por:

$$
\delta=\frac{\rho_{\mathrm{u}}}{\rho_{\mathrm{y}}}
$$

sendo:

$\rho_{\mathrm{u}}$ : curvatura última correspondente ao momento resistente $\rho_{y}$ : curvatura de "escoamento".

Fazendo uma analogia para a situação de compressão axial tem-se:

$\mathrm{d}_{\mathrm{u}}$ : deslocamento axial correspondente à força máxima aplicada

$d_{y}$ : deslocamento de "escoamento", considerado conforme ilustra a FIGURA 5.13, como início de comportamento não-linear no diagrama Força x Deslocamento

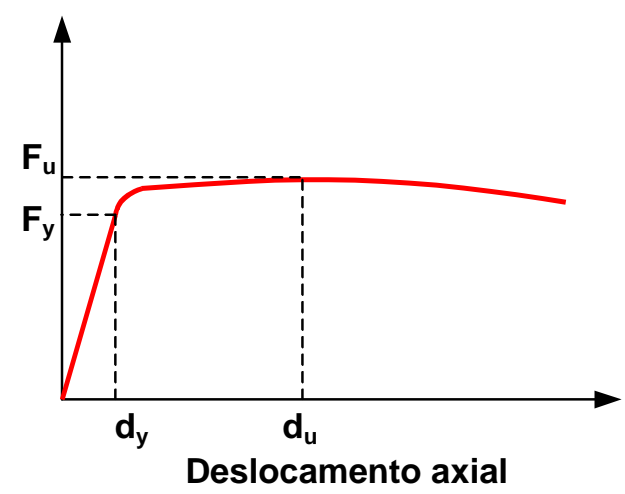

FIGURA 5.13 - DIAGRAMA PARA CÁLCULO DO ÍNDICE DE DUCTILIDADE ADAPTADO DE UY (1998A) 
E o índice de ductilidade é calculado através da equação 5.17 :

$$
\sigma_{\mathrm{c}}=\frac{\mathrm{d}_{\mathrm{u}}}{\mathrm{d}_{\mathrm{y}}}
$$

Em seus estudos, UY (1998a) constatou que para a situação de flexão pura, o índice de ductilidade diminui à medida que a resistência do concreto aumenta. Assim, para concreto com $32 \mathrm{MPa}$ de resistência à compressão encontrou-se $\delta=7,5$ e para concretos com $80 \mathrm{MPa}$ este índice vale 4,5 . Quanto à resistência do aço, ele constatou que a utilização de aços de alta resistência $\left(f_{y}=690 \mathrm{MPa}\right)$ conduziu a $\delta=7,5$ enquanto que para aços de resistência usual $\left(f_{y}=300 M P a\right)$ encontrou-se $\delta=2,9$.

Outro fator que interfere no valor do índice de ductilidade é a intensidade da força axial aplicada. Para flexão pura $\delta=7,5$ e para flexo-compressão com $\mathrm{N}=0,75 \mathrm{~N}_{\mathrm{u}}$, sendo $\mathrm{N}_{\mathrm{u}}$ a capacidade resistente a compressão axial, este índice vale 2,2 .

Os resultados obtidos a partir dos modelos para avaliação da ductilidade aqui propostos são apresentados e discutidos no capítulo 8.

\subsection{A SEÇÃO MISTA EM SITUAÇÃO DE INCÊNDIO}

A questão da resistência da seção mista preenchida à ação do fogo foi motivo de algumas investigações a fim de confirmar que, embora o material concreto não esteja envolvendo o perfil de aço, ainda assim oferece melhorias frente à ação do fogo.

Neste sentido, BAILEY \& NEWMAN (1998) afirmam que os pilares mistos preenchidos podem resistir a até 3 horas de fogo, conforme ensaio padronizado ISO 834. Uma vez aquecido o pilar misto preenchido, parte da força suportada pelo perfil é redistribuída para o núcleo de concreto, que perde resistência e rigidez mais lentamente que o perfil tubular. Portanto, para a seção mista preenchida dimensionada para resistir à ação do fogo são usados perfis com pequena espessura e como material de preenchimento, concreto de alta resistência e se necessário, em função do tempo de resistência ao fogo que se deseje, barras longitudinais de armadura. Desta forma, a maior parcela de resistência da seção 
mista caberá ao concreto, que apresenta maior rigidez e por isso resiste mais tempo à ação do fogo.

Buscando fornecer dados experimentais da resistência dos pilares mistos preenchidos à ação do fogo, LIE \& CHABOT (1998) investigaram experimentalmente a capacidade resistente destes elementos mistos quando submetidos à ação do fogo. Para eles, dentre os diversos fatores que influenciam a resistência ao fogo estão: intensidade da força aplicada, área da seção transversal, comprimento do pilar, tipo de material de preenchimento e a presença ou não de armaduras longitudinais no concreto. No estudo em questão foi avaliada a influência do material de preenchimento. Neste sentido foram investigadas seções com área total de $500 \mathrm{~cm}^{2}$, preenchidas com os seguintes materiais: concreto simples, concreto armado com fibras e concreto com armadura convencional (barras). Os pilares mistos preenchidos foram ensaiados dentro de um forno (FIGURA 5.14), o qual simulava as elevações de temperatura produzidas pela ação do fogo.

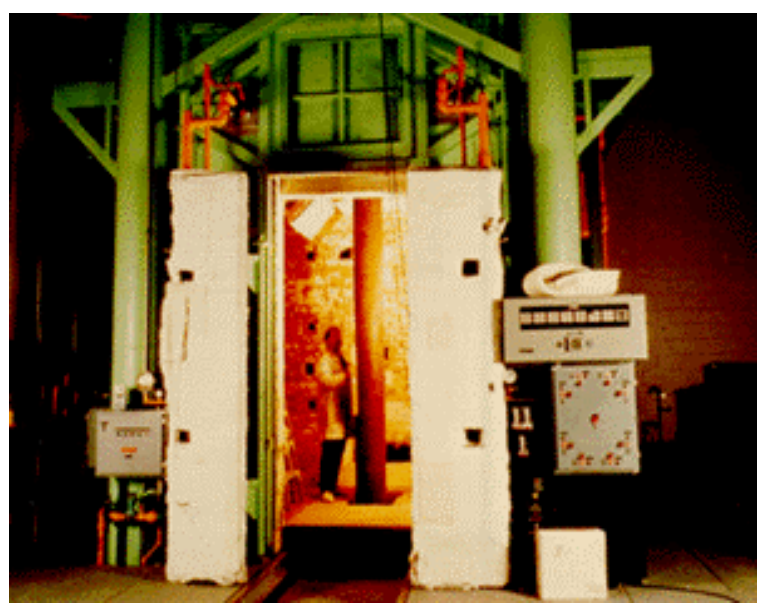

FIGURA 5.14 - FORNO QUE SIMULA A ELEVAÇÃO DE TEMPERATURA PRODUZIDA PELA AÇÃO DO FOGO E ONDE FORAM ENSAIADOS OS PILARES MISTOS PREENCHIDOS ${ }^{4}$

Os resultados mostraram que inicialmente o perfil tubular encontra-se mais solicitado, por isso sofre rápida expansão lateral e atinge 0 escoamento gradualmente porque sua resistência diminui com o aumento da temperatura. $A$ partir deste instante, o concreto passa a absorver grande parte da força aplicada. Sua resistência vai diminuindo até atingir a ruína. A FIGURA 5.15 ilustra o comportamento típico deste fenômeno. 


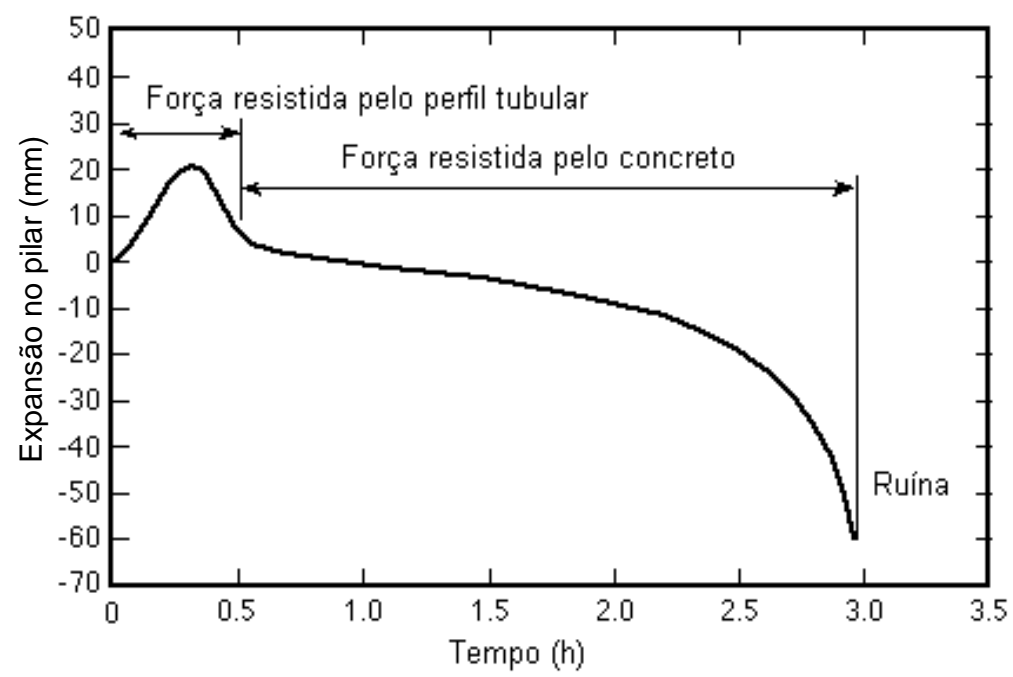

FIGURA 5.15 - EXPANSÃO DO PILAR MISTO PREENCHIDO DURANTE EXPOSIÇÃO AO FOGO ${ }^{5}$

Quanto à eficiência do material de preenchimento, LIE \& CHABOT (1998) encontraram os resultados mostrados na TABELA 5.5.

TABELA 5.5 - Resistência ao fogo de pilares mistos preenchidos ${ }^{6}$

\begin{tabular}{|c|c|}
\hline Tipo de preenchimento & Resistência ao fogo (em horas) \\
\hline sem preenchimento & $0,2-0,3$ \\
\hline concreto simples & $1,0-2,0$ \\
\hline Concreto armado com fibras (taxa de $2 \%$ ) & $2,0-3,0$ \\
\hline concreto com armadura convencional & $>3,0$ \\
\hline
\end{tabular}

LIE (1998) investigou a influência da resistência do concreto de preenchimento no comportamento dos pilares mistos preenchidos, submetidos à ação do fogo. Foram consideradas duas resistências: concreto de resistência usual (35 MPa) e concreto de alta resistência (70 MPa).

Os pilares investigados possuem seção quadrada de lado igual a $300 \mathrm{~mm}$ e a elevação de temperatura proveniente da ação do fogo foi conseguida com a utilização de um forno, onde os elementos foram ensaiados.

A FIGURA 5.16 ilustra a resistência ao fogo de pilares mistos, preenchidos com concreto de resistência usual e de alta resistência, submetidos a 2 horas de exposição.

\footnotetext{
${ }^{4}$ fonte: http://www.nrc.ca/irc/practice/fir3_E.html

5 fonte: http://www.nrc.ca/irc/practice/fir3_E.html

${ }^{6}$ fonte: http://www.nrc.ca/irc/practice/fir3_E.html
} 


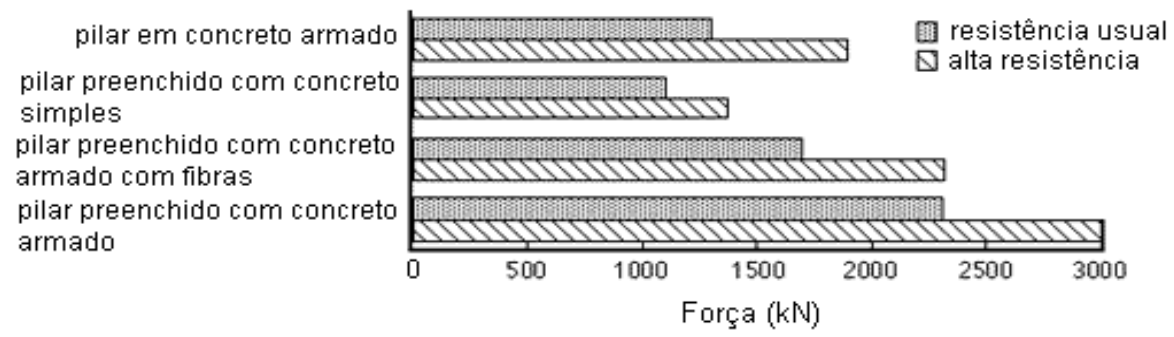

FIGURA 5.16 - CAPACIDADE RESISTENTE PARA PILARES MISTOS, PREENCHIDOS COM CONCRETO DE RESISTÊNCIA USUAL E DE ALTA RESISTÊNCIA, SUBMETIDOS A 2 HORAS DE EXPOSIÇÃO ${ }^{7}$

A análise dos diversos resultados apresentados indica que de fato, o núcleo de concreto funciona como uma espécie de "dissipador de calor", e embora não esteja revestindo o perfil tubular, pode ser usado como proteção contra a ação do fogo.

7 fonte: http://www.nrc.ca/irc/practice/fir4_E.html 


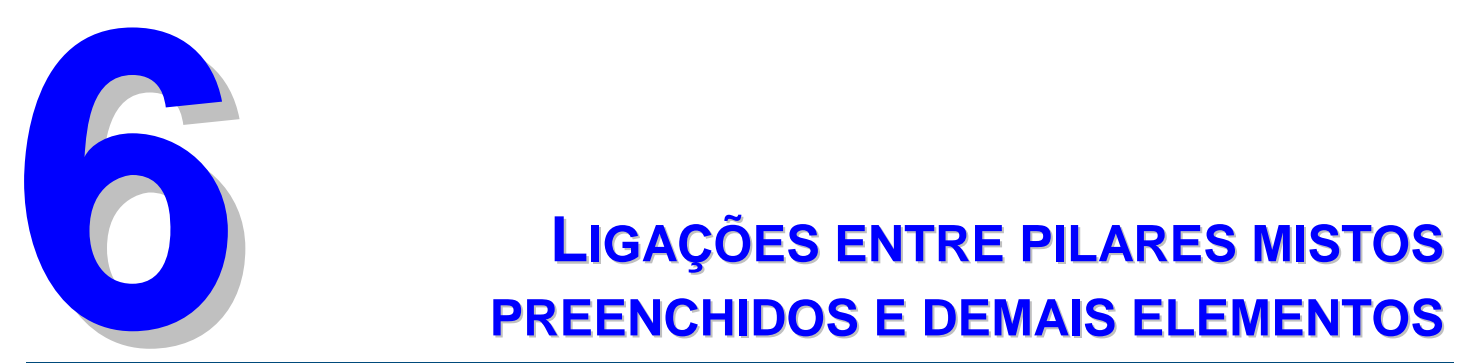

\subsection{INTRODUÇÃO}

A ligação entre os pilares preenchidos e outros elementos estruturais constitui um dos obstáculos para a utilização deste tipo de pilar misto. Alguns detalhes de ligações têm sido investigados de forma analítica e experimental a fim de minimizar os problemas relativos à falta de normas de projeto, à falta de experiência e de recomendações executivas, bem como à complexidade deste tipo de ligação.

As pesquisas realizadas até o momento abordam sobretudo, formas de ligar pilares preenchidos a vigas metálicas, principalmente de seção I. Estes detalhes não diferem muito dos utilizados para ligar pilares e vigas metálicas, entretanto é preciso estudar e propor formas de realizar a ligação entre tais pilares mistos e vigas em concreto armado, ou ainda, entre eles e as lajes ou elementos de fundação.

No momento, verifica-se a ausência de normas que apresentem recomendações quanto aos detalhes de ligações entre os pilares mistos e os demais elementos estruturais, sejam eles lajes, vigas ou elementos de fundação. 


\subsection{LIGAÇÕES ENTRE PILARES MISTOS PREENCHIDOS E VIGAS METÁLICAS}

As ligações entre pilares preenchidos e vigas metálicas podem ser:

1 - ligações em que a viga é simplesmente fixada à face externa do perfil tubular por solda (FIGURA 6.1);

2 - ligações em que a viga ou algum dispositivo de ligação é ancorado no concreto de preenchimento (FIGURAS 6.2).

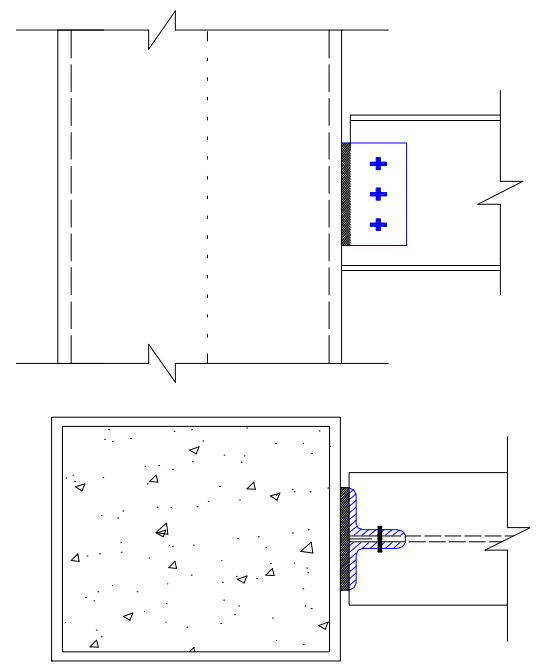

a) soldagem direta da viga no perfil
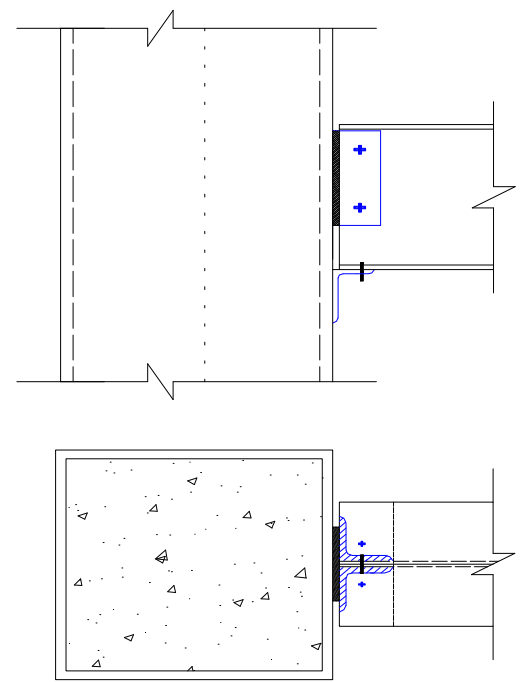

b) soldagem através de chapas metálicas

FIGURA 6.1 - ALGUNS TIPOS DE LIGAÇÕES VIGA METÁLICA - PILAR PREENCHIDO, ATRAVÉS DE SOLDAGEM

AZIZINAMINI \& PRAKASH (1993) ressaltam alguns inconvenientes dos detalhes de ligações em que a viga é diretamente soldada ao pilar:

- o processo de soldagem introduz tensões residuais significativas nas paredes do perfil tubular;

- para seções tubulares circulares, a concentração de tensões no perfil tubular pode comprometer o confinamento do concreto, considerado na etapa de dimensionamento;

- a transferência das tensões de tração do perfil para o núcleo de concreto pode resultar na separação entre estes materiais.

Buscando minimizar os inconvenientes da transferência direta de esforços da viga para o perfil tubular, AZIZINAMINI \& PRAKASH (1993) e PRION \& 
McLELLAN (1994) estudaram alguns detalhes de ligação, que serão apresentados a seguir.

AZIZINAMINI \& PRAKASH (1993) investigaram os dois detalhes mostrados na FIGURA 6.2.
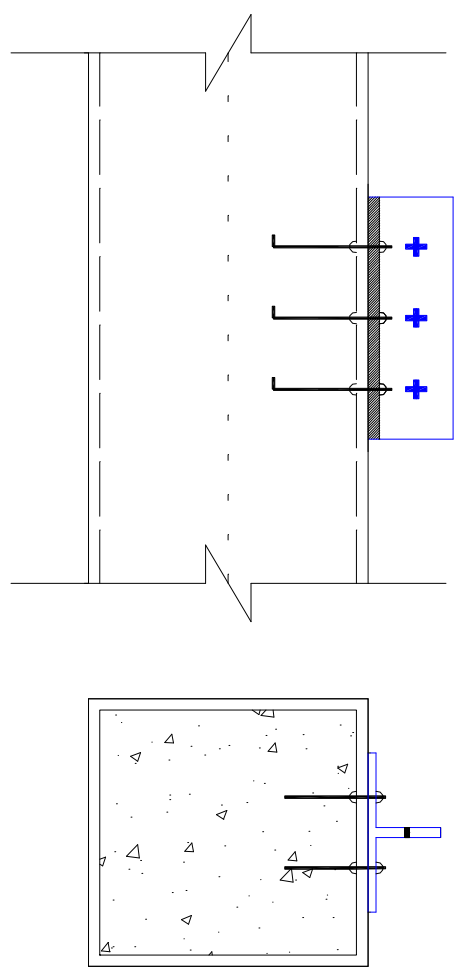

a) parafusos ancorados no concreto
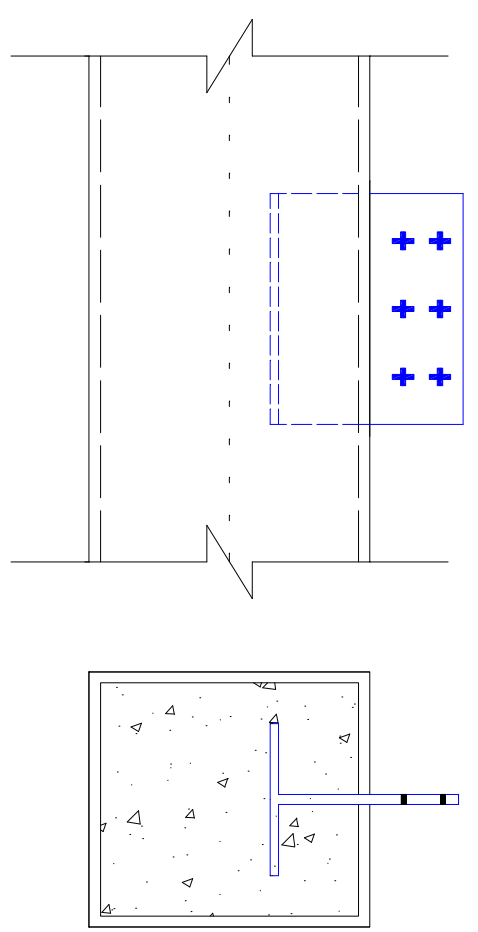

b) viga ancorada no concreto

FIGURA 6.2 - DETALHES DE LIGAÇÕES COM DISPOSITIVOS ANCORADOS NO NÚCLEO DE CONCRETO, ESTUDADOS POR AZIZINAMINI \& PRAKASH (1993)

No detalhe (a) as forças são transferidas para o núcleo de concreto por meio de parafusos nele ancorados. A capacidade resistente desta ligação é limitada pela resistência ao arrancamento dos parafusos e pela concentração de tensões no perfil tubular. A mesma filosofia de ancoragem é utilizada no detalhe (b). Neste, a viga é introduzida no perfil através de aberturas em forma de I, e ancorada no núcleo de concreto. A ruína ocorre por arrancamento da viga. Uma variação deste detalhe de ligação consiste em fazer a viga atravessar completamente o pilar. Neste caso, o perfil tubular pode ser fabricado com o trecho que passa por ele, posicionado e soldado, formando uma única peça em forma de cruz. 
PRION \& McLELLAN (1994) investigaram o detalhe de ligação apresentado na FIGURA 6.3. O objetivo deste estudo foi desenvolver um detalhe de ligação que fosse eficiente na transmissão de esforços cortantes da viga para o concreto do pilar, sem causar danos ao perfil, ou comprometer a continuidade circunferencial do mesmo na região da ligação. Esta continuidade tem grande importância para seções circulares, onde o efeito do confinamento é considerado no dimensionamento como um fator favorável.

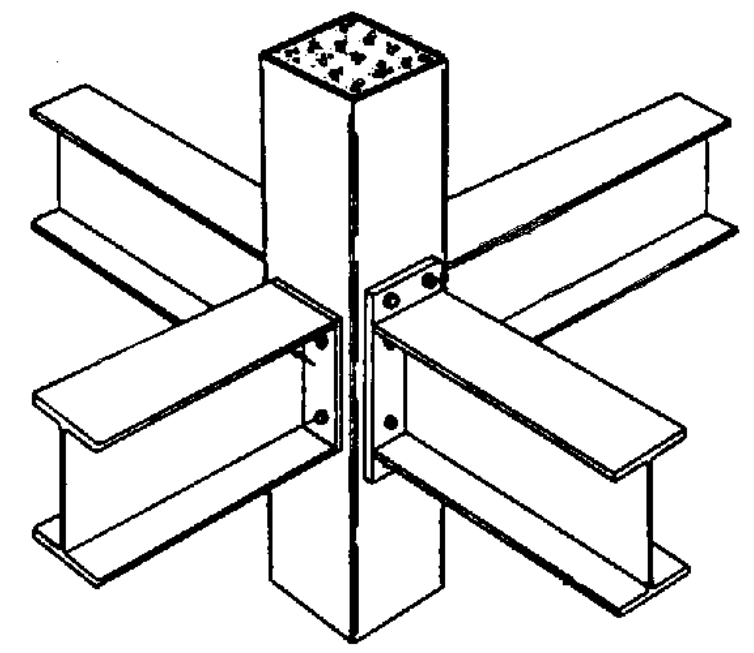

a) perspectiva
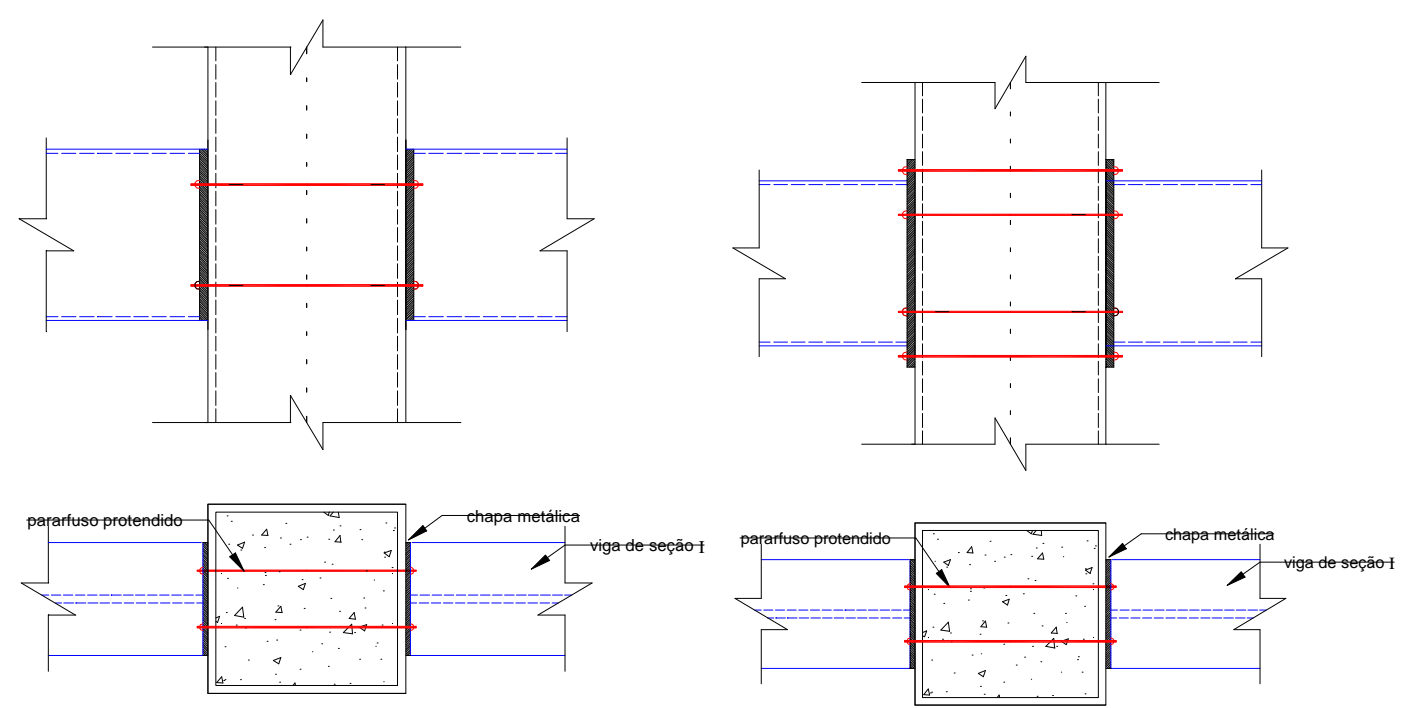

b) vistas laterais

FIGURA 6.3 - LIGAÇÃO VIGA METÁLICA - PILAR PREENCHIDO ATRAVÉS DE LONGOS PARAFUSOS PROTENDIDOS, ESTUDADA POR PRION \& MCLELLAN (1994) 
A ligação proposta e investigada experimentalmente consiste em unir a viga metálica de seção I ao pilar misto preenchido por meio de longos parafusos, os quais são protendidos quando o concreto atinge resistência adequada.

O dispositivo de ligação investigado por PRION \& McLELLAN (1994) possui as seguintes características:

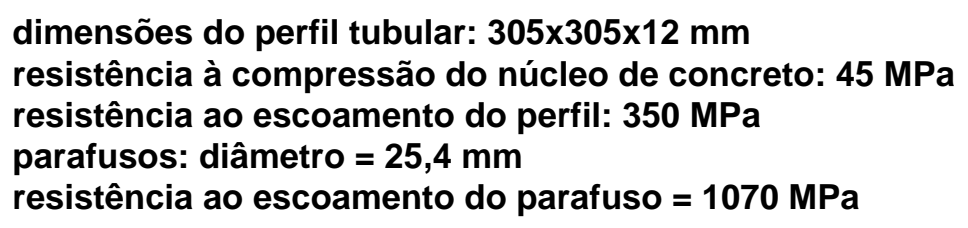

Embora seja um dispositivo de ligação aparentemente eficiente, apresenta desvantagens como: necessidade de fabricação especial dos longos parafusos, a falta de experiência faz com que alguns problemas durante a execução não sejam identificados, e a ausência de normas para o projeto de tal dispositivo de ligação.

A investigação experimental permitiu identificar alguns problemas neste dispositivo de ligação:

1 - a transferência de forças de um lado para o outro do pilar é feita por longos parafusos. Para compensar as perdas de protensão devidas aos fenômenos de fluência e retração do núcleo de concreto, são necessárias forças de protensão de grande intensidade, que geram altas tensões no concreto e as quais podem, inclusive, exceder a resistência à compressão deste material. Como solução sugere-se a utilização de concretos de alta resistência;

2 - para uma seção mista ser efetiva, é preciso que as forças de cisalhamento provenientes das vigas sejam transferidas para o núcleo de concreto do pilar. Neste tipo de dispositivo de ligação tal transferência ocorre por meio dos longos parafusos envoltos pela massa de concreto e pela fricção entre o perfil, o núcleo de concreto e a viga metálica - produzida pela protensão dos longos parafusos. Estes mecanismos de transferência de forças apresentam problemas, sobretudo a transferência de forças por fricção e novos estudos são recomendados pelos pesquisadores.

Quanto à forma de ruína, esta pode ocorrer por cisalhamento do parafuso ou esmagamento e fissuração do concreto.

O estudo mostrou que a protensão dos parafusos aumenta a rigidez à rotação da ligação, melhorando substancialmente o comportamento da região de ligação, quando comparado com as ligações soldadas. 
Ainda abordando a questão das ligações viga $x$ pilar, SCHNEIDER \& ALOSTAZ (1998) investigaram experimentalmente o comportamento de cinco detalhes de ligações viga metálica $x$ pilar preenchido, as quais incluem elementos diretamente fixados no perfil tubular e outros ancorados no concreto. As ligações estudadas são apresentadas na FIGURA 6.4.
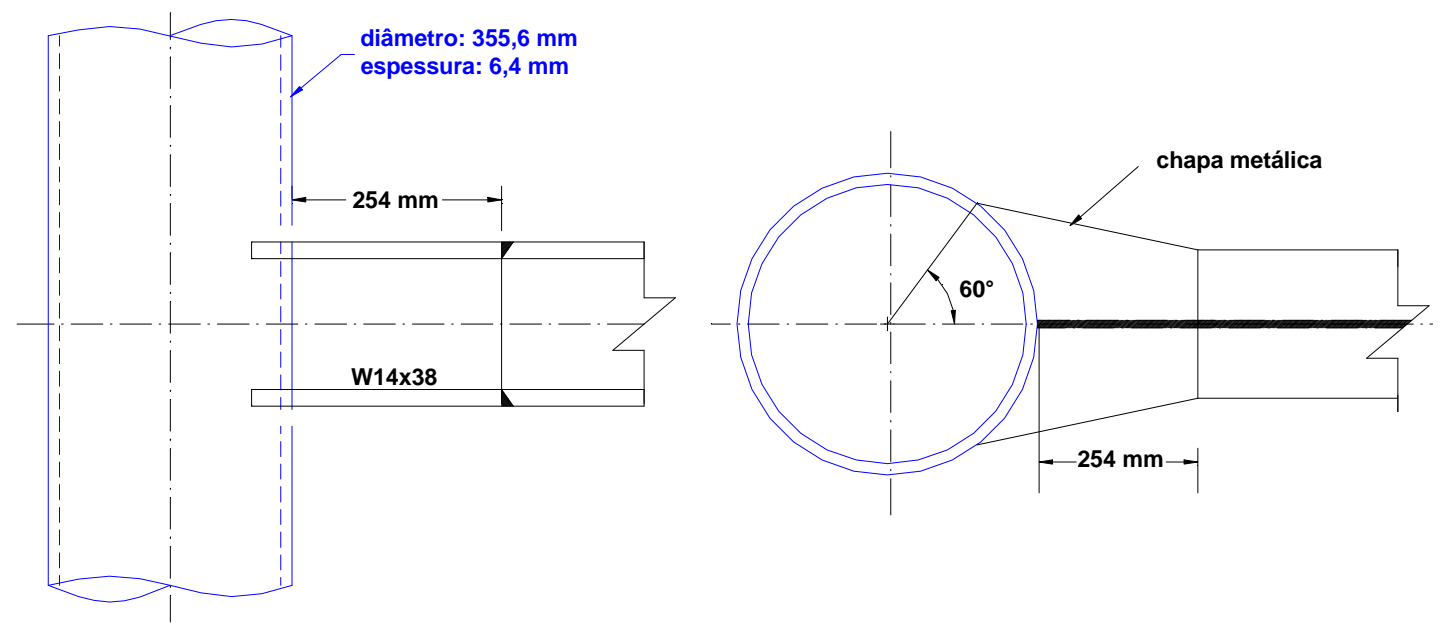

DETALHE 01: VIGA SOLDADA DIRETAMENTE À FACE EXTERNA Do PERFIL TUBULAR
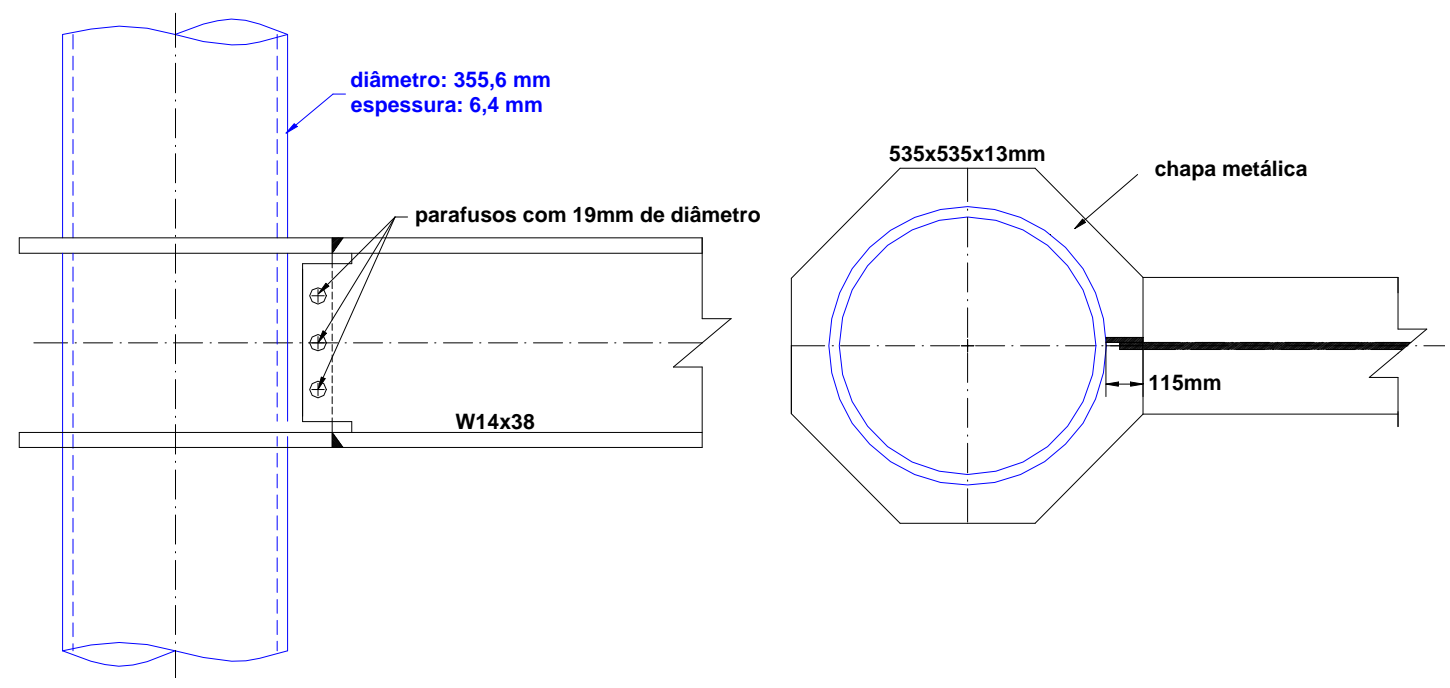

DETALHE 02: DIAFRAGMA EXTERNO SOLDADO À PAREDE DO PERFIL TUBULAR 


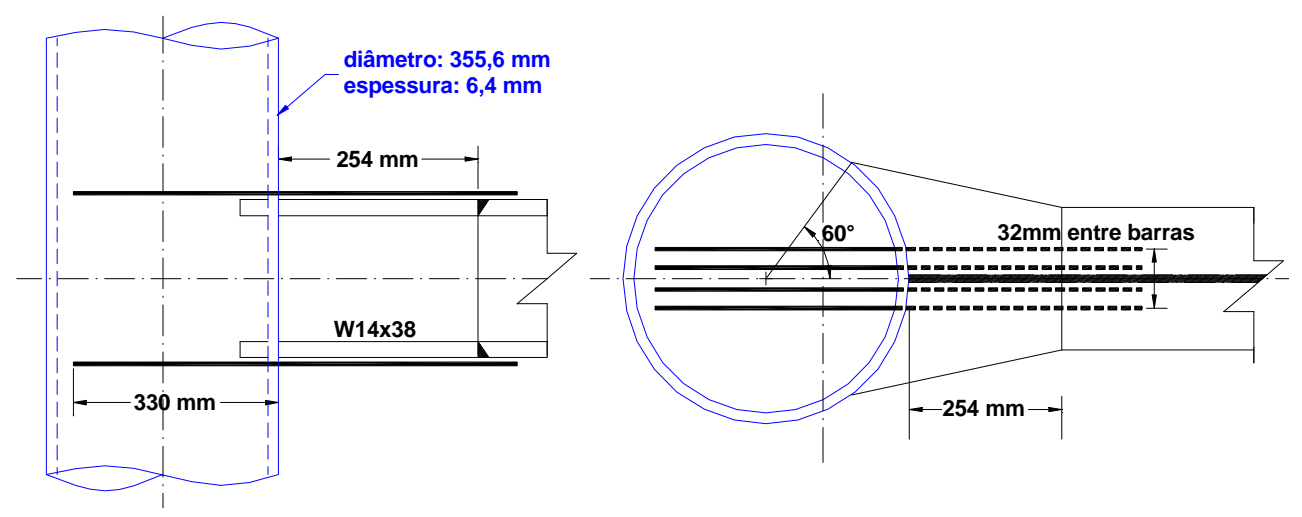

DETALHE 03: 4 BARRAS DE ARMADURA SOLDADAS ÀS FACES DA VIGA E ANCORADAS NO CONCRETO DE PREENCHIMENTO
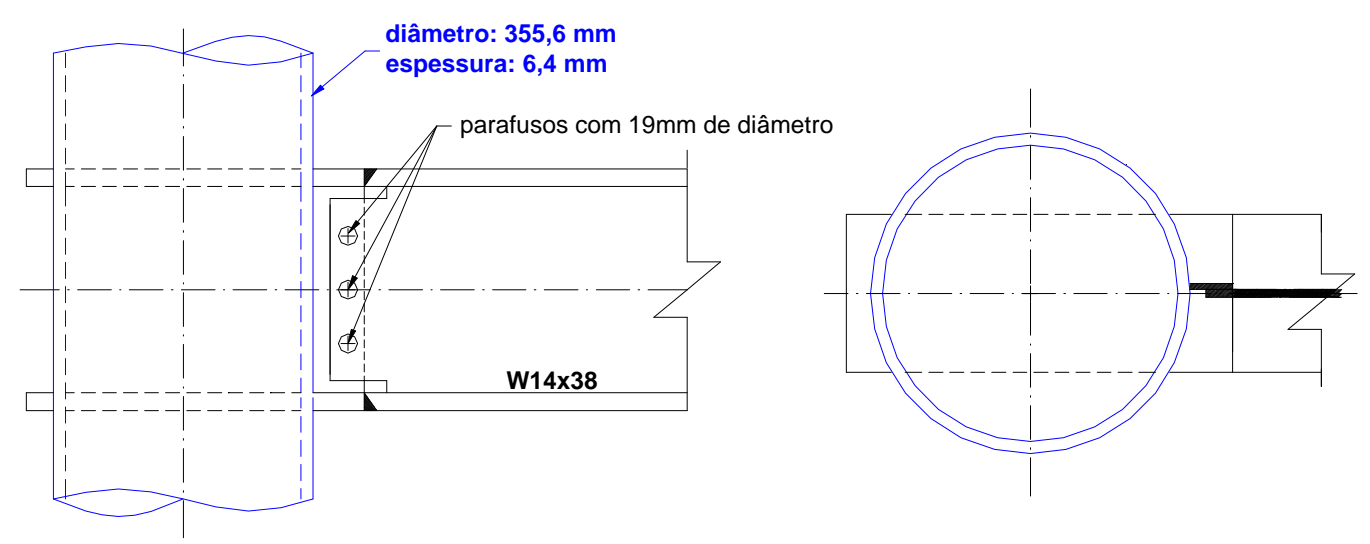

DETALHE 04: MESAS DA VIGA I PROLONGADAS PARA O INTERIOR DO NÚCLEO DE CONCRETO E NELE ANCORADAS

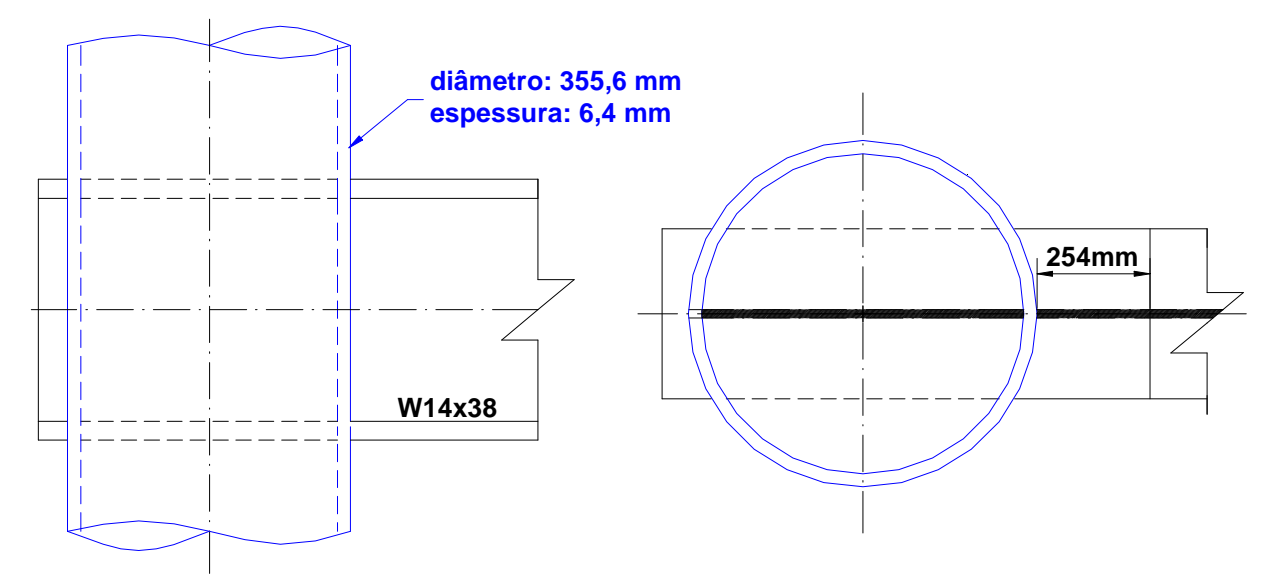

DETALHE 05: SEÇÃo INTEGRAL DA VIGA PROLONGADA PARA O INTERIOR DO NÚCLEO DE CONCRETO

FIGURA 6.4 - DETALHES DE LIGAÇõES VIGA I METÁLICA X PILAR MISTO PREENCHIDO, PROPOSTAS POR SCHNEIDER \& ALOSTAZ (1998) 
O dispositivo de ligação investigado por SCHNEIDER \& ALOSTAZ (1998) possui as seguintes características:

\section{resistência à compressão do núcleo de concreto: $\sim 55 \mathrm{MPa}$} resistência ao escoamento do perfil: $397 \mathrm{MPa}$

Os detalhes de ligações estudados por SCHNEIDER \& ALOSTAZ (1998), embora limitados a poucos elementos ensaiados, permitiram algumas conclusões parciais importantes:

- a soldagem direta da viga ao perfil tubular (DETALHE 01) não é um detalhe de ligação recomendável, sobretudo para regiões sujeitas a intensa atividade sísmica. Embora seja de simples execução, as grandes deformações que ocorrem na região de ligação dificultam a redistribuição de esforços e a ruína pode ocorrer por ruptura da solda, da mesa ou das paredes do perfil tubular;

- a utilização de diafragmas externos (DETALHE 02) melhora o comportamento da ligação simplesmente soldada pois permite uma melhor distribuição das forças de tração entre a viga e o perfil tubular, podendo ser empregada em regiões de pequena atividade sísmica. $O$ diafragma externo deve ter dimensões mínimas que evitem grandes distorções nas paredes do perfil;

- utilizar barras de armadura (DETALHE 03) soldadas ao topo da viga e ao perfil tubular, ancorando-as ao núcleo de concreto melhora significativamente a transferência de esforços da viga para o núcleo de concreto, garantindo capacidade de plastificação à região de ligação. Este detalhe é sugerido para regiões com moderada atividade sísmica devido à capacidade de rotação plástica da mesma;

- o DETALHE 04, onde as mesas da viga I são prolongadas além da face do perfil tubular e ancoradas no núcleo de concreto, conduz a grandes deformações no perfil tubular pois ocorre o escorregamento entre as mesas da viga e o concreto do núcleo;

- a continuidade da viga até o interior do concreto (DETALHE 05) é um detalhe de ligação indicado para regiões sujeitas a alta atividade sísmica, embora seja de difícil execução. 
$\mathrm{Na}$ FIGURA 6.5 são apresentados os resultados obtidos por SCHNEIDER \& ALOSTAZ (1998), através dos quais é possível comparar o comportamento de cada detalhe de ligação quanto à sua rigidez, verificando-se que o detalhe 03 apresenta melhor rigidez à flexão. Tal detalhe apresenta ainda grande capacidade de deformar-se plasticamente sem atingir a ruína e sem perdas significativas de capacidade resistente. O detalhe 05 apresenta comportamento semelhante ao 03 , no entanto é preciso fazer aberturas no perfil para que seja possível introduzir a viga metálica, tornando sua execução trabalhosa.

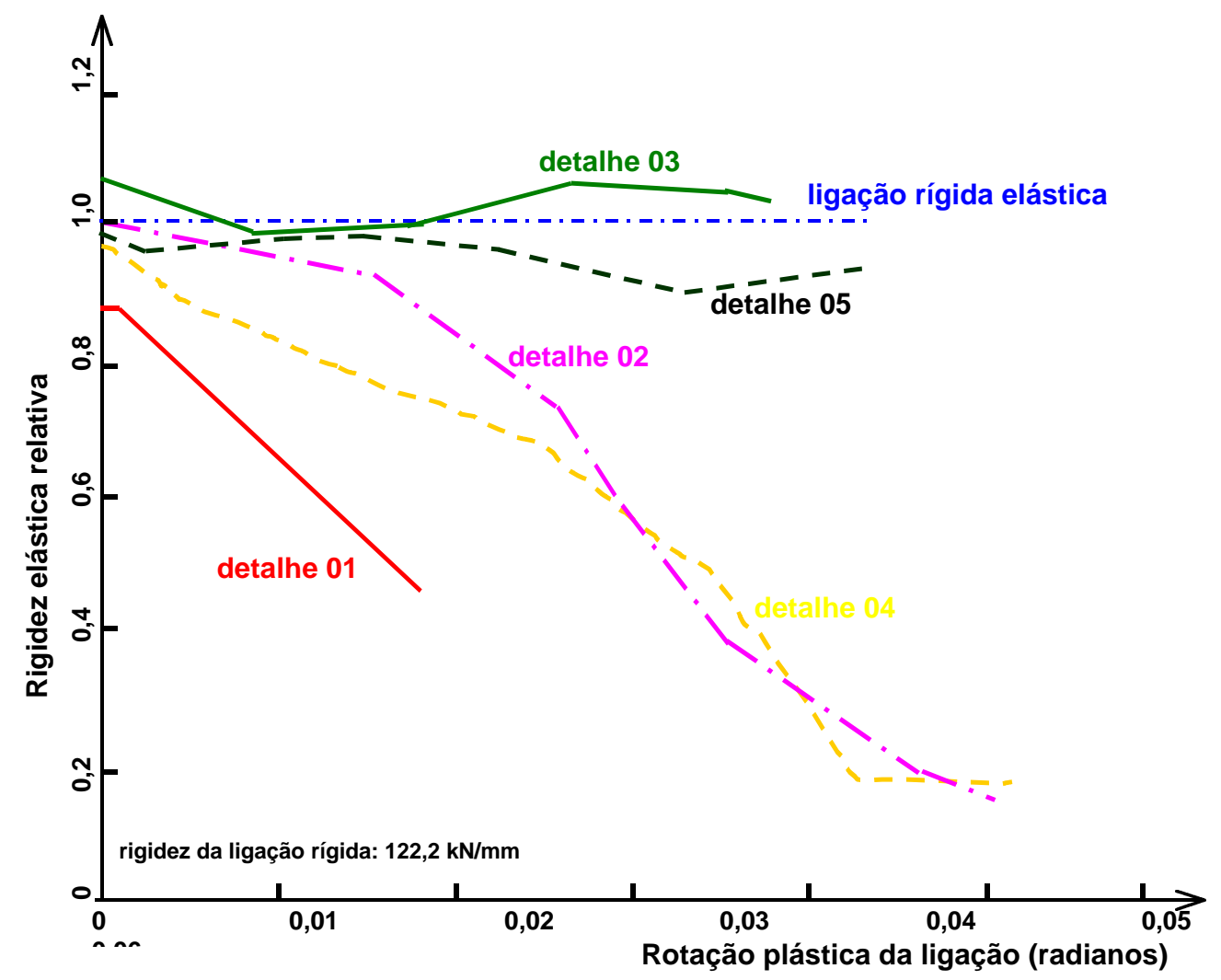

FIGURA 6.5 - VARIAÇÃO DA RIGIDEZ DOS DETALHES DE LIGAÇÃO ESTUDADOS POR SCHNEIDER \& ALOSTAZ (1998)

Algumas pesquisas procuram desenvolver detalhes de ligação simples, eficientes e de baixo custo. Os esforços são válidos, entretanto ainda são necessárias várias investigações experimentais e teóricas para que se chegue a um detalhe de ligação otimizado, que reuna bom comportamento estrutural, facilidade de execução e baixo custo. Outro aspecto importante, é que se faz 
necessário desenvolver estudos quanto à forma de ligar os pilares preenchidos a vigas de concreto armado, o que até então não foi estudado.

Convém lembrar que a ligação entre elementos como lajes e pilares mistos e destes com os elementos de fundação também precisam ser estudadas e compreendidas, a fim de que seja possível utilizar o sistema estrutural formado por elementos mistos de forma a obter o maior número de vantagens possível. 


\section{ESTUDO TEÓRICO-EXPERIMENTAL DE PILARES MISTOS PREENCHIDOS}

\subsection{CONSIDERAÇÕES INICIAIS}

Neste estudo teórico-experimental foi investigado o comportamento de pilares mistos preenchidos submetidos à compressão axial.

Os pilares mistos aço-concreto, preenchidos com concreto de alta resistência foram estudados de forma teórica e experimental. O estudo teórico consistiu na análise numérica, via método dos elementos finitos, dos mesmos modelos investigados experimentalmente, por meio de modelos físicos levados à ruína.

A investigação de modelos numéricos e físicos de seções quadradas, circulares e retangulares tem por objetivo a análise dos seguintes fatores:

1 - capacidade resistente da seção mista;

2 - comportamento do pilar misto preenchido quando axialmente comprimido;

3 - parcelas de resistência atribuídas a cada um dos materiais;

4 - acréscimo de capacidade resistente da seção mista, devido ao efeito de confinamento do concreto;

5 - variação das deformações axiais e transversais nos componentes da seção mista; 
6 - comportamento força $x$ deformação para os materiais isolados, ou seja, perfil tubular e concreto simples, e associados na forma de pilares mistos preenchidos;

7 - comportamento dos pilares mistos preenchidos quanto à ductilidade.

A realização deste estudo partiu de um planejamento inicial no qual, através de revisão bibliográfica, foi possível identificar os diversos parâmetros que interferem no comportamento dos pilares mistos preenchidos. Identificados estes parâmetros, alguns deles foram escolhidos a fim de avaliar sua influência no comportamento do pilar misto, através de ensaios em modelos matemáticos (análise numérica) e físicos (investigação experimental). Os parâmetros de investigação escolhidos foram:

- forma da seção transversal; e

- espessura do perfil tubular

Outros parâmetros como atuação de força excêntrica, forças dinâmicas, influência da aderência e fenômenos de retração e fluência, embora importantes, não foram analisados neste estudo.

Definidos os parâmetros a serem investigados, os pilares mistos foram divididos em três séries, as quais são função da forma da seção transversal, conforme ilustra a TABELA 7.1.

TABELA 7.1 - Séries analisadas no estudo teórico-experimental

\begin{tabular}{|c|c|c|c|c|}
\cline { 2 - 3 } \multicolumn{1}{c|}{} & Modelo & dimensões $(\mathbf{m m})$ & Seção & espessura $(\mathbf{m m})$ \\
\hline \multirow{2}{*}{ SÉRIE 01 } & 1 & $150 \times 150$ & \multirow{2}{*}{ quadrada } & 3,0 \\
\cline { 2 - 3 } & 2 & $150 \times 150$ & & 6,3 \\
\hline \multirow{2}{*}{ SÉRIE 02 } & 1 & 127 & \multirow{2}{*}{ circular } & 3,20 \\
\cline { 2 - 3 } & 2 & 127 & & 4,85 \\
\hline \multirow{2}{*}{ SÉRIE 03 } & 1 & $100 \times 200$ & \multirow{2}{*}{ retangular } & 3,0 \\
\cline { 2 - 3 } & 2 & $100 \times 200$ & & 6,3 \\
\hline REFERÊNCIA & $\mathrm{R}$ & $150 \times 150$ & quadrada & concreto simples \\
\hline
\end{tabular}

A princípio, pretendia-se variar a forma da seção transversal sem alterar as áreas de aço e de concreto. Isto foi possível para as séries 1 e 3, entretanto, para a série 2 não foi possível encontrar no mercado as espessuras $(3,0$ e 6,0 $\mathrm{mm})$ e diâmetro (180mm) desejados. 
Todos os modelos mistos estudados foram denominados CFT (concrete filled steel tube), acompanhados por dois números que representam a série e o modelo respectivamente, da seguinte forma:

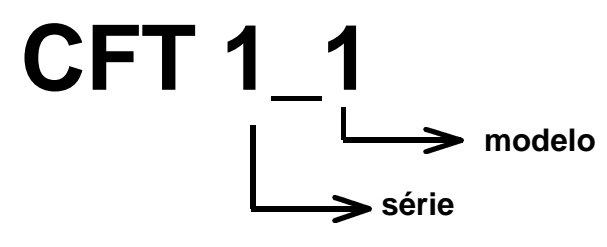

As características gerais de cada elemento são apresentadas na TABELA 7.2 , lembrando que todos eles possuem altura total igual a $\underline{120} \mathbf{c m}$.

TABELA 7.2 - Características gerais dos pilares mistos preenchidos estudados

\begin{tabular}{|c|c|c|c|c|c|}
\hline Elemento & Seção & Tipo de aço & Espessura $(\mathbf{m m})$ & $\mathbf{A}_{\mathbf{c}}\left(\mathbf{c m}^{2}\right)$ & $\mathbf{A}_{\mathbf{s}}\left(\mathbf{c m}^{2}\right)$ \\
\hline R 1_1 & $150 \times 150$ & --- & --- & 225 & --- \\
\hline CFT 1_1 & $150 \times 150$ & SAE 1020 & 3,0 & 207,28 & 17,64 \\
\hline CFT 1_2 & $150 \times 150$ & SAE 1020 & 6,3 & 188,45 & 36,21 \\
\hline CFT 2_1 & 127 & USI-SAC 41 & 3,20 & 114,23 & 12,45 \\
\hline CFT 2_2 & 127 & USI-SAC 41 & 4,85 & 108,06 & 18,61 \\
\hline CFT 3_1 & $100 \times 200$ & SAE 1020 & 3,0 & 182,28 & 17,64 \\
\hline CFT 3_2 & $100 \times 200$ & SAE 1020 & 6,3 & 163,45 & 36,22 \\
\hline
\end{tabular}

Conhecidas as principais características dos elementos a serem estudados, será descrita a seguir a metodologia empregada no desenvolvimento dos estudos teóricos e experimentais.

\subsection{ANÁLISE NUMÉRICA}

A análise numérica foi realizada com o objetivo de representar, através de modelos numéricos, o comportamento dos pilares mistos axialmente comprimidos. Como parâmetros de avaliação e calibração do modelo numérico foram utilizados os resultados obtidos na investigação experimental.

Para realização da análise numérica utilizou-se o programa computacional de análise via método dos elementos finitos denominado Ansys ${ }^{1}$.

\footnotetext{
${ }^{1}$ Ansys release 5.4 - Engineering Analysis System
} 
Embora se pretendesse analisar numericamente todos os modelos investigados experimentalmente, devido a dificuldades de modelagem atribuídas à forma cúbica do elemento finito utilizado, os elementos CFT 2_1 e CFT 2_2 não foram analisados. Isto não representa grandes danos à análise uma vez que seu comportamento já é conhecido.

\subsubsection{ELEMENTO UTILIZADO NA ANÁLISE}

Para modelagem dos pilares mistos preenchidos foi empregado o elemento tridimensional SOLID 45, disponível na biblioteca de elementos do Ansys.

Trata-se de um elemento cúbico com oito nós, cada um com três graus de liberdade: translações nas direções x, y e z, conforme ilustra a FIGURA 7.1.

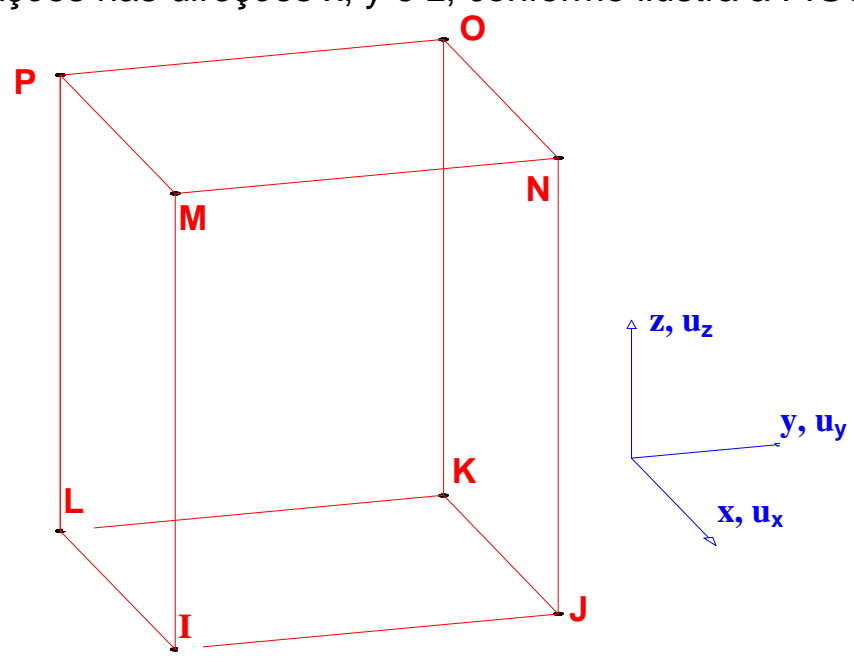

FIGURA 7.1 - ELEMENTO CÚBICO SOLID 45 (BIBLIOTECA DO ANSYS)

Os materiais aço e concreto foram considerados isotrópicos e as seguintes características mecânicas foram atribuídas como dados de entrada:

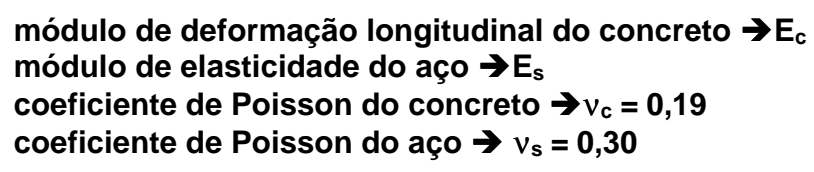

Os valores de $E_{c}$ e $E_{s}$ são apresentados em item posterior.

\subsubsection{MODELAGEM DO PILAR MISTO PREENCHIDO}

O pilar misto preenchido foi dividido da forma apresentada na FIGURA 7.2. 

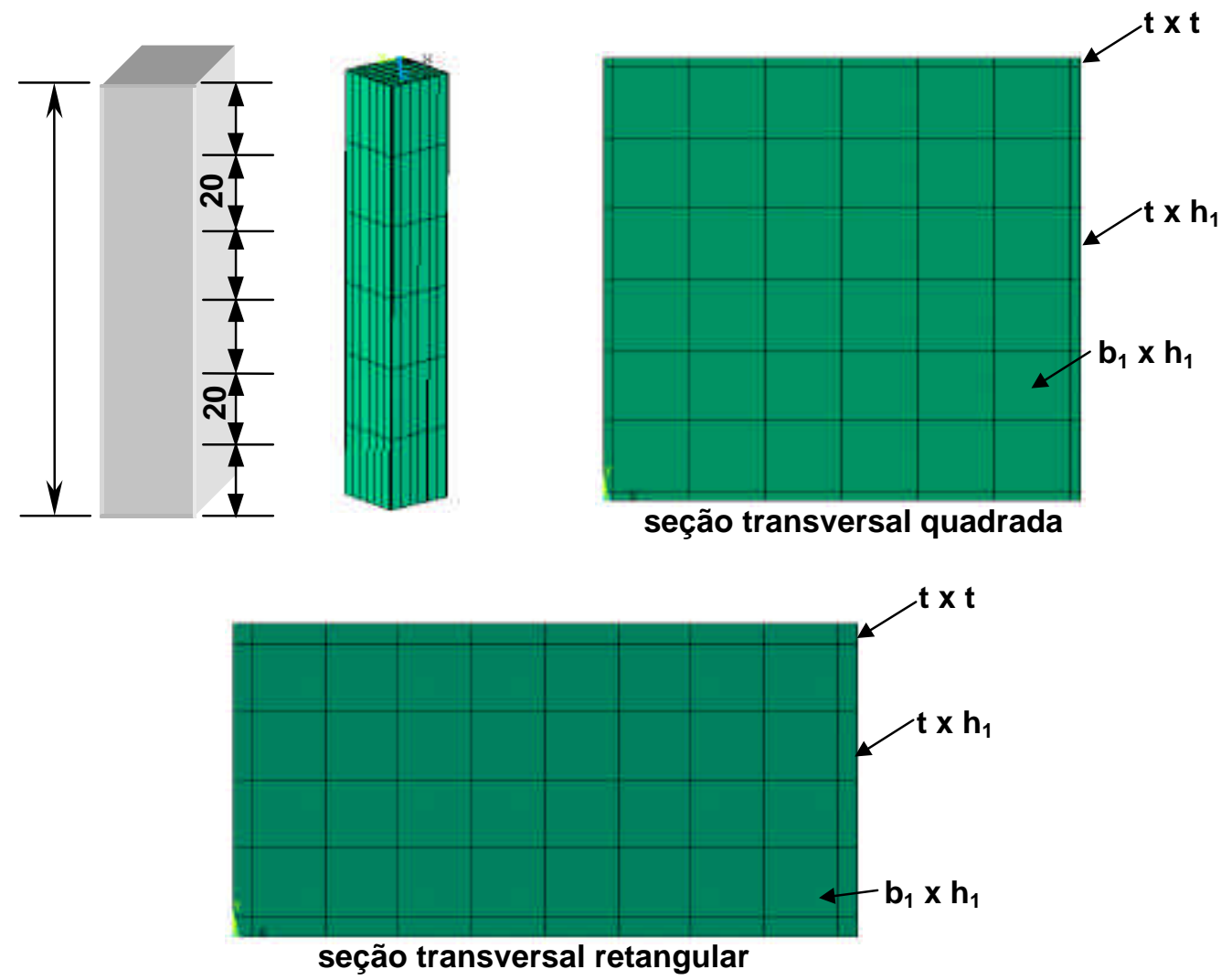

FIGURA 7.2 - MODELAGEM DO PILAR MISTO PREENCHIDO

Na TABELA 7.3 são apresentados os valores de $t, b_{1}$ e $h_{1}$ para cada um dos elementos analisados.

TABELA 7.3 - Dimensões da malha utilizada na modelagem dos pilares mistos preenchidos

\begin{tabular}{|c|c|c|c|}
\hline Modelo & $\mathbf{t}(\mathbf{m m})$ & $\mathbf{b}_{\mathbf{1}}(\mathbf{m m})$ & $\mathbf{h}_{\mathbf{1}}(\mathbf{m m})$ \\
\hline CFT 1_1 & 3,0 & 24,00 & 24,00 \\
\hline CFT 1_2 & 6,3 & 22,90 & 22,90 \\
\hline CFT 3_1 & 3,0 & 24,25 & 23,50 \\
\hline CFT 3_2 & 6,3 & 23,425 & 21,85 \\
\hline
\end{tabular}

\subsubsection{Critérios PARA ANÁLISE}

O critério de resistência adotado foi o de von Mises para os dois materiais. Embora não seja o critério ideal para o material concreto, foi a única opção permitida ao elemento finito SOLID 45. 
Para aproximar a análise numérica das condições reais de ensaio, o qual foi realizado com controle de deslocamento do pistão, foi imposto deslocamento no topo de cada pilar misto, aplicado em 10 etapas e ocorrendo nos dois materiais simultaneamente.

Como condições de vinculação, os pilares mistos foram considerados engastados na base, devido à presença de uma chapa soldada na face inferior do pilar, e articulados no topo (condição oferecida pela rótula da máquina de ensaio). $A$ condição de articulação do topo foi conferida pela rótula da máquina de ensaio. Tais condições de vinculação podem ser vistas na FIGURA 7.3, na qual são apresentadas as condições reais de ensaio do elemento misto.

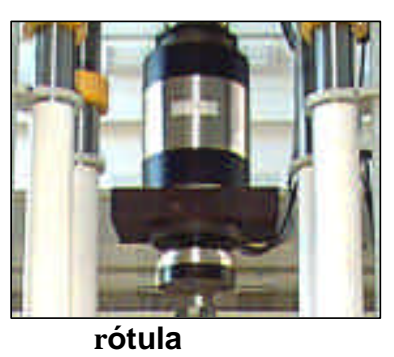

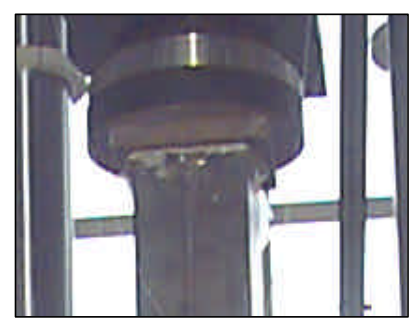

detalhe do topo articulado

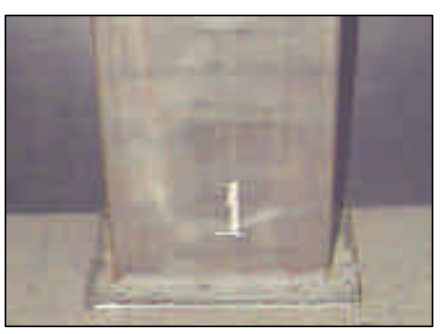

detalhe da chapa na base

FIGURA 7.3 - CONDIÇÕES DE VINCULAÇÃO DOS PILARES MISTOS PREENCHIDOS

\subsubsection{MODELOS CONSTITUTIVOS PARA OS MATERIAIS}

O programa Ansys permite a entrada de dados para a construção do diagrama tensão $\mathrm{x}$ deformação dos materiais. Tal procedimento foi adotado para compor o modelo constitutivo do material concreto.

\section{- CONCRETO}

O modelo constitutivo para o concreto de preenchimento foi elaborado a partir de resultados experimentais de ensaios em corpos-de-prova com dimensões $10 \times 20 \mathrm{~cm}$, submetidos à compressão uniaxial e cujos ensaios foram realizados com controle de deformações. Tal modelo é apresentado na FIGURA 7.4 e é denominado multi-linear isotrópico (MISO) pelo programa Ansys. O módulo de deformação longitudinal $E_{c}$ é calculado para cada segmento de reta do diagrama tensão x deformação. 


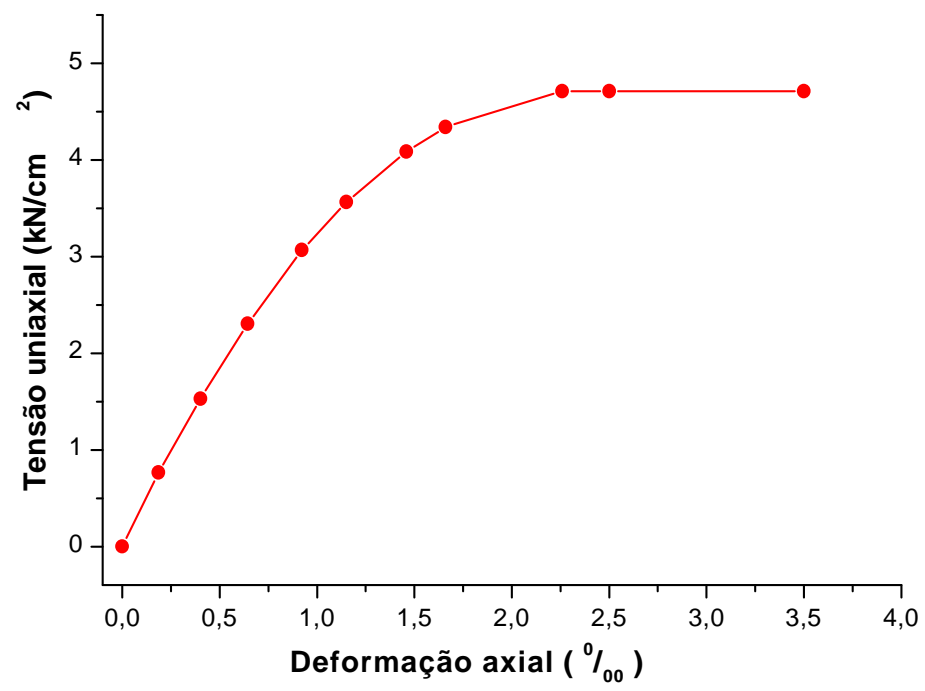

FIGURA 7.4 - MODELO CONSTITUTIVO PARA O MATERIAL CONCRETO

\section{- AÇO}

Para o material aço considerou-se o modelo elasto-plástico perfeito, com o início de plastificação ocorrendo para um nível de tensão equivalente à resistência ao escoamento $f_{y}$ do material, e desprezando-se o efeito das tensões residuais devidas ao processo de formação a frio do perfil tubular. O modelo constitutivo considerado é mostrado na FIGURA 7.5 e denominado bi-linear isotrópico (BISO) pelo programa Ansys.
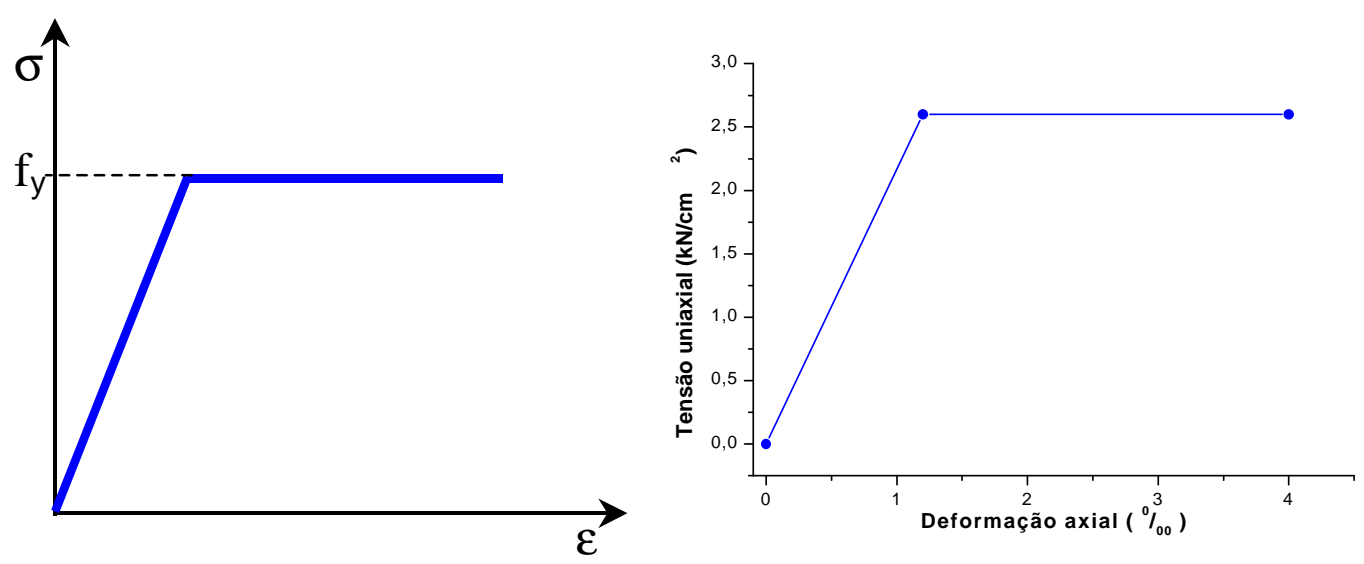

FIGURA 7.5 - MODELO CONSTITUTIVO PARA O MATERIAL AÇO 
Para a análise numérica foram considerados os valores de resistência ao escoamento determinados através de ensaios de tração segundo ASTM A370/92.

Os resultados obtidos na análise numérica serão apresentados no próximo capítulo.

\subsection{INVESTIGAÇÃO EXPERIMENTAL}

$\mathrm{Na}$ realização da investigação experimental, diversos setores da Escola de Engenharia de São Carlos estiveram envolvidos. No Laboratório de Construção Civil do Departamento de Arquitetura e Urbanismo foram realizados os ensaios de caracterização dos materiais areia e brita ํ‥1. No Laboratório de Mecânica das Rochas do Departamento de Geotecnia foram realizados os ensaios de compressão axial com deformação controlada, para determinação do módulo de deformação longitudinal do concreto.

No Laboratório de Ensaios Mecânicos do Departamento de Engenharia de Materiais foram realizados os ensaios de caracterização do aço dos perfis tubulares e no setor Serviço de Oficina de Motores foram executados os trabalhos de soldagem dos perfis.

Os demais ensaios foram realizados no departamento de Engenharia de Estruturas.

\subsubsection{CONSIDERAÇÕES INICIAIS}

Com a investigação experimental pretende-se analisar, através de ensaios em modelos físicos, os fatores apresentados no início deste capítulo. Para tanto, foram ensaiados os elementos apresentados na TABELA 7.1.

Os procedimentos envolvidos na experimentação física foram:

- ensaios preliminares de caracterização dos materiais e determinação de um traço para obtenção de concreto com resistência média à compressão aos 7 dias de $50 \mathrm{MPa}$;

- ensaio de pilares mistos e de referência (em concreto simples);

- ensaio de espécimes de perfis tubulares (full test). 


\subsubsection{MATERIAIS UTILIZADOS NA CONFECÇÃO DO CONCRETO}

$\mathrm{Na}$ confecção do concreto foi utilizado o cimento portland de alta resistência inicial CP V ARI, por possibilitar a obtenção da resistência desejada aos 7 dias, acelerando a realização dos ensaios.

Este material foi recebido como doação, fruto de um convênio estabelecido entre a Escola de Engenharia de São Carlos e a Camargo Côrrea S.A. e é denominado cimento Eldorado. A massa específica real do cimento foi caracterizada pelo fabricante de acordo com a NBR 6474 (1984).

Foi utilizado o aditivo superplastificante $R X 3000 A$ da REAX Indústria e Comércio Ltda, também fruto de doação.

A água empregada no amassamento dos concretos é proveniente da rede pública de abastecimento da cidade de São Carlos.

Quanto aos agregados, foram adquiridos na cidade de São Carlos. Como agregado miúdo utilizou-se areia de origem quartzosa, proveniente do rio Mogi município de Rincão e cuja análise granulométrica, realizada de acordo com a NBR 7217 (1987) é apresentada na TABELA 7.4.

TABELA 7.4 - Análise granulométrica do agregado miúdo (NBR 7217/87)

\begin{tabular}{|c|c|c|c|c|c|c|}
\hline \multirow[t]{2}{*}{ Peneira mm } & \multicolumn{2}{|c|}{ material retido $(\mathrm{g})$} & \multicolumn{2}{|c|}{$\%$ retida } & \multicolumn{2}{|c|}{$\%$ retida acumulada } \\
\hline & $\mathbf{M}_{1}$ & $\mathbf{M}_{2}$ & $\mathbf{M}_{1}$ & $\mathbf{M}_{2}$ & $\mathbf{M}_{1}$ & $\mathbf{M}_{2}$ \\
\hline 9,5 & 0 & 0 & 0 & 0 & 0 & 0 \\
\hline 6,3 & 1 & 0 & 0,2 & 0 & 0,2 & 0 \\
\hline 4,8 & 0,5 & 0,5 & 0,1 & 0,1 & 0,3 & 0,1 \\
\hline 2,4 & 5 & 7 & 1 & 1,4 & 1,3 & 1,5 \\
\hline 1,2 & 35,5 & 51,5 & 7,1 & 10,3 & 8,4 & 11,8 \\
\hline 0,6 & 146 & 165 & 29,2 & 33 & 37,6 & 44,8 \\
\hline 0,3 & 215 & 199 & 43 & 39,8 & 80,6 & 84,6 \\
\hline 0,15 & 85 & 65,5 & 17 & 13,1 & 97,6 & 97,7 \\
\hline Fundo & 4,5 & 2,5 & 0,9 & 0,5 & 98,5 & 98,2 \\
\hline \multicolumn{5}{|c|}{ Dimensão máxima característica } & \multicolumn{2}{|c|}{$2,4 \mathrm{~mm}$} \\
\hline \multicolumn{5}{|c|}{ Módulo de Finura médio } & \multicolumn{2}{|c|}{2,33} \\
\hline
\end{tabular}

obs.: $M_{1}$ e $M_{2}$ correspondem às amostras 1 e 2 respectivamente 
O agregado graúdo foi brita de origem basáltica, extraída da Pedreira Morada do Sol - município de Araraquara. Sua composição granulométrica é mostrada na TABELA 7.5.

TABELA 7.5 - Análise granulométrica do agregado graúdo (NBR 7217/87)

\begin{tabular}{|c|c|c|c|c|c|c|}
\hline Peneira $\mathbf{m m}$ & \multicolumn{2}{|c|}{ Material retido $(\mathbf{g})$} & \multicolumn{2}{c|}{$\%$ retida } & \multicolumn{2}{c|}{ \% retida acumulada } \\
\hline & $\mathbf{M}_{\mathbf{1}}$ & $\mathbf{M}_{\mathbf{2}}$ & $\mathbf{M}_{\mathbf{1}}$ & $\mathbf{M}_{\mathbf{2}}$ & $\mathbf{M}_{\mathbf{1}}$ & $\mathbf{M}_{\mathbf{2}}$ \\
\hline 25 & 0 & 0 & 0 & 0 & 0 & 0 \\
\hline 19 & 0 & 26,5 & 0 & 0,53 & 0 & 0,53 \\
\hline 12,5 & 1740 & 1750 & 34,8 & 35 & 34,8 & 35,5 \\
\hline 9,5 & 2200 & 2250 & 44 & 45 & 78,8 & 80,5 \\
\hline 6,3 & 1000 & 920 & 20 & 18,4 & 98,8 & 98,9 \\
\hline 4,8 & 100 & 87,5 & 2 & 1,75 & 100,8 & 100,7 \\
\hline Fundo & 17,5 & 19 & 0,35 & 0,38 & 101,1 & 101,1 \\
\hline Dimensão máxima característica & & & & $19 \mathrm{~mm}$ \\
\hline
\end{tabular}

obs.: $M_{1}$ e $M_{2}$ correspondem às amostras 1 e 2 respectivamente

Na TABELA 7.6 são dadas as principais características dos materiais que compõem o concreto.

TABELA 7.6 - Principais características dos materiais que compõem o concreto

\begin{tabular}{|c|c|}
\hline Material & Características \\
\hline areia fina & $\begin{array}{c}\text { módulo de finura: M.F. }=2,33 \\
\text { massa unitária: } 1,436 \mathrm{~g} / \mathrm{m}^{3} \\
\text { massa específica: } 2,682 \mathrm{~g} / \mathrm{m}^{3}\end{array}$ \\
\hline brita & $\begin{array}{c}\text { massa unitária: } 1,485 \mathrm{~g} / \mathrm{m}^{3} \\
\text { massa específica: } 2,864 \mathrm{~g} / \mathrm{m}^{3}\end{array}$ \\
\hline cimento ** & $\begin{array}{c}\text { CPV ARI PLUS ELDORADO } \\
\text { massa específica: } 3,10 \text { a } 3,15 \mathrm{~g} / \mathrm{m}^{3}\end{array}$ \\
\hline superplastificante & $\begin{array}{c}\text { aditivo líquido de cor marrom; densidade de } \\
1,16 \mathrm{~g} / \mathrm{cm}^{3} ; \text { isento de cloretos e obedecendo } \\
\text { às normas ASTM C494 e EB } 1763\end{array}$ \\
\hline
\end{tabular}

obs.: normas utilizadas:

NBR 7251 (1982) Agregado em estado solto - Determinação da massa unitária NBR 7211(1983) Agregado para concreto

NBR 9776 (1987) Agregados - Determinação da massa específica de agregados miúdos por meio do frasco de Chapman

** os dados apresentados foram fornecidos pelo fabricante 


\subsubsection{DOSAGEM DE MATERIAIS}

Um traço inicial foi obtido no Departamento de Construção Civil da Escola de Engenharia de São Carlos - EESC/USP, o qual foi então testado através de ensaios de compressão axial em corpos-de-prova $10 \times 20 \mathrm{~cm}$, em idades de 3 e 7 dias. Foi realizado também o ensaio de abatimento com cone de Abrams, para verificar se o concreto apresentava boa trabalhabilidade. O traço inicial apresentou resultados de resistência à compressão e trabalhabilidade satisfatórios. O concreto confeccionado com este traço apresentou um abatimento, medido no tronco de cone, segundo a NBR 7223/82, de $8 \mathrm{~cm}$.

O consumo de materiais empregados na confecção de concreto com resistência média de $50 \mathrm{MPa}$ aos sete dias foi:

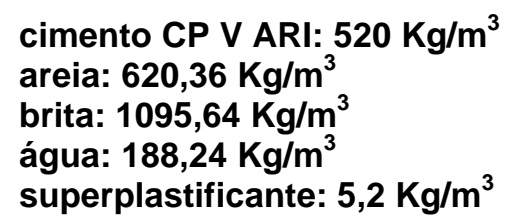

resultando o seguinte traço em massa:

\section{1: $1,193: 2,107: 0,368$}

No consumo de água foi descontado o volume contido no aditivo superplastificante, admitido ser de $70 \%$ da massa. O teor de superplastificante utilizado foi de $1 \%$ do consumo de cimento.

Para controle da resistência do concreto foram utilizados corpos-de-prova cilíndricos de dimensões $10 \times 20 \mathrm{~cm}$. Sua moldagem foi executada em duas etapas, utilizando-se uma pequena mesa vibratória para o adensamento. A operação de moldagem dos corpos-de-prova pode ser vista na FIGURA 7.6.

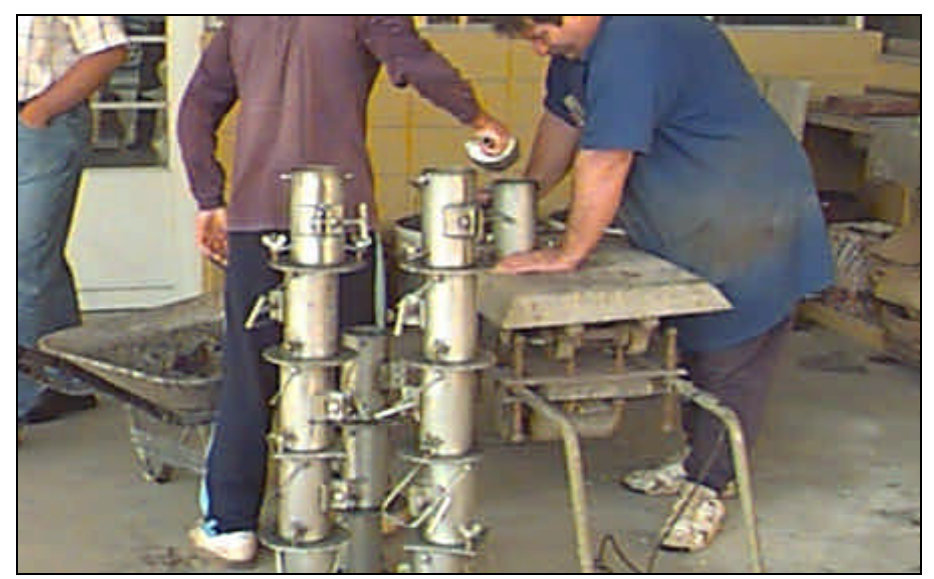

FIGURA 7.6 - OPERAÇÃO DE MOLDAGEM DOS CORPOS-DE-PROVA CILÍNDRICOS DE DIMENSÕES $(10 \times 20) \mathrm{cm}$ 
Também foi determinada a resistência à tração $\left(f_{t, D}\right)$ do concreto de preenchimento, através do ensaio à tração por compressão diametral.

Quanto á seqüência de mistura, acrescentava-se: brita, areia, cimento, água + superplastificante. Para mistura utilizou-se betoneira basculante. Na FIGURA 7.7 apresentam-se os materiais dentro da betoneira, após a mistura.

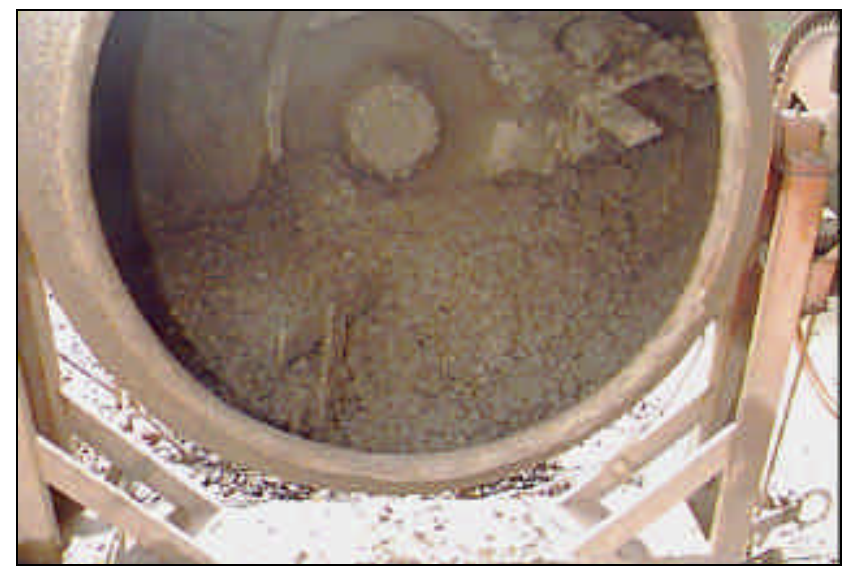

FIGURA 7.7 - DETALHE DOS MATERIAIS DENTRO DA BETONEIRA, APÓS A MISTURA

Os valores médios de resistência à tração por compressão diametral $\left(\mathfrak{f}_{t, D}\right)$, determinados de acordo com a NBR 5739 (1980), e de resistência à compressão $f_{c}$ - determinados segundo NBR 7222 (1982) - são apresentados no capítulo 8. Tais valores médios correspondem à média de três corpos-de-prova.

\subsubsection{CARACTERIZAÇÃo do PERFIL TUBULAR}

As seções quadradas e retangulares investigadas foram obtidas a partir da soldagem de perfis $U$, formados a frio por dobramento de chapas de aço tipo SAE. As seções circulares também são formadas a frio e doadas pela ALUSUD - Eng. e Ind. de Construções Espaciais Ltda.

A caracterização mecânica do aço foi feita através de ensaio de tração axial, conforme especificação da ASTM A370/92. Os corpos-de-prova, cujas dimensões são mostradas na FIGURA 7.8, foram ensaiados numa máquina universal INSTRON (FIGURA 7.9) e instrumentados com extensômetro removível (clip gage) - (FIGURA 7.9). 


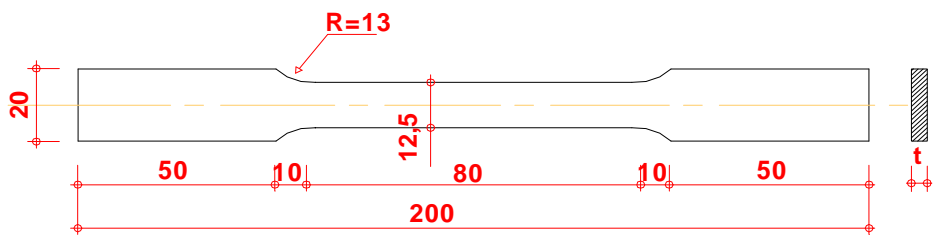

FIGURA 7.8 - DIMENSÕES DO CORPO-DE-PROVA PARA ENSAIO À TRAÇÃO SEGUNDO ASTM A370/92 (MEDIDAS EM mm)

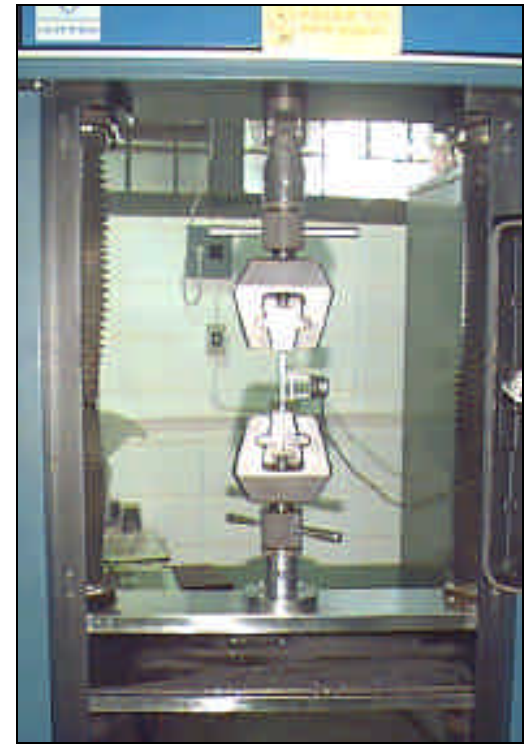

MÁQUINA INSTRON

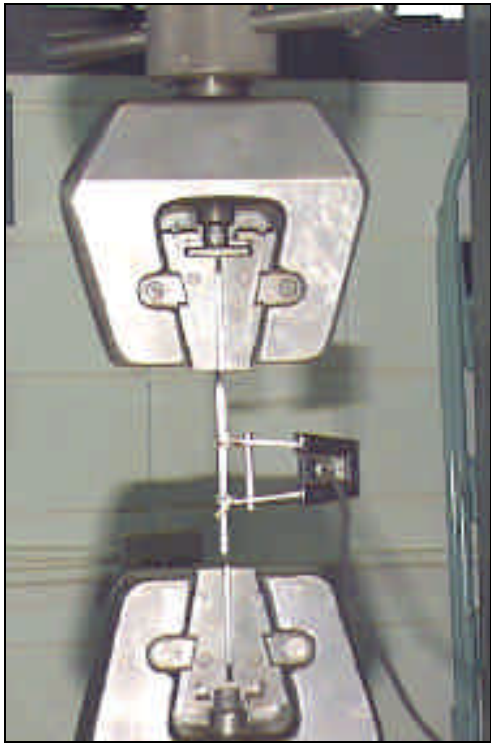

DETALHE DA INSTRUMENTAÇÃO

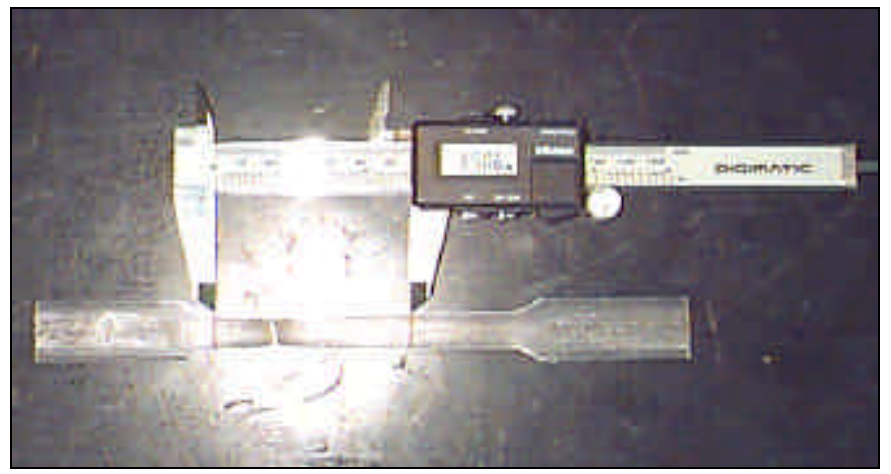

DETERMINAÇÃO DO ALONGAMENTO

FIGURA 7.9 - CARACTERIZAÇÃO MECÂNICA DO AÇO DOS PERFIS

Para cada perfil, foram retirados quatro corpos-de-prova, incluindo as regiões de solda. As amostras foram extraídas de pequenos perfis com altura de 40 cm (FIGURA 7.10). 


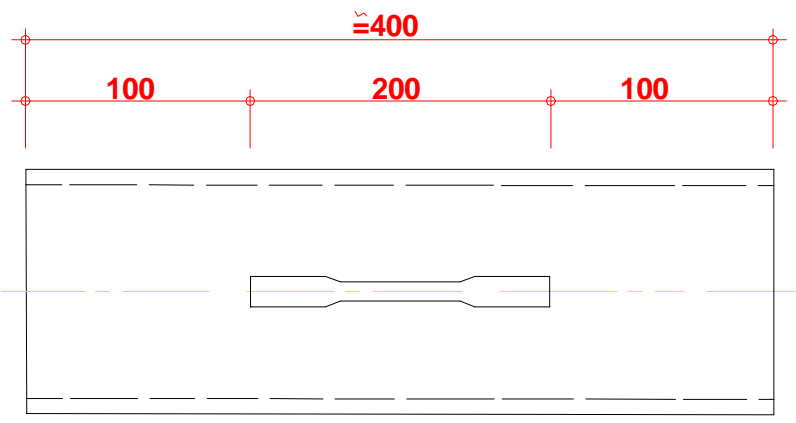

FIGURA 7.10 - REGIÃO DE EXTRAÇÃO DOS CORPOS-DE-PROVA PARA ENSAIO À TRAÇÃO

Na TABELA 7.7 são apresentados os resultados médios da caracterização do aço dos perfis tubulares.

TABELA 7.7 - Resultados da caracterização mecânica do aço dos perfis tubulares

\begin{tabular}{|c|c|c|c|c|}
\hline Amostra & $\mathbf{E}_{\mathbf{s}}(\mathbf{M P a})$ & $\mathbf{f}_{\mathrm{y}}(\mathbf{M P a})$ & $\mathbf{f}_{\mathrm{u}}(\mathbf{M P a})$ & $\mathbf{A}(\%)$ \\
\hline CFT 1_1 & 183890 & 357,5 & 430,2 & 21,9 \\
\hline CFT 1_2 & 197350 & 262,1 & 336,2 & 22,2 \\
\hline CFT 2_1 & 187500 & 355,0 & 414,6 & 21,6 \\
\hline CFT 2_2 & 199000 & 329,1 & 401,3 & 22,1 \\
\hline CFT 3_1 & 180600 & 251,2 & 310,7 & 23,0 \\
\hline CFT 3_2 & 201510 & 247,1 & 313,4 & 22,9 \\
\hline
\end{tabular}

\subsubsection{PILARES MISTOS PREENCHIDOS}

\subsubsection{INSTRUMENTAÇÃO}

Os pilares mistos foram instrumentados de forma a possibilitar a leitura das deformações axiais e transversais nos materiais aço e concreto. Assim, foram posicionados extensômetros elétricos nos pontos médios das quatro faces dos perfis, nos materiais aço e concreto, conforme as FIGURAs 7.11, 7.12 e 7.13 Quatro transdutores de deslocamento foram fixados nas faces de cada perfil a fim de medir o encurtamento relativo dos pilares. Em todas estas figuras, as letras " $A$ " e " $T$ " referem-se a deformações nas direções axial e transversal, respectivamente. 


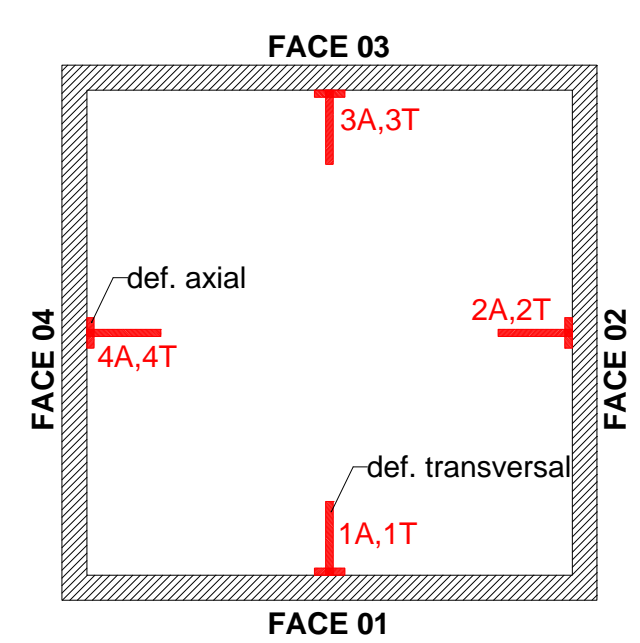

A) CONCRETO

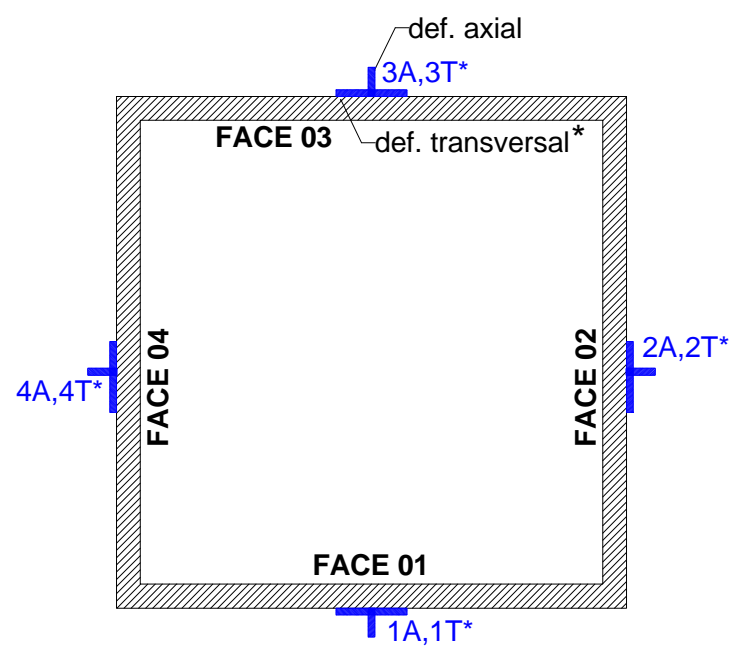

B) PERFIL TUBULAR

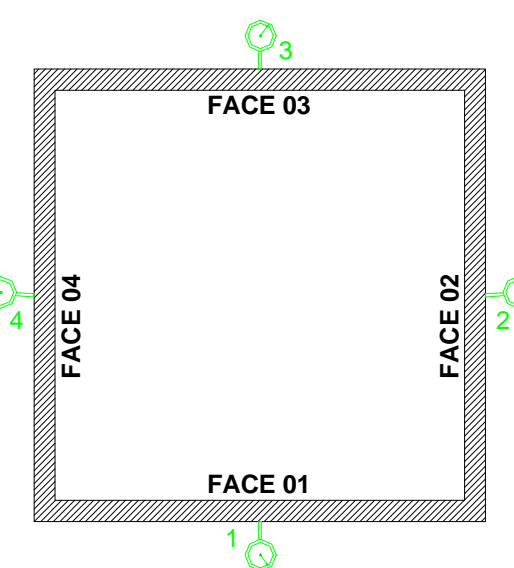

C) TRANSDUTORES

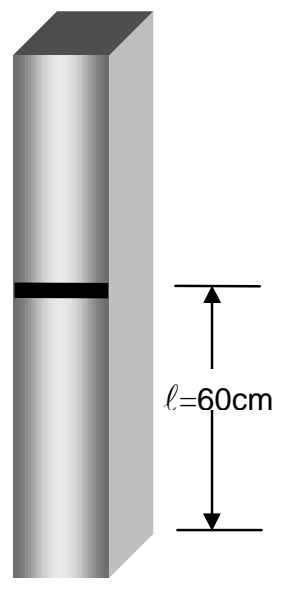

D) SEÇÃO INSTRUMENTADA

FIGURA 7.11 - INSTRUMENTAÇÃO DO PILAR MISTO COM SEÇÃO QUADRADA

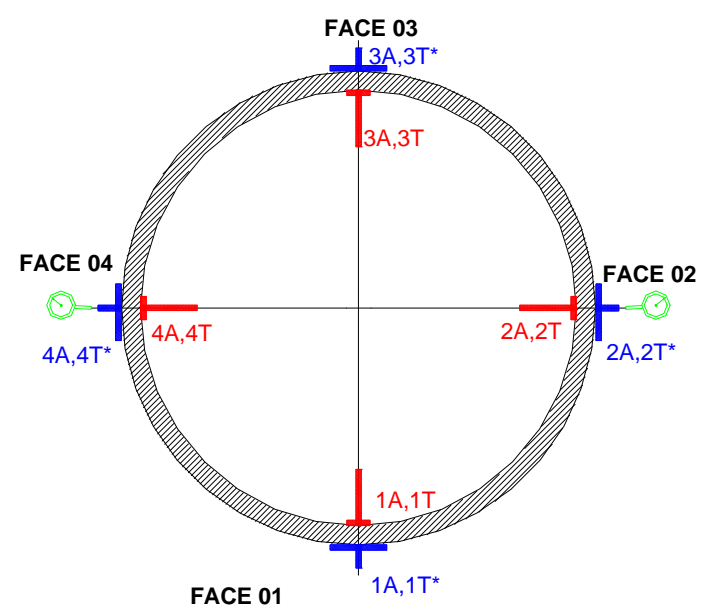

FIGURA 7.12 - INSTRUMENTAÇÃO DO PILAR MISTO COM SEÇÃO CIRCULAR 


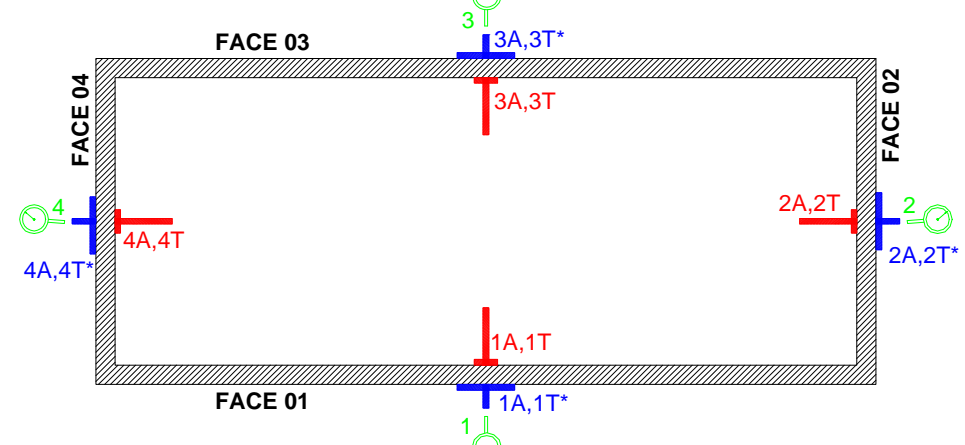

FIGURA 7.13 - INSTRUMENTAÇÃO DO PILAR MISTO COM SEÇÃO RETANGULAR

Os extensômetros para medir deformações no concreto foram fixados num dispositivo de papel para garantir que durante o adensamento do concreto, estes não se deslocassem. Na FIGURA 7.14 são apresentados os dispositivos utilizados nas seções quadradas, circulares e retangulares.
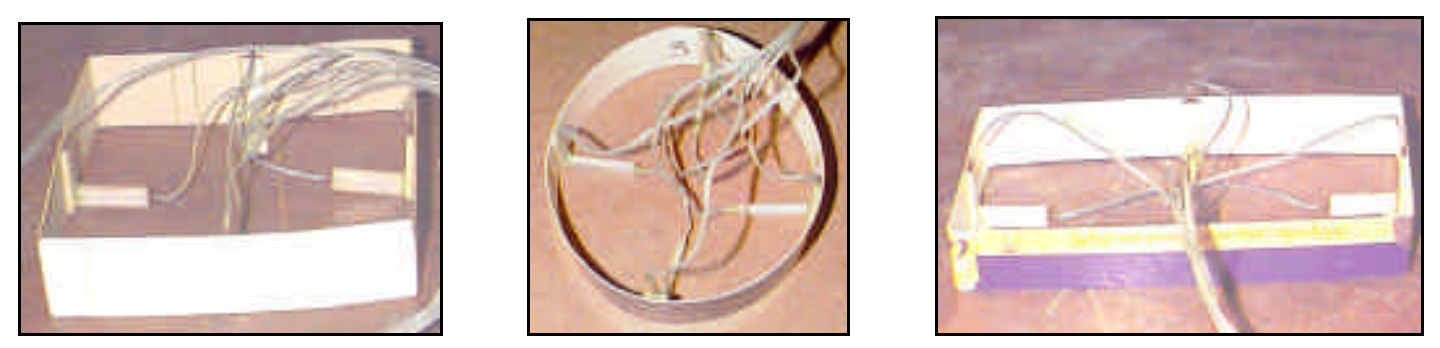

FIGURA 7.14 - INSTRUMENTAÇÃO PARA O CONCRETO DE PREENCHIMENTO

\subsubsection{Moldagem, ADENSAMENTO E CURA}

Os elementos foram moldados na posição vertical e o adensamento executado usando mesa vibratória. A concretagem foi executada em etapas: o concreto foi adicionado aos poucos até atingir uma altura de $60 \mathrm{~cm}$; neste ponto, a concretagem foi interrompida e o dispositivo com os extensômetros (mostrado na FIGURA 7.14) foi posicionado no interior do perfil tubular, conforme ilustra a FIGURA 7.15. A concretagem foi reiniciada tomando-se o cuidado de não deslocar os extensômetros durante o lançamento e adensamento do concreto. Os cabos dos extensômetros foram retirados do interior do perfil através de um furo localizado a $70 \mathrm{~cm}$ da base do deste. Foi dada atenção especial à regularidade da superfície de concreto, para garantir que aço e concreto fossem carregados simultaneamente durante o ensaio. 


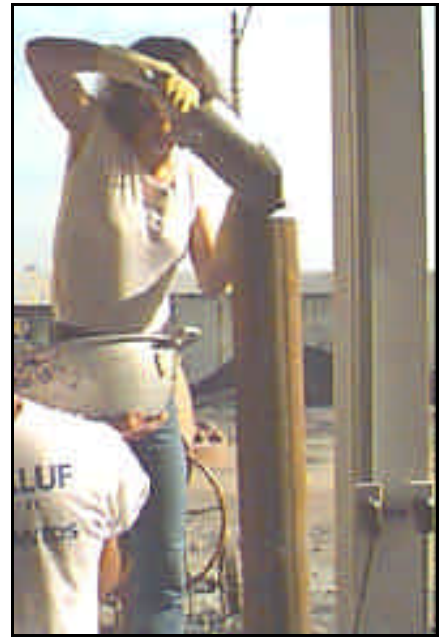

a) concretagem

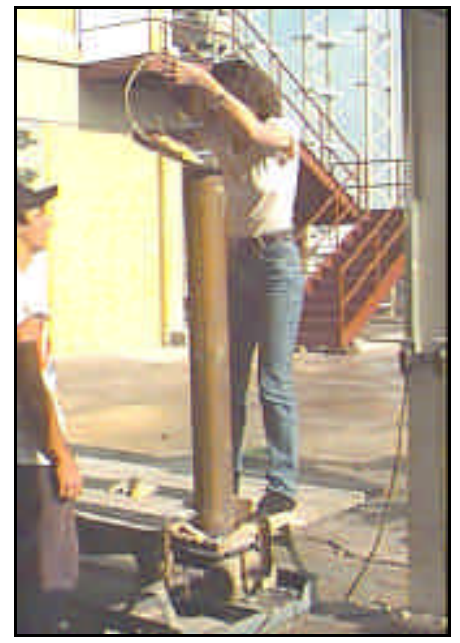

b) colocação da instrumetação

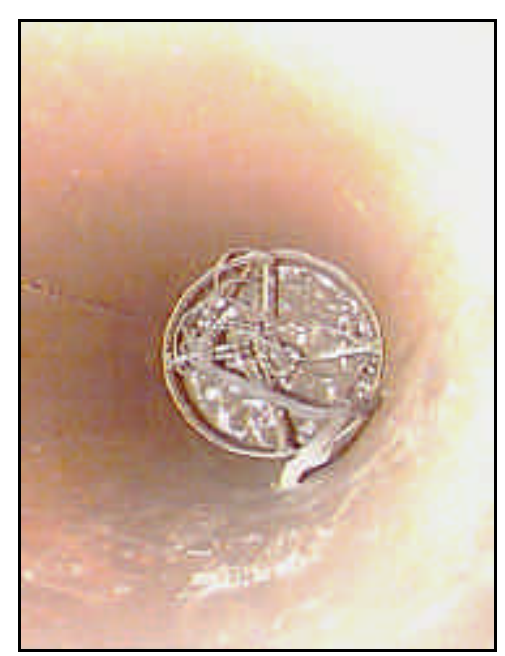

c) detalhe da instrumentação na massa de concreto

FIGURA 7.15- LANÇAMENTO DO CONCRETO E POSICIONAMENTO DOS EXTENSÔMETROS NO INTERIOR DO PERFIL TUBULAR

A cura dos pilares foi realizada ao ar livre, protegendo-se a superfície de concreto com manta de espuma umedecida.

\subsubsection{PILAR DE REFERÊNCIA}

O pilar de referência, confeccionado em concreto simples, foi instrumentado na seção média com o intuito de acompanhar a evolução das deformações durante a aplicação do carregamento. Para tanto, os extensômetros foram posicionados no ponto médio das quatro faces do pilar, acompanhados de transdutores de deslocamento, conforme a FIGURA 7.16.
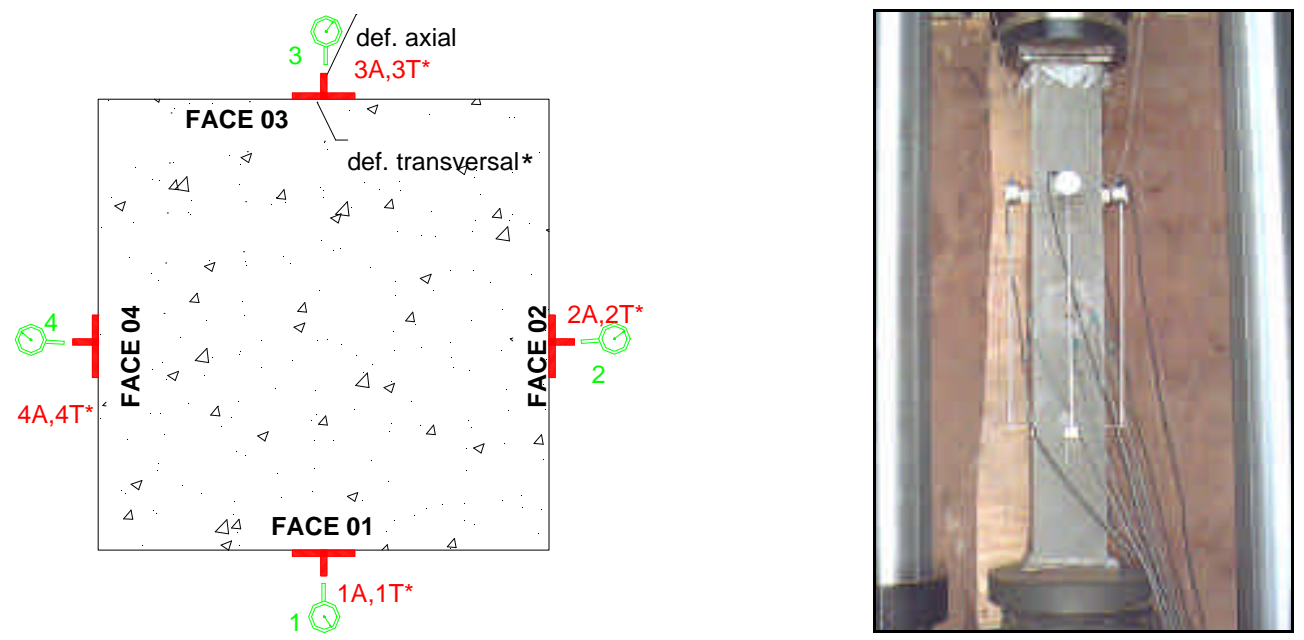

FIGURA 7.16 - INSTRUMENTAÇÃO DO PILAR DE REFERÊNCIA 
A concretagem ocorreu com o modelo na posição horizontal, estando a fôrma de madeira sobre a mesa vibratória. A cura foi realizada ao ar livre, com manta de espuma umedecida.

\subsubsection{INSTRUMENTOS E EQUIPAMENTOS EMPREGADOS}

Os instrumentos e equipamentos de medição empregados no ensaio dos pilares mistos e de referência estão discriminados na TABELA 7.8.

TABELA 7.8 - Instrumentos de medição utilizados

\begin{tabular}{|c|c|c|c|c|}
\hline Instrumento & Tipo & Finalidade & Marca & Características \\
\hline $\begin{array}{c}\text { sistema de } \\
\text { aquisição de } \\
\text { dados por } \\
\text { extensometria }\end{array}$ & $\begin{array}{c}\text { SYSTEM } \\
5000 \\
\text { PROGRAM } \\
\text { POWER-UP }\end{array}$ & $\begin{array}{c}\text { coleta e } \\
\text { gravação } \\
\text { automática de } \\
\text { dados }\end{array}$ & $\begin{array}{c}\text { MEASUREMENTS } \\
\text { GROUP }\end{array}$ & GF=1,8 \\
\hline $\begin{array}{c}\text { extensômetros } \\
\text { elétricos de } \\
\text { resistência }\end{array}$ & $\begin{array}{c}\text { uniaxiais } \\
\text { encapsulados } \\
\text { KM 30-120 }\end{array}$ & $\begin{array}{c}\text { medição das } \\
\text { deformações } \\
\text { no concreto }\end{array}$ & KYOWA & GF=2,12 \\
\hline $\begin{array}{c}\text { extensômetros } \\
\text { elétricos de } \\
\text { resistência }\end{array}$ & $\begin{array}{c}\text { biaxiais } \\
\text { KFC-5-D16 }\end{array}$ & $\begin{array}{c}\text { medição das } \\
\text { deformações } \\
\text { no aço }\end{array}$ & KYOWA & base $=57 \mathrm{~cm}$ \\
\hline $\begin{array}{c}\text { transdutores de } \\
\text { deslocamento }\end{array}$ & $\begin{array}{c}\text { Medição de } \\
\text { deslocamentos }\end{array}$ & KYOWA & controle de \\
\hline $\begin{array}{c}\text { Máquina de ensaio } \\
\text { servo-hidráulica, } \\
\text { com controle } \\
\text { digital por } \\
\text { computador }\end{array}$ & Modelo 8506 & $\begin{array}{c}\text { do pistão } \\
\text { aplicação da } \\
\text { força }\end{array}$ & INSTRON & \\
\hline
\end{tabular}

Na FIGURA 7.17 é apresentada a máquina INSTRON, que permite realizar ensaios com controle de deslocamento. Este tipo de controle de ensaio é importante porque possibilita a coleta de dados após o modelo atingir sua capacidade máxima, permitindo a análise do comportamento no pós-pico de resistência. Todos os modelos apresentados na TABELA 7.1 foram ensaiados com controle de deslocamento, na máquina INSTRON. 


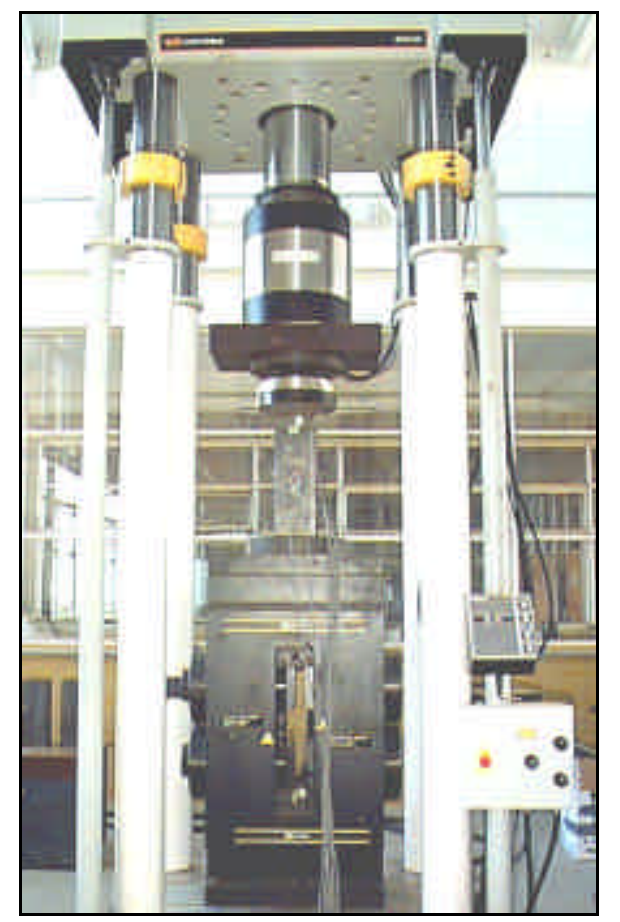

FIGURA 7.17- MÁQUINA INSTRON 8506, QUE PERMITE ENSAIO COM CONTROLE DE DESLOCAMENTO

\subsubsection{PROCEDIMENTO de ENSAIO}

Os pilares mistos e de referência foram ensaiados estando o concreto com 7 dias de idade, ambos submetidos a força axial de compressão. Em ambos os casos, o carregamento foi aplicado em etapas, sendo para cada uma delas, registradas as deformações e a correspondente força aplicada. A velocidade de deslocamento aplicada foi de $0,005 \mathrm{~mm} / \mathrm{seg}$.

Em todos os ensaios foi realizada a aplicação de uma força de aproximadamente $10 \%$ da força de ruptura, a fim de fazer o escorvamento, ou seja, verificar se todos os instrumentos de medição estavam funcionando e tentar centralizar a aplicação da força. Cumprida esta etapa, iniciava-se o ensaio propriamente dito, aplicando força até se verificar deformações acentuadas nas paredes do perfil tubular, decorrentes da flambagem local do mesmo.

Os resultados obtidos nos ensaios dos modelos são apresentados e discutidos no próximo capítulo. 


\subsubsection{Perfis tubulares}

O comportamento do perfil tubular isolado foi analisado através de ensaio à compressão em pequenos espécimes com $40 \mathrm{~cm}$ de altura e possibilitaram, além da avaliação do seu comportamento, a determinação de sua resistência $\left(\mathbf{F}_{\mathbf{s}}\right)$. Este tipo de ensaio é denominado pela literatura inglesa de "full test".

Para cada modelo misto, foram ensaiados dois perfis tubulares, instrumentados no ponto médio das suas quatro faces com extensômetros que permitiram medir a deformação axial destes elementos. Um dos espécimes ensaiados pode ser visto na FIGURA 7.18.

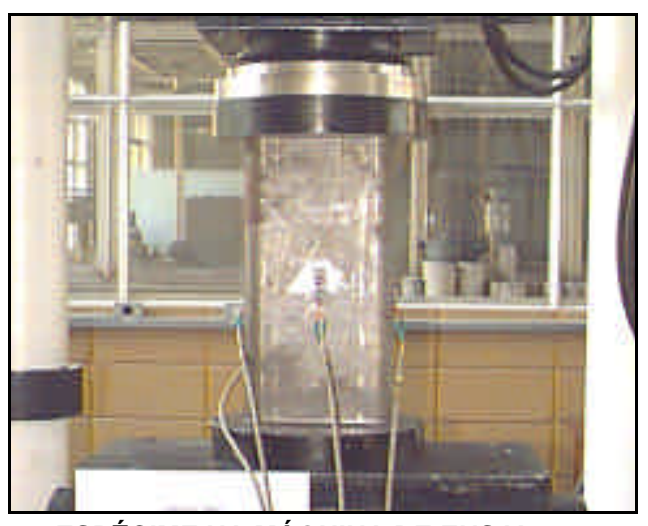

ESPÉCIME NA MÁQUINA DE ENSAIO

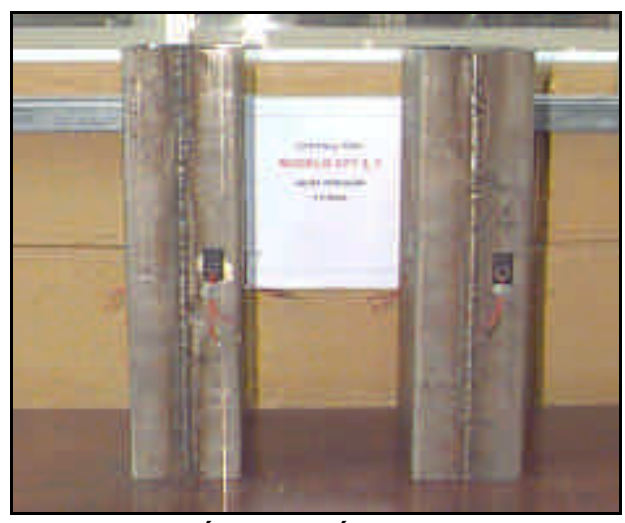

ESPÉCIME APÓS ENSAIO

FIGURA 7.18 - ESPÉCIME DE PERFIL TUBULAR ENSAIADO À COMPRESSÃO AXIAL

Para cada modelo CFT foram ensaiados dois espécimes de perfil. Os ensaios foram realizados com controle de deslocamento e velocidade de deslocamento de $0,005 \mathrm{~mm} / \mathrm{seg}$.

A resistência obtida, denominada $\mathbf{F}_{\mathbf{s}}$, juntamente com os demais resultados, serão apresentados no próximo capítulo. 


\section{RESULTADOS E ANÁLISE}

Neste capítulo são apresentados os resultados obtidos na análise numérica e na investigação experimental, seguidos da análise dos mesmos.

É importante ressaltar que foi ensaiado apenas um exemplar de cada elemento e portanto os comentários aqui apresentados têm caráter parcial e não são conclusivos.

\subsection{CAPACIDADE RESISTENTE À COMPRESSÃo AXIAL}

A capacidade resistente dos pilares mistos preenchidos foi calculada por meio de:

- análise numérica realizada no programa Ansys;

- empregando equações propostas por diversas normas;

- considerando a resistência isolada dos materiais, partindo da determinação da resistência do perfil tubular através do ensaio "full test".

Na TABELA 8.1 são apresentados os dados necessários à determinação da capacidade resistente dos pilares mistos submetidos à compressão axial.

Os resultados de resistência do perfil isolado submetido à compressão axial são mostrados na TABELA 8.2. A capacidade resistente neste caso, foi calculada através da equação 8.1, que considera a soma das resistências dos materiais : 


$$
F_{t}=f_{c m} \cdot A_{c}+F_{s}
$$

Todos os resultados de capacidade resistente obtidos neste estudo são apresentados na TABELA 8.3. Nela apresenta-se também a relação entre a força última teórica e a experimental.

TABELA 8.1 - Propriedades gerais dos pilares mistos preenchidos

\begin{tabular}{|c|c|c|c|c|c|c|c|c|c|}
\hline Elemento & $\mathbf{t}(\mathbf{m m})$ & $\begin{array}{c}\mathbf{A}_{\mathbf{c}} \\
\left(\mathbf{c m}^{2}\right)\end{array}$ & $\begin{array}{c}\mathbf{A}_{\mathbf{s}} \\
\left(\mathbf{c m}^{2}\right)\end{array}$ & $\mathbf{f}_{\mathbf{c}}(\mathbf{M P a})$ & $\mathbf{f}_{\mathrm{cm}}(\mathbf{M P a})$ & $\mathbf{f}_{\mathrm{t}, \mathrm{D}}(\mathbf{M P a})$ & $\mathbf{f}_{\mathbf{y}}(\mathbf{M P a})$ & $\mathbf{E}_{\mathrm{c}}(\mathrm{MPa})$ & $\mathbf{E}_{\mathbf{s}}(\mathbf{M P a})$ \\
\hline R 1_1 & - & 225 & - & 48,20 & 43,4 & 4,10 & - & 32260 & - \\
\hline CFT 1_1 & 3,0 & 207,28 & 17,64 & 48,20 & 43,4 & 4,10 & 357,5 & 32260 & 183890 \\
\hline CFT 1_2 & 6,3 & 188,45 & 36,21 & 53,43 & 48,1 & 2,67 & 262,1 & 32260 & 197350 \\
\hline CFT 2_1 & 3,2 & 114,23 & 12,45 & 53,04 & 47,7 & 2,97 & 355,0 & 32260 & 187500 \\
\hline CFT 2_2 & 4,85 & 108,06 & 18,61 & 65,93 & 59,3 & 4,46 & 329,1 & 32260 & 199000 \\
\hline CFT 3_1 & 3,0 & 182,28 & 17,64 & 50,95 & 45,8 & 3,65 & 251,2 & 32260 & 180600 \\
\hline CFT 3_2 & 6,3 & 163,45 & 36,22 & 57,34 & 51,6 & 3,46 & 247,1 & 32260 & 201510 \\
\hline
\end{tabular}

lembrando que: $\mathrm{f}_{\mathrm{cm}}=0,9 \cdot \mathrm{f}_{\mathrm{c}}$

TABELA 8.2 - Resistência à compressão dos perfis tubulares isolados: resultados do full test

\begin{tabular}{|c|c|}
\hline $\begin{array}{c}\text { Elemento Isolado } \\
\text { correspondente ao modelo }\end{array}$ & Capacidade resistente Fs (kN) \\
\hline CFT 1_1 & 463,7 \\
\hline CFT 1_2 & 923,5 \\
\hline CFT 2_1 & 381,6 \\
\hline CFT 2_2 & 669,7 \\
\hline CFT 3_1 & 351,1 \\
\hline CFT 3_2 & 856,4 \\
\hline
\end{tabular}


TABELA 8.3 - Capacidade Resistente dos Pilares Mistos Preenchidos

\begin{tabular}{|c|c|c|c|c|c|c|c|}
\hline $\begin{array}{c}\text { Capacidade } \\
\text { Resistente }\end{array}$ & R & CFT 1_1 & CFT 1_2 & CFT 2_1 & CFT 2_2 & CFT 3_1 & CFT 3_2 \\
\hline$F_{\mathrm{u}}(\mathrm{kN})$ & $\mathbf{8 2 5 , 1 5}$ & $\mathbf{1 5 3 4 , 6}$ & $\mathbf{1 8 3 6}$ & $\mathbf{1 0 5 1 , 5}$ & $\mathbf{1 2 9 2 , 1}$ & $\mathbf{1 2 9 6}$ & $\mathbf{1 7 1 0}$ \\
\hline $\mathrm{F}_{\mathrm{sn}}(\mathrm{kN})$ & - & $\mathbf{1 4 4 0 , 2}$ & $\mathbf{1 8 4 2 , 1}$ & - & - & $\mathbf{1 3 2 3 , 1}$ & $\mathbf{1 7 2 4 , 2}$ \\
& & 0,938 & 1,003 & & & 1,021 & 1,008 \\
\hline ACI 318 & $\mathbf{9 7 6 , 1}$ & $\mathbf{1 5 2 9 , 8}$ & $\mathbf{1 8 5 5 , 3}$ & $\mathbf{9 8 7 , 6}$ & $\mathbf{1 2 5 3 , 7}$ & $\mathbf{1 2 7 8 , 9}$ & $\mathbf{1 7 3 8 , 3}$ \\
& 1,183 & 0,997 & 1,010 & 0,939 & 0,970 & 0,987 & 1,016 \\
\hline AISC-LRFD & - & $\mathbf{1 4 8 2 , 1}$ & $\mathbf{1 8 0 9 , 9}$ & $\mathbf{9 3 0 , 4}$ & $\mathbf{1 1 8 2 , 9}$ & $\mathbf{1 2 5 4 , 8}$ & $\mathbf{1 7 1 1 , 1}$ \\
& & 0,966 & 0,986 & 0,885 & 0,915 & 0,968 & 1,000 \\
\hline BS 5400 & - & $\mathbf{1 3 5 9 , 0}$ & $\mathbf{1 6 8 3 , 1}$ & $\mathbf{1 1 2 3 , 4}$ & $\mathbf{1 4 0 6 , 2}$ & $\mathbf{1 1 2 0 , 1}$ & $\mathbf{1 5 7 8 , 0}$ \\
& & 0,886 & 0,917 & 1,068 & 1,088 & 0,864 & 0,923 \\
\hline CAN/CSA & - & $\mathbf{1 6 1 1 , 7}$ & $\mathbf{2 0 0 2 , 2}$ & $\mathbf{1 0 2 3 , 5}$ & $\mathbf{1 2 8 8 , 7}$ & $\mathbf{1 2 5 9 , 6}$ & $\mathbf{1 7 8 1 , 4}$ \\
& & 1,050 & 1,091 & 0,973 & 0,997 & 0,972 & 1,042 \\
\hline Eurocode 4 & - & $\mathbf{1 5 2 9 , 8}$ & $\mathbf{1 8 5 5 , 3}$ & $\mathbf{9 9 2 , 2}$ & $\mathbf{1 2 6 2 , 8}$ & $\mathbf{1 2 7 8 , 9}$ & $\mathbf{1 7 3 8 , 3}$ \\
& & 0,997 & 1,010 & 0,939 & 0,977 & 0,987 & 1,016 \\
\hline "Full test" & - & $\mathbf{1 3 6 3 , 3}$ & $\mathbf{1 8 2 9 , 9}$ & $\mathbf{9 2 6 , 5}$ & $\mathbf{1 3 1 0 , 5}$ & $\mathbf{1 1 8 5 , 9}$ & $\mathbf{1 6 9 9 , 7}$ \\
& & 0,888 & 0,997 & 0,881 & 1,014 & 0,915 & 0,994 \\
\hline
\end{tabular}

obs.: os valores abaixo das capacidades resistentes correspondem à relação $F_{t} / F_{u}$ ou $\mathbf{F}_{\mathrm{sn}} / \mathbf{F}_{\mathbf{u}}$

e:

R: pilar de referência

CFT: Concrete Filled steel Tube

$F_{\mathrm{u}}$ : força última experimental

$\mathrm{F}_{\mathrm{sn}}$ : capacidade resistente prevista através de análise numérica

$F_{\mathrm{t}}$ : capacidade resistente prevista através de normas técnicas

A análise dos resultados da TABELA 8.3 indica que:

- a análise numérica possibilitou uma boa estimativa da capacidade resistente dos pilares mistos preenchidos de seção quadrada e retangular, diferindo no máximo 6,2\% - modelo CFT 1_1 - do resultado experimental. Diante desta boa correlação de resultados, o modelo utilizado na análise numérica pode ser empregado para o estudo da influência de fatores como variação das dimensões da seção transversal, da espessura do perfil e da resistência dos materiais. Assim, os dados experimentais servem para aferir o modelo numérico e dar-lhe confiabilidade;

- as normas aqui abordadas permitem uma boa estimativa da capacidade resistente à compressão axial, entretanto em alguns casos tais valores 
são um pouco superiores aos experimentais. Isto ocorre com a norma BS 5400: parte 5 aplicada ao modelo CFT 2_2 que excede em 8,8\% o valor experimental e com a norma CAN/CSA e modelos CFT 1_1 e CFT 1_2, para os quais encontram-se diferenças de $5 \%$ e $9,1 \%$, em relação aos valores experimentais;

- quanto à questão do efeito de confinamento, constatou-se que a norma BS 5400: parte 5 superestima tal efeito. Entretanto, deve-se lembrar que tal situação pode ser decorrente da utilização de concreto de alta resistência para o qual, a princípio tal norma não se aplica. A norma Eurocode 4, que inclui coeficientes a fim de levar em conta tal efeito, produziu resultados inferiores aos experimentais, contudo esta diferença é insignificante.

\subsection{ANÁLISE NUMÉRICA}

A análise numérica através do programa Ansys permitiu a observação da distribuição de tensões axiais no aço e no núcleo de concreto. Nas figuras 8.1 e 8.2 são apresentadas tais distribuições de tensões para os modelos CFT 1_2 e CFT 3_1. As distribuições de tensões apresentadas referem-se ao último passo de deslocamento, correspondente à força última. 

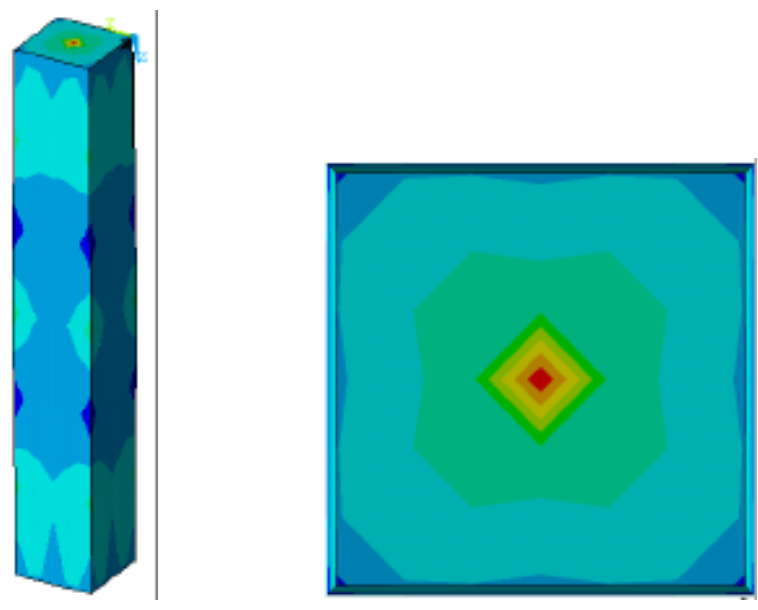

$-4.874$

$-4.787$

$-4.7$

$-4.613$

$-4.527$

$-4.44$

$-4.353$

$-4.266$

$-4.18$

$-4.093$

TENSÕES NO CONCRETO
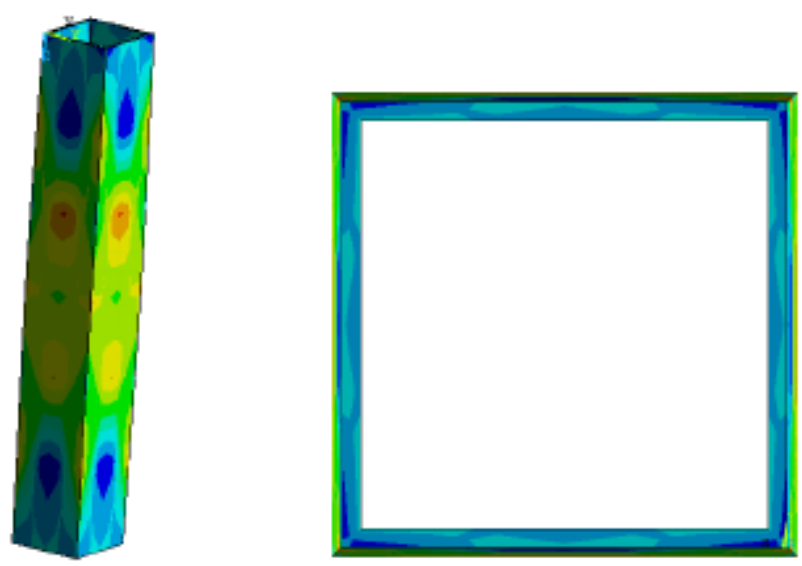

$-26.971$

$-26.846$

$-26.721$

$-26.595$

$-26.47$

$-26.345$

$-26.22$

$-26.094$

$-25.969$

$-25.844$

TENSÕES NO PERFIL TUBULAR

FIGURA 8.1 - DISTRIBUIÇÃO DE TENSÕES AXIAIS NO NÚCLEO CONCRETO E NO PERFIL TUBULAR: MODELO CFT 1_2 (KN/ $\left.\mathrm{CM}^{2}\right)$
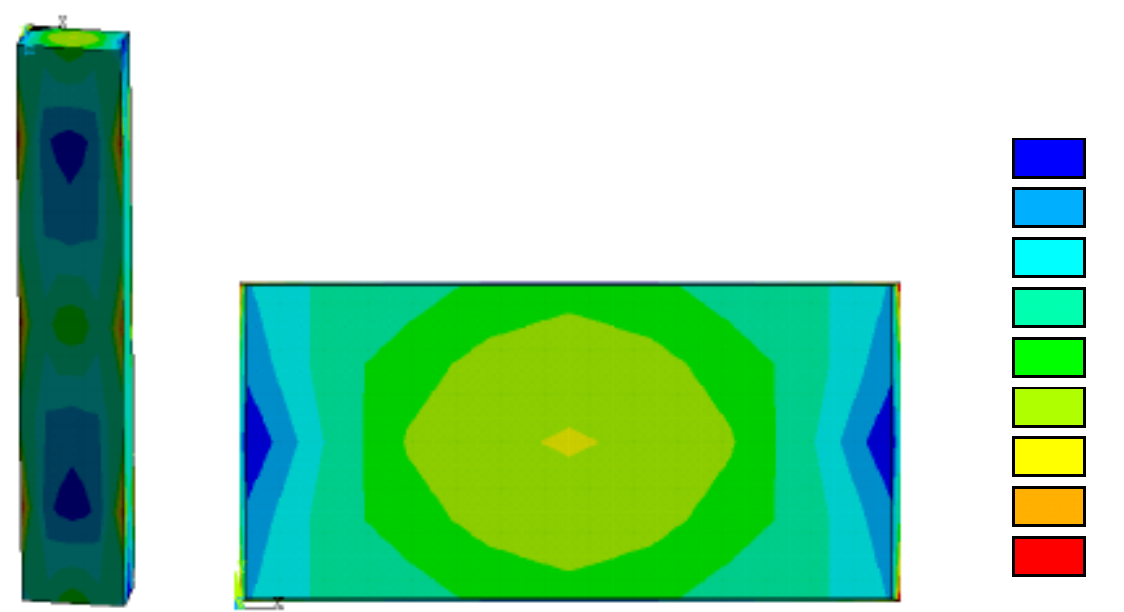

$-4.365$

$-4.345$

$-4.326$

$-4.307$

$-4.287$

$-4.268$

$-4.248$

$-4.229$

$-4.209$

$-4.19$

TENSÕES NO CONCRETO 

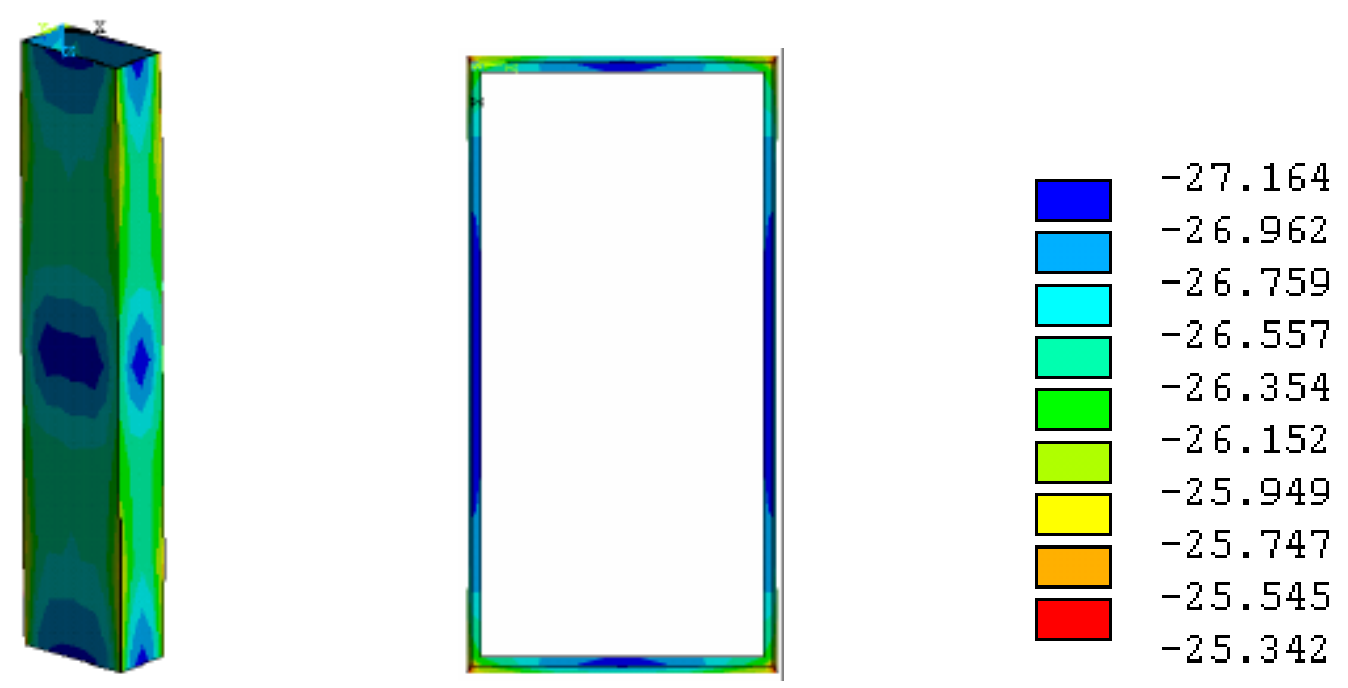

TENSÕES NO PERFIL TUBULAR

FIGURA 8.2 - DISTRIBUIÇÃO DE TENSÕES AXIAIS NO NÚCLEO CONCRETO E NO PERFIL TUBULAR: MODELO CFT 3_1 (KN/ $\left.\mathrm{CM}^{2}\right)$

\subsection{INVESTIGAÇÃO EXPERIMENTAL X ANÁLISE NUMÉRICA}

O comportamento da seção mista foi estudado por meio de análise numérica e investigação experimental. Em ambas, foram determinadas as deformações axiais e transversais nos materiais aço e concreto, em função de parcelas de deslocamento aplicadas. Nas figuras 8.3 a 8.6 podem ser observados os resultados obtidos para os modelos CFT 1_1, CFT 1_2, CFT 3_1 e CFT 3_2. Conforme comentado anteriormente, os modelos de seção circular não foram analisados numericamente devido a dificuldades de modelagem.

Nas figuras a seguir, o termo "encurtamento axial" refere-se à média dos encurtamentos medidos pelos transdutores de deslocamento. O termo "deformação axial média" corresponde à média dos extensômetros. 
1) Modelo CFT 1_1
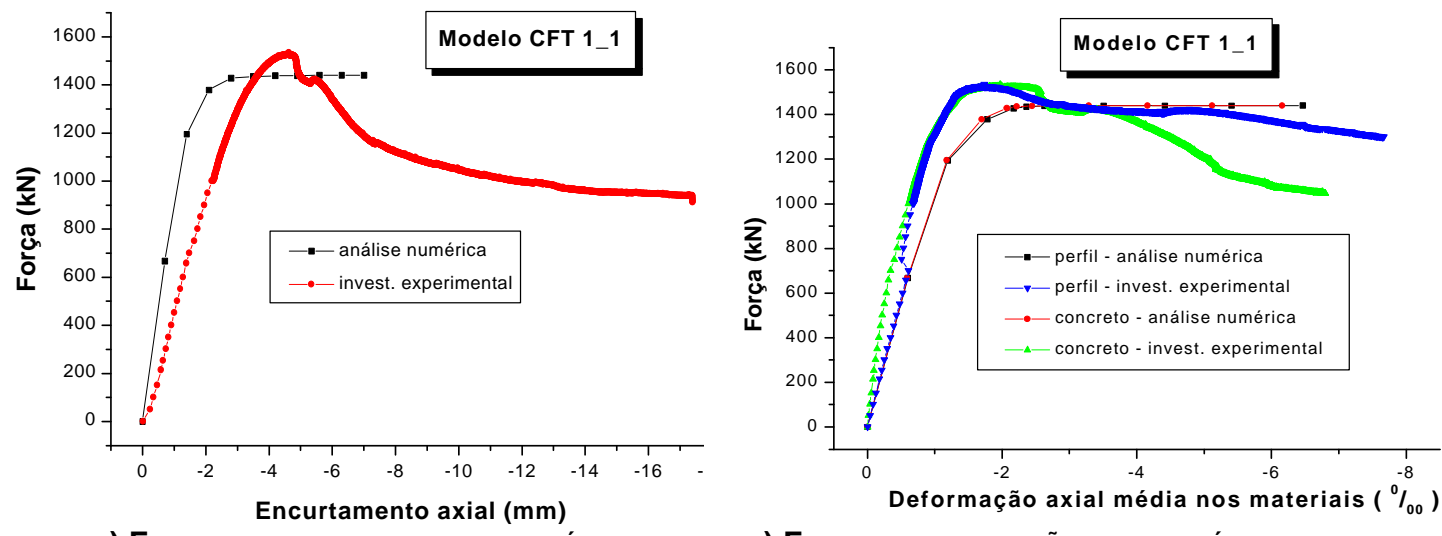

A) FORÇA X ENCURTAMENTO AXIAL MÉDIO

B) FORÇA X DEFORMAÇÕES AXIAIS MÉDIAS NO PERFIL TUBULAR E NO CONCRETO

FIGURA 8.3 - RESULTADO DA INVESTIGAÇÃo EXPERIMENTAL E DA ANÁLISE NUMÉRICA PARA O MODELO CFT 1_1

\section{2) MODELO CFT 1_2}

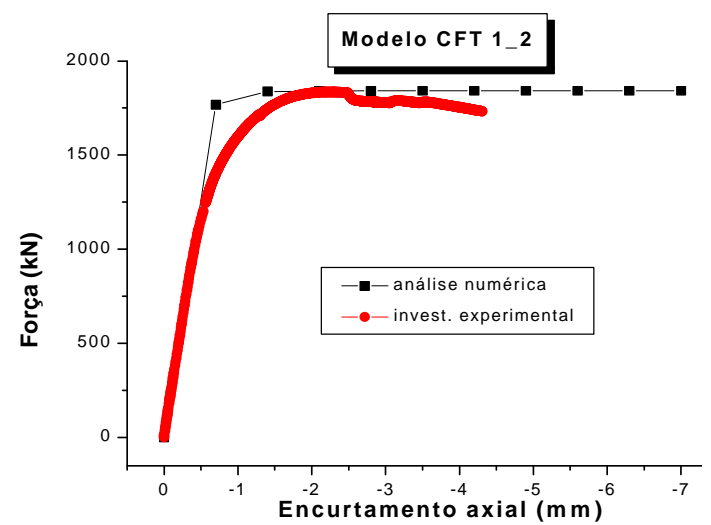

A) ForÇA X ENCURTAMENTO AXIAL MÉDIO

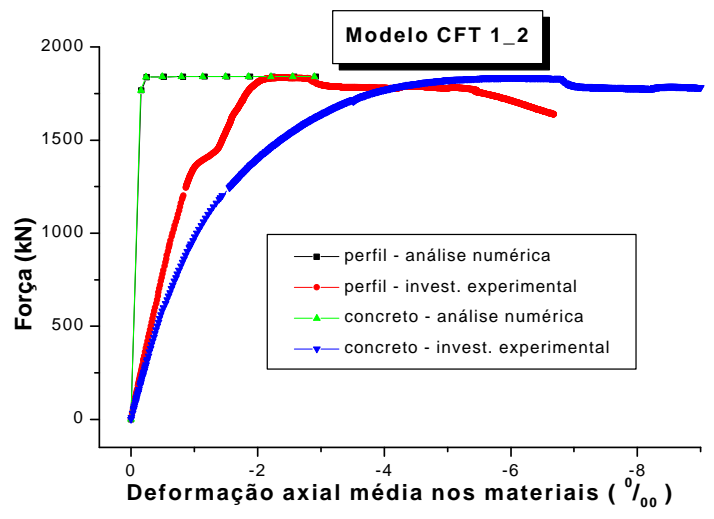

B) FORÇA X DEFORMAÇõES AXIAIS MÉDIAS NO PERFIL TUBULAR E NO CONCRETO

FIGURA 8.4 - RESULTADO DA INVESTIGAÇÃo EXPERIMENTAL E DA ANÁLISE NUMÉRICA PARA O MODELO CFT 1_2

3) MODELO CFT 3_1

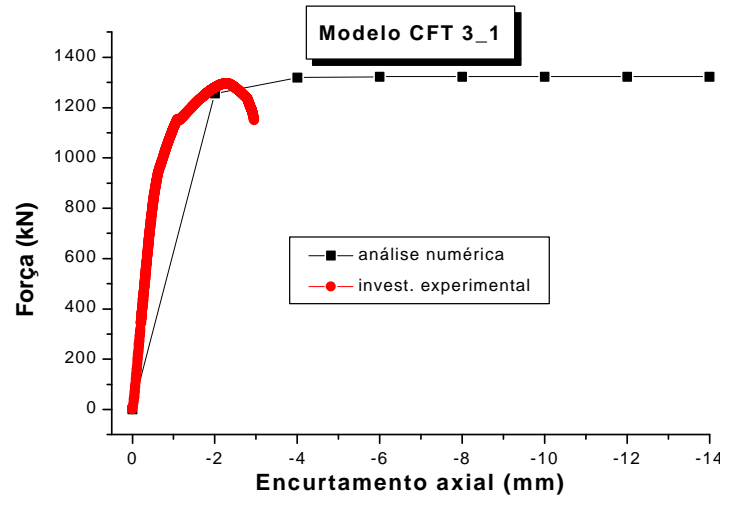

A) ForÇA X ENCURTAMENTO AXIAL MÉdIO

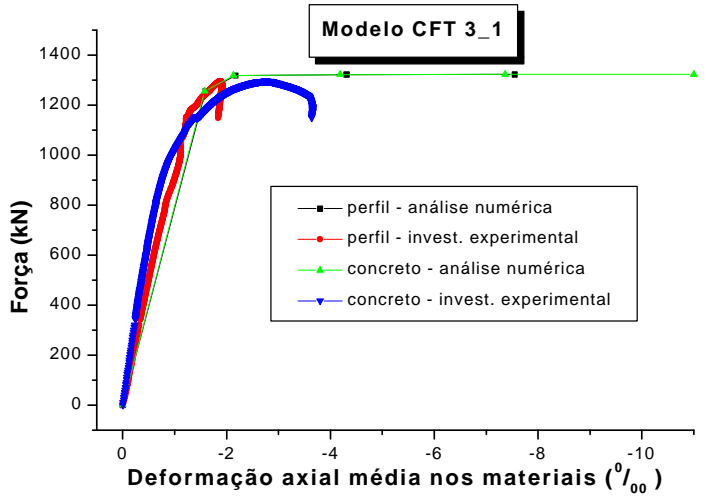

B) FORÇA X DEFORMAÇÕES AXIAIS MÉDIAS NO PERFIL TUBULAR E NO CONCRETO

FIGURA 8.5 - RESULTADO DA INVESTIGAÇÃo EXPERIMENTAL E DA ANÁLISE NUMÉRICA PARA O MODELO CFT 3_1 


\section{4) MODELO CFT 3_2}

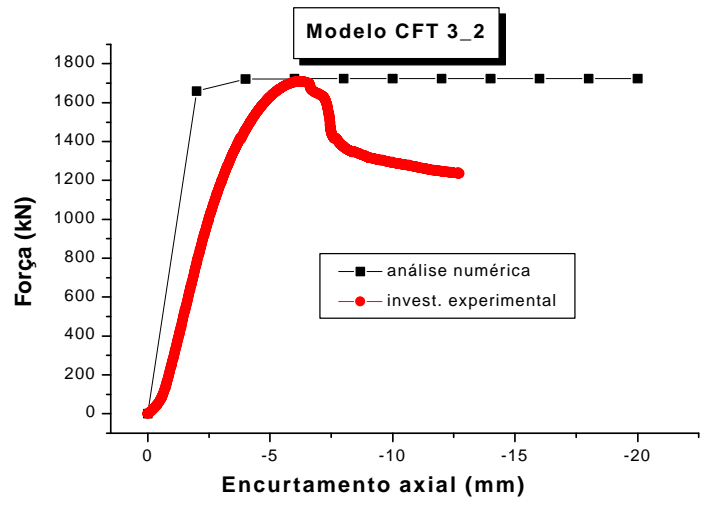

A) ForÇA X ENCURTAMENTO AXIAL MÉDIO

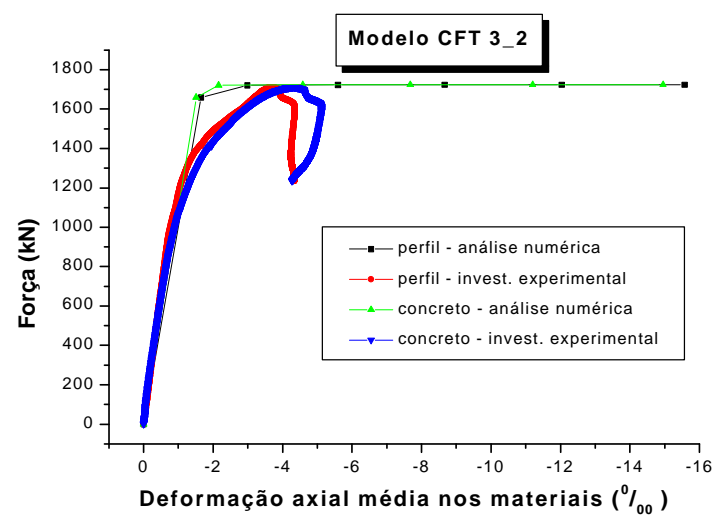

B) FORÇA X DEFORMAÇÕES AXIAIS MÉDIAS NO PERFIL TUBULAR E NO CONCRETO

FIGURA 8.6 - RESULTADO DA INVESTIGAÇÃo EXPERIMENTAL E DA ANÁLISE NUMÉRICA PARA O MODELO CFT 3_2

A observação das figuras 8.3 a 8.6 indica que:

- o modelo empregado na análise numérica consegue representar bem o comportamento das deformações até que o modelo investigado atinja a força última. A partir deste ponto, o modelo teórico não consegue representar adequadamente o comportamento real. Isto ocorre devido a limitações do programa Ansys, o qual não consegue trabalhar com o modelo constitutivo real do concreto, pois os valores do ramo descendente do seu diagrama tensão deformação são ignorados. Sendo assim, a análise numérica apresenta bons resultados até que seja atingida a força última. Deste ponto em diante, os valores das deformações axiais já não são tão representativos;

- embora o comportamento pós-pico de resistência não consiga ser representado, é importante reafirmar que, desde que não se pretenda analisar o elemento misto após ser atingida a força última, a análise numérica aqui realizada é uma forma muito interessante de prever a capacidade resistente e o comportamento dos pilares mistos axialmente comprimidos. Tal análise, conforme já comentado pode ser empregada para investigar de forma teórica, outros fatores que interferem no comportamento do pilar misto preenchido e que não foram investigados experimentalmente; 


\subsection{CONFIGURAÇõES FINAIS}

Na FIGURA 8.7 são apresentadas as configurações finais dos modelos investigados experimentalmente.
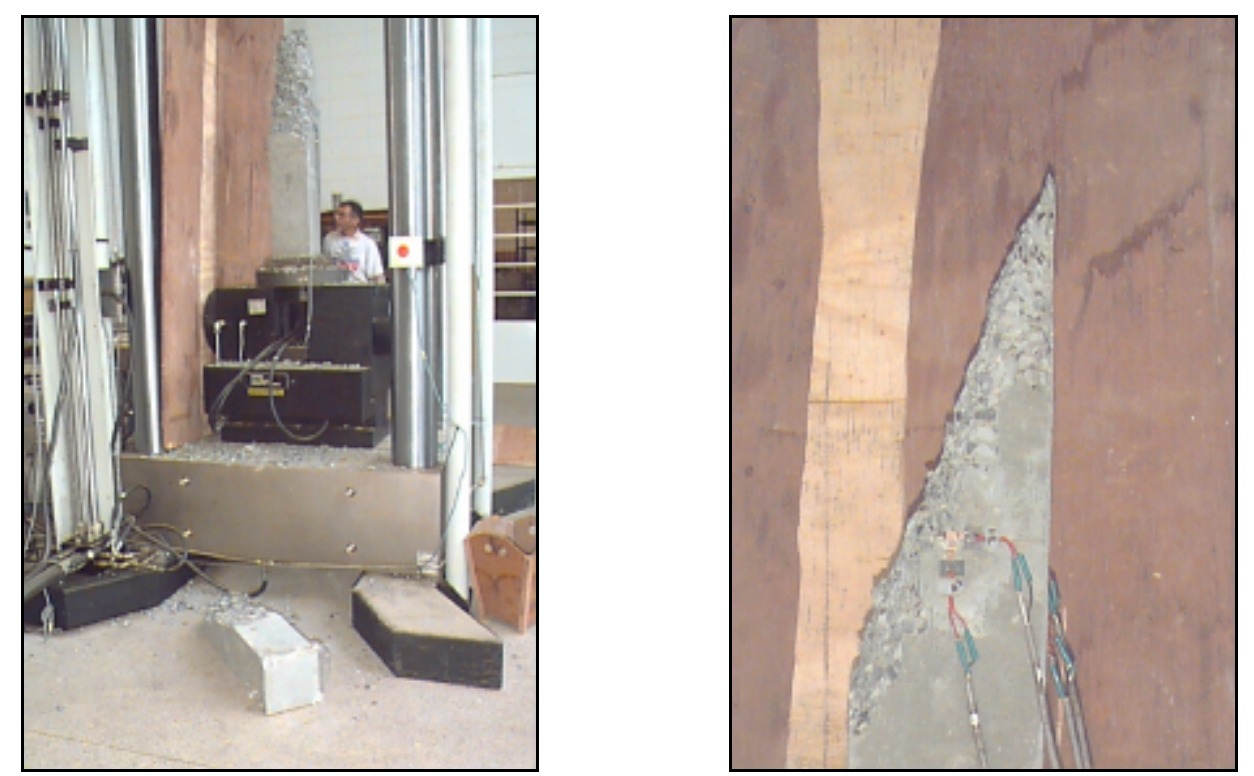

A) MODELO $\mathbf{R}$
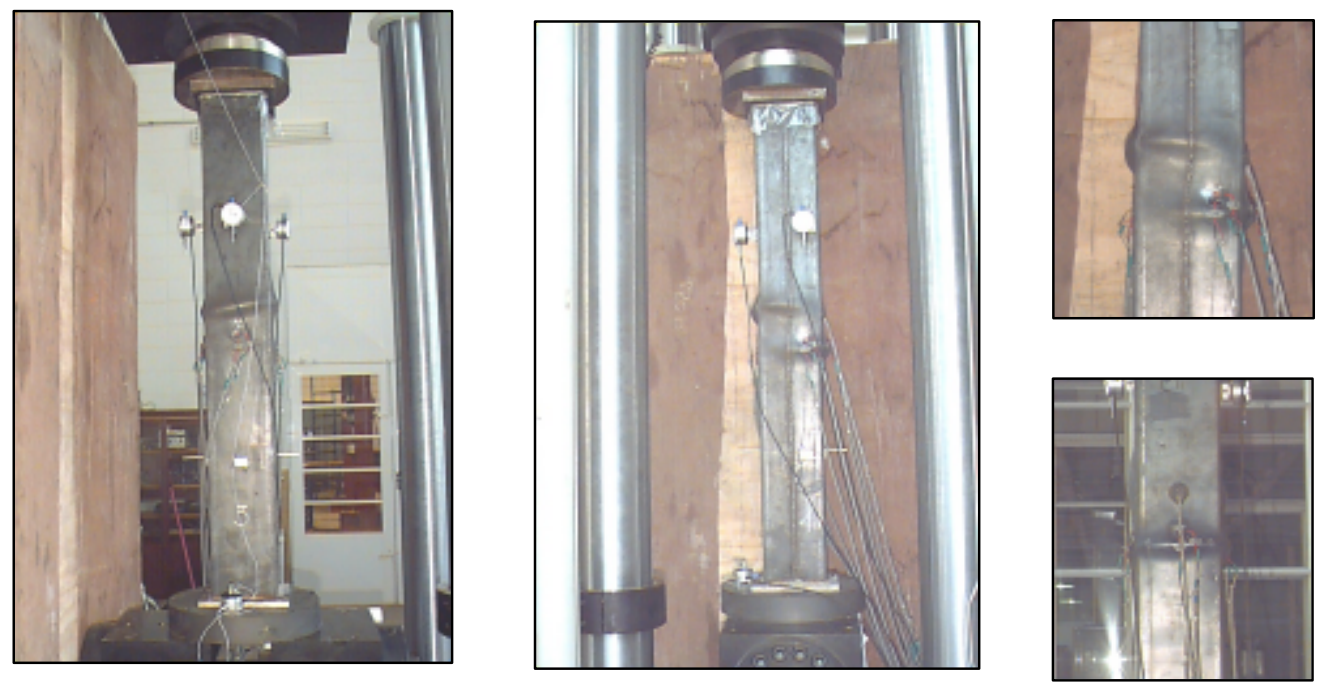

B) MODELO CFT 1_1 

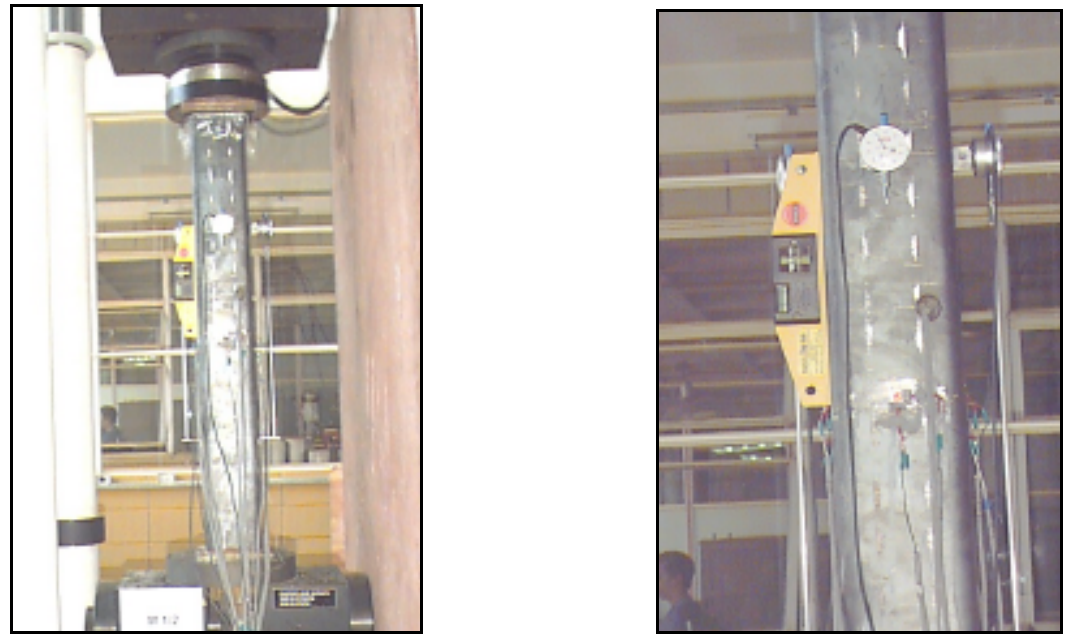

C) Modelo CFT 1_2
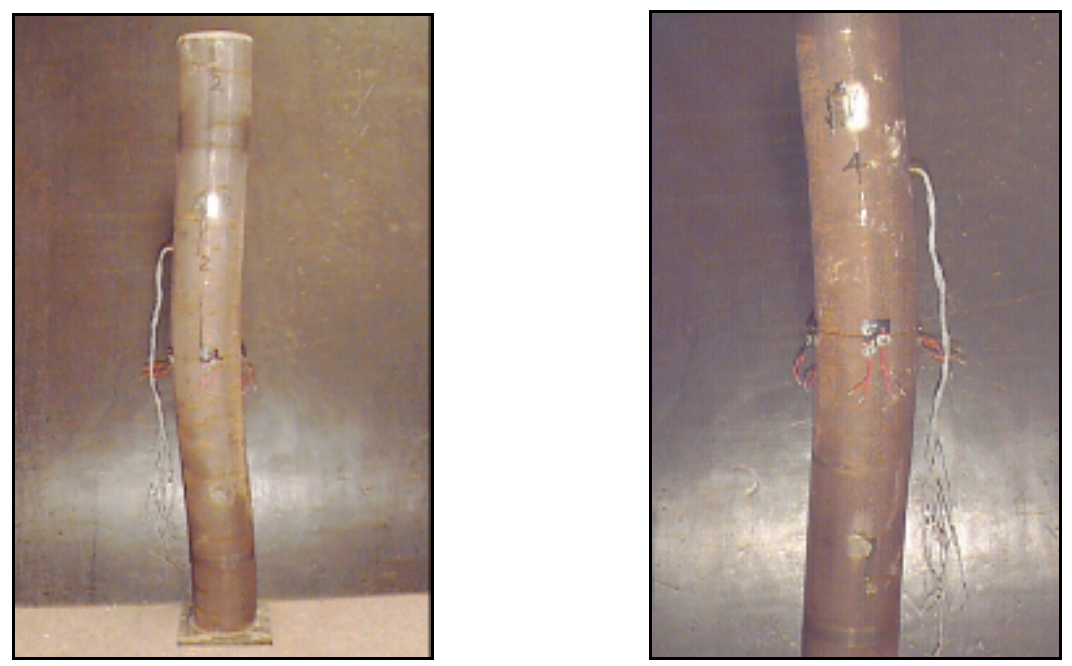

D) MOdelo CFT 2_1
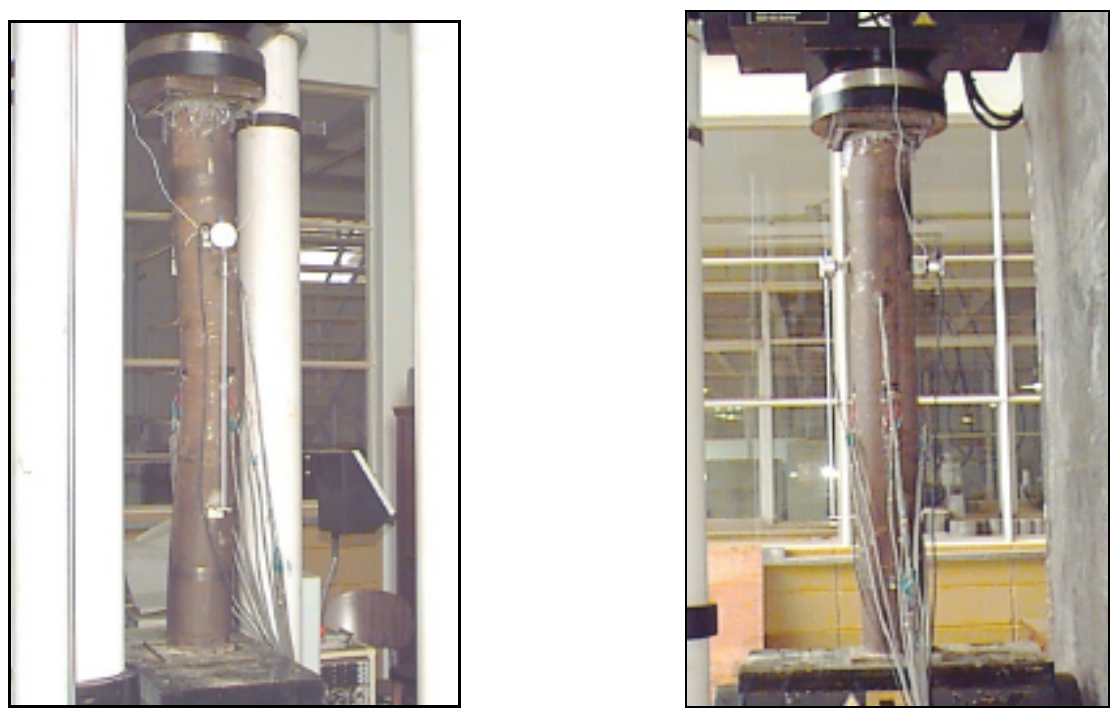

E) MOdelo CFT 2_2 

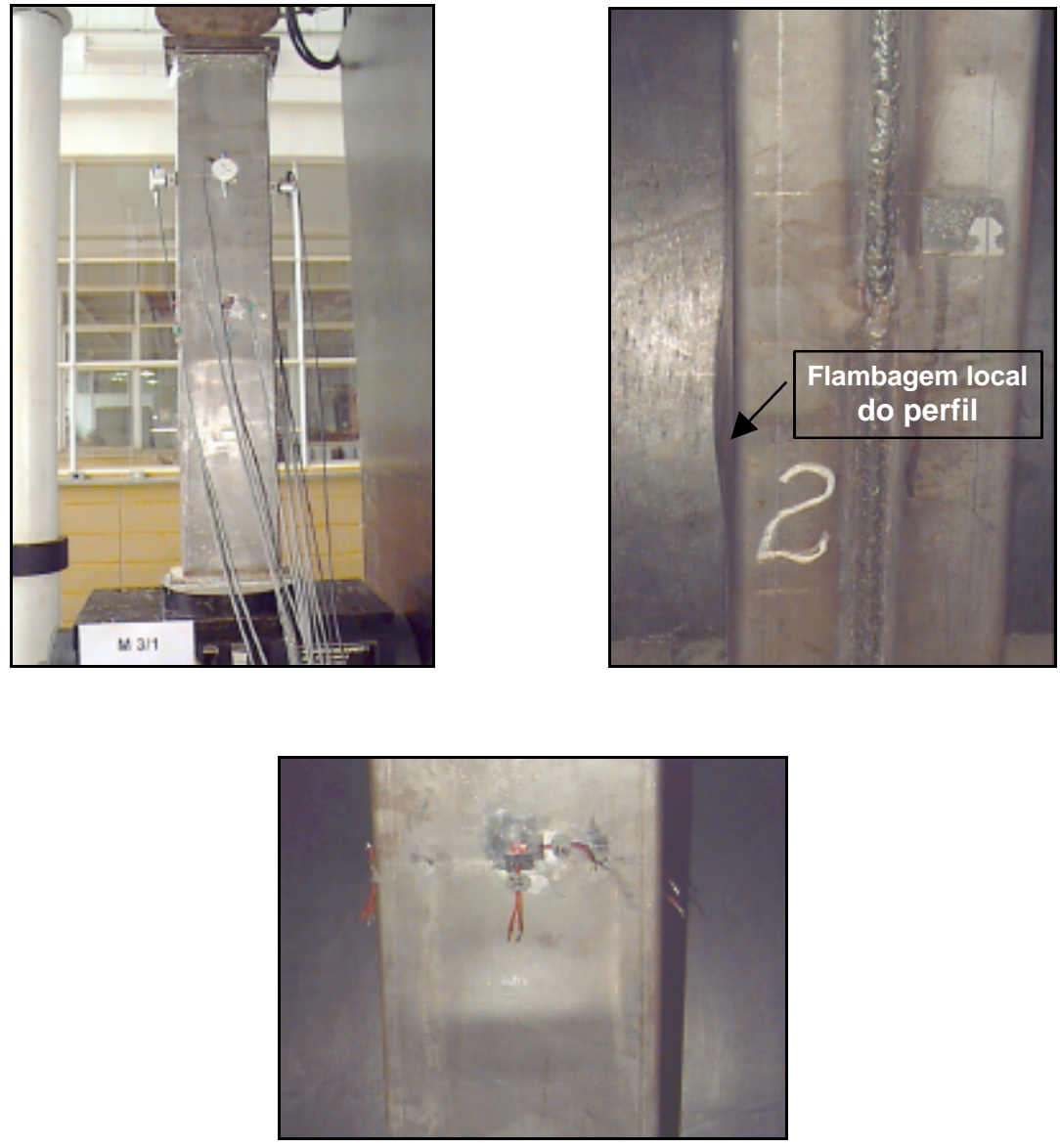

F) MODELO CFT 3_1
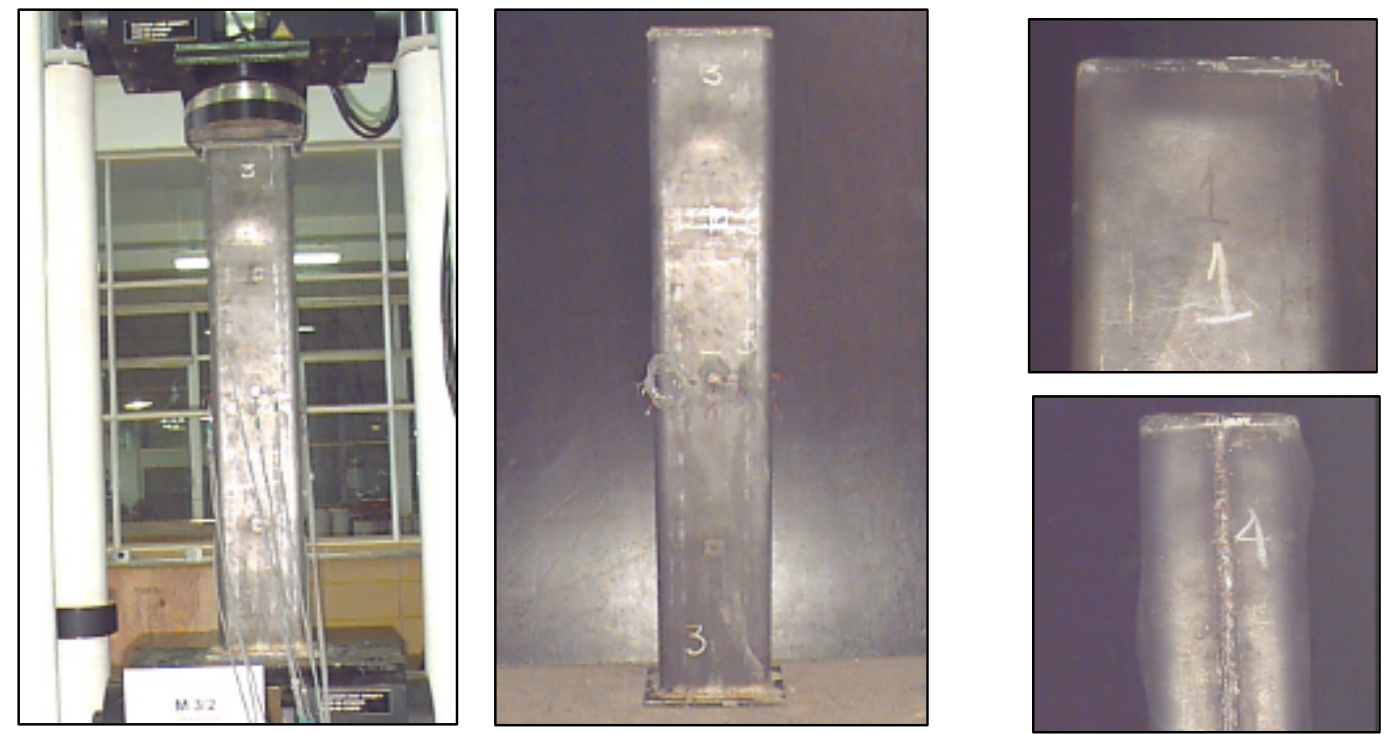

G) MODELO CFT 3_2

FIGURA 8.7 - CONFIGURAÇõES FINAIS DOS MODELOS INVESTIGADOS, SUBMETIDOS À COMPRESSÃO AXIAL 
Com exceção do modelo $R$ que foi levado de fato à ruína, os demais foram submetidos à aplicação de força até que se configurasse uma tendência de ruína.

A partir da FIGURA 8.7 e da observação do ensaio pode-se afirmar que:

- a ruína do modelo $\mathrm{R}$ ocorreu de forma brusca, com separação total entre partes do modelo, definindo-se um plano de ruína inclinado de aproximadamente $30^{\circ}$ da vertical. O nível de tensões em que ocorreu a ruína foi inferior ao esperado. Esperava-se que tal ocorresse para tensões próximas de $4,82 \mathrm{kN} / \mathrm{cm}^{2}$ - valor determinado através de ensaios em corpos-de-prova 10x20 cm - entretanto esta ocorreu para um nível de tensões igual a $3,67 \mathrm{kN} / \mathrm{cm}^{2}$. Isto leva a uma correlação modelo/corpo-de-prova igual a 0,761 diferente do valor 0,9 comumente aceito pelos pesquisadores de concreto de alta resistência;

- a ruína do modelo CFT 1_1 ocorreu por esmagamento do concreto e posterior flambagem local do perfil tubular. A flambagem local teve início após ter sido atingida a força última. Esta pode ser identificada facilmente na FIGURA 8.7B pelas ondulações presentes principalmente na região central do modelo. Já a ruína do modelo CFT 1_2 não ocorreu da forma esperada. Tudo indica que ocorreu o esmagamento do núcleo de concreto, entretanto o modelo apresentou grande inclinação vertical após o término do ensaio. Este comportamento não esperado pode ter sido provocado por um possível desaprumo do modelo, não verificado no início do ensaio. Na FIGURA 8.7C pode ser observada tal inclinação;

- $\quad$ nos modelos de seção circular - CFT 2_1 e CFT 2_2 - a ruína ocorreu por esmagamento do concreto e posterior flambagem global do modelo. Esta foi mais acentuada no modelo CFT 2_1 devido à sua menor espessura. A configuração final do modelo indica que sua base de fato estava engastada e o topo possui uma vinculação intermediária entre articulação e engaste;

- os modelos CFT 3_1 e CFT 3_2 também atingiram a ruína por esmagamento do concreto e posterior flambagem local. No modelo CFT 3_1 a ocorrência de flambagem local concentrou-se na seção média, conforme a FIGURA 8.7F. Para o modelo CFT 3_2 esta se concentrou no topo do modelo. 


\subsection{COMPORTAMENTO DOS PILARES MISTOS PREENCHIDOS}

A seguir são apresentados, na forma de gráficos, os resultados obtidos nos ensaios dos modelos mistos, submetidos à compressão axial.

\subsubsection{VARIAÇÃO DAS DEFORMAÇõES NAS FACES}

As deformações axiais e transversais foram medidas nos quatro lados dos modelos mistos, nas direções axial e transversal. Na FIGURA 8.8 são apresentados os resultados obtidos.

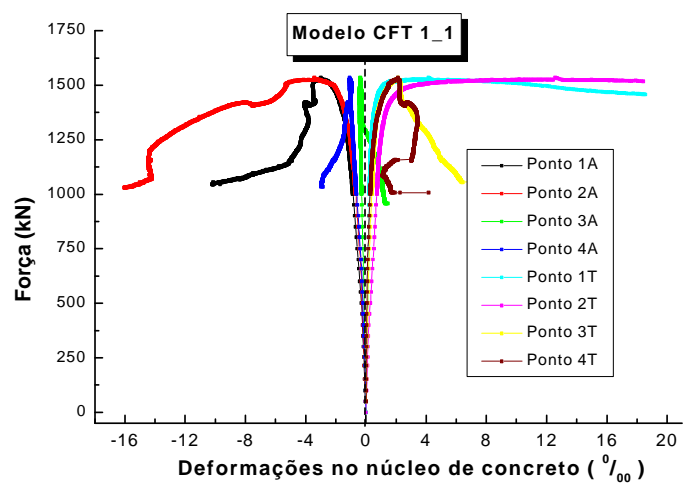

Força x Deformações no concreto do núcleo

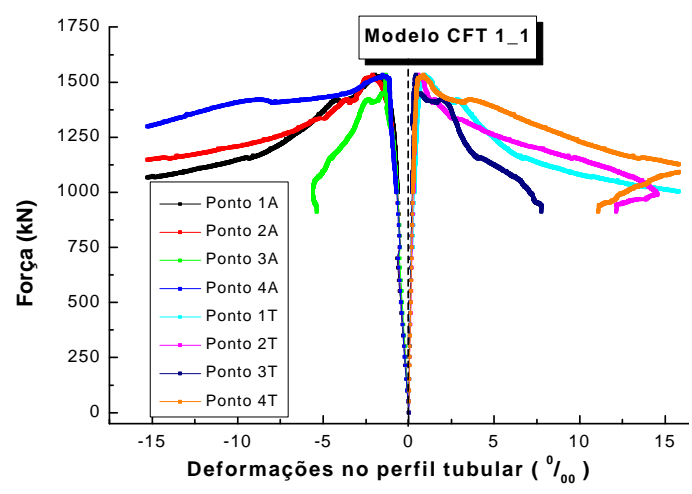

Força x Deformações no perfil tubular

a) Modelo CFT 1_1

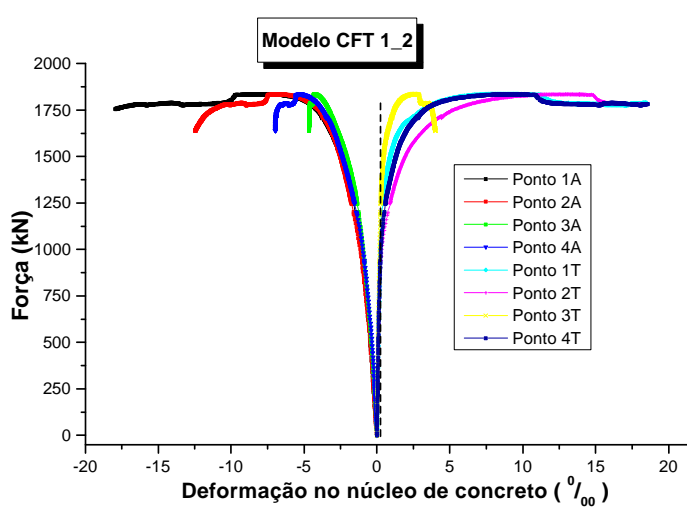

Força x Deformações no concreto do núcleo

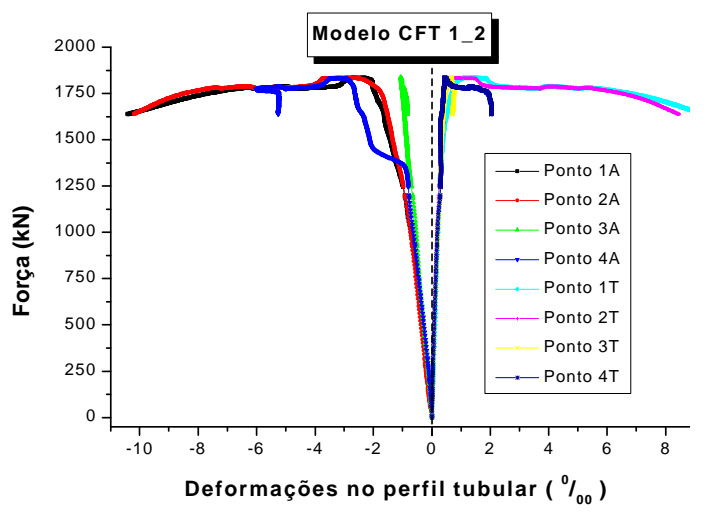

Força x Deformações no perfil tubular

b) MODELO CFT 1_2 


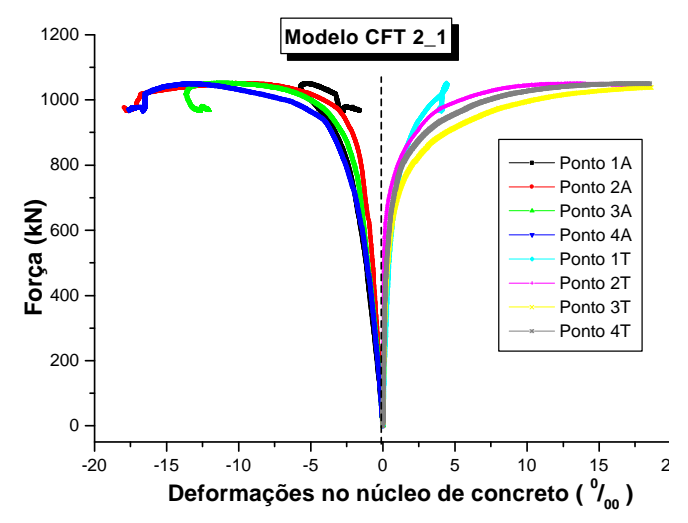

Força x Deformações no concreto do núcleo

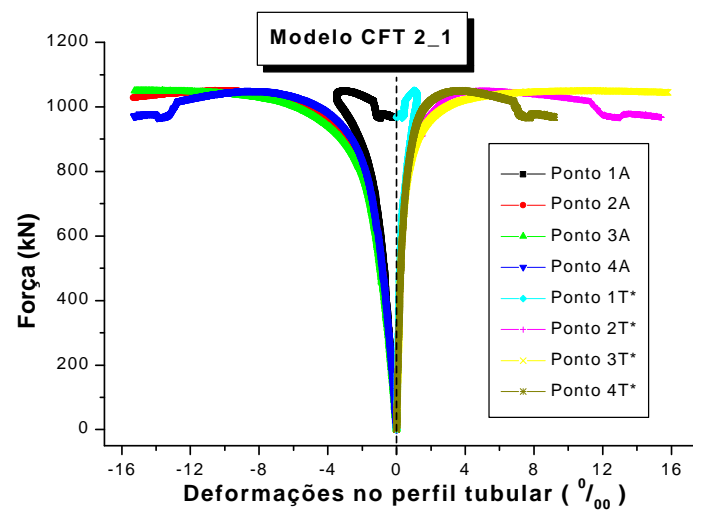

Força x Deformações no perfil tubular

c) Modelo CFT 2_1

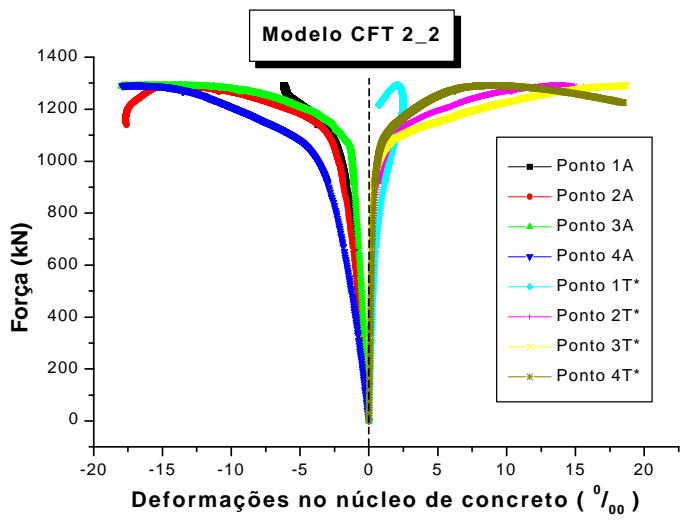

Força x Deformações no concreto do núcleo

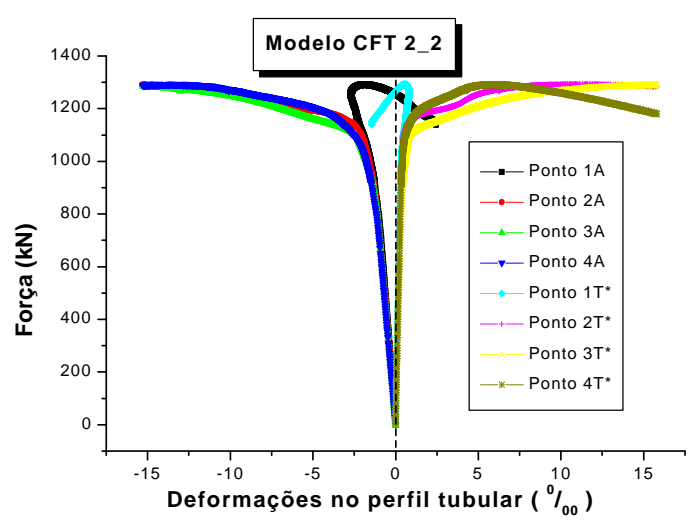

Força x Deformações no perfil tubular

d) Modelo CFT 2_2

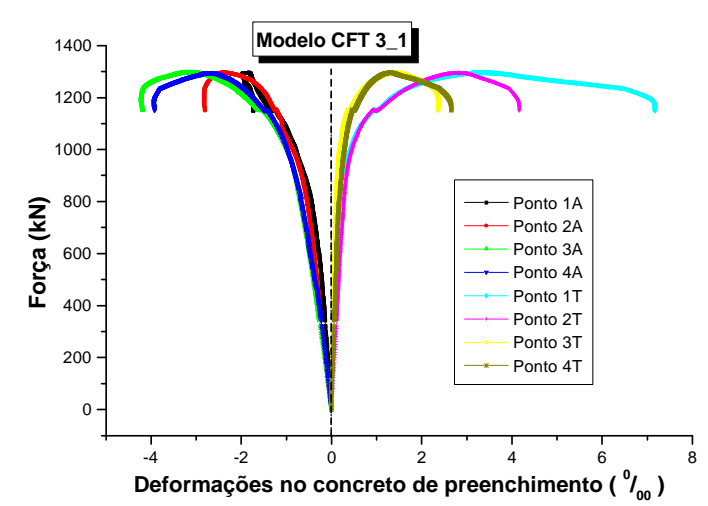

Força x Deformações no concreto do núcleo

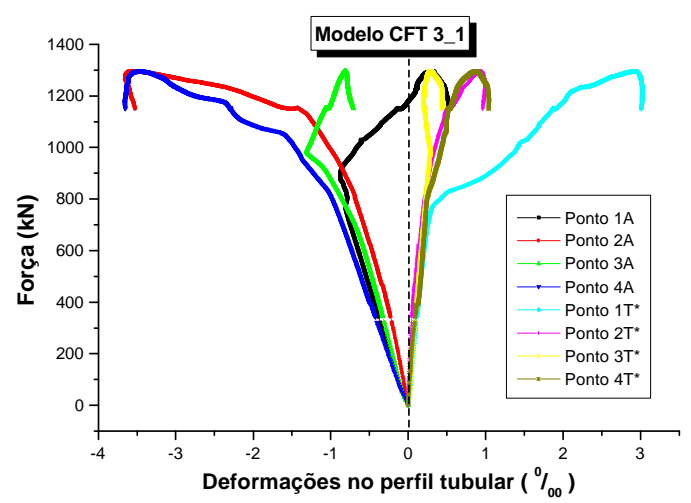

Força x Deformações no perfil tubular

e) Modelo CFT 3_1 


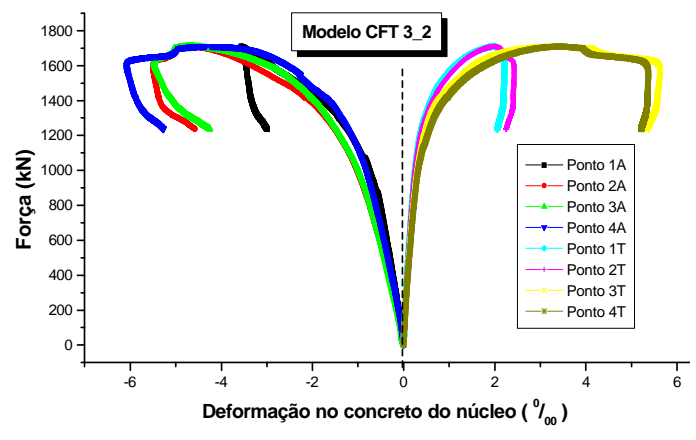

Força x Deformações no concreto do núcleo

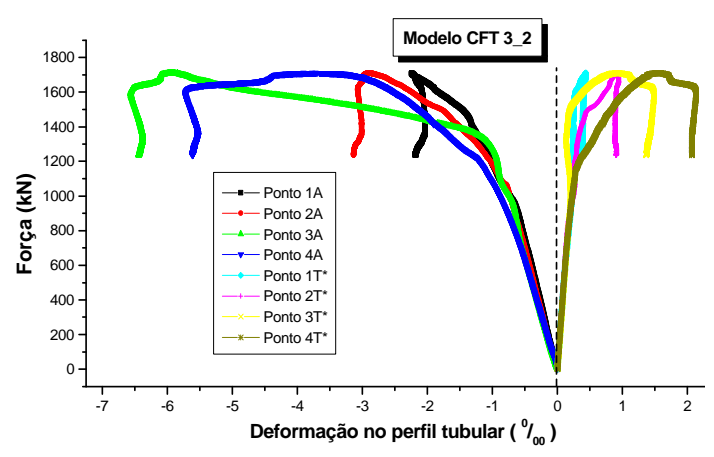

Força x Deformações no perfil tubular

\section{f) MODELO CFT 3_2}

FIGURA 8.8 - COMPORTAMENTO DAS DEFORMAÇÕES AXIAIS E TRANSVERSAIS NO CONCRETO E NO PERFIL

$\mathrm{Na}$ observação dos gráficos da FIGURA 8.8 constata-se que, embora se tivesse a pretensão de aplicar força axial e tenham sido tomados todos os cuidados possíveis para isso, tal força foi introduzida com certa excentricidade. Esta excentricidade provoca variações nas deformações axiais e transversais de uma face para outra. Entretanto, estas variações são muito pequenas e não comprometem a análise.

A instrumentação no núcleo de concreto mostrou dificuldades, tanto de execução quanto de incertezas em relação às leituras registradas. Em alguns pontos nos gráficos apresentados verifica-se a inversão do sentido das deformações. Provavelmente os extensômetros se soltaram do dispositivo em que estavam fixados, giraram e passaram a medir deformações em direções diferentes das iniciais. Em alguns pontos verifica-se também que os valores das deformações no concreto são muito grandes, indicando que ocorreu o escorregamento do extensômetro.

Apesar destas dificuldades, as deformações axiais e transversais no núcleo de concreto, até que seja atingida a força última, são confiáveis e coerentes. A partir de então, pode ocorrer o esmagamento do concreto na região instrumentada e o comprometimento das leituras. 


\subsubsection{COMPORTAMENTO CONJUNTO DOS MATERIAIS}

Verificar se os materiais aço e concreto comportam-se conjuntamente, ou seja, se ocorre aderência entre eles é possível através da FIGURA 8.9. Nela podese concluir que de fato, até atingir a força última, aço e concreto trabalham juntos e apresentam por isso, o mesmo nível de deformações. Após atingir a força última, passa a haver a separação dos materiais, pois a aderência vai sendo destruída pelos fenômenos de esmagamento do concreto e flambagem local do perfil tubular.

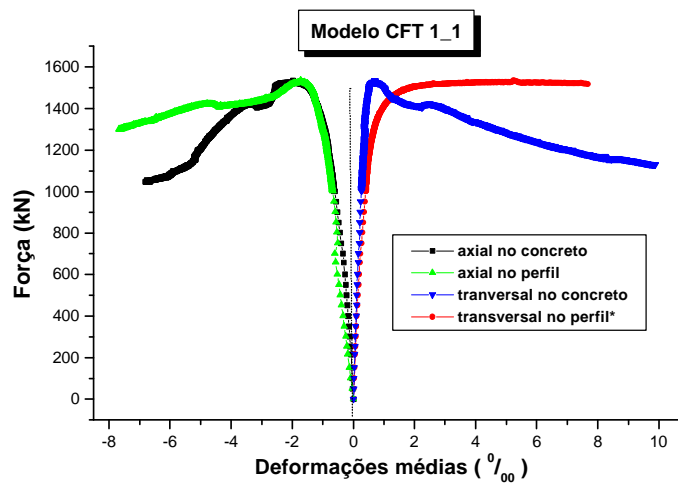

a) Modelo CFT 1_1

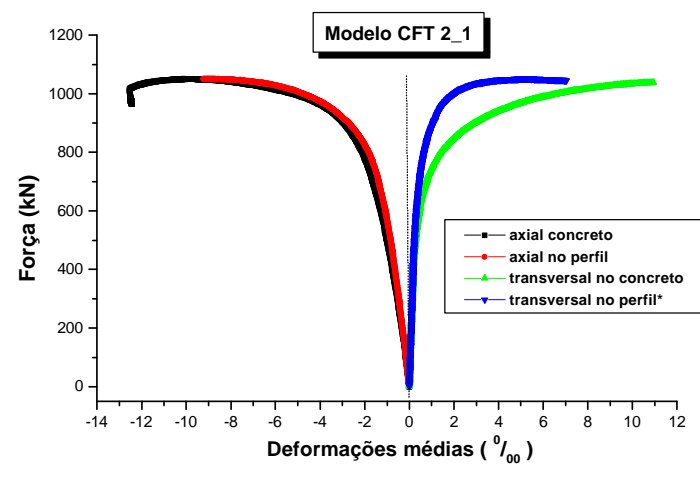

c) Modelo CFT 2_1

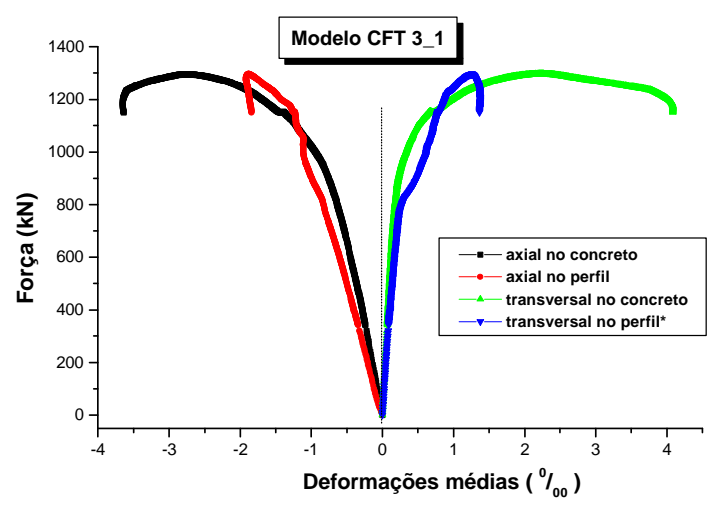

e) Modelo CFT 3_1

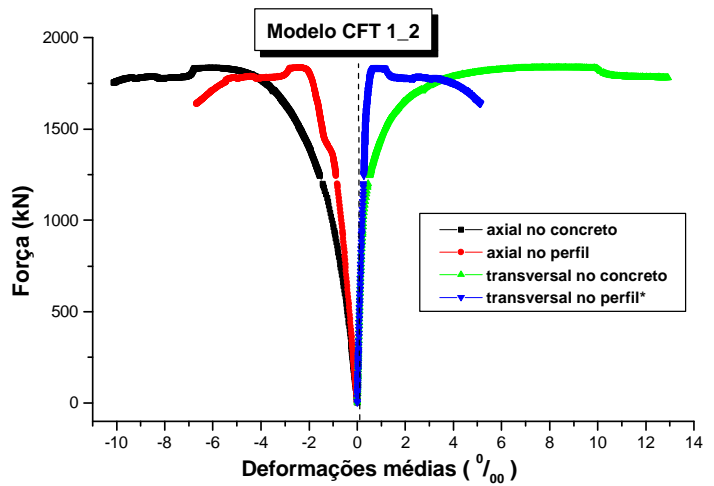

b) Modelo CFT 1_2

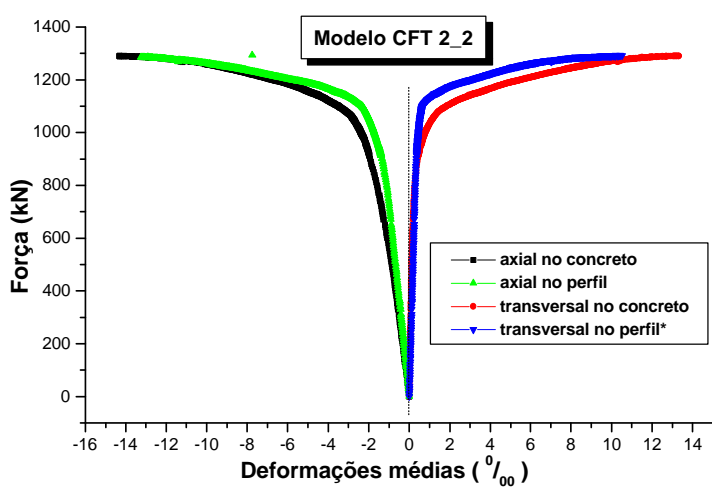

d) Modelo CFT 2_2

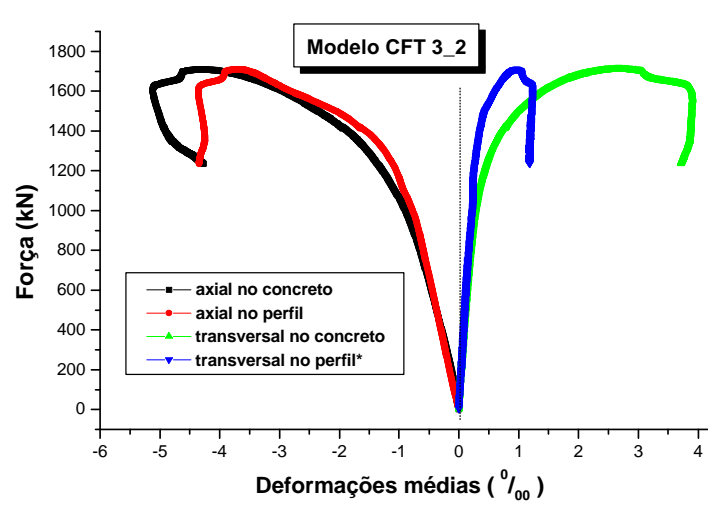

f) Modelo CFT 3_2

FIGURA 8.9 - COMPORTAMENTO CONJUNTO DOS MATERIAIS AÇO E CONCRETO 


\subsubsection{COMPORTAMENTO DOS ELEMENTOS ISOLADOS E ASSOCIADOS}

O comportamento isolado e conjunto do concreto e do perfil tubular pode ser analisado a partir das figuras a seguir. A fim de avaliar qualitativamente tal comportamento, são apresentadas as variações de deformações axiais para aço e concreto quando isolados (elemento de referência e full test respectivamente) e associados na forma de pilares preenchidos.

As deformações médias aqui mencionadas representam a média das deformações axiais registradas pelos extensômetros colocados no perfil e no concreto.

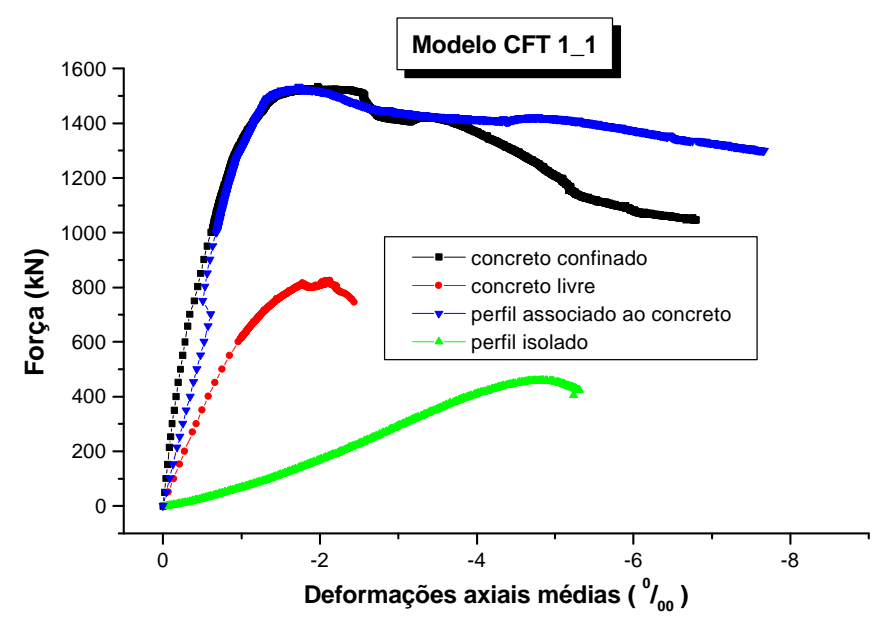

FIGURA 8.10 - COMPORTAMENTO DOS ELEMENTOS ISOLADOS E ASSOCIADOS FORMANDO O MODELO CFT 1_1

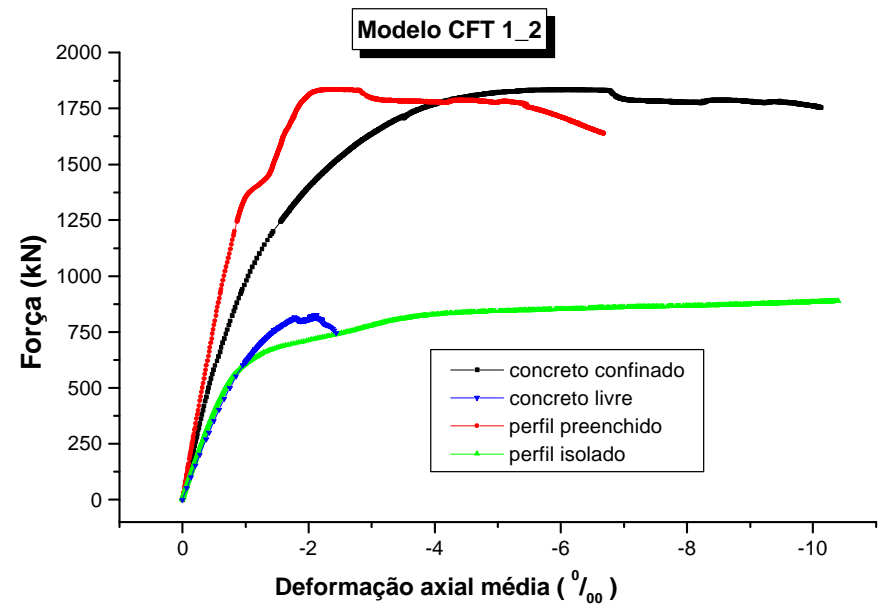

FIGURA 8.11 - COMPORTAMENTO DOS ELEMENTOS ISOLADOS E ASSOCIADOS FORMANDO O MODELO CFT 1_2 


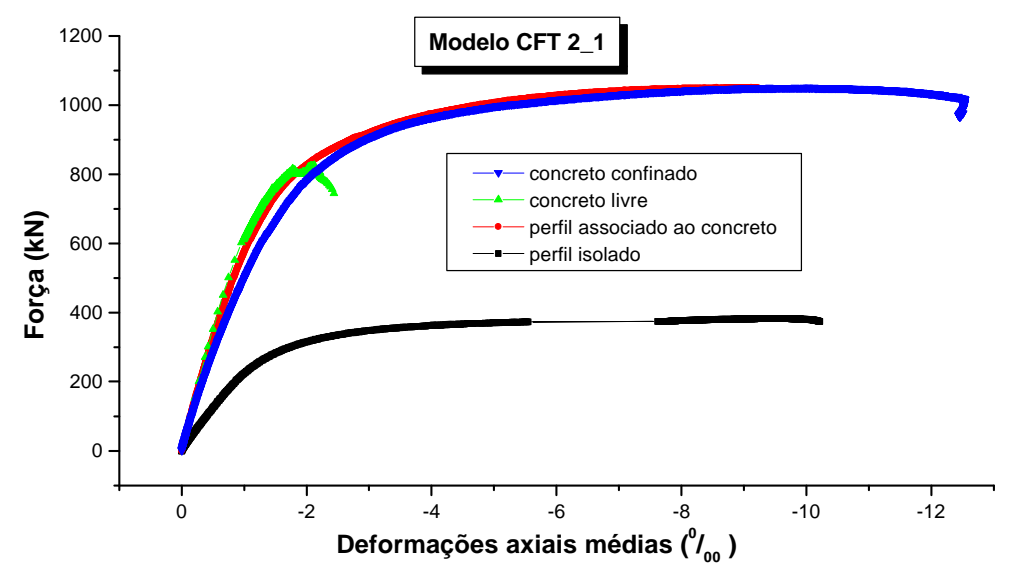

FIGURA 8.12 - COMPORTAMENTO DOS ELEMENTOS ISOLADOS E ASSOCIADOS FORMANDO O MODELO CFT 2_1

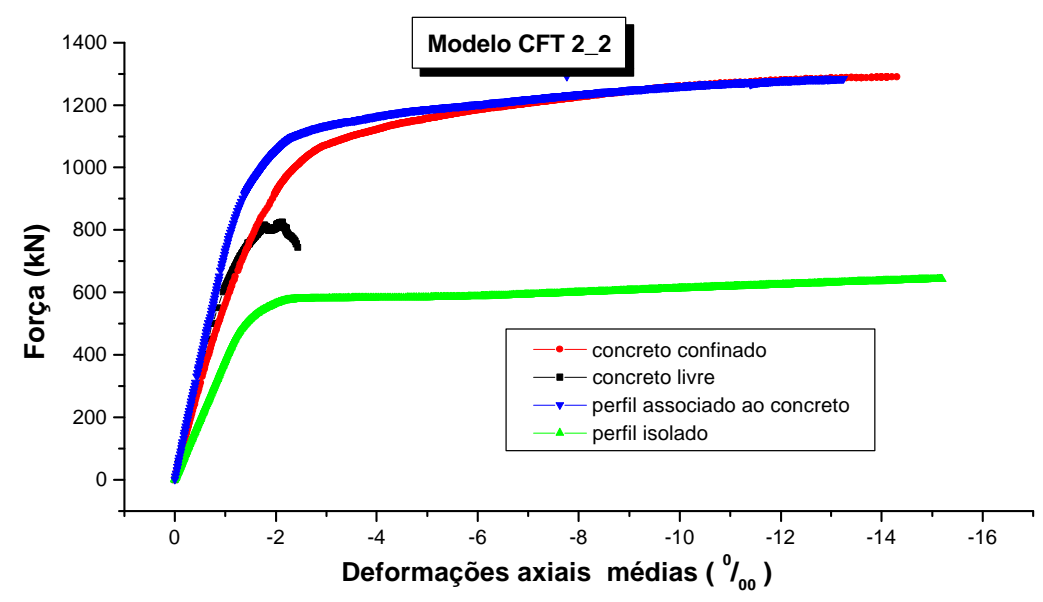

FIGURA 8.13 - COMPORTAMENTO DOS ELEMENTOS ISOLADOS E ASSOCIADOS FORMANDO O MODELO CFT 2_2

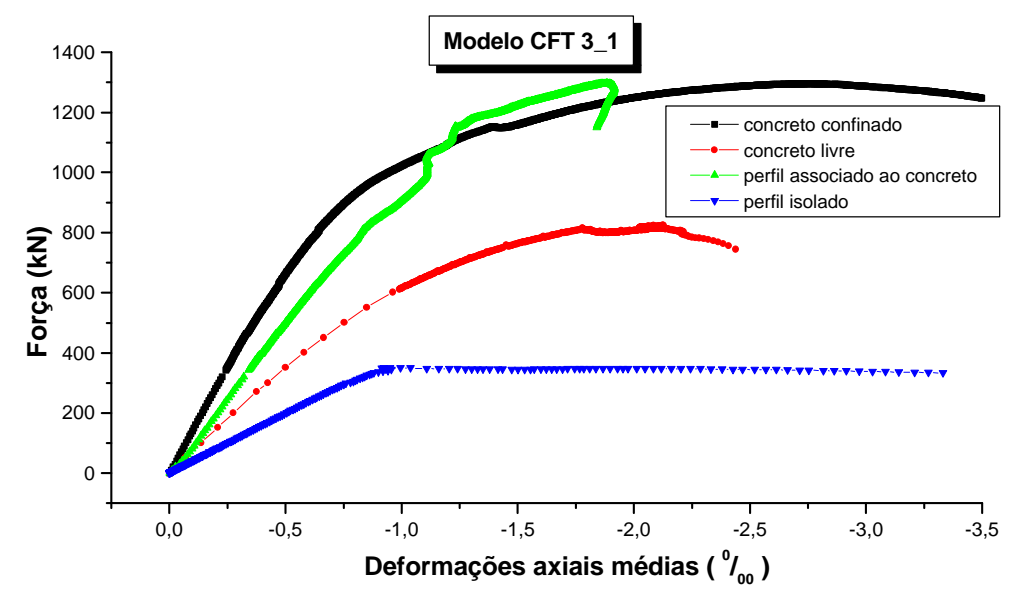

FIGURA 8.14 - COMPORTAMENTO DOS ELEMENTOS ISOLADOS E ASSOCIADOS FORMANDO O MODELO CFT 3_1 


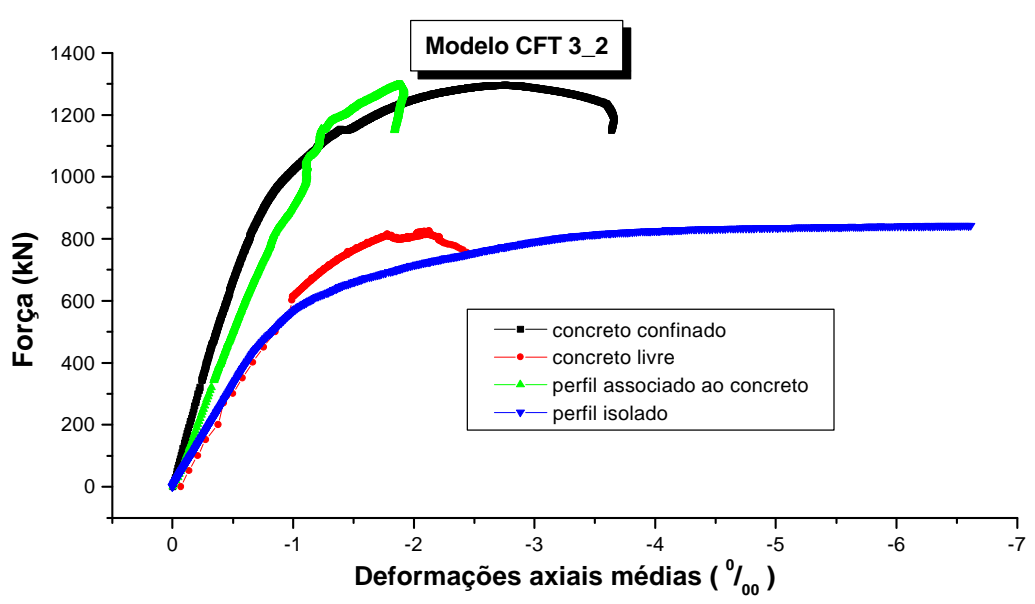

FIGURA 8.15 - COMPORTAMENTO DOS ELEMENTOS ISOLADOS E ASSOCIADOS FORMANDO O MODELO CFT 3_2

O comportamento frágil do concreto de alta resistência constatado no ensaio do modelo $\mathrm{R}$ sofre melhoras substanciais quando revestido por um perfil tubular metálico. Este, conforme os dados apresentados nas figuras 8.10 a 8.15, apresenta comportamento de material dúctil. A associação de aço e concreto na forma de pilares mistos preenchidos confere ao concreto de alta resistência certa capacidade de sofrer deformações plásticas. Estes resultados vêm confirmar uma das vantagens destacadas por diversos pesquisadores: a associação aço-concreto na forma de pilares mistos preenchidos melhora o comportamento isolado dos materiais, aumentando a resistência dos mesmos.

Em todos os modelos mistos investigados esta melhoria de comportamento foi constatada, tornando-se mais acentuada nos pilares de seção circular, que apresentam comportamento muito próximo do elasto-plástico perfeito. Nas seções quadradas o comportamento também tende ao elasto-plástico perfeito, porém a partir da força última o concreto passa a apresentar perdas de resistência, ou seja, trata-se de comportamento elasto-plástico com "encruamento". Nas seções retangulares a partir da força última verifica-se um decréscimo acentuado da resistência do concreto, indicando a fragilidade do material.

Este comportamento diferenciado entre os modelos de seção circular, quadrada e retangular pode ser atribuído às diferentes distribuições de tensões de confinamento para as diferentes formas de seções transversais estudadas. 


\subsubsection{INFLUÊNCIA DA ESPESSURA E DA FORMA DA SEÇÃO TRANSVERSAL NO COMPORTAMENTO DA SEÇÃO MISTA PREENCHIDA}

A influência de fatores como a forma e a espessura da seção transversal pode ser avaliada através das figuras a seguir. Nelas a deformação média no modelo corresponde à deformação calculada a partir das leituras de deslocamento nos transdutores. Estes dispositivos medem o deslocamento numa extensão de $570 \mathrm{~mm}$ e para se calcular a deformação média nesta região basta fazer:

$$
\varepsilon=\frac{\delta}{\Delta L}=\frac{\delta}{570}
$$

A média das quatro leituras de $\delta$, aplicada à equação 8.2 foi denominada "deformação média".

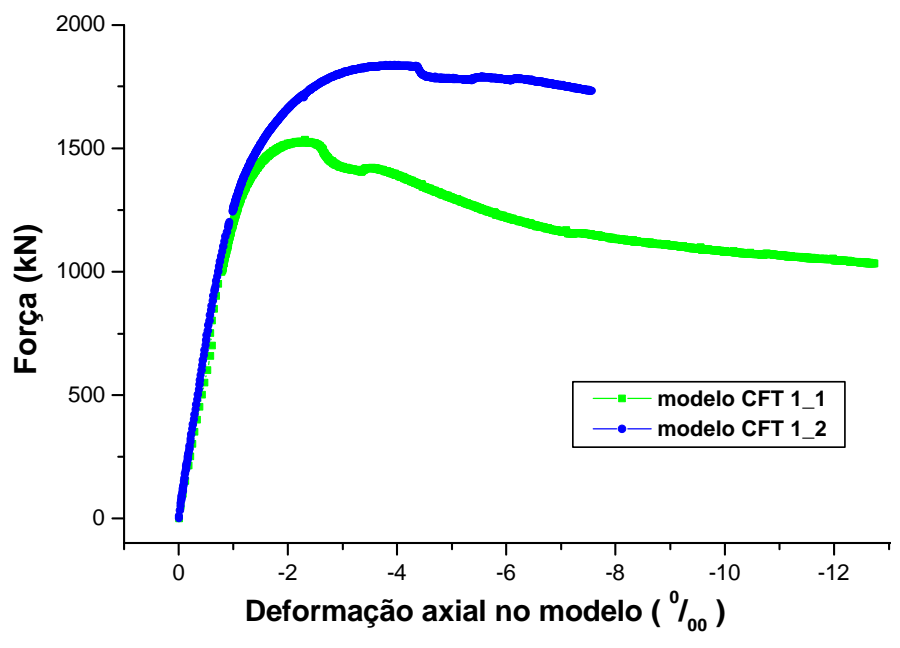

FIGURA 8.16 - SEÇõES QUADRADAS CFT 1_1 E CFT 1_2

Aparentemente, o comportamento das seções quadradas CFT 1_1 e CFT 1_2 é diferente. A FIGURA 8.16 mostra que o modelo CFT 1_1 apresenta, após atingir a capacidade resistente, uma região de encruamento, seguida por um "patamar de escoamento". Já para o modelo CFT 1_2 após atingir a capacidade resistente, ocorre o "patamar de escoamento" sem perda considerável de resistência, caracterizando o comportamento de material elasto-plástico perfeito.

O comportamento do modelo CFT 1_2 é semelhante ao de chapas de aço ensaiadas à tração. 


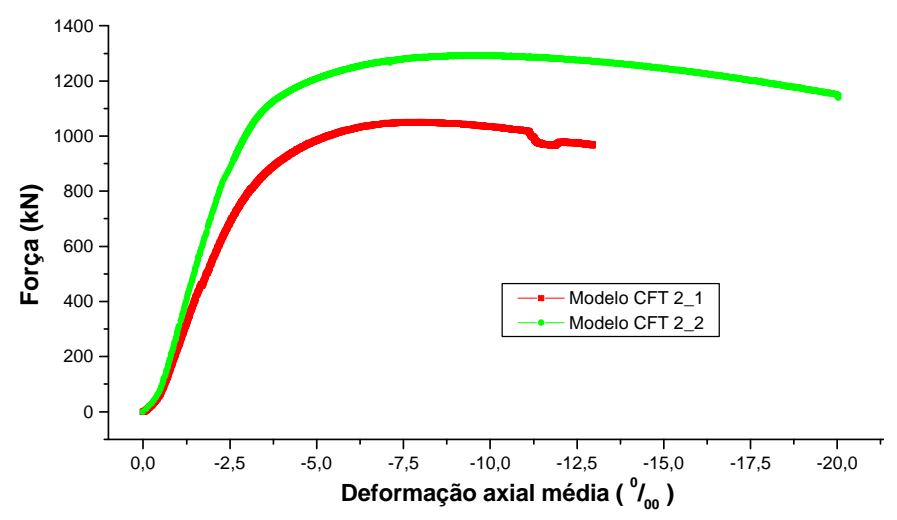

FIGURA 8.17 - SEÇõES CIRCULARES CFT 2_1 E CFT 2_2

Para os modelos CFT 2_1 e CFT 2_2, ambos de seção circular constata-se que a espessura do perfil tubular não influencia o comportamento do modelo à compressão axial. Há um ganho de resistência e este é função do aumento da área de aço e conseqüente aumento da parcela de resistência referente a ele $\left(A_{s} \cdot f_{y}\right)$. Os dois modelos apresentam comportamento elasto-plástico perfeito.

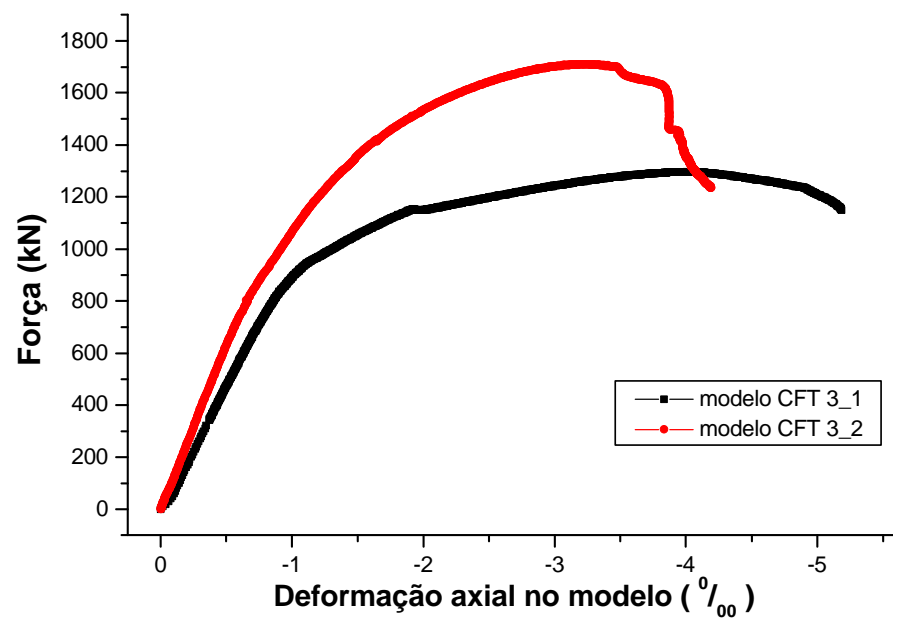

FIGURA 8.18 - SEÇõES RETANGULARES CFT 3_1 E CFT 3_2

O comportamento do modelo CFT 3_1 difere do comportamento do modelo CFT 3_2. No primeiro tem-se um comportamento próximo do elasto-plástico perfeito, verificando-se início de perda de resistência quando o perfil já sofreu flambagem local. Para o modelo CFT 3_2, logo após atingir a força última, há uma queda brusca de resistência. 


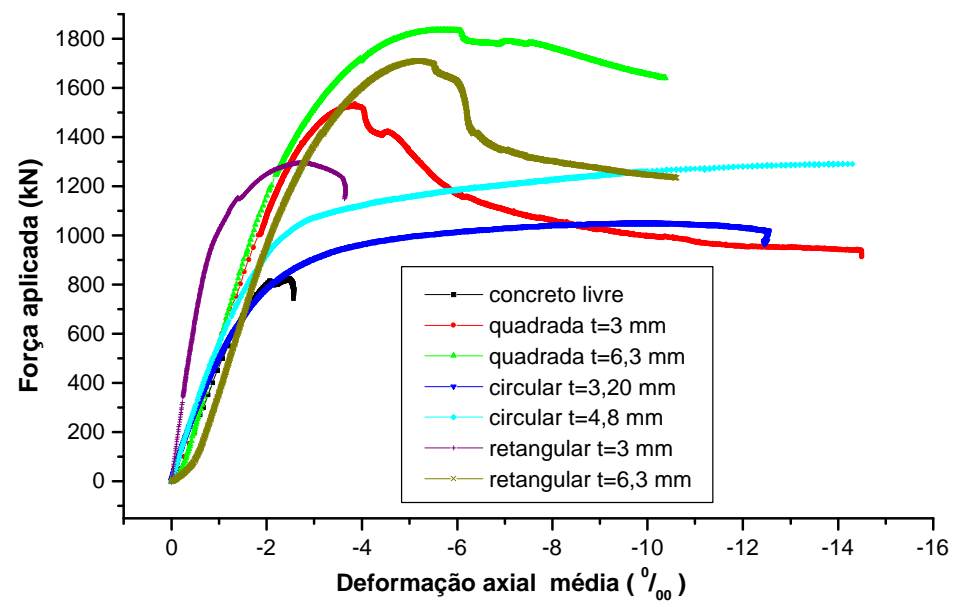

FIGURA 8.19 -INFLUÊNCIA DA FORMA E DA ESPESSURA NO COMPORTAMENTO DO MODELO MISTO SUBMETIDO À COMPRESSÃO AXIAL

Na FIGURA 8.19 pode ser observada a diferença de comportamento existente entre as diferentes formas de seção transversal. As seções circulares têm comportamento elasto-plástico perfeito enquanto que as seções quadradas e retangulares não apresentaram um comportamento padrão, pois este variou em função da variação da espessura do perfil tubular.

Não se pode afirmar que o comportamento dos modelos investigados seja o comportamento típico dos pilares mistos preenchidos, pois foi analisado apenas um modelo de cada tipo.

Embora de exemplar único, o comportamento dos modelos de seção circular pode ser considerado típico porque se assemelha muito a alguns resultados encontrados por outros pesquisadores (TOMII et al (1977), por exemplo). O mesmo ocorre para os modelos CFT 1_1 e CFT 1_2. Quanto aos pilares de seção retangular, não foram encontrados resultados anteriores que pudessem ser comparados.

\subsubsection{AvALIAÇÃo DA DUCTILIDADE}

Com base no exposto no capítulo 05, a avaliação da ductilidade dos pilares mistos preenchidos partiu do gráfico $\mathrm{F} \times \delta$, de onde foi calculada a área sob esta curva e aplicados os critérios adaptados da norma japonesa JSCE-SF5 (1984) e de UY (1998a). 
Os resultados obtidos aplicando os critérios citados são apresentados na TABELA 8.4, partindo das expressões 8.3 e 8.4:

$$
I=\frac{d_{u}}{d_{y}}
$$

obs.: $d_{u}$ e $d_{y}$ podem ser observados na pg. 73 .

$$
\begin{aligned}
& \delta_{\mathrm{tc}}=0,0075 \cdot \frac{\ell}{2}=0,0075 \cdot 600= 4,5 \mathrm{~mm} \\
& \sigma_{\mathrm{c}}=\frac{\tau_{\mathrm{c}}}{\mathrm{A}_{\mathrm{t}} \cdot \delta_{\mathrm{tc}}}
\end{aligned}
$$

TABELA 8.4 - Índices de Ductilidade dos pilares mistos preenchidos

\begin{tabular}{|c|c|c|c|c|c|}
\cline { 2 - 6 } \multicolumn{1}{c|}{} & \multicolumn{3}{c|}{ UY (1998a) } & \multicolumn{2}{c|}{ JSCE-SF5 } \\
\hline Modelo & $\mathbf{d}_{\mathrm{y}}$ (mm) & $\mathbf{d}_{\mathrm{u}}$ (mm) & I & $\tau_{\mathrm{c}}(\mathbf{k N} / \mathbf{m m})$ & $\sigma_{\mathrm{c}}\left(\mathbf{k N} / \mathbf{m m}^{2}\right)$ \\
\hline R 1_1 & 0,52 & 1,02 & 1,96 & 773,52 & 0,00764 \\
\hline CFT 1_1 & 0,65 & 1,32 & 2,03 & 5567,68 & 0,0550 \\
\hline CFT 1_2 & 0,52 & 2,21 & 4,25 & 6889,10 & 0,0681 \\
\hline CFT 2_1 & 3,06 & 9,73 & 3,18 & 3951,52 & 0,0693 \\
\hline CFT 2_2 & 3,03 & 11,20 & 3,69 & 4852,41 & 0,0851 \\
\hline CFT 3_1 & 0,60 & 1,48 & 2,47 & 3116,78 & 0,0345 \\
\hline CFT 3_2 & 0,41 & 1,85 & 4,52 & 3110,71 & 0,0346 \\
\hline
\end{tabular}

A partir dos índices de ductilidade encontrados constatou-se que:

- as adaptações feitas no modelo proposto por UY (1998a) possibilitaram uma avaliação razoável da ductilidade. $O$ índice de ductilidade aumenta à medida que a área de aço aumenta. Analisando os índices dos modelos CFT 1_1 e CFT 1_2, verifica-se que ao duplicar a área de aço ocorre o mesmo com tal índice. Isto também ocorre para os modelos CFT 3_1 e CFT 3_2. Em contrapartida, com os modelos CFT 2_1 e CFT 2_2, onde a área de aço não aumenta nesta proporção, o acréscimo no índice de ductilidade também é menor;

- enquanto analisamos apenas os modelos mistos os resultados de índice de ductilidade apresentam coerência. Quando o índice de ductilidade do modelo $\mathrm{R}$ é comparado com os demais, se constata que um elemento frágil 
apresenta I muito próximo do obtido para o modelo CFT 1_1, cuja ductilidade pode se comprovada através da FIGURA 8.20. Assim, conclui-se que este critério não deve ser aplicado a elementos que não sejam mistos;
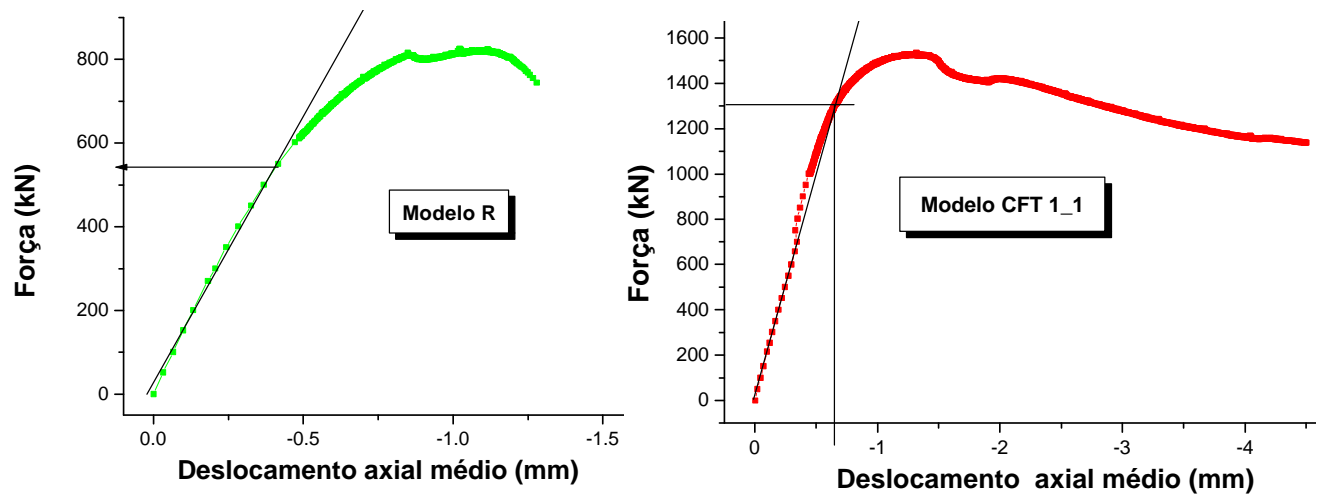

FIGURA 8.20 - AVALIAÇÃo DA DUCTILIDADE PARA O MODELO CFT 1_1

- quanto aos índices de ductilidade calculados a partir de adaptações da norma japonesa, os resultados não apresentam muita coerência. Apenas para os modelos CFT 2_1 e CFT 2_2 se encontra um aumento significativo de I; para os demais as variações são insignificantes. Estes resultados mostram que é preciso desenvolver um critério específico para avaliar a ductilidade dos pilares mistos preenchidos. Aplicar os critérios da norma japonesa, implica em calcular a área do diagrama Força $x$ Deslocamento axial até o ponto em que tal deslocamento é igual a 0,75\% $\ell / 2$. Entretanto, o aço confere ao pilar misto preenchido a característica de sofrer deslocamentos superiores aos verificados para elementos em concreto armado. Desta forma, ao ser atingido o deslocamento pré-fixado, nem sempre o modelo misto atingiu a região pós-pico onde se verifica o patamar de escoamento e ao qual corresponderia um grande valor de $\tau_{c}$ e conseqüente aumento de $\sigma_{\mathrm{c}}$.

\subsubsection{A QUESTÃO DO CONFINAMENTO}

$O$ efeito de confinamento proporcionado pelo perfil tubular contribui para melhorar o comportamento frágil que o concreto de alta resistência apresenta quando material isolado. Este ganho de ductilidade, resultante do efeito de confinamento pode 
ser constatado, em maior ou menor grau, em todos os modelos mistos investigados.

Verificou-se que esta melhoria é função da forma da seção transversal e da espessura do perfil tubular.

Na FIGURA 8.21 são mostradas as deformações axiais e transversais para os componentes da seção mista.
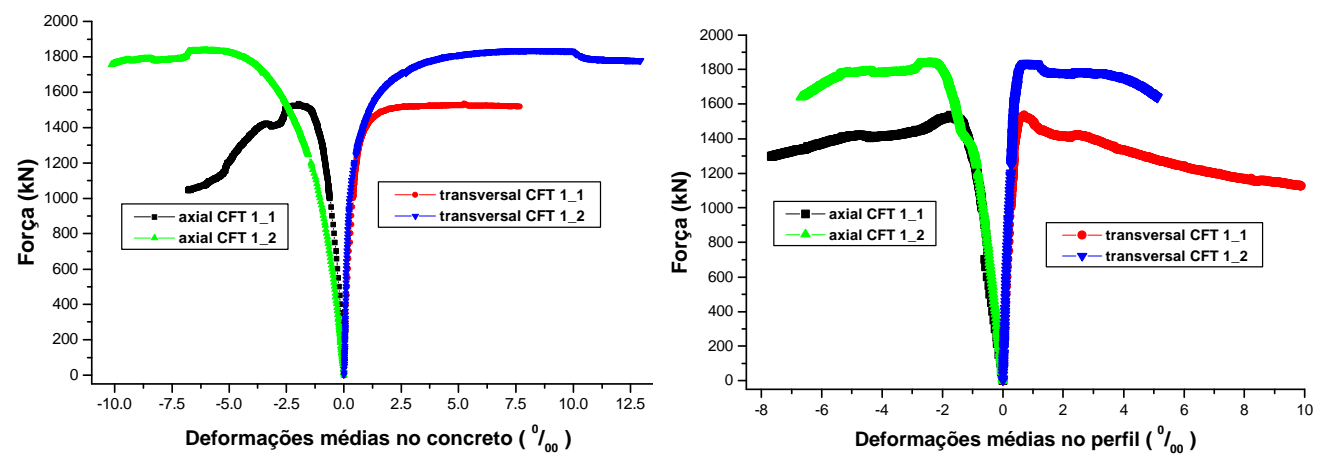

a) Modelos CFT 1_1 e CFT 1_2
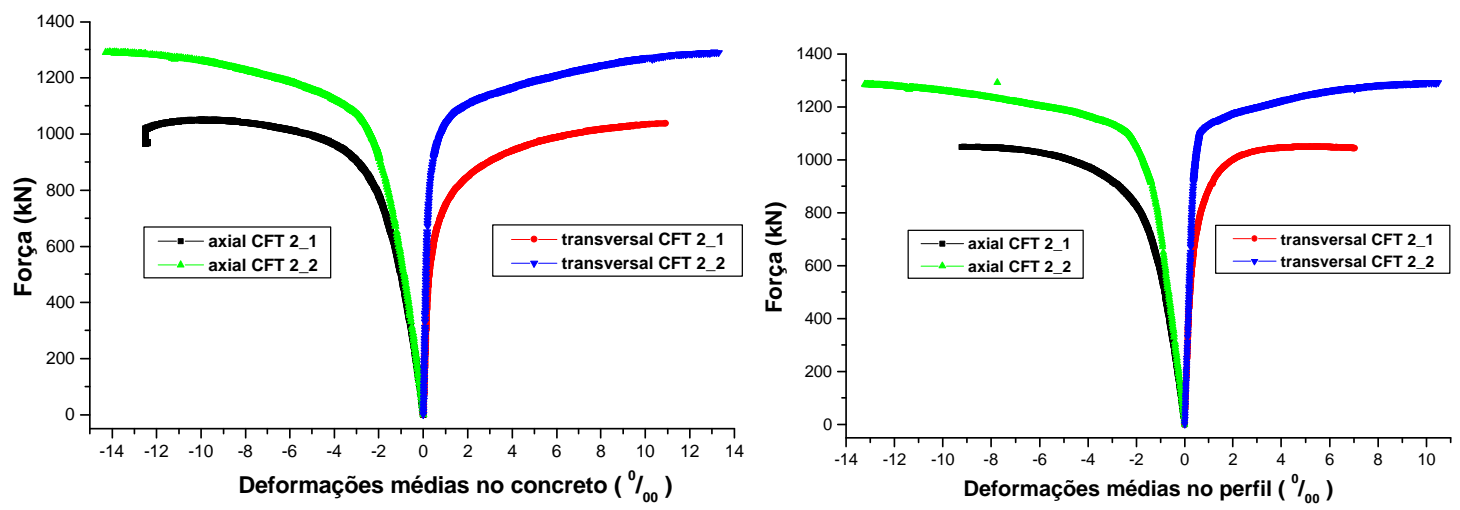

b) Modelos CFT 2_1 e CFT 2_2
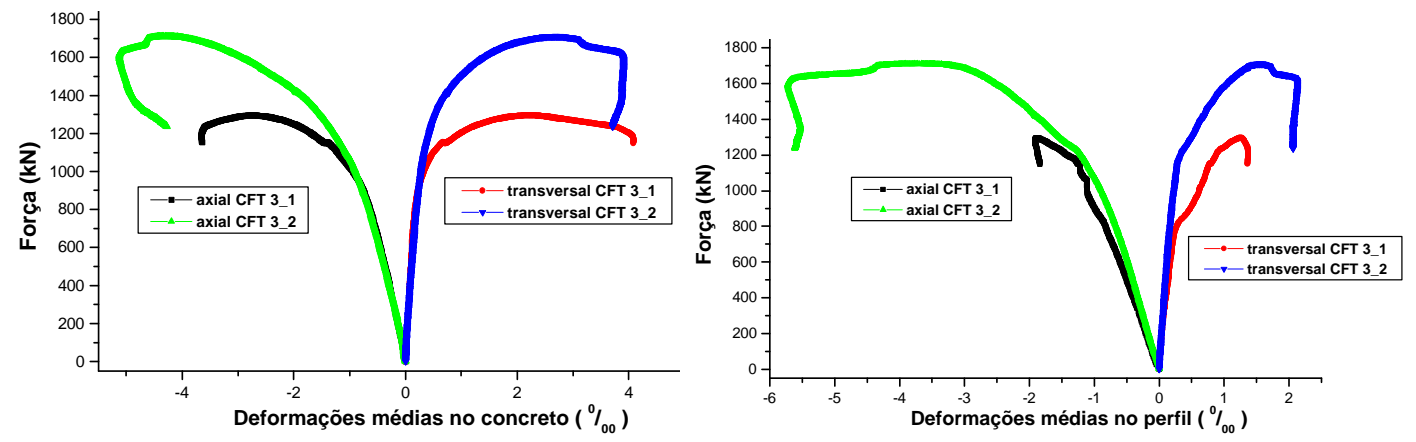

c) Modelos CFT 3_1 e CFT 3_2

FIGURA 8.21 - PRESENÇA DO EFEITO DE CONFINAMENTO NAS DIFERENTES SEÇÕES E ESPESSURAS ANALISADAS 
O comportamento das deformações axiais e transversais ilustra claramente o ganho de ductilidade do concreto de alta resistência, confinado pelo perfil tubular.

Algumas tentativas no sentido de quantificar as tensões de confinamento foram realizadas, partindo de alguns modelos propostos para o cálculo destas tensões em pilares de concreto de alta resistência, armados com altas taxas de armaduras longitudinais e transversais. Os modelos propostos foram adaptados de forma a introduzir no lugar da distribuição discreta de barras de armadura, a armadura contínua representada pelo perfil tubular. Tais tentativas deram resultados ruins, resultando em valores para a resistência do concreto confinado muito superiores aos valores de $f_{c m}$ (resistência do concreto à compressão uniaxial). Todos os modelos analisados consideram o arqueamento das tensões de confinamento próximo aos cantos das seções transversais quadradas e retangulares, entretanto parece que este arqueamento comporta-se de forma muito diferente para os pilares mistos preenchidos. Para os pilares de seções retangulares e quadradas foram analisados os modelos propostos por CUSSON \& PAULTRE (1993), FRANGOU \& PILAKOUTAS \& DRITSOS (1995) e SAATCIOGLU \& RAZVI (1992), todos desenvolvidos para pilares em concreto de alta resistência, armados com altas taxas de armadura longitudinal e transversal. Para os pilares circulares, foi aplicado o modelo proposto por KNOWLES \& PARK (1969).

Os resultados obtidos ficaram muito distantes dos experimentais e isto pode ser atribuído aos coeficientes $a$ e $b$, determinados experimentalmente e que são empregados para calcular a tensão de confinamento $\mathrm{f}_{\ell}$ e posteriormente, a capacidade resistente considerando o efeito de confinamento. 


\section{CONCLUSÕES}

\subsection{ConClusÃo}

O pilar misto aço-concreto, preenchido com concreto de alta resistência integra um amplo sistema estrutural formado por elementos mistos. Embora seu surgimento tenha sido casual, fruto de uma variação na forma de proteção do perfil tubular contra a ação do fogo e da corrosão, as diversas vantagens inerentes à sua utilização têm sido responsáveis pela ampliação de sua utilização em diversos tipos de estruturas como portos, pontes e sobretudo edifícios altos.

Aos pilares mistos preenchidos são atribuídas características como: alta resistência e ductilidade, economia de materiais e mão-de-obra, otimização do processo construtivo minimizando perdas com materiais e eliminando a necessidade de fôrmas, proteção contra a ação do fogo e da corrosão, e ação conjunta de materiais. Trata-se portanto, de um elemento estrutural cuja escolha implica também na opção por um processo construtivo otimizado e ao qual estão agregados bom comportamento estrutural, tecnologia construtiva, racionalidade, economia e funcionalidade.

A utilização diversificada dos pilares mistos preenchidos verificada no exterior, não ocorre no Brasil; isto devido ao desconhecimento dos engenheiros e profissionais envolvidos na construção civil e à cultura preferencial por estruturas em concreto armado. Pelas referências bibliográficas consultadas, pode-se notar a quase inexistência de referências nacionais sobre o tema. 
Deve-se entretanto citar que já existe um texto base de norma brasileira (ABNT 1997), que trata do dimensionamento de pilares mistos.

Os estudos desenvolvidos ao longo das últimas três décadas deram origem a algumas normas de dimensionamento, entretanto estas apresentam uma série de limitações sobretudo quanto à utilização de aços e concretos de alta resistência, que são uma tendência mundial e para a qual são ampliadas algumas características destes elementos mistos. Constatou-se a necessidade de adequar as normas existentes aos avanços tecnológicos já incorporados pela construção civil.

Quanto aos trabalhos que procuram conhecer o comportamento dos pilares mistos, pode-se dizer que eles consistem basicamente na identificação dos parâmetros que interferem na capacidade resistente e como esta interferência ocorre. Estes trabalhos procuram confrontar resultados teóricos e experimentais, donde resultam sugestões para consideração destes parâmetros, ou a indicação de novas pesquisas sobre o assunto. Como exemplos da necessidade de novos estudos pode-se citar a questão da deformabilidade do concreto ao longo do tempo. Os primeiros estudos teóricos indicaram que os fenômenos de retração e fluência provocam a redistribuição de tensões nos materiais, aliviando as tensões no núcleo de concreto e sobrecarregando o perfil tubular. Estes estudos não foram conclusivos e tais fenômenos precisam ser quantificados a fim de serem introduzidos nas normas de dimensionamento. Quanto à aderência, foi um dos primeiros fatores a serem estudados. No caso dos pilares mistos axialmente comprimidos, sua presença exerce pouca influência na capacidade resistente e no comportamento. Os estudos mostraram que o mesmo ocorre para os pilares mistos flexo-comprimidos, mas isto têm sido questionado e parece razoável admitir que nas situações de flexo-compressão, a aderência seja essencial na distribuição de esforços entre os materiais aço e concreto.

O estudo teórico-experimental de alguns pilares mistos preenchidos atingiu seu objetivo geral que era contribuir no sentido de divulgar estes elementos mistos, buscando introduzí-los no Brasil de forma efetiva, uma vez que representa uma fonte para consulta à disposição de engenheiros civis e afins.

O estudo dos modelos teóricos para cálculo da capacidade resistente, apresentados por algumas normas técnicas, mostrou bons resultados. A comparação com os resultados experimentais mostra diferenças que atingem no máximo $15,5 \%$, constatada para o modelo CFT 1_1, previsto pela norma americana 
ACI 318R-92 (1992). Na sua grande maioria, os resultados previstos ficaram abaixo dos experimentais e portanto, qualquer uma das normas apresentadas pode ser usada para o dimensionamento dos pilares mistos. Em alguns casos, os valores previstos superam os experimentais, mas as diferenças são pequenas e não passam de $9,1 \%$. Como qualquer uma das cinco normas apresentadas pode ser utilizada com segurança, sugere-se a utilização da norma americana ACl 318R-92 (1992) pois apresenta equações de fácil compreensão e utilização.

As normas BS 5400: parte 5 (1979) e Eurocode 4 (1994) consideram o efeito do confinamento sobre as resistências dos materiais aço e concreto. Isto é feito através de coeficientes determinados experimentalmente. A aplicação da norma britânica BS 5400: parte 5, aos modelos CFT 2_1 e CFT 2_2 não apresentou bons resultados pois, ao que tudo indica, as resistências dos materiais são superestimadas, resultando em valores superiores aos experimentais. Para o modelo CFT 2_1 a diferença foi de $6,8 \%$ e para o modelo CFT 2_2, de 8,8\%. No caso da norma Eurocode 4, resultaram valores abaixo dos reais e muito próximos dos obtidos sem considerar o efeito de confinamento. Portanto, com base nestes resultados, para qualquer forma de seção transversal pode-se empregar a norma americana sem perdas significativas de segurança.

Os ensaios de espécimes de perfis, denominados "full tests" foram realizados com o objetivo de quantificar a resistência do perfil tubular isolado, considerando a variação nas propriedades mecânicas devidas ao trabalho de formação a frio e ao processo de soldagem. Os resultados obtidos substituindo a parcela de resistência correspondente ao perfil, calculada por $A_{s} \cdot f_{y}$, pela resistência obtida no "full test", mostrou que a diferença na capacidade resistente é insignificante. Portanto, é suficiente conhecer a resistência ao escoamento, determinada pelo ensaio ASTM A370 pois os resultados obtidos são satisfatórios.

A análise numérica foi realizada com o objetivo de empregar os dados experimentais para aferição de modelos teóricos. Os resultados mostraram que a aplicação de deslocamento no topo do pilar misto se aproxima muito da condição de ensaio. Partindo da comparação dos resultados da análise numérica e da investigação experimental, e das pequenas diferenças entre eles, pode-se utilizar o programa Ansys para a análise de outras dimensões de seções transversais, outras espessuras de perfil e ainda, variações nas resistências dos materiais. Desta forma, os resultados experimentais foram usados para validar o modelo numérico e com isto, agilizar e simplificar novas análises, que podem ser realizadas apenas através 
da simulação de modelos numéricos, sem a necessidade de ensaios em modelos físicos.

A configuração de ruína dos elementos investigados confirmou os dados encontrados na revisão bibliográfica. Ela de fato ocorre devido ao esmagamento do concreto do núcleo. Ocorrendo a perda da parcela de resistência correspondente ao concreto, toda a tensão atuante passa a ser suportada pelo aço do perfil tubular, que então sofre flambagem local. Apenas no caso das seções circulares, para as quais a rigidez à flambagem local é muito grande, a flambagem global ocorre antes.

O modelo $R$, em concreto simples, foi ensaiado apenas para conhecer 0 comportamento do concreto não confinado e como era esperado, sua ruína ocorreu de forma brusca e explosiva, por esmagamento do concreto na seção média. A forma de ruína ocorrida verificada comprova a fragilidade do concreto de alta resistência.

Quanto ao comportamento dos pilares mistos prenchidos, os resultados indicam que os pilares circulares apresentam comportamento elasto-plástico perfeito; os pilares de seção quadrada e retangular apresentam variação de comportamento em função da espessura do perfil tubular. Para ambos, o comportamento é elasto-plástico porém, em alguns casos verifica-se uma região de encruamento.

As deformações registradas no aço e no concreto permitem concluir que os dois materiais trabalham juntos até que seja atingida a força última. A partir de então, o esmagamento do concreto e o início da flambagem local contribuem para a separação dos materiais.

A realização de ensaios com controle de deslocamento permitiu obter dados dos elementos após ser atingida a força última. O conhecimento destes dados possibilitou a análise do comportamento pós-pico e a avaliação da ductilidade.

A ductilidade é uma característica muito destacada na literatura e sempre associada aos pilares mistos preenchidos. Sua importância é fundamental em algumas situações e, embora seja importante, não há nenhuma recomendação normalizada que aborde a avaliação da ductilidade à compressão de pilares mistos preenchidos. As adaptações feitas nas recomendações de UY (1998a) mostraram bons resultados e podem ser utilizadas para calcular o índice de ductilidade dos pilares mistos preenchidos. Os resultados obtidos indicam que, ao aumentar a área de aço e diminuir a de concreto, o índice de ductilidade aumenta na mesma 
proporção. Conclui-se então que quanto maior a parcela de material dúctil na seção, no caso o aço, maior será o índice de ductilidade e conseqüentemente, maior a ductilidade do elemento misto. Os resultados de ductilidade obtidos servem para confirmar a recomendação de alguns pesquisadores quanto à utilização dos pilares mistos preenchidos em regiões com incidência de ações sísmicas, mostrando que tal recomendação tem razão de ser.

Identificar a presença do confinamento em seções mistas era um dos objetivos deste trabalho. Ele pode ser identificado na mudança de comportamento verificada no concreto confinado, quando comparado com o concreto livre. O confinamento promove a ductilização do concreto, mudando seu comportamento de material frágil para um material com certa ductilidade. Isto ocorreu em todas as seções investigadas, entretanto foi mais significativa nas seções circulares, onde de fato era esperado o maior grau de confinamento. Para as seções quadradas, a intensidade do confinamento é menor e decresce para as seções retangulares. Estas diferenças de comportamento verificadas são função do arqueamento das tensões de confinamento.

Procurou-se quantificar o grau de confinamento do concreto para as diferentes seções investigadas, contudo isto não foi possível. Para as seções circulares, a aplicação de alguns modelos encontrados na literatura resultou em capacidade resistente muito superior à experimental, indicando que tais modelos não eram aplicáveis a concretos de alta resistência. Quanto às seções quadradas e retangulares, alguns modelos desenvolvidos para pilares em concreto armado foram adaptados mas não apresentaram bons resultados. Em todas as situações verificou-se que era melhor prever a capacidade resistente desconsiderando o efeito de confinamento, pois para esta situação resultam valores muito próximos dos experimentais.

Conclui-se então, com base nos modelos investigados, que o efeito de confinamento é responsável por melhorar o comportamento do concreto à compressão, mas não precisa ser levado em conta no cálculo da capacidade resistente pois sua contribuição neste sentido foi irrelevante. 


\subsection{SUGESTÕES PARA NOVAS PESQUISAS}

A revisão bibliográfica mostrou que há uma série de questões pendentes e que precisam de resposta. A carência de estudos é ainda maior no Brasil, onde os elementos mistos começam a ser utilizados e estudados, mas ainda de forma tímida.

No sentido de suprir algumas deficiências, sugere-se o estudo dos pilares mistos submetidos à flexo-compressão, sobretudo o estudo de sua capacidade resistente e influência de fatores como índice de esbeltez e resistência dos materiais no comportamento da seção mista.

Outro aspecto importante é o estudo de formas de ligar os pilares mistos a outros elementos estruturais, sejam eles vigas, lajes ou elementos de fundação.

São necessários estudos que permitam quantificar os fenômenos de retração e fluência e sua importância e influência no comportamento dos elementos mistos e na distribuição de tensões nestes. 


\section{REFERÊNCIAS BIBLIOGRÁFICAS}

AMARAL FILHO, E. M. (1992a). Concreto de alta resistência (1를 parte). Revista IBRACON, ano II, n. 4, p.40-49, abril/maio/junho.

AMARAL FILHO, E. M. (1992b). Concreto de alta resistência (2 $2^{a}$ parte). Revista IBRACON, ano II, n. 5, p.52-59, julho/agosto/setembro.

AMERICAN CONCRETE INSTITUTE (1989). ACI 544.2R: Measurement of properties of fiber reinforced concrete. Committee 544. 11p.

AMERICAN CONCRETE INSTITUTE (1992). ACI 363R-92 - State-of-the-art report on high-strength concrete. Detroit. 55p.

AMERICAN CONCRETE INSTITUTE (1992). ACI 318R-92 - Building code requirements for reinforced concrete. Detroit.

AMERICAN CONCRETE INSTITUTE (1996). ACl 441R-96 - High-strength concrete columns: state of the art. Detroit. 13p.

AMERICAN INSTITUTE OF STEEL CONSTRUCTION (1994). AISC-LRFD: Load and resistance factor design. Chicago.

AMERICAN IRON AND STEEL INSTITUTE (1996). AISI-LRFD: load and resistance factor design. Specification for the desing of cold-formed steel structural members - cold-formed steel design manual: part V. Washington.

AMERICAN SOCIETY FOR TESTING AND MATERIALS (1992). ASTM C1018-92: Standard test method for flexural toughness and first-crack strength of fiberreinforced concrete (using beam with third-point loading). Philadelphia, 7p.

AMERICAN SOCIETY FOR TESTING AND MATERIALS (1992). ASTM A370: standard test methods for tension testing of metallic materials (metric). Philadelphia.

ASSOCIAÇÃO BRASILEIRA DE NORMAS TÉCNICAS (1997). Texto para revisão da NB-1 e comentários. 
ASSOCIAÇÃO BRASILEIRA DE NORMAS TÉCNICAS (1978). NBR 6118 - Projeto e execução de obras em concreto armado. Rio de Janeiro.

ASSOCIAÇÃO BRASILEIRA DE NORMAS TÉCNICAS (1980). NBR 5739 - Ensaio de compressão de corpos-de-prova cilíndricos de concreto. Rio de Janeiro.

ASSOCIAÇÃO BRASILEIRA DE NORMAS TÉCNICAS (1982). NBR 7251 Agregado em estado solto: determinação da massa específica. Rio de Janeiro.

ASSOCIAÇÃO BRASILEIRA DE NORMAS TÉCNICAS (1983). NBR 7211 Agregado para concreto. Rio de Janeiro.

ASSOCIAÇÃO BRASILEIRA DE NORMAS TÉCNICAS (1987). NBR 9776 Agregados: determinação da massa específica de agregados miúdos por meio do frasco de Chapman. Rio de Janeiro.

ASSOCIAÇÃO BRASILEIRA DE NORMAS TÉCNICAS (1987). NBR 7217 Agregados: determinação da composição granulométrica. Rio de Janeiro.

ASSOCIAÇÃO BRASILEIRA DE NORMAS TÉCNICAS (1987). NBR 8800 - Projeto e execução de estruturas de aço de edifícios. Rio de Janeiro.

ASSOCIAÇÃO BRASILEIRA DE NORMAS TÉCNICAS (1982). NBR7222 Argamassas e concretos-determinação da resistência à tração por compressão diametral de corpos-de-prova cilíndricos. Rio de Janeiro.

AZIZINAMINI, A.; PRAKASH, B. (1993). A tentative design guideline for a new steel beam connection detail to composite tube column. Engineering Journal, v.31, n.01, p.108-115, 3\%/4.

BACCIN, A. G.; PINHEIRO, L. M. (1997). Propriedades mecânicas do concreto de alto desempenho para aplicação em edifícios. 39ạ REIBRAC Reunião Comemorativa de 25 anos do IBRACON. São Paulo, 5 a 8 de agosto,v.02, p.687-700.

BAILEY, C. G.; NEWMAN, G. M. (1998). The design of steel framed buildings without applied fire protection. The structural engineer, v.76, n. 5, p.77-81, March.

BJERKELI, L.; TOMASZEWICZ, A.; JENSEN, J. J. (1990). Deformation properties and ductility of high-strength concrete. In: HESTER, W.T, ed. Highstrength concrete: second international symposium. Detroit, ACI. p.215-238. (ACI SP-121). 
BRAUNS, J. (1999). Analysis of stress state in concrete-filled steel column. Journal of constructional steel research, v. 49, n.2, p.189-196, February.

BRITISH STANDARD INSTITUTION (1979). BS 5400, part 5: steel, concrete and composite bridges: code of practice for design of composite bridges. London.

CAI, S.; GU, W. (1996). Behaviour and ultimate strength of steel-tube-confined high-strength concrete columns. In: FOURTH INTERNATIONAL SYMPOSIUM ON THE UTILIZATION OF HIGH STRENGTH/HIGH PERFORMANCE CONCRETE, Paris, 29-31 may, 1996. Proceedings. Paris, v.3, p.827-833.

CANADIAN INSTITUTE OF STEEL CONSTRUCTION. (1991). Handbook of steel construction. Ontario.

CANADIAN STANDARDS ASSOCIATION (1989). CAN/CSA-S16.1-M89 - Limit states design of steel structures. Toronto, CSA. 147p.

CEB (1990). Working group on High-strength concrete (1990), High stregth concrete - state of the art report. CEB bulletin n.197, ago.

CEB (1998). Ductility of reinforced concrete structures. CEB-FIP Bulletin n. 242, 332p, may.

CEDERWALL, K.; ENGSTROM, B.; GRAUERS, M. (1990). High-strength concrete used in composite columns. In: HESTER, W. T., ed. High-strength concrete: second international symposium. Detroit, ACI. p.195-214. (ACI SP121).

COUNCIL ON TALL BUILDINGS AND URBAN HABITAT. Committee 3 (1995). Structural systems for tall buildings. New York, McGraw-Hill. 422p.

CUSSON, D.; PAULTRE, P. (1993). Confinement model for high-strength concrete tied columns. University of Sherbrooke, SMS - 93/02, October, 54p.

DAL MOLIN, D.C. (1995). Contribuição ao estudo das propriedades mecânicas dos concretos de alta resistência com adição de microssílica. São Paulo. 286p. Tese (doutorado) - Escola Politécnica da Universidade de São Paulo.

EUROPEAN COMMITTEE OF STANDARDIZATION (1992). ENV 1992-11:Eurocode 2 - Design of concrete structures, Part 1.1: general rules and rules for buildings. Brussels. 
EUROPEAN COMMITTEE OF STANDARDIZATION (1994). ENV 1994-1-1: Eurocode 4 - Design of composite steel and concrete structures, Part 1.1: General rules and rules for buildings. Brussels.

FRANGOU, M.; PILAKOUTAS, K.; DRITSOS, S. (1995). Structural repair/strengthening of $\mathrm{RC}$ columns. Construction and building materials, v.9, n.5, p.259-266.

FIGUEIREDO, L. M. B. (1998). Projeto e construção de pilares mistos açoconcreto. São Carlos. 142p. Dissertação (mestrado) - Escola de Engenharia de São Carlos, Universidade de São Paulo.

GE, H.; USAMI, T. (1992). Strength of concrete-filled thin-walled steel box columns: experiment. Journal of structural engineering, v.118, n.11, p.3036-3055, November.

GOMES, N. S. (1994). Pilares mistos tubulares de aço e concreto. São Paulo. Tese (doutorado) - Escola Politécnica da Universidade de São Paulo.

GRIFFIS, L. G. (1994). The 1994 T.R. High lecture: Composite frame construction. In: NATIONAL STEEL CONSTRUCTION CONFERENCE, Pittsburgh, Pennsylvania, 18-20 may, 1994. Proceedings. New York, AISC. V.01, p.1.11.72 .

HUNAITI, Y. (1992). Experimental evaluation of the effect of bond on the maximum capacity of composite columns. Journal constructional steel research, v.22, p.39-55.

HUNAITI, Y.; WAKABAYASHI, M. (1992). Experimental evaluation of the effect of bond on the maximum capacity of composite columns. Journal of constructional steel research, v.22, p.39-55.

JAPAN SOCIETY OF CIVIL ENGINEERS. (1984). Method of test for compressive strength and compressive toughness of steel fiber reinforced concrete. JSCESF5. Concrete Library of JSCE. Part III-2 Method of tests for steel fiber reinforced concrete. n. 3, June p-63-66.

KNOWLES, R.; PARK, R. (1969). Strength of concrete filled steel tubular columns. Journal of structural division, v. 95, n.st12, p.2565-2587, December. 
KVEDARAS, A. K.; SAPALAS, A. (1999). Research and practice of concrete-filled steel tubes in Lithuania. Journal of constructional steel research, v. 49, n.2, p.197-212, February .

LIE, T. T. (1998). Recent developments in structural fire resistance. Construction Practice. http://www.nrc.ca/irc/practice/fir4_E.html (6 October).

LIE, T. T. ; CHABOT, M. (1998) Concrete filling: fire protection for steel columns. Construction Practice. http://www.nrc.ca/irc/practice/fir3_E.html (6 October).

LIMA, F. B. (1997). Pilares de concreto de alto desempenho: fundamentos e experimentação. São Carlos. 170p. Tese (doutorado) - Escola de Engenharia de São Carlos, Universidade de São Paulo.

MALITE, M.; SÁlES, J. J.; TAKEYA, T. (1995). Contribuição ao dimensionamento de colunas mistas aço-concreto. In: JORNADAS SUDAMERICANAS DE INGENIERÍA ESTRUCTURAL, 27. Tucumán, Argentina, 18-22 septiembre. Memórias. Tucumán, ASAIE/ Laboratório de Estructuras - FCET-UNT, v.1, p483-494.

MERRIT, F. S. (1972). Structural steel designer's handbook. New York. McGrawHill. Part 1, p.1-26.

METHA, P. K.; MONTEIRO, P. J. M. (1994). Concreto: estrutura, propriedade e materiais. São Paulo, Pini, 573p.

NS 3473 E (1992). Concrete structures: design rules. 4ed. Oslo, Norway, nov. (english version).

PEREIRA NETO, P. M.; DJANIKIAN, J. G. (1995). Concretos de alta resistência: algumas características do módulo de elasticidade de concretos de alta resistência. Revista IBRACON, n. 12, p.28-35.

PRION, H. G. L.; BOEHME, J. (1994). Beam-column behaviour of steel tubes filled with high strength concrete. Canadian journal of civil engineering, n.21, p.207218.

PRION, H. G. L.; McLELLAN, A. B. (1994). Through-bolt connections for concretefilled hollow structural steel sections. In: ANNUAL TASK GROUP TECHNICAL SESSION 1994. Proceedings. Bethlehem. p.239-250. 
RAGAN, B. V. (1991). Design of slender hollow steel columns filled with concrete. In: INTERNATIONAL CONFERENCE ON STEEL AND ALUMINIUN STRUCTURES ICSAS 91, Singapore, 22-24 May.

SAADEGHVAZIRI, M. ALA; SHAMS, M. (1997). State of the art of concrete-filled steel tubular columns. ACl structural journal, v.94, n.05, p.558-571, September/October.

SAATCIOGLU, M.; RAZVI, S. R. (1998). Strength and ductility of confined concrete. Journal of structural engineering, v.118, n.06, p. 1590-1607, June.

SCHNEIDER, S. P.; ALOSTAZ, Y. M. (1998). Experimental behaviour of connections to concrete-filled steel tubes. Journal constructional steel research, v.45, n.03, p.312-352.

SHAKIR-KHALIL, H. (1988). Steel-concrete composite columns I. Steel-concrete composite structures: stability and strength, CAP. 06, p.163-193.

SHAKIR-KHALIL, H. (1993a). Pushout strength of concrete-filled steel hollow sections. The structural engineer, v.71, n.13/6, p.230-233, July.

SHAKIR-KHALIL, H. (1993b). Resistance of concrete-filled steel tubes to pushout forces. The structural engineer, v.71, n.13/6, p.234-243, July.

SHAKIR-KHALIL, H. (1994). Experimental study of concrete-filled rectangular hollows section columns. Structural engineering review, v. 06, n.2, p.85-96.

SHAKIR-KHALIL, H.; ZEGHICHE, J. (1989). Experimental behaviour of concretefilled rolled rectangular hollow-section columns. The structural engineer. v.67, n.19/3, p.346-353, October.

SHAKIR-KHALIL, H.; MOULI, M. (1990). Further tests on concrete-filled rectangular hollow-section columns. The structural engineer, v.68, n.20/16, p.405-413, October.

VALLENILLA, R.; BJORHOVDE, R. (1990). Behaviour of composite frames during construction. Journal constructional steel research, v.15, p.3-21.

VIRDI, K. S.; DOWLING, P. J. (1980). Bond strength in concrete filled steel tubes. IABSE-International association for bridge and structural engineering, n.03, p.125-137, August. 
UY, B. (1996). Behaviour and design of thin-walled concrete-filled steel box columns. Australian civil / Structural engineering transactions, v.CE39, n.1, p.31-38.

UY, B. (1998a). Ductility, strength and stability of concrete-filled fabricated steel box columns for tall buildings. The structural design of tall buildings, v.7, n.2, p.113-133, June.

UY, B. (1998b). Local and post-local bucking of concrete filled steel welded box columns. Journal of constructional steel research, v.47, p. 47-72.

UY, B.; DAS, S. (1997). Time effects in concrete-filled steel box columns in tall buildings. The structural design of tall buildings, v.06, p.1-22, March.

UY, B.; PATIL, S. B. (1996). Concrete filled high strength steel box columns for tall buildings: behaviour and design. The structural design of tall buildings, v.5, p.75-94, February.

ZANDONINI, R. (1994). Composite Construction Research and Practice: recent developments in Europe. In: ANNUAL TASK GROUP TECHNICAL SESSION 1994, Bethlehem Pennsylvania. Proceedings. Bethlehem, Reports on Current Research Activities, p.251-274.

WANG, Y. C.; MOORE, D. B. (1997). A design method for concrete-filled, hollow section, composite columns. The structural engineer, v.75, n.21/4, p.368-373, November.

YU, W.W. (1985). Cold-formed steel design. New York. John Wiley \& Sons. 545p. 


\section{BIBLIOGRAFIA COMPLEMENTAR}

AMERICAN CONCRETE INSTITUTE (1992). ACI 363R-92 - State-of-the-art report on high-strength concrete. Detroit. 55p.

ASSOCIAÇÃO BRASILEIRA DE NORMAS TÉCNICAS (1986). NBR8800 - Projeto e execução de estruturas de aço de edifícios. Rio de Janeiro.

ASSOCIAÇÃO BRASILEIRA DE NORMAS TÉCNICAS (1980). NBR5739 - Ensaio de compressão de corpos-de-prova cilíndricos de concreto. Rio de Janeiro.

ASSOCIAÇÃO BRASILEIRA DE NORMAS TÉCNICAS (1987). NBR7216 Amostragem de agregados. Rio de Janeiro.

BELLEI, I. H. (1994). Edifícios Industriais de aço. São Paulo, Pini. Cap. 2, p.7-16.

CITVARAS, M. D.; PAULON, V.A. (1997). Caracterização e otimização do traço de concretos de alta resistência. 39a REIBRAC Reunião Comemorativa de 25 anos do IBRACON. São Paulo, 5 a 8 de agosto,v.01, p.311-325.

COLLINS, M. P.; MITCHELL, D.; MAcGREGOR, J. G.(1993). Structural design considerations for high-strength concrete. ACI Structural Journal, p.27-34, May.

FERNANDES, J. F. (1997). Pilares mistos: tubos de aço com seções quadradas e retangulares e núcleo de concreto de alta resistência. Campinas. Dissertação (mestrado) - Universidade Estadual de Campinas.

FURLONG, R. W. (1997). Steel-concrete composite columns. Transportation research record, n.1594, p.57-63.

GE, H.; USAMI, T. (1996). Cyclic tests of concrete-filled steel box columns. Journal of structural engineering, v.122, n.122, p.1169-1177, October.

HANBIN, G.; USAMI, T. (1992). Strength of concrete-filled thin-walled steel box columns: experiment. Journal of structural engineering, v.118, n.11, p.30363054, November. 
KARBHARI, V. M.; GAO, Y. (1997). Composite jacketed concrete under uniaxial compression: verification of simple design equations. Journal of materials in civil engineering, v.9, n.4, p.185-193, April.

MANDER, J. B.; PRIESTLEY, M. J.; PARK, R. (1989a). Theoretical stress-strain model for confined concrete. Journal of structural engineering, v.114, n.08, p.1804-1826, August.

MANDER, J. B.; PRIESTLEY, M. J.; PARK, R. (1989b). Observed stress-strain behaviour of confined concrete. Journal of structural engineering, v.114, n.08, p.1827-1821849, August.

MALITE, M. (1994). Estruturas mistas aço-concreto: dimensionamento de colunas. Construção Metálica, ABCEM, n.16, p.E4-E8.

NEOGI, P.K.; SEN, H. K.; CHAPMAN, J. C. (1969). Concrete-filled tubular steel columns under eccentric loading. The structural engineer, v.47, n.5, p.187195, May.

PARK, R.; PRIESTLEY, N.; GILL, W. D. (1982). Ductility of square-confined concrete columns. Journal of structural division, v.108, n.st4, p.929-950, April.

SHEIKH, S. A.; UZUMERI, S. M. (1982). Analytical model for concrete confinement in tied columns. Journal of the structural division, v.108, n.st12, p.2703-2722, December.

SMADI, M. M.; SLATE, F. O. (1989). Microcraking of high and normal strength concretes under short an long-term loadings. ACl Structural journal, n.86, p.117-127, March-April.

VIRDI, K. S.; DOWLING, P. J. (1980). Bond strength in concrete filled steel tubes. IABSE-International association for bridge and structural engineering. n.03, p.125-137, August. 